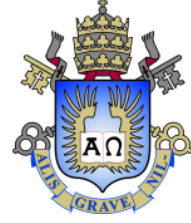

Bruno Azevedo Chagas

\title{
Metacommunication and Appropriation in the Design of the Interactive Internet of Things
}

Tese de Doutorado

Thesis presented to the Programa de Pós-graduação em Informática of PUC-Rio in partial fulfillment of the requirements for the degree of Doutor em Ciências Informática.

Advisor : Profa. Clarisse Sieckenius de Souza

Co-advisor: $\quad$ Prof. David Francis Redmiles 


\section{Metacommunication and Appropriation in the Design of the Interactive Internet of Things}

Thesis presented to the Programa de Pós-graduação em Informática of PUC-Rio in partial fulfillment of the requirements for the degree of Doutor em Ciências Informática. Approved by the Examination Committee.

Profa. Clarisse Sieckenius de Souza

Advisor

Departamento de Informática - PUC-Rio

Prof. David Francis Redmiles

Co-Advisor

$\mathrm{UCl}$

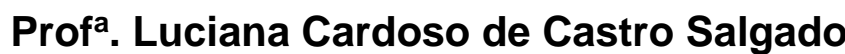

UFF

Profa. Ana Cristina Bicharra da Silva

UNIRIO

Dr. Renato Fontoura de Gusmão Cerqueira

IBM Research Brazil

Profa. Simone Diniz Junqueira Barbosa

Departamento de Informática - PUC-Rio

Prof. Alberto Barbosa Raposo

Departamento de Informática - PUC-Rio

Rio de Janeiro, May $14^{\text {th }}, 2020$ 
All rights reserved.

\section{Bruno Azevedo Chagas}

Bruno holds a M.Sc. degree in Informatics from Pontifical Catholic University of Rio de Janeiro (PUC-Rio, 2015) and a Computer Engineering degree from Universidade Estadual de Campinas (UNICAMP, 2000). Currently, he is a researcher, developer and entrepreneur in the tech industry.

Bibliographic data

Chagas, Bruno Azevedo

Metacommunication and Appropriation in the Design of the Interactive Internet of Things / Bruno Azevedo Chagas ; advisor: Clarisse Sieckenius de Souza ; co-advisor: David Francis Redmiles. 2020.

265 f. : il. (color.) ; $30 \mathrm{~cm}$

Tese (doutorado) - Pontifícia Universidade Católica do Rio de Janeiro, Departamento de Informática.

Inclui referências bibliográficas.

1. Informática - Teses. 2. Interação Humano-Computador. 3. Internet das Coisas. 4. Engenharia Semiótica. 5. Apropriação de Tecnologia. I. De Souza, Clarisse Sieckenius. II. Redmiles, David Francis. III. Pontifícia Universidade Católica do Rio de Janeiro. Departamento de Informática. IV. Título. 


\section{Acknowledgments}

I thank God for the beginnings and ends.

I thank my parents - Mericler and Epaminondas - and my brother-Alexandrefor the comprehensive support and full companionship.

I thank Prof. Clarisse S. de Souza, my advisor, for her time, dedication, patience and invaluable guidance. Clarisse made this research happen in a number of different ways. Among so many valuable teachings that I would not find elsewhere, Clarisse has taught me semiosis in theory and in practice. Every time I read or re-read one of her writings or comments to mine I find out a new meaning that I could not reach at first. I am pretty sure she had already inscribed it all there intentionally. Her scientific rigor and way of thinking taught me what Science is and how to do it, which I hope I have learned and can retain in a minimum level.

I thank Prof. David F. Redmiles, my co-advisor, initially for hosting me in a foreign land and, thereafter, for the invaluable support and friendship. David also made this research happen and come to a conclusion in a number of different ways. I am grateful for all the research and life lessons he shared with me, not to mention his time, dedication and practical advices. I consider myself rather lucky to find people that besides being brilliant are kind and committed to high standards of human values, and David is one of them.

Research, especially a doctorate research, is not something that one can accomplish by himself. I am indebted to several other people who helped me throughout the way, sometimes in critical times and unreplaceable ways. The following is not a complete list, but one for myself to remember how many people we need for practically anything we want to accomplish in this world.

Among professors, I thank in particular: Prof. Hugo Fuks from PUC-Rio for advising me in the beginning; Prof. Alessandro Garcia from PUC-Rio for the support without which my internship abroad would not be possible; Prof. Volkmar Pipek from the University of Siegen for the support and insightful discussions that helped me to do the diary study; and Prof. Tayana Conte from UFAM for some great discussions and insights which she need not to share with me, but she did. I thank all my colleagues from research groups SERG at PUC-Rio and CRADL at UCI for being around and engaging in thoughtful discussions and "free" feedback. Especially, I thank Dr. Tao Wang, colleague researcher at UCI and currently at SAP - the most meticulous experiment designer I have ever met.

I thank Prof. Noemi Rodriguez and Dr. Adriano Branco for lending the Gist Lab's space at PUC-Rio, allowing some insightful exchanges and a nice place that made the final leg of my research possible and much more enjoyable.

I thank Audrey Wilson and family for the kindness of having me abroad and the friendship that developed thereafter.

I thank the folks at Triad Systems for the job and understanding during a certain time, especially Luciana Fabris, Silvio Rodrigues, Salvador Nakada and Ricardo Sardano, he who was actually with me in the beginning of all this.

I thank all my studies' volunteers, PUC-Rio and UCI kind and competent staffs. This study was financed in part by the Coordenação de Aperfeiçoamento de Pessoal de Nível Superior - Brasil (CAPES) - Finance Code 001.

Research financed in part also by Brazilian government agencies CNPq - grants 153902/2015-9 and 140568/2018-2 — and CAPES - grant 88887.122734/2016-00. 


\section{Abstract}

Chagas, Bruno Azevedo; De Souza, Clarisse Sieckenius (Advisor). Metacommunication and Appropriation in the Design of the Interactive Internet of Things. Rio de Janeiro, 2020. 269p. Tese de Doutorado - Departamento de Informática, Pontifícia Universidade Católica do Rio de Janeiro.

The Internet of Things (IoT) refers to the emerging technological infrastructure formed by everyday objects and environments endowed with computing and networking power in order to provide digitally enhanced services and responsive behaviors in the physical world. As with every technology, at the end points of the IoT, there are people designing and using this technology somehow. Designing interaction for the IoT presents old and new challenges. In this thesis, I address two of them, namely metacommunication and appropriation. The former has to do with the people who design the IoT; the latter, with those who use it. By applying Semiotic Engineering as a theoretical lens to the study of IoT technology, I conducted six studies using different research methods which results were combined in three contributions. Firstly, I am proposing a semiotic model of technology appropriation, which is proposed as an epistemic tool to support designers reflect on how users adopt IoT technology. Secondly, I am proposing a semiotic characterization of IoT technology as metacommunication called the semiotic engineering of multi-level and multi-sided technologies, as an initial framework for the application of Semiotic Engineering principles and methods to IoT technology. Thirdly, my research design was generalized into a macro-method for approaching innovative technologies research. I claim that it is an useful alternative in research domains where there is a lack of methodological and epistemological consensus and/or diversity, such as with new technologies. These contributions both extend the body of knowledge of semiotic engineering as a theory and provide powerful resources for designers and researchers to reflect on technology in a human-centered way, I argue.

\section{Keywords}

Internet of Things; Semiotic Engineering; Interaction design; HumanCentered Computing. 


\section{Resumo}

Chagas, Bruno Azevedo; De Souza, Clarisse Sieckenius (Orientadora). Metacomunicação e Apropriação no Projeto da Internet Interativa das Coisas. Rio de Janeiro, 2020. 269p. Tese de Doutorado Departamento de Informática, Pontifícia Universidade Católica do Rio de Janeiro.

A Internet das Coisas (IoT, do inglês Internet of Things) refere-se à infraestrutura tecnológica emergente formada por objetos cotidianos e ambientes dotados de computação e conectividade a fim de fornecer serviços digitalmente enriquecidos e comportamentos responsivos no mundo físico. Como com toda tecnologia, nas pontas da IoT há as pessoas que projetam e as que usam essa tecnologia de alguma forma. Projetar a interação para a IoT apresenta desafios novos e antigos. Nesta tese, eu abordo dois deles, a metacomunicação e a apropriação. O primeiro tem a ver com as pessoas que projetam a IoT; o último, com as que usam. Aplicando a Engenharia Semiótica como uma lente teórica ao estudo da IoT, realizei seis estudos usando diferentes métodos cujos resultados foram combinados em três contribuições. Primeiro, proponho um modelo semiótico de apropriação de tecnologia como uma ferramenta epistêmica para apoiar projetistas a refletirem sobre como os usuários adotam a tecnologia de IoT. Segundo, proponho uma caracterização semiótica para a tecnologia da IoT como metacomunicação, chamada de engenharia semiótica de tecnologias multiníveis e multilaterais, uma ferramenta inicial para a aplicação de princípios e métodos de Engenharia Semiótica à tecnologia da IoT. Terceiro, minha abordagem de pesquisa foi generalizada em um macro-método para pesquisa em tecnologias inovadoras como uma alternativa útil para pesquisas onde há falta de consenso e/ou diversidade metodológica e epistemológica, como em novas tecnologias. Essas contribuições estendem os conhecimentos da Engenharia Semiótica como teoria e fornecem recursos poderosos para projetistas e pesquisadores refletirem sobre a tecnologia de uma maneira centrada no ser-humano, eu argumento.

\section{Palavras-chave}

Internet das Coisas; Engenharia Semiótica; Projeto de interação; Computação Centrada no Ser Humano. 


\section{Table of contents}

1 Introduction 15

1.1. The Internet of Things 17

1.2. Opportunities and Challenges 19

1.3. Looking for Answers in a Human-Centered Way 23

1.4. This Thesis 25

2 Framing the Problem 28

2.1. The Design of Interaction for The Internet of Things 28

2.2. Technology Appropriation 35

2.3. Research Questions 40

3 Theoretical Foundation 45

3.1. Semiotic Engineering 45

3.2. Semiotics: Signs and Semiosis 50

3.3. Abduction, Interpretation, and Pragmatism 56

3.4. Culture and the Signifying Order 62

3.5. Changing the Signifying Order: Poetry and Idiolects 68

4 Research Design (1): Mapping the Problem Space 72

4.1. Study 1: Theoretical Inspections Based on Semiotic Engineering 75

4.1.1. Method 76

4.1.2. Analysis 77

4.1.3. Results 79

4.1.4. Conclusion $\quad 81$

4.2. Study 2: A Qualitative Analysis of IFTTT Applets Using Some Grounded Theory Techniques 83

4.2.1. Method 83

4.2.2. Analysis 84

4.2.3. Results 84

4.2.4. Conclusion 88 
4.3. Study 3: Autoethnography 91

4.3.1. Method 92

4.3.2. Results 93

4.3.3. Conclusions 95

4.4. Study 4: Diary Study $\quad 97$

4.4.1. Method 98

4.4.2. Analysis 99

4.4.3. Results 101

4.4.4. Conclusion 113

5 Research Design (2): Converging and Evaluating Results 116

5.1. Study 4 Continued: Proposing an Appropriation Model 117

5.1.1. Method 118

5.1.2. Analysis 119

5.1.3. Results 120

5.1.4. Conclusion 130

5.2. Study 5: Thematic Analysis on Literature Reports 132

5.2.1. Method 132

5.2.2. Analysis 133

5.2.3. Results 134

5.2.4. Conclusion 139

5.3. Study 6: Model Evaluation Study 141

5.3.1. Method 141

5.3.2. Analysis 145

5.3.3. Results 146

5.3.4. Conclusion 152

6 Consolidating and Discussing the Results 153

6.1. A Semiotic Model of loT Technology Appropriation 153

6.1.1. Theoretical Derivations and Working Hypotheses: Semiotic Idiolects, the Personal Signifying System, and the Poetic Function of Technology155

6.1.2. The Emergence of Users' Interactive Idiolects 159

6.1.3. Discussion and Some Implications for the Design of Appropriable IoT Technologies 
6.1.4. On Breakdowns 175

6.1.5. Related Work (and How to Use My Model) 179

6.2. Multiple Layers of Metacommunication: A Semiotic Characterization of $\begin{array}{ll}\text { loT Technology } & 187\end{array}$

6.2.1. Substratum, Superstratum, and Semiotic Contiguities 188

6.2.2. The Interpretive Abstraction and Semiotic Continuum Principles (Revisited)

6.2.3. The Semiotic Engineering of Multi-Level and Multi-Sided Technologies 195

6.2.4. Ethical Implications towards a Human-Centered IoT 207

6.3. Methodological and Epistemological Considerations 210

6.3.1. A Macro-Method for Researching New Technologies (or for New Researches in Technology) 215

7 Conclusion 222

7.1. Limitations 226

7.2. Future Work 230

7.3. Final Remarks 238

$\begin{array}{ll}\text { References } & 241\end{array}$ 


\section{List of figures}

Figure 3-1 - The semiotic engineering design space (adapted from: DE SOUZA, 2005a, p. 88, Fig. 3.2).

Figure 3-2 - A depiction of a Peircean sign "S" denoting a tree. The word "tree" is a sign S1 composed by its representamen " $\mathrm{R}$ " ("tree"), its object "O" (e.g. an actual tree in a forest that was seen by the writer), and its interpretant "I," which is another sign S2. Unlimited semiosis is the process by which a sign Si determines its meaning through another

sign $\mathrm{Sj}$, which in can go on infinitely in theory

Figure 3-3 - The Signifying Order, adapted from (DANESI \& PERRON, 1999, p. 63) 68

Figure 4-1 - A depiction of my research approach: a triangulation of different methods as a form of mapping the problem space.

Figure 4-2 - A Semiotic Engineering framing of EUD for the IoT: Who's telling what to whom and how in the IoT ecosystem? (originally published in: CHAGAS, REDMILES \& DE SOUZA, 2017). 78

Figure 4-3 - A graphic displaying the occurrence of four categories of presumed intent found in the set of 462 IFTTT applets using the Philips Hue smart lights. First row is the number of applets and second row is the number of installations, the number of times each applet has been turned on by some user, a proxy for applet popularity.

Figure 4-4 - A photo of IoT products exposed in an electronics retail store in the USA in January 2017 at Irvine, California. These are products targeted to the general consumer in the smart home domain. (Photo taken by the author at Irvine, California, USA (C) BAC 2017).

Figure 4-5 - Breakdowns with IoT technology and EUD as repair activities (from a poster presented at the 2017 IEEE Symposium on Visual Languages and Human-Centric Computing - VL/HCC).

Figure 4-6 - Appropriation as states and the stabilizing process in-between them (originally published in: CHAGAS, REDMILES \& DE SOUZA, 2018). 
Figure 4-7 - The scope of cross-device coherence and cross-interface consistency (originally published in: CHAGAS, REDMILES \& DE SOUZA, 2018).

Figure 5-1 - Our macro-methodology laid over the problem space.

Figure 5-2 - Our macro-methodology laid over time.

Figure 5-3 - Visualizing the data analysis process.

Figure 5-4 - The current codebook of the qualitative analysis of the diary study data registered in the QDA Miner software. The picture illustrates the richness of our data inventory.

Figure 5-5 - Semiotic processes codes.

Figure 5-6 - My semiotic appropriation model showing appropriation as states, breakdowns triggering users' abduction, and the semiotic processes in between two states.

Figure 5-7 - The illustration of the seven semiotic processes of our appropriation model that was shown to the interviewees.

Figure 5-8 - Coding themes appearing in designers' interviews. 146

Figure 6-1 - An expanded model of the communication and design space for semiotic engineering representing the one-shot metacommunication message from designers to users. Adapted from (ECO, 2017, p. 129, Fig. 29).

Figure 6-2 - The semiotic processes of the semiotic appropriation model. 162

Figure 6-3 - An example of a rejection supportive interface: advanced configurations can be rejected by users not willing to deal with them in certain situations. Nevertheless, they are always accessible without compromising user's experience for the more frequent use cases. (Photos taken by the author at the Gist Lab, PUC-Rio, Brazil (C BAC 2020).

Figure 6-4 - An example of designers generating breakdowns on purpose by releasing a new version of a technology (Screenshots from a marketing email received by the author on 18-Feb-2020 - (C) LIFX 2020 used under permission).

Figure 6-5 - The D-Link DCH-S150 smart motion sensor deconstructed. (Photos taken by the author at the Gist Lab, PUC-Rio, Brazil @ $\mathrm{C}$ BAC 
2020).

Figure 6-6 - The Panasonic PIR wall installation type detection field (adapted from: PANASONIC, 2016, p. 8).

Figure 6-7 - The semiotic engineering of multi-sided technologies.

Figure 6-8 - Leaking signs from APIs in the IFTTT web application in three different moments: (A) IFTTT asking for authorization from Philips Hue; (B) Names and parameters from the Philips Hue appearing in the IFTTT interface while creating an action for a new applet in IFTTT (C).

Figure 6-9 - The multi-sided aspect of the IFTTT platform: (A) an intentional leaking sign in the very bottom of the IFTTT web application points to the IFTTT interface targeted to its ad-users; (B) the IFTTT ad-user main interface.

Figure 6-10 - The metacommunicative dimensions of IoT multi-level and multi-sided technologies

Figure 6-11 - A macro-method for researching new technologies or for new researches in technology. 


\section{List of tables}

Table 4-1 - Communicative dimensions of configurations of IoT devices: .88

Table 4-2 - Diary study participants profiles, quantity of diary submissions and of reported breakdowns: 100

Table 4-3 - Summary of observed breakdowns, tags, and their relation to appropriation (originally published in: CHAGAS, REDMILES \& SOUZA, 2019):

Table 5-1 - Study 6 interviewees: IoT technology designers' profiles and backgrounds:

Table 6-1 - Types and dimensions of signs in multi-sided technologies:. 203 


\section{List of boxes}

Box 2-1 - My research questions on appropriation: .......................................... 43

Box 2-2 - My research questions on design for appropriation: ........................... 43

Box 3-1 - The metacommunication message template (De Souza, 2005, p.

84):

Box 5-1 - Summarized version of the interview scenario: ................................. 144 


\section{Introduction}

This thesis takes a human-centered approach to the Internet of Things (IoT) as an emerging new technology. It is about some challenges that two more or less distinct groups of people - namely, users and designers - face regarding the IoT, and how to approach these challenges in a human-centered perspective. Users and designers face different but tightly coupled challenges, in the sense that the success of one can be usually associated with the success of the other. Designers need to understand the users in order to provide functions and tools to support users' needs, goals, contexts and preferences in the technology they design. Users in turn need to decipher and deal appropriately with the possibilities and limits of the designed technology in order to accomplish their goals in their preferred ways. At the technology's interface, designers and users meet, a metaphor that will be discussed and explored throughout the way in the following chapters.

With this metaphor in mind, I can say that the ultimate goal of this thesis is very pragmatic: to find and propose ways or tools that can help technology designers and researchers to study and design IoT technology that really fits users' needs, goals, abilities, and preferences. These are long-lasting challenges of the technology industry that the IoT technology will probably not address directly, at least not automatically. They are inherent to the process by which we design and built any technology and, although the whole process has gotten more interactive and agile over time, nothing has really changed in its essence. Still, designing IoT technology or any other technology means getting to know the users, identifying requirements and possibilities, creating, elaborating and testing ideas, taking decisions, packing a solution and delivering it to the world. Except, of course, for the fact that the technologies and the contexts in which they are used are getting increasingly more complex and sophisticated with the IoT, which can make each of these steps painfully harder, as well as dealing with their intended and unintended consequences. 
From my pragmatic goal stated above to the production of scientifically valid knowledge that can meet it, there is quite a long way to go. Needless to say, there are actually multiple possible ways to go, each with its own strengths and weaknesses, advantages and disadvantages, and that should complement each other in the long term. Here, my approach to tackle such challenge is a combination of theoretically grounded analysis based on Semiotic Engineering (DE SOUZA, 2005a) and empirical analysis derived from qualitative studies which developed in three contributions. Firstly, I am proposing a semiotic model of technology appropriation, which describes how users adopt IoT technology in a way that can be used by technology designers to improve their designs. Secondly, I am proposing a semiotic characterization of IoT technology as metacommunication, which I called the semiotic engineering of multi-sided and multi-level technologies. It is an initial framework for the application of semiotic engineering principles and methods to IoT technologies. Thirdly, my research design was generalized into a macro-method for approaching innovative technologies research. I claim that it is an advantageous alternative in research domains where there is a lack of methodological and epistemological consensus and/or diversity, such as with new technologies.

Perhaps because of the inherent complexity of the domain or of my approach or both, this thesis describes this research as a journey in which I share with the reader not only my results and findings, but my own reflections, rationale, and decisions over the way. Although everything contributes for the reader's deepest understanding of this thesis, a broader audience of researchers and designers with different backgrounds and expectations may find useful to pursuit different reading paths. This first chapter provides the reader with a glance at the current state of IoT technology development and its issues that form the contextual, cultural and historical background where this research was conducted. In the following sections, I will describe IoT technology as the topic of this thesis (Section 1.1), some of its existing challenges and issues (Section 1.2), and the human-centered perspective that guided us through this entire research (Section 0 ). By the end of this chapter, my research approach is summarized and the overall structure of this thesis is presented (Section 1.4). Those who are familiar with IoT and similar technologies and with Human-Centered Computing (HCC) may skip this introduction and jump directly to Section 1.4. 


\section{1.}

\section{The Internet of Things}

Technologically, the Internet of Things (IoT) refers to the emerging technological infrastructure formed by everyday objects and environments endowed with computing and networking power able to sense, actuate, compute, and communicate with each other and with the Internet in order to provide and support digitally enhanced services and responsive behaviors in the physical world. It has been referred as a paradigm (ATZORI; IERA; MORABITO, 2010; WHITMORE; AGARWAL; XU, 2015), a vision (KOPETZ, 2011), a network (GERSHENFELD; KRIKORIAN; COHEN, 2004), or the network-the future of the Internet (GUBBI et al., 2013; LI; XU; ZHAO, 2015). Put simply, "IoT refers to the networked interconnection of everyday objects, which are often equipped with ubiquitous intelligence" (XIA et al., 2012), presupposing computation at its core, as the enabler element of digital networking and whatever degree of intelligence is assumed.

The IoT is used in this thesis as an umbrella term to refer to technologies appearing as closely related concepts, such as ubiquitous computing, pervasive computing, ambient intelligence, and of course Internet of Things itself. Although there are historical and technical differences between them (cf. MANWARING; CLARKE, 2015), I will use all terms interchangeably here because for the purposes of this work their similarities are more relevant than their differences, as will be discussed further in Chapter 2 (Section 2.1). These concepts are all related to what Manwaring \& Clarke call "the third wave of computing." "Sometimes these terms are used interchangeably, other times they are used in different but overlapping contexts and with wider or narrower scopes of meaning" (op. cit.). Their "third wave of computing" is what I would call computing beyond computers $^{1}$ or without computers (GREENFIELD, 2010, p. 11), the concrete infrastructure realizing Mark Weiser's (1991, 1993) vision for ubiquitous computing in an expanded and updated way.

Stefan Poslad (2011) provides some examples that, although a little outdated in terms of the enabling technologies he discussed, may illustrate well the core

1 I am not sure about the first time I have heard or read about "computing beyond computers," but as far as I can remember it was in Prof. Hugo Fuks (PUC-Rio) talks and classes during my 
idea behind the IoT and most of its challenges. He mentions four illustrative applications; A personal memories system where users can record and keep audiovideo contents, detecting their contexts and allowing rich annotations to be viewed and reviewed later; An adaptive "twenty-first-century" transport service able to adjust preset schedules and plans to the actual status of the environment and distribute this information to users in real-time; A foodstuff scenario where "analog" real-world objects such as food are digitally interfaced and fed into a computing system in order to monitor their human usage, potentially including robots for moving them around and taking care of the logistics (in a warehouse or a supermarket, for example); A utility management application (e.g. potable water, electricity, heating, or sewage management) where consumer devices and a distribution network are managed according to their usage "in a user-centered way by enabling them to cooperate to achieve common goals." These scenarios illustrate the great potential that the IoT opens up in a great variety of social activities and domains. They comprise different human scales where IoT technology is already applied, ranging from personal, to households, to communities, to cities or nations. And they are not so futuristic as they used to be anymore.

Indeed, all the illustrative applications and scenarios suggested by Poslad above already exist, to some degree. A social network app running over a sensorpowered mobile smartphone is nothing less than a personal memories system. Uber and similar apps are nothing less than adaptive transport services able to self-regulate according to market conditions and publicize the service's state to users in real-time. Amazon Go stores sell "analog food" by using computer vision, a combination of sensors, and machine (deep) learning algorithms to provide a "checkout-free" experience to customers (AMAZON INC., 2018) as well as to optimize supply chain and inventory management (GREWAL; ROGGEVEEN; NORDFÄLT, 2017). "Smart grids" and similar technologies are being adopted all over the world in different scales in order to afford more reasonable and sustainable resource consumptions (e.g. HERZOG, 2013). As of "today," several technological challenges envisioned by ubiquitous computer pioneers have already been met, pulled by shrinking costs in silicon technologies, widespread

early graduate studies between 2013-2016, for whom I give the credit about it. Other very similar ideas appear in Weiser's papers and their offspring. 
wireless networks presence, mobile phones impressing dissemination everywhere, and of course, advancements in several fields of Computer Science (KUNIAVSKY, 2010, cap. 1; SCHMIDT, 2010).

\section{2. Opportunities and Challenges}

The IoT is a fast-changing area of research and technology development that brings together the latest advancements from different fields, from Engineeringsuch as new materials, electronics, sensors and actuators - to Computer Sciencesuch as distributed systems, computer networks, artificial intelligence, and human-computer interaction, to name a few. According to Kuniavsky (2010), "writing about ubiquitous computing is like trying to draw a supersonic plane as it's flying overhead. At best you can try to get the general outline, and leave the details a blur" (p. vii). This is motivated by some impressing numbers.

It is been a while since companies and market studies project a strong growth in the number of connected devices in the order of tenths of billions per year. Castillo O'Sullivan \& Thierer (2015) report that the total number of connected IoT devices in use all over the world was projected to be somewhere between 19 to 40 billion by 2019 crossing estimates from different companies and market research institutes such as Gartner, IDC, and Cisco. Among these connected devices, there would be smart home appliances, wearable devices, smart metering systems, and autonomous vehicles, to name a few. Some companies went even further, projecting an astonishing 200 billion of connected devices by 2020 in their mix of futurology and marketing strategies (INTEL, 2006). Exaggerations apart, this is 2020 and it seems that we have passed the 20 billion connected devices already according to some market specialists and specialized tech press (e.g. HELPNETSECURITY, 2019). Ejaz et al. (2016) say that projections for the 2020 were for an average of 6-7 connected devices per person leading to the 20-40 billion connected devices. In a world of approximately 7.5 billion people and 4 billion internet users (WORLDOMETER, 2020) we may not be really far. Assuming an "ideal" internet user in a high developed country with a mobile phone, a notebook, and a tablet, adding a voice assistant, a smart home appliance and a smart something else already takes us there. In addition, 
new technologies such as the emerging $5 \mathrm{G}$ cellular networks are poised to boost this number even further (EJAZ et al., 2016).

Naturally, the economic impact of the IoT is expected to be huge, in the order of trillions of dollars in associated revenue from IoT products, services and related businesses. After all, from a business perspective, the bottom-line purpose in connecting "anything and anyone at any time and any place" with IoT technology is to give rise to "innovative new applications and services" (LU; PAPAGIANNIDIS; ALAMANOS, 2018). According to Castillo O'Sullivan \& Thierer (2015), "the total global impact of IoT technologies could generate anywhere from $\$ 2.7$ trillion to $\$ 14.4$ trillion in value by 2025." Business and economic challenges and opportunities related to the advent of the IoT are focus of considerable interest (CHUI; LÖFFLER; ROBERTS, 2010; LEE; LEE, 2015; LU; PAPAGIANNIDIS; ALAMANOS, 2018; MADAKAM; RAMASWAMY; TRIPATHI, 2015; WHITMORE; AGARWAL; XU, 2015). This has been motivating specific public policies directed towards IoT innovations all over the world (BNDES, 2017; e.g. EUROPEAN COMMISSION, 2015).

But that does not mean everything is a bed of roses. How is this technology being designed and used, what for, and how it is actually enhancing human life are completely different topics. Thankfully, a group of researchers from the human-computer interaction (HCI) field have made questions in this line too as back as in 2008:

"What will our world be like in 2020? Digital technologies will continue to proliferate, enabling ever more ways of changing how we live. But will such developments improve the quality of life, empower us, and make us feel safer, happier and more connected? Or will living with technology make it more tiresome, frustrating, angst-ridden, and security-driven? What will it mean to be human when everything we do is supported or augmented by technology? What role can researchers, designers and computer scientists have in helping to shape the future?" (HARPER et al., 2008, p. 10)

This is 2020, and the extent to which Harper and others' questions have been or even can be answered is not clear yet. For instance, by 2008 the authors have defined Twitter - the now well-known social network app —as "a miniblogging tool for people to send small text-based nuggets of information to friends, family and co-workers to let them know what they're up to throughout the course of the day" (ibid., p. 24). Right now, Twitter, as most social networks, is used as a propaganda tool in order to influence nations' elections, and not by 
positive means or in a positive way only (BOVET; MAKSE, 2019; VOSOUGHI; ROY; ARAL, 2018). This demonstrates how technology is changing fast and some challenges are products of this fast-development and how society appropriate it. We have reasons to believe that the same will happen with the IoT. And the IoT era is just starting.

In spite of the potential positive impact coming with the IoT, chances are things get increasingly complicated. Ren et al. (2019) have just recently found that, from a set of 81 consumer IoT devices in the US and the UK (mostly smart home devices), the majority of them were exposing their users to privacy and even security risks. Besides the manufacturer (a "first-party" who could be said to be expected to receive users' data in this scenario), devices were sharing data with what they called "support-parties" (that is, "companies providing outsourced computing resources, such as $\mathrm{CDN}^{2}$ and cloud providers") and third-parties (that is, "any party that is not a first or support party, including advertising and analytics companies"). Most of these data can reveal patterns of devices and their usage and thus be used for identification and profiling, and some contained location, audio and video data in what they considered to be "unexpected ways." These are very sensitive information that were found to be transferred across country borders in several cases, even bypassing national regulations on privacy and data protection policies.

In a similar vein, Moghaddam et al. (2019) found that smart TV streaming devices (e.g. Roku and Amazon Fire TV) perform heavy user tracking, collecting and transmitting unique identifiers over the internet for profiling and advertising purposes, sometimes over unencrypted connections. At yet another similar vein (and perhaps even more disturbing), the Press has been warning about the increasing adoption of sophisticated facial recognition surveillance technologies that threatens the right to privacy and can be used to restrict people's freedom (KUO, 2019; e.g. MOZUR, 2019; MURGIA; YANG, 2019), or to change people's habits in strange new ways (HARWELL, 2020). Privacy and security issues have always been well-known concerns of IoT technologies to researchers (e.g. ATZORI; IERA; MORABITO, 2010; LATIF; ZAFAR, 2017) and to

2 CDN stands for Content Delivery Networks, that is, geographically distributed servers in charge of delivering internet content with high availability and performance based on users' locations and distribution. 
industry/business (e.g. CHUI; LÖFFLER; ROBERTS, 2010; LU; PAPAGIANNIDIS; ALAMANOS, 2018). But somehow, their worst sides just seem to be gaining life.

If general IoT users' lives can get complicated, we cannot say designers have easy ones. Think about everything that an IoT technology builder (that is, an IoT product or service company, designer or development team, if you like) has to deal with in order to combine hardware and software in such a way to offer an attractive piece of technology to users and, still, build a sustainable business. IoT designers' lives are not a bed of roses either. Designing a commercial IoT device, for example, comprises merging industrial design and engineering, hardware and software, interaction design and business offers, all these under adverse pressures from market, regulation and competition. The website "Postscapes" has been collecting a directory of failed IoT products and services since 2010 (POSTSCAPES, 2010). Among their list, it features "Pebble," the first smartwatch ever, which was brought to life by a successful crowdfunding campaign in 2012 (CANALES; WEINBERGER, 2018). They could not compete with Apple and other big players that entered the market they have first explored and smoothed the way ${ }^{3}$. Others, became a worldwide joke by trying to sell $\$ 400$ dollars smart juice machines that did no better than hand-squeezed packs (HUET; ZALESKI, 2017; LEVIN, 2017). "Juicero" started with a successful investment round and ended up as an overly sophisticated and unnecessary "solution" for a problem that did not even exist (KLEINA, 2017). All these cases are meant here to illustrate the complexity and risks inherent to designing innovative technologies, perhaps not exclusively IoT.

For the time being, the assertiveness of Harper and colleagues (2008) futurology exercise is impressively high. The quantitative and qualitative changes in the nature of computing technologies, the emergence of more diverse types and modes of interfaces and interactions, the growth of techno-dependency and hyperconnectivity, the persistency of our digital footprints and the spread of surveillance technologies were posed by them among the main HCI challenges for the 2020s. It seems that they knew what they were talking about, and they were talking about the IoT without calling it by the current name. To address these

3 One can say Pebble "fell upwards" since they ended up being acquired by FitBit (RUTHERFORD, 2018). 
challenges, they suggested that "HCI needs to extend its methods and approaches so as to focus more clearly on human values. This will require a more sensitive view about the role, function and consequences of design, just as it will force $\mathrm{HCI}$ to be more inventive" (ibid., p. 52). If and how we are doing it though is the question to answer now.

\section{3. \\ Looking for Answers in a Human-Centered Way}

A relatively recent paradigm for the study of technology (and people) that seems particularly suited to the perspective suggested by Harper et al. (2008) above is called Human-Centered Computing (HCC). HCC has been defined as "an emerging field that aims at bridging the existing gaps between the various disciplines involved with the design and implementation of computing systems that support human's activities" (SEBE, 2010). Traditionally, Computer Science is recognized by being built from mathematical and technical disciplines, such as logic and formal languages, programming and algorithms, and (software) engineering disciplines. Gradually, researchers and practitioners started to pay attention to the several human aspects involved in the design and use of computer technologies, like the cognitive, psychological and social aspects of the people in relationship with systems and the contexts in which systems are used and, why not, built.

To build a fruitful integration between these apparently incompatible worlds - the technical and the human - is a tough job. HCC arises as a relatively novel field proposed to foster the dialog between different sciences and perspectives aiming "at tightly integrating human sciences (e.g. social and cognitive) and computer science (e.g. human-computer interaction (HCI), signal processing, machine learning, and ubiquitous computing) for the design of computing systems with a human focus from the beginning to the end" (SEBE, 2010, our emphasis). According to Flanagan et al. (1997), this is not only an integrative effort of different sciences and perspectives but a necessary shift in the way we think about information technology. "A shift that embraces human activity, technological advances, and the interplay between human activity and technological systems as inextricably linked and equally important aspects of 
analysis, design, and evaluation" (idem). The grand vision of HCC is that technology is not only about technology; it is about the knowledge, the people, and everything surrounding and tying them together (SEBE, 2010). According to Sebe (idem), this calls for both the creation of theoretical frameworks and the design and implementation of systems guided by this vision. But what kind of theoretical frameworks, how to do it in the design and implementation practice, and even how to evaluate what is being done are completely open questions, both for the design of technologies in general and IoT technologies in particular.

For reasons that will become clear throughout this work, this thesis is an effort to look at the two sides of the IoT story. This is a particular vision of HCC also shared by other researchers who have applied this perspective in the study of software developers, their development processes and tools (BASTOS; AFONSO; SOUZA, 2017; e.g. DE SOUZA et al., 2016; MYERS et al., 2016). The IoT is as much about technology as about the people who relate with it in different social contexts and from different standpoints. If a user-centered approach arguably centers its focus in the user, a human-centered one needs to try to make it differently. And the reason is actually very practical and straightforward. According to Whitmore et al. (2015), the IoT paradigm is about combining identifying, sensing, networking, and processing capabilities in order "to accomplish some objective." We can assume that this implies human objectives in the real world inhabited by humans. Designers are also part of this group of humans whose objectives the technology should meet. If several technological advancements are making the IoT possible, equally important is hence that we study the humans, their objectives and experiences with this technology, that manifest in the way by which people use, interact, and, why not, design this technology in order to accomplish their goals, whoever's goals these are.

No matter how different IoT applications are, in terms of their goals, architecture and technology, in common, they will have people at the ends, building and interacting with the technology somehow. More precisely, at both ends of any "network of things" there are the people who use it and those who build it. At both ends, a challenge for one becomes a challenge for the other. A pain-point at the users' side need to be addressed in the technology design and the hardest the challenge, the hardest or more technologically sophisticated and expensive the solution can get. An untreated or unresolved design issue during the 
design eventually emerges at use time to users, who can always look for alternatives, such as not using the technology at all. To a large extent, the success of a technology depends that both parties can understand each other appropriately. Sometimes, it's hard to tell whose fault is that, as when a requirement is not met because it has not been identified before, or a silent critical issue causes a harmless, a serious or a complete product failure.

\section{4.}

\section{This Thesis}

I cannot address all challenges users and designers face with IoT technologies. This thesis investigates two of them, namely metacommunication ${ }^{4}$ and appropriation. The former has to do with the people who design the technology, the meanings they inscribe in the technology and communicate to the users through the interfaces they design. The latter, with those who use the technology, and what they do with the meanings that are communicated to them. The identification and relevance of these challenges in a human-centered perspective will be discussed in the next chapter, as I frame my research questions in a more tractable way. I applied Semiotic Engineering (DE SOUZA, 2005a) as a theoretical lens to the study of IoT technology and conducted six qualitative studies using different research methods, whose results were combined and consolidated in three main contributions for the human-centered design and research of IoT technology. My contributions both extend the body of knowledge of Semiotic Engineering theory and provide powerful tools for designers and researchers to reflect on technology in a human-centered way.

Firstly, I am proposing a model of technology appropriation as an epistemic tool which describes how users can adopt IoT technologies in their actual contexts and practices. I have identified appropriation as a core phenomenon of user experience with IoT technology and developed a theoretical model grounded in both empirical data and semiotic theory that describes the appropriation process by users. Although other descriptive models of technology appropriation exist, my

4 Technically, metacommunication is "communication about (aspects of) communication itself" (DE SOUZA, 2005a, p. 83). In Semiotic Engineering, metacommunication refers to the underlying message that designers convey through a system's interface that tells users how they are supposed to interact (communicate) with the system. It is a technical concept that will be explained further in Chapter 3 (Section 3.1). 
appropriation model can distinctively support designers to improve their designs because it links appropriation to the interactive features of the technology. In so doing, it offers an orienting framework to support designers to think reflectively about how to design the interaction of appropriable IoT technologies, I claim.

Secondly, I am proposing a semiotic characterization of IoT technology as metacommunication, which I called the semiotic engineering of multi-sided technologies. It is an initial theoretical framework for the application of Semiotic Engineering principles and methods to IoT and similar technologies. This framework is unprecedented in literature and was derived as a theoretical account that is consistent with Semiotic Engineering principles, which were specialized to address IoT technologies core features. Its purpose is to leverage what Semiotic Engineering already tells us about interactive technologies in general to IoT technologies and applications. In so doing, I propose that it is particularly suited for evaluation and research of IoT technologies in the human-centered perspective. Although theoretical, I show that this framework resonates with some existing applications and empirical findings.

Thirdly, my research design was generalized into a macro-method for approaching innovative technology research. I claim that it is an advantageous alternative in research domains where there is a lack of methodological and epistemological consensus and/or diversity, such as with new technologies.

This thesis is organized as following. This introduction is followed by a literature review about the main topics of this thesis in Chapter 2. This review includes works about designing interaction for the IoT and some of its main challenges (Section 2.1). Technology appropriation is also introduced to the reader and reviewed in terms of most relevant works (Section 2.2). These topics are combined in the research questions that guide the following chapters of this thesis (Section 2.3).

Chapter 3 introduces Semiotic Engineering in particular and semiotic theory in deeper level that ground the answers to my research questions and the theoretical extensions I am proposing. Readers willing to learn Semiotic Engineering and a bit of semiotic theory are advised to read it carefully. Those already familiar with it or more interested specifically in my contributions can skip it, and try to cope with the concepts used later through the cross-references I provide throughout the text. 
Chapter 4 and Chapter 5 describe my overall research design and the studies that I conducted, one per sub-section. They provide a historical perspective that shares with the reader my path and reflections at the respective time, as I was gradually building and developing my contributions. Those interested in research design can read it entirely, or the initial sections for an overview. Each particular study description is more or less independent from each other and those who read them entirely will be able to trace the birth and development of my contributions in a gradual way. Those more interested specifically in my contributions in a more polished form can skip to Chapter 6, where they are finally described and discussed.

Chapter 6 consolidates all the results in terms of the three contributions described above, organizing the results and discussing their implications. Each sub-section is somewhat independent from the other, allowing for a partial reading: read Section 6.1 for the semiotic model of appropriation; Section 6.2 for the semiotic engineering of multi-sided and multi-level technologies; and Section 6.3 for the research macro-method. Again, cross-references are provided to link to other parts where the reader can find related discussions, when applicable.

Finally, in Chapter 7, I discuss some limitations of the work, present interesting possibilities of future work, and conclude with my final remarks. 


\section{2 \\ Framing the Problem}

The overall topic of this thesis is interaction with the Internet of Things and how to design it. In this section, I will introduce this overall topic by means of a review of the state-of-the-art that frames the inherent problems of interacting with IoT. Among all other possible framings, which are infinite in number, this particular framing is determined by a human-centered perspective of the topic, which leaded to the topic of technology appropriation, that was highlighted as a core phenomenon of user interaction with the IoT. After introducing these topics, the framing will be summarized in the core research questions that this thesis addresses. I will start by a review about interaction for the IoT in literature that highlights what I identified as the most relevant aspects and points to the perspective of this work over the topic. This is neither an extensive description of problems nor a systematic literature review about interaction with the IoT. Rather, it is an organized summary of relevant characteristics and challenges that impact or influence interaction with IoT technology in order to orient the design thereof in tractable way.

\section{1.}

\section{The Design of Interaction for The Internet of Things}

User interaction or experience with the IoT is a good starting point for a HCC approach because they allow us to depart from the somewhat technocentric or engineering-oriented nature of the prevailing research about IoT. The locus of user interaction is the technology interface, the very place where both users and designers "meet," through the mediation of the technology.

According to Kuniavsky (2010), "after more than twenty years [thirty years now] of mobile phone design and nearly as long since the initial definition of ubiquitous computing, there is still no common agreement about what constitutes the ubiquitous computing user experience and who is responsible for it" (p. 13). He says that because Ubicomp products merge hardware, software and services, it 
is not clear the kind of skills that are required to design in such context, what is aggravated by the rapid pace of technological and social changes in this domain.

Interaction challenges and issues with IoT technology tend to be very application- and context-specific, naturally. But I can identify some general characteristics inherent to IoT technology that distinguish interacting with it from interacting with other kinds of computing technologies. Poslad (2011) gives a comprehensive outlook of ubiquitous computing technologies and some applications and say that they can be designed according to a general model of smart devices, environments, and interactions ("Smart DEI") to address the core different aspects inherent to this kind of technology. He provides a good starting point by proposing a taxonomy of ubiquitous computing system properties grouped into five categories: distributed systems, implicit interaction, contextaware, autonomous and intelligent. As he recognizes himself, "there is [no] single definition which accurately characterizes ubiquitous computing: rather there is a range of properties and types for ubiquitous computing which vary according to the application." These properties can be partially or fully supported in varying degrees depending on the practical needs of the application.

Using Poslad and others to be added bellow, I will try to outline a comprehensive conceptual backdrop appearing in literature that fits the grand IoT vision and highlights the core characteristics or properties that distinguish IoT technology and can influence or impact user interaction with it:

- Technology is distributed, causing people to actually interact with many smart devices and applications spread in their environments (DEY; LJUNGSTRAND; SCHMIDT, 2001). Sometimes interfaces can be deliberately designed to be invisible (WEISER, 1994) but not always, since personal devices and ubiquitous applications can be designed to be seen, explicitly controlled and engage people (ROGERS, 2006). In addition, since the advent and popularization of mobile computing devices (smartphones), the scope of places, contexts, and time that people use technology have greatly increased, which is expected to increase even further with the IoT. The immediate consequence is that interaction is distributed across devices, and accordingly, in space and time;

- The "system" is actually an ecosystem. This is a consequence of the previous feature but intended to emphasize the diverse and heterogeneous nature of 
IoT. The IoT vision comprises a set of smart devices and applications that work as building blocks of larger systems (KORTUEM et al., 2010). It is unlikely that a single manufacturer or brand will be able to provide unified, perfectly integrated and homogenous solutions for all needs of all users in every scale (e.g. person, households, communities, cities, etc.). IoT ecosystems are likely to be built by combinations of specialized parts growing organically (BRUSH et al., 2011), in a piecemeal fashion (EDWARDS; GRINTER, 2001), with combinatorial possibilities and often producing messiness (in the sense of a messy infrastructure) (BELL; DOURISH, 2007). Furthermore, ecosystems embrace more people. As technology occupies social spaces, from households to smart cities, users' experiences may be influenced by the other people sharing the same space and technology. Similar concepts have been proposed in literature in terms of multi-device environments (MDE) (FROSINI; PATERNÒ, 2014; MARTINEZ-MALDONADO; CARVALHO; GOODYEAR, 2018), ensembles (ENCARNAÇÃO; KIRSTE, 2005; HELLENSCHMIDT; KIRSTE, 2004), and digital ecologies (KUUTTI; BANNON, 2014; LUDWIG; TOLMIE; PIPEK, 2019).

- Smart devices and the emerging ecosystems are cyber-physical in nature, in the sense that they blend the digital and physical worlds by integrating computing power with capabilities of sensing and actuating in the physical world (LEE, 2008). Of course, every computer is "cyber-physical" in some sense, but the cyber-physical nature of IoT emphasizes systems engineered with the particular purpose of sensing and acting in the physical world, with a tight coupling between "the cyber" and "the physical" (RAJKUMAR et al., 2010) (in contrast with the standardized form factor and general purpose of "standard information devices" such as desktop computers and mobile phones). The design of cyber-physical systems is usually realized by the coupled design (or co-design) of hardware and software (e.g. RAJKUMAR et al., 2010; SHI et al., 2011). Horváth \& Wang (2015) proposed "a comprehensive theory of multi-aspect interaction of cyber-physical systems (CPS)" that resonates with several of the IoT features highlighted here, as we will see in the following property.

- Possibilities of interaction are greater and more diverse. We may call it multifactors interaction following Horváth \& Wang (op. cit.) to embrace all sorts 
of "post-GUI" (including touch screen GUI) interfaces. Their theory is comprised of multiple factors that should be considered together in the design of interaction for cyber-physical systems. Among their factors, they highlight that interaction can take place through different modalities of interfaces related to system's inputs and outputs vs. human senses (visual, acoustic, tactile, gustatory and olfactory). Multimodal interfaces seem to be important (cf. DUMAS; LALANNE; OVIATT, 2009). Similarly, other characterizations highlight the multiplicity of possibilities and the physicality of interfaces in the IoT domain (BUTZ, 2010). In addition, interaction can explicit or implicit. Implicit interaction - that is, when sensors and perceptual mechanisms enable the system to respond and react without users' explicit command (SCHMIDT, 2000) — used to be emphasized in ubiquitous computing literature, but IoT technologies may include both implicit and explicit interactions (POSLAD, 2011, cap. 5; ROGERS, 2006).

- The ecosystems are autonomous, intelligent and context-aware in varying degrees. Context-aware means the system will perceive the context based on data and events gathered from sensors, devices, other systems, the Internet, etc. (PERERA et al., 2014). Intelligent as in "ambient intelligence" (COOK; AUGUSTO; JAKKULA, 2009), meaning systems will use some sort of inference engine to make decisions on what to do. Autonomous because systems may behave without user intervention. The three aspects are tightly coupled and are usually studied together from an interaction standpoint (e.g. RUYTER; AARTS, 2010). The combination of them supports the realization of the kind of outcomes and applications usually associated with the IoT, such as the responsive behaviors of smart homes, smart offices, smart hospitals, etc. They provide smart environments or spaces with capabilities that range from simple automations (e.g. turning on the lights when somebody enters a room) to sophisticated behaviors (e.g. continually adjust the internal temperature of a building based on external weather conditions, the preferences of the persons inside, and with optimal energy consumption). In summary, that's what "smart" usually means in "smart-*" technologies.

- Finally, Kuniavsky (2010) proposes that we should look at IoT devices as "service avatars," that is, as parts or "agents" participating in providing services to users (KUNIAVSKY, 2010, cap. 8). This vision is particularly 
appropriate for commercial IoT technology and has to do with the objectives of the technology mentioned before. He defines "services" as "end user experiences that are delivered through a mix of software, hardware, and people following a prescribed set of business logic as defined by contractual agreements" (ibid., p. 100). This concept is related to business models called "product-service systems" (BAINES et al., 2007; BEUREN; GOMES FERREIRA; CAUCHICK MIGUEL, 2013; cf. TUKKER, 2004) which comprise an integrated combination of products and services in order to provide an enhanced value proposition to customers (and to companies, of course). The importance of taking this perspective here is that it greatly determines the final user experience and, for some, should be considered an integral part of interaction design (cf. ZIMMERMAN; FORLIZZI, 2013). Kuniasvky gives the example of analog televisions, which depended on the analog television broadcasting network, content producers, etc.; once the network was shut down in the USA, the device (i.e., the analog TV) became instantly useless and lost its value to users, who threw their TVs away. In modern IoT technologies we can see this associated with the idea of ecosystems mentioned above, where a single device (e.g. a smart watch, a music player, an e-book reader, or a smart security camera) is usually enhanced by and coupled with other devices, apps, and services (e.g. a mobile phone, an online music or book store, and a cloud storage service). Users interact with the entire service ecosystem through its "access points," that is, the devices or "avatars" in Kuniavsky's terms. The user holistic experience with the "service" needs to be considered by designers, increasing the complexity of designing for the IoT.

The technological features and properties above are crosscutting aspects that can be observed in different ways in IoT technologies and make them rather distinct from the more "traditional" information and communication technologies. A number of human-centered challenges that have been identified in literature can be related to one or more of these features (ABOWD; MYNATT, 2000; BELL; DOURISH, 2007; BELLOTTI et al., 2002; BELLOTTI; EDWARDS, 2001; BRUSH et al., 2011; DAVIDOFF et al., 2006; DOURISH; BELL, 2011; EDWARDS; GRINTER, 2001; GRINTER et al., 2005; HARPER, 2006; JESSUP; 
ROBEY， 2002; MENNICKEN; HUANG， 2012; OULASVIRTA， 2008; ROGERS, 2006). Most of these works report on application specific interactive challenges or focus on one property more or less isolatedly, which tends to produce independent lists of problems and/or design guidelines. This is valuable in itself and can be used to inform the design of specific applications or refinements regarding a certain aspect. But to start bottom-up may hinder our ability to see the whole since users are exposed to everything together, one thing intertwined with another. A different alternative is to take an integrative (holistic) perspective able to grapple the interaction between the different technologies' properties, features and of course people, that is, the user experience as a whole.

The concept of user experience (popularly known as "UX") was originally proposed by Donald Norman and colleagues (1995) as an effort to have a more holistic perspective on the design of user interaction and interfaces (popularly known as "UI"). There are many definitions and perspectives on user experience (GARRETT, 2010; HASSENZAHL, 2013; ISO, 2019; e.g. LAUGWITZ; HELD; SCHREPP, 2008). Kuniavsky (2010) is probably one of the firsts to try to systematize it for ubiquitous computing technologies. Here is his definition:

“The user experience is the totality of end users' perceptions as they interact with a product or service. These perceptions include effectiveness (how good is the result?), efficiency (how fast or cheap is it?), emotional satisfaction (how good does it feel?), and the quality of the relationship with the entity that created the product or service (what expectations does it create for subsequent interactions?)." (KUNIAVSKY, 2010, p. 14)

For every practical reason, experience and interaction design will be used interchangeably in this work. Following Bill Buxton's approach, their precise difference is not relevant here once we take a non-shallow concept of interaction and understand that the design of the interaction entails what is "designable" in terms of user experience (BUXTON, 2010, p. 127).

One of the phenomena that was identified as a component of user experience is appropriation (KARAPANOS et al., 2009; MCCARTHY; WRIGHT, 2004; TURNER, 2012). Appropriation is related with the process of technology adoption by people over time and comprises the fitting of technology into people's practices and vice-versa. Its more philosophical meaning is linked to ownership, taking something for one's own possession and use, and is probably rooted in Marxism (DESANCTIS; POOLE, 1994; OLLMAN, 1976, cap. 11). 
Marxism's derivations can be found in Vygotsky and Bakhtin, who used the concept in educational psychology and language studies, respectively (cf. ROGOFF, 1995). The concept is often used in educational contexts in a way that helps to understand its meaning in simple terms: when a learner is observed applying a skill or knowledge wisely and/or creatively he or she is said to have appropriated it (e.g. CAMPOS, 2011; MAGNUSSON; PRAMLING, 2011).

To study crosscutting aspects influencing the user experience, we need a crosscutting concept. By studying appropriation, we can "touch" all the crosscutting aspects of IoT technology mentioned above in an integrative way. Appropriation as a phenomenon is "ubiquitous" and "technology-proof" in the sense that it can be observed with different kinds of technologies, applications, and contexts, even with those yet to appear, manifesting in different ways. Moreover, it fits well with the idea of IoT ecosystems (composite systems) and services because it accounts for how technology is used in actual contexts, which rarely involves one single isolated device. In addition, differently from some perspectives (e.g. COUTAZ; CROWLEY, 2016), appropriation does not oppose to adaptable (where the user takes the initiative to adapt the technology) and adaptive (where the system adapts itself, such as in intelligent user interfaces and artificial intelligence systems) interfaces; rather it is a sign of good quality of the user experience in both cases. I assume that user appropriation of the technology is one of the signs of a successful interaction IoT design. How then do we provide strong support for it in the technology we design? 


\section{2.}

\section{Technology Appropriation}

In Computer Science, technology appropriation has been defined as "the way in which technologies are adopted, adapted and incorporated into working practices" (DOURISH, 2003) and "making the technology our own" (TURNER, 2011). Research on appropriation has been mainly conducted in the computer supported cooperative work (CSCW) and human-computer interaction ( $\mathrm{HCI})$. It refers to the process by which users become able to make effective use of technology in their personal contexts, fitting and incorporating systems into their actual practices, often in creative ways not originally anticipated by designers (DIX, 2007). It is closely related to the idea of customization but it is a broader term that emphasizes the "ongoing, incremental adaptation of interactive technologies [...] inherent to the emergence of practice" (DOURISH, 2003)rather than the isolated act or task of customizing a system.

Appropriation is a rich and multi-faceted interaction phenomenon, full of complex dimensions. A strong tradition comes from the socio-technical perspective. Naturally, these studies tend to emphasize the social dimension of appropriation, that is, how a technology, usually groupware (i.e. a collaborative software), is adopted and appropriated by groups or organizations and the social aspects and issues thereof. According to Andriessen et al. (2003), this perspective is theoretically grounded in structuration theory from the social sciences (GIDDENS, 1979). This perspective was developed by several researchers (DESANCTIS; POOLE, 1994; e.g. ORLIKOWSKI, 1992, 2000) and describes appropriation in terms of how technology supports practices while it structures and is structured by the people and their actions in organizations. In this vision, technology appropriation takes place in the dynamic and complex interplay between technology, people and practices. This calls for flexibility and adaptability when using technology, as Orlikowski poses it:

"The interpretive flexibility of technology operates in two modes of interaction. In the design mode, human agents build into technology certain interpretive schemes (rules reflecting knowledge of the work being automated), certain facilities (resources to accomplish that work), and certain norms (rules that define the organizationally sanctioned way of executing that work). In the use mode, human agents appropriate technology by assigning shared meanings to it, which influence their appropriation of the interpretive schemes, facilities, and norms designed into the technology, thus allowing those elements to influence their task 
execution. In many organizations, individuals may have little control over when or how to use technology, and hence little discretion over which meanings and elements influence their interaction with it. But, these constraints are institutional, and are not inherent in the technological artifact itself. Users can always choose (at the risk of censure) not to utilize a technology, or choose to modify their engagement with it. The notion that technology needs to be appropriated by humans retains the element of control that users always have (however slight) in interacting with technology." (ORLIKOWSKI, 1992, p. 16, author's emphasis in italics, my emphasis in bold)

The design of technology to support such interpretive flexibility must also address technical flexibility in order to promote the "evolving use," as posed by Andriessen et al. (2003):

"With the concept of 'evolving use' we imply a multi-theoretical approach to analyze both the technical and the social side of this mutual adjustment. It includes the design of flexible software in the sense of customizable or tailorable applications which are the prerequisite for certain appropriation processes." (ANDRIESSEN; HETTINGA; WULF, 2003, p. 371)

Pipek (2005) developed the socio-technical line drawing from the Star \& Bowker's (2006) concept of infrastructure, e.g. a city metro, a road network, or information systems in an organization. His goal was "to address a connected multitude of technologies, tools and devices that we usually encounter in organizational settings" (PIPEK, 2005, p. 90). According to Pipek \& Wulf (2009), Star \& Bowker identified some "salient features of infrastructures" that poses particular challenges for the design and appropriation of digital infrastructures in organizations. From the designer's side, they are embedded into social contexts and depend on other technological structures, they embody social conventions, they resort on standards to work properly, and they have inertia in the sense that they are resistant to changes due to existing dependencies and installed base. From the user's side, they are seen as dependable and taken for granted by users, becoming practically transparent when in use, going to the background of the practices they are supporting. However, infrastructures require work to be configured and maintained, and they become apparent upon breakdowns.

In this perspective, a breakdown becomes a particular important moment, a “point of infrastructuring” as Pipek \& Wulf call it (PIPEK; WULF, 2009, p. 458), where both designers and users are challenged by a tension (real or perceived) between technology in use and technology as designed and are forced to look at 
the technology, that is, to bring it to the foreground of whatever they are doing. A new technological innovation at the designers' side or a change in the organizational context or work practice at the users' side cause breakdowns, which play an important role in Pipek and collaborators' studies of appropriation (LUDWIG; PIPEK; TOLMIE, 2018; LUDWIG; TOLMIE; PIPEK, 2019; PIPEK; WULF, 2009).

The duality between technology in use versus technology as designed was explored by Carroll and colleagues (CARROLL, 2004; CARROLL et al., 2001, 2002, 2003). They observed that appropriation unfolds in three levels: first users' encounters with the technology, evaluation through use, and long-term use of technology (CARROLL et al., 2003). In each level, user interaction is influenced by attractors and criteria that can motivate, reinforce or block the flow from a lower to a higher level of appropriation. A set of attractors, criteria and reinforcers (e.g. fashion and style, ease of use, availability of features, etc.) were identified for the case of mobile phones appropriation by young people based on qualitative data collected through different methods in Australia (CARROLL et al., 2001, 2002). Their findings were generalized into a model of technology appropriation (CARROLL et al., 2003) later turned into a technology appropriation cycle of designing for appropriation, appropriation and designing from appropriation. In summary, its grand vision is that designers start by providing possibilities of appropriation to users, who appropriate the technology as they pass by the three levels afore mentioned, and whose appropriations then feed the design process back with new insights about the technology that can be incorporated in new versions of the technology (CARROLL, 2004).

Descriptions in terms of time lapses (phases, stages, etc.) appear often, pointing to the crucial role of time during the appropriation process. Appropriation unfolds over time, as users explore, learn and get familiar with the technology, until they incorporate it into their practices, by making more consistent use of it, adapting the technology, themselves and their practices to the technology (CARROLL, 2004). In this vein, Bødker \& Christiansen (2012) applied the concept of appropriation from Werstch (1998) to identify four stages of the appropriation process of mobile apps: anticipation, initial familiarity, development of repertoires of routines, and the development of new forms of use. The timeframe probably depends on the kind of system, but Carroll studied cases 
where it took from one to several months, depending on complexity of the technology and the setting (op. cit.). This poses methodological challenges to the study of appropriation because it takes time and depends deeply on the psychological and social contexts of users, as much as on the technology design (SALOVAARA, 2009).

In another dimension, research on appropriation investigates different kinds of systems, such as collaborative software (DOURISH, 2003), open software ecosystems (DRAXLER; STEVENS, 2011), mobile technologies (CARROLL et al., 2003), among others. More recently, appropriation of IoT technologies started to be investigated, too (BØDKER, 2017; JAKOBI et al., 2017, 2018; LUDWIG; BODEN; PIPEK, 2017). Empirical investigations of appropriation are usually done by means of case studies in actual scenarios in order to take into account the differences in technologies, domains, users, and contexts. These studies provide rich descriptions and thick evidence of the appropriation phenomenon in "closeto-natural" contexts. However, the focus (goal) of the research (e.g. inform design or understand social contexts), the level of the descriptions (e.g. social, sociotechnical or individual appropriation), and the different paradigms and theoretical perspectives (e.g. social theories or psychology) make results hard to compare, to relate, and to use for practical design purposes.

Appropriation is closely related to some "brother" and "cousin" concepts, sometimes appearing as a core phenomenon under investigation (e.g. DOURISH, 2003), other times as a part or aspect of something bigger - e.g. an element of user experience over time (KARAPANOS et al., 2009), "epistemic interaction" (TURNER, 2012), "technology domestication" (SILVERSTONE; HADDON, 1996) - , and also as a desired effect, a positive result of a successful design approach or technical solution, such as in End-User Development (LIEBERMAN et al., 2006) and related topics (BELLUCCI et al., 2015; DERBOVEN; GEERTS; DE GROOFF, 2017; PIPEK, 2005; RETORE; ALMEIDA, 2019; STEVENS; PIPEK; WULF, 2009). Although they all agree in the general concept of technology appropriation, different terminologies and levels of descriptions make it hard to make sense of the results in terms of what is really "appropriate" and useful to know about appropriation and the design therefor.

Indeed, designing for appropriation has been recognized as a challenge and/or a research gap regardless of the technology. According to Belin \& Prié 
(2012), "an important gap [on appropriation research] appears between overdescriptive and theoretically scattered works on the one hand, and pragmatic designers' needs of concepts clearly related to the system they have to design on the other hand."

Dourish (2003) was one of the first to make an effort in trying to identify the "technical features that support appropriation." Based on case studies of a novel document management system, he proposed three design principles-flexible information organizing, composable functionality, and support for group workas technical features that are able to support appropriation. Alan Dix (2007) proposed seven guidelines for designing for appropriation, namely: allow interpretation, provide visibility, expose intentions, support (not control), pluggability and configuration, encourage sharing, and learn from appropriation. His guidelines were "based on his own experience and published literature," and demonstrated in two small examples. However, he concludes by saying that "validating design principles is hard as simple post-hoc evaluation is methodologically unsound." He grounds this claim referring to previous work, where Ellis \& Dix (2006) showed that post-hoc evaluations of interfaces ${ }^{5}$ can, at most, validate an instance of a design principle (that is, one single designed system), but not the design principle in itself. To remedy that, Dix calls for "a more thorough theoretical framework or model of appropriation" that "would be valuable to both validate these principles and suggest future directions of study" (op. cit., p. 30).

As intentional or unintentional responses to Dix's call for "thorough theoretical frameworks" to inform research and design for appropriation, there are much fewer works. To date, four reasonably developed works were found to follow this line (BELIN; PRIÉ, 2012; BENAMAR; BALAGUÉ; ZHONG, 2019; SALOVAARA, 2008; TCHOUNIKINE, 2017). They take the shape of theoretical models, frameworks or accounts of appropriation grounded in different theoretical backgrounds, such as cognitive psychology (SALOVAARA, 2008), instrumental theory (BELIN; PRIÉ, 2012; TCHOUNIKINE, 2017), and business and marketing literature (BENAMAR; BALAGUÉ; ZHONG, 2019). These works are

5 Although referring to the evaluation of visualization systems, Ellis \& Dix (2006) generalized their claim as applicable to all kinds of interfaces and "generative artifacts," that is, "things that are not something of value in and of themselves, but only yield results in some context." 
closer to this thesis' goal but before I examine them in detail (what will be done in Section 6.1.5), it makes more sense to know what are my research questions and the kind of answers that I am looking for.

\section{3. \\ Research Questions}

All studies and dimensions of technology appropriation discussed above can inform the design of appropriable technologies in one way or another, if results are used wisely. This review was conducted by backward and forward snowballing of the literature about appropriation until saturation (cf. WEBSTER; WATSON, 2002). Although it is limited, it's quite representative of the overall shape of the field based on the fact that it includes most of what can be considered relevant (cited) and influential (recurring) references about the topic in literature (cf. JALALI; WOHLIN, 2012). However, the models or accounts of appropriation discussed so far do not seem to help much. At one hand, we have "overdescriptive and theoretically scattered works," as Belin \& Prié (2012) said, that cannot be directly applied or translated into practical design guidance. At another, we have the proposal of design guidelines based on case studies or experience for post hoc validation, which is "methodologically unsound," as we saw (DIX, 2007).

In addition, in spite of some work, appropriation of IoT technology is still a rather new topic, in which existing challenges inherent to research on technology appropriation in general are added to new ones arising from IoT specificities and characteristics. For instance, how do these findings and results about technology appropriation relate to others that were not framed or related by the authors as appropriation problems but clearly have something to do with the topic, in particular studies about interaction with ubicomp mentioned in the previous sections? For instance, how are Dourish's (2003) or Dix's (2007) principles for the design of appropriable systems different, complementary, related, or even equal to Davidoff et al.'s "principles for smart home control" (DAVIDOFF et al., 2006)? I am not posing these questions in a philosophical or abstract sense. Rather, I mean it from the very practical perspective of a designer trying or needing to design an appropriable piece of IoT technology, for example, a smart 
home device or system. Does everything apply? How? If not, what do I choose or prioritize and why?

It seems that there is something wrong or missing: if we know all this about appropriation already, how come we do not know how to design for it yet? And if everything we know cannot be related to the domain-specific knowledge (e.g. "standard" interactive research in the Ubicomp domain), why is technology appropriation found to be so context-dependent? Following this road, it seems we will arrive in a dead-end, if we are not there already. The gap seems to be not only to produce knowledge about IoT technology appropriation but also to make the appropriation knowledge we produce appropriate for the design of appropriable technology.

One way to bridge this gap is to turn to theoretical accounts. A valuable theoretical tool in sciences is a model. According to Morrison \& Morgan (1999), "models fulfil a wide range of functions in building, exploring and applying theories; in various measurement activities; and in the design and production of technologies for intervention in the world" (p. 24). A theoretical model is a simplification of the modeled object or phenomenon made for some purpose in order to enable, support or promote some sort of analysis or action (RUSE, 2005a).

According to Vermaas (2014), "a general description of what a scientific model is and of what a model is aimed at, is not so easily found in philosophy" (p. 51). There are different kinds of scientific models that can be proposed, each one with a different "power" and purpose e.g. scale models (physical objects), ideal (fictional) objects, diagrams, symbolic and mathematical formulae, descriptions, etc. (cf. FRIGG; HARTMANN, 2020). According to Frigg \& Hartmann (idem), models in science can be subsidiary to theories (e.g. an ideal pendulum is a model within Newton's mechanics theory) or independent from theories in the sense that they may mix different theories (e.g. models of complex phenomena such as the global climate), be loosely related to theories (e.g. a preliminary theory or a mediator for the application of a theory in the real world), or refer to no theory at all (e.g. a simulation based on common-sense is a model). In a similar vein, Morrison \& Morgan (1999) say that models can be "autonomous agents" in sciences possessing their particular modes of construction, functioning, 
representing and learning, becoming thus an instrument of investigation on their own.

Nevertheless, models and theories are tightly coupled in sciences. According to Ruse (2005b), "a scientific theory is an attempt to bind together in a systematic fashion the knowledge that one has of some particular aspect of the world of experience." Theories can be said to be sets of theoretical models (idem) and models are thus components of the structures of scientific theories (cf. WINTHER, 2016). In practice, sometimes "models and theories can get so entangled that it becomes unclear where a line between the two should be drawn: where does the model end and the theory begin?" (FRIGG; HARTMANN, 2020). Considering that the meaning of models and theories can mingle and are tightly coupled to scientists and researchers (BAILER-JONES, 2002; e.g. FINGER; DIXON, 1989), I will draw from the four types of goals for a theory in information sciences as typified by Gregor $(2006)^{6}$, and classify theoretical models as: Descriptive, if they aim at describing a phenomenon or object of study; Explanatory, which are similar to descriptive but also are able to provide explanations, that is, describe causal relationships between observed facts to some degree; Predictive, if the main model goal is to predict scenarios and future results from observable facts; or Prescriptive, if they aim at providing prescriptions (recommendations) for something based on predictions they are able to find. These goals denote an increasing level of sophistication and maturity. Of course, they can be combined because models and theories are not static and evolve as they are put under test and mature, but they point to descriptive models as a good starting point.

Descriptive models help us to reflect on observed and potential scenarios of a given phenomenon, describing aspects and relationships that are not apparent or obvious and that enrich our understanding about the object or phenomenon under consideration. In addition, this type of model organizes the problem space, what drives our attention to particular aspects and questions that have been previously

6 Gregor (2006) identified four primary goals of theories in information sciences: Analysis and description, when the theory provides generalized concepts and relationships of the phenomena of interest; Explanation, when besides generalized constructs the theory provides explanations of how, why and when things happened based on causal relationships; Prediction, when the theory is targeted at predicting what will happen based on a set of conditions and measurable variables; and Prescription, an advancement of predictions where, based on them, the theory aims to recommend interventions of a certain kind. 
identified as relevant. Instead of providing straightforward answers, they guide the search thereof. They are, therefore, epistemic tools that can be used in technology research and design (BOON; KNUUTTILA, 2009). As put by Minsky (1965) in a classical paper, "to an observer $\mathrm{B}$, an object $\mathrm{A}^{*}$ is a model of an object $\mathrm{A}$ to the extent that $\mathrm{B}$ can use $\mathrm{A}^{*}$ to answer questions that interest him about A." By representing some aspects and ignoring others, a model captures and highlights what is worthy of attention for its intended purposes, hiding what is not for the sake of efficiency and tractability and providing a tangible dimension that can be worked on concretely or abstractly (BOON; KNUUTTILA, 2009, p. 8-10). If the intended purpose of the model is design, it functions as design instruments by providing "the kind of information that allows us to intervene in the world" (MORRISON; MORGAN, 1999, p. 23).

Although some theoretical models of technology appropriation have already been proposed in literature (see previous section), none of them have been particularly shown to be useful for the design of appropriable IoT technologies, for the reasons argued so far. I am looking for a particular kind of descriptive model that can answer two research questions:

Box 2-1 - My research questions on appropriation:

- R1) How do people appropriate IoT technology?

$\circ$ R1-A) What does "to appropriate" IoT technology mean?

In addition, it should answer these questions in a certain way that is useful for the design of appropriable IoT technology. This prompts to another two closely related research questions:

Box 2-2 - My research questions on design for appropriation:

- R2) How to design appropriable IoT technology?

○ R2-A) What does "to design" IoT technology mean? 
These questions address the two ends of an IoT technology, where the human-challenges actually emerge. Therefore, they delimit the space of possible answers in a useful way. In addition, it is irrelevant which one comes first, because design for appropriation, appropriation and design from appropriation forms a cycle (CARROLL, 2004). I want to understand appropriation of IoT technology in a way that is able to provide actionable insight in order to improve the support for appropriation in the technology we design. At the same time, I want to understand the design of IoT technology in a way that whatever I learn about appropriation can actually be addressed in the technology by design. These boxes above tie together and synthetize the overall goals of this thesis.

Finally, by looking for theoretical models, I am also trying to build theory "by design" (by research design). But I will try not to start from the ground. An existing theory can leverage the analysis of a phenomenon by means of established knowledge: instead of starting from the ground, one starts from the second or third floors by leveraging from important connections and relationships discovered before and that can easily get hidden underneath the surface of observed empirical data. A theory provides ontologies that help us navigate complex problem spaces and relate findings in order to avoid adding complexity by the use of different terminologies when referring to the same things. In addition, a theory can help by guiding research questions and analysis in certain directions that have proven to be worthy of attention. On the other hand, theories demand epistemological rigor, in the sense that their application requires adhering to a preexisting ontology and philosophy, and respecting the goals and limits of the theory. Finally, theories need to be taken as "work-in-progress:" since they are limited by (human) nature, they are subject to be partially or completely refuted, confronted, and refined, as they evolve, improve or become abandoned in face of new facts, findings, and empirical evidence.

In this case, I chose Semiotic Engineering (DE SOUZA, 2005a) as the theory to guide this research, which I will describe in the next chapter. 


\section{3 \\ Theoretical Foundation}

In this chapter, I will introduce the core theoretical background needed to understand this thesis and its results. This thesis is theoretically grounded in Semiotic Engineering (DE SOUZA, 2005a), a semiotic theory of HCI mostly based on Peircean Semiotics and its developments made by Umberto Eco (2017). Although Semiotic Engineering is "self-contained" and limited in scope to Computer Science, the use I made of it in this work demands a small recapitulation and deepening of some core concepts and principles from general semiotic theory. Semiotics is a huge and rich field of studies, which can be as broad as thriving, used in studies from biology (cf. SEBEOK, 2006), to advertising, literature, institutions, and arts (cf. SANTAELLA, 2002). The cut-out of Semiotics I will describe here is not a comprehensive neither a complete description of the field or of any particular theory. Rather, it is intended to provide a minimal holistic understanding of Semiotics with the minimal additional overhead necessary to understand this work, mostly resorting to established text books and fundamental literature. I will start by describing Semiotic Engineering and then summarizing some concepts from Semiotics. In a broad way, the theory described here will appear as the background against which the studies in chapters 4 and 5 were analyzed and their results obtained. More specifically, it will be further developed and used in Chapter 6, where I tie my results together.

\section{1. \\ Semiotic Engineering}

Semiotic Engineering (DE SOUZA, 2005a) is a theory originally proposed for studying human-computer interaction (HCI) that views interaction between users and computer technologies as a special case of computer-mediated human communication (cf. KAMMERSGAARD, 1985). It is based on Semiotics, a science that studies the human processes of signification and representation of meanings originally developed mostly (though independently) by the Swiss 
linguist Ferdinand de Saussure (1857-1913) as a branch of Linguistics and by philosopher Charles Sanders Peirce (1839-1914) as a branch of Logic in the United States. Semiotics will be further described in the next sections, but it has been applied in the study of human-computer interaction in several different ways that are grounded in the Saussurean and/or Peircean concept of signs. Very generally and briefly, a sign is something that means something to someone in a certain context. Representations, meaning and signification processes are the core objects of study of Semiotics and all derived semiotic approaches.

The advantages we gain from studying appropriation using this particular theoretical foundation are two: Firstly, we can apply knowledge that is already developed and accepted from semiotic theory to this particular phenomenon; Secondly, since Semiotics is an area of human knowledge specifically concerned with studying meanings and the processes of signification and representation, it is particularly poised to clarify aspects and relationships inherent to the process of appropriation. Appropriation is closely linked to the way people signify and resignify things around them, such as words, concepts, and technology, in our case. As cited above, some visions of technology appropriation have already called for "interpretive flexibility" mentioned by Orlikowski (1992), which points to the process of interpretation, that is, the signification process by which people ascribe meaning to whatever they perceive or experience. Indeed, meaning was identified as a core component of appropriation by Dourish (2003):

\begin{abstract}
"These explorations of appropriation, which began with the attempt to take a broader view of the role of customization, have suggested that appropriation is best thought of as the incorporation of technology not simply into practice but into systems of meaning. Appropriation is the creation, management and communication of meaning, within a community of practice." (DOURISH, 2003, p. 487, my emphasis in italics)
\end{abstract}

I mentioned before that the technology interface is the very place where both users and designers "meet" during interaction time. To Semiotic Engineering, this is not a metaphor (DE SOUZA, 2005b). Any human-computer interaction is seen as a special case of technology-mediated communication between technology producers - that is, designers and developers - and technology consumers - that is, users - that happens through the technology interface(s). Semiotic engineering is just one of several semiotic approaches in 
HCI (for a brief overview of other semiotic approaches to HCI see: DE SOUZA, 2017a). Most approaches make use of semiotic concepts in the design or evaluation of interaction and interfaces. Semiotic engineering has the special feature of having defined its own object of study as the metacommunication process that happens between technology designers and users through interaction (DE SOUZA, 1993, 2005a, 2017a).

Metacommunication is the process by which technology designers and developers send a one-shot high-level message to their users (DE SOUZA, 2005a, passim). This message unfolds while users interact with the technology interface and engage with the interactive conversations that the designers had made available for them through the interface language. In this vision, the system works as a deputy or proxy (ibid., p. 89 et seq.) of its designers since it "speaks" on behalf of them and can only "say" what they have been previously designed to. The metacommunication phenomenon is thus a high-level designer-user communication about a low-level system-user communication. Over time, after successive interactive conversations with the technology, the designers' high-level message is revealed and it will contain conscious and unconscious, implicit and explicit beliefs designers hold about their users, the system and the tasks or activities that the system is intended to support. The gist of what designers tell their users through the technology interface can be described with the metacommunication message template below:

Box 3-1 - The metacommunication message template (De Souza, 2005, p. 84):

"Here is my understanding of who you are, what I've learned you want or need to do, in which preferred ways, and why. This is the system that I have therefore designed for you, and this is the way you can or should use it in order to fulfill a range of purposes that fall within this vision."

The identification of metacommunication as the central phenomenon of interest in human-computer interaction determines Semiotic Engineering's ontology. It is an inclusive perspective that is very important to the humancenteredness of this theory and that makes it particularly suited to the questions I am posing in this thesis and the kind of answers I am looking for. This principle allows us to investigate interactive phenomena not losing sight of the pertaining 
human agents. As metacommunication happens between developers and users, we are guided to consider all the human parties and their abilities, intentions, concerns, values, contexts, etc. The designer speaks through his or her deputythe system - who can only say what it was designed to. In communication and semiotic terms, the technology interface comprises a unique language, an artificial code designed by the designer in order to support the exchange of inputs and outputs between the user and the designer's deputy. The design space to be considered in Semiotic Engineering should include all parties and the essential elements of communication happening between them. Deriving from Jakobson (1960) communication model, the semiotic engineering design space is composed by: the emitter (the designer), the messages (the high-level metacommunication and the lower-level interactive messages), the code (the interface language), the technology as the channel (the interface), the receiver (the user), and the (user) context in which the interaction takes place (DE SOUZA, 2005a, p. 85 et seq.), as depicted in Figure 3-1.

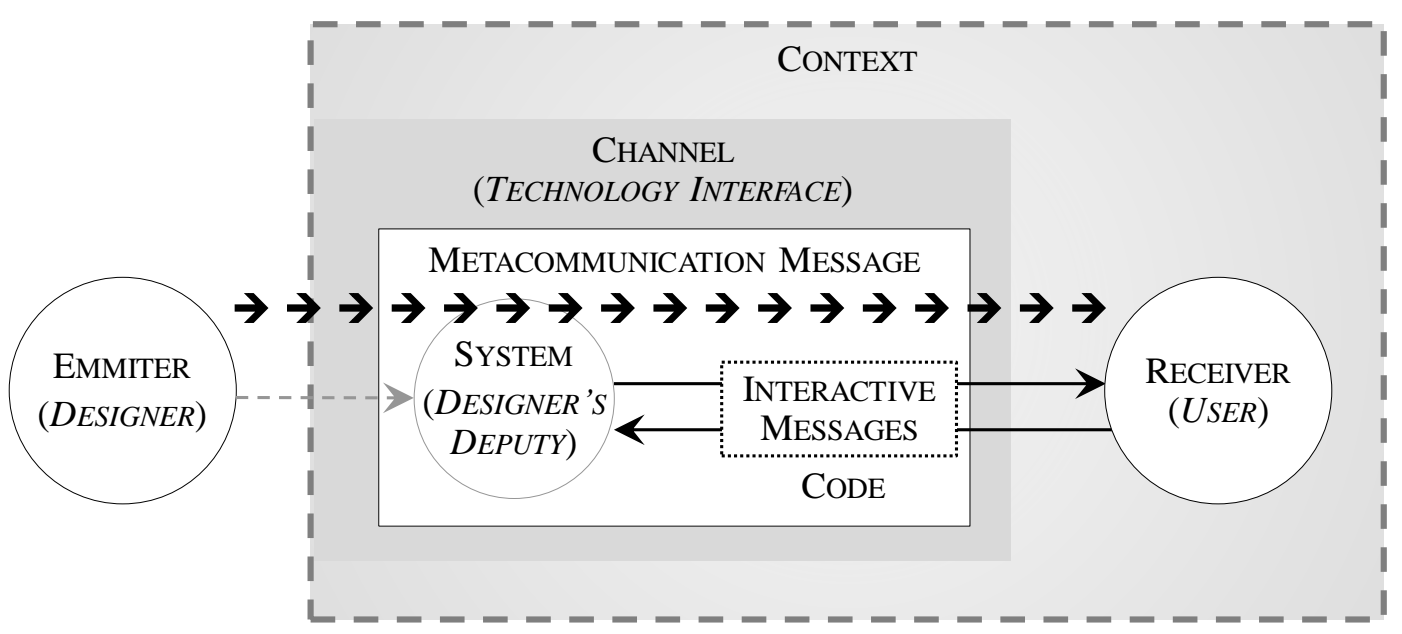

Figure 3-1 - The semiotic engineering design space (adapted from: DE SOUZA, 2005a, p. 88, Fig. 3.2).

According to Semiotic Engineering, the quality of user interaction is determined by the quality of the metacommunication process. The main operational property of interaction to Semiotic Engineering is called communicability, "the property of software that efficiently and effectively conveys to users its underlying design intent and interactive principles" (also DE SOUZA, 2005a, p. 112 et seq.; PRATES; DE SOUZA; BARBOSA, 2000). In this 
sense, Semiotic Engineering has proposed two methods to evaluate the communicability of software interfaces, namely the Semiotic Inspection Method (SIM), targeted at evaluating communicability based on the quality of the emission of the metacommunication message; and the Communicability Evaluation Method (CEM), targeted at evaluating communicability on the side of the reception of the metacommunication message (DE SOUZA; LEITÃO, 2009). Parts and concepts of these methods were used in my methodology and will be described further ahead when I describe the studies that used them (Chapter 4).

In a recent work, De Souza et al. (2016) propose the use of Semiotic Engineering not only for the study of interaction, but as a theory for the investigation of the whole process of software development. They propose a series of methods and tools that apply Semiotic Engineering principles adapted to each artifact and stage of a typical technology development life-cycle (interaction, modeling, programming, researching). This shows this theory's suitability in meeting the HCC top goal of designing "computing systems with a human focus from the beginning to the end" (SEBE, 2010). Nevertheless, little has been tried or done in IoT contexts and applications (one of the few exceptions that I am aware about is: FERRARI; BIM; AQUINO, 2017) or in studying technology appropriation in particular. This is the moment when we face a theory as "workin-progress." In order to extend it to the study of our objects and phenomena of interest (namely, IoT, technology appropriation and the design therefor) with the required epistemological rigor mentioned before, we need to dive into the core theoretical foundation of Semiotic Engineering, namely Semiotic theory, what we will do in the following. 


\section{2.}

\section{Semiotics: Signs and Semiosis}

Semiotics has been defined as "the science that studies signs and how they produce meaning" (DANESI; PERRON, 1999, p. 40), "the science of signs, symbolic behavior, and communication systems" (LYONS, 1984, p. 14), "both a science among the sciences and an instrument of the sciences" which studies "things or the properties of things in their function of serving as signs" (MORRIS, 1938, p. 1-2). In common, all these definitions are based on the idea of the sign, this fundamental entity that is used by humans to refer to, capture and convey meaning, references to concrete objects, abstract concepts, or complex ideas. According to Danesi \& Perron (1999, p. 40-41), its origins can be traced to the ancient Greek medicine, when semiotics (semeion is the Greek word for "mark, sign") referred to the science of studying physical symptoms in order to find their causing diseases. This is very illustrative of the essence of what is a signsomething (for example, a symptom) that stands for something else (for example, a disease). Our striking innate ability to make and use signs as the elementary units for meanings and the ubiquitous presence of signs of every kind in the world around us justified the birth of Semiotics as the science devoted to study the underlying laws of signs and signification processes.

The establishment of Semiotics as the science that we know today has to do with the work of linguist Ferdinand de Saussure (1857-1913) in Europe and of the scientist, logician and philosopher Charles Sanders Peirce (1839-1914) in the United States (DANESI; PERRON, 1999, p. 47-49; DE SOUZA, 2005a, p. 3640; ECO, 2017, p. 9-11). Despite some intersection, the two had very different foci and approaches and originated two significantly different branches of study around the idea of the sign. As a linguist, Saussure was more concerned with natural language and defined a sign in terms of its signifier - the representation itself (a word) — and the signified — what the sign refers to (the word's meaning). Peirce in turn was concerned with the mechanics of thought, the production and discovery of knowledge, and the role of representations during these processes, a much broader and deeper scope of analysis. He left a large body of writings where the study of the sign - which he called Semiotic - and Logic were themes as frequent as intertwined (PEIRCE, 1931-1958). Among several other topics which 
are today objects of inquiry of Semiotics' entire field of study, Peirce made extensive developments of the concepts of sign, semiosis, abduction, and pragmatics. These concepts are very important in this work, the reason why I will discuss them further ahead.

In one of his several definitions, Peirce defined a sign as "something which stands to somebody for something in some respect or capacity" (CP 2.228) ${ }^{7}$. Moreover, this "something" could be characterized in terms of a triadic relationship composed by a representamen - the representation-, an object - the referent-, and an interpretant - the meaning of the sign:

Sign [Lat. signum, a mark, a token]: Ger. zeichen; Fr. signe; Ital. segno; Por. signo. (I) Anything which determines something else (its interpretant) to refer to an object to which itself refers (its object) in the same way, the interpretant becoming in turn a sign, and so on ad infinitum. (HOOPES, 1991, p. 239)

An important idea behind these definitions is that the representation is separated from the object that it represents or refers to. For instance, why do we use the word "tree" to refer to a tall woody-trunk plant in a garden or a forest? Or "red" for the certain color characteristic of apples, blood, and roses? Or "colors" for the different visual impressions caused by the light in the perceptions captured by our eyes, "red" being one of them? Notice that even if we can define "red" in terms of its precise known physical characteristics there is nothing in the word "red" that could be associated with "the visible electromagnetic wave having wavelength between $700-635 \mathrm{~nm}$ " by means of a causal relationship or a straightforward "physical" law. Nevertheless, most English-speaking people can immediately recognize and imagine which color we are talking about simply based on the word "red" and know how to relate and distinguish it from "yellow," "orange," "green," and other "colors." In other words, several times signs are arbitrary and a matter of social convention, such as in most of the wordslinguistic verbal signs - that we use in spoken and written language to communicate with each other. Notice that this feature makes a sign independent even from any concrete or "true" existence of the referent. In other words, a sign can exist and be used in spite of its object or referent. Indeed, Umberto Eco

7 I will refer to The Collected Papers of Charles Sanders Peirce (Peirce, 1931-1958) using an abbreviated form following a tradition in Semiotic studies, which is to use the prefix "CP" followed by the volume and paragraph numbers that identify the referred passage, e.g. (CP 4.541) stands for Collected Papers, Volume 4, Paragraph 541. 
defined Semiotics as "the discipline which studies everything that can be used to lie" (ECO, 2017, p. 4), the sign being the "lying device." He says, "if something cannot be used to lie it cannot be used to tell the truth either. In fact, it cannot be used to tell anything at all." If a sign is conveying something, true or false, a sign will produce an effect, which is to produce an interpretant, the other part of the triadic relationship proposed by Peirce.

The meaning of the sign will be then captured by its interpretant. According to Peirce, the interpretant of a sign is by itself another sign. This other sign is not the object (the referent), but another idea or concept evoked by the representamen that is another representation of the object in some respect or capacity to the person interpreting the sign. With this characterization, Peirce emphasized that signs need to and only exist when they are interpreted (by someone or something) and that any manipulable meaning is by itself a sign too. Signs are thus not only the units that we use to express and communicate meanings but the very units of meanings that we use to think. The meaning of a sign unfolds when it is interpreted by means of other signs, in a process where a sign evokes a sign that evokes a sign, and so on and so forth, which Peirce called semiosis, later called by Umberto Eco (2017, p. 60) unlimited semiosis (Figure 3-2). 


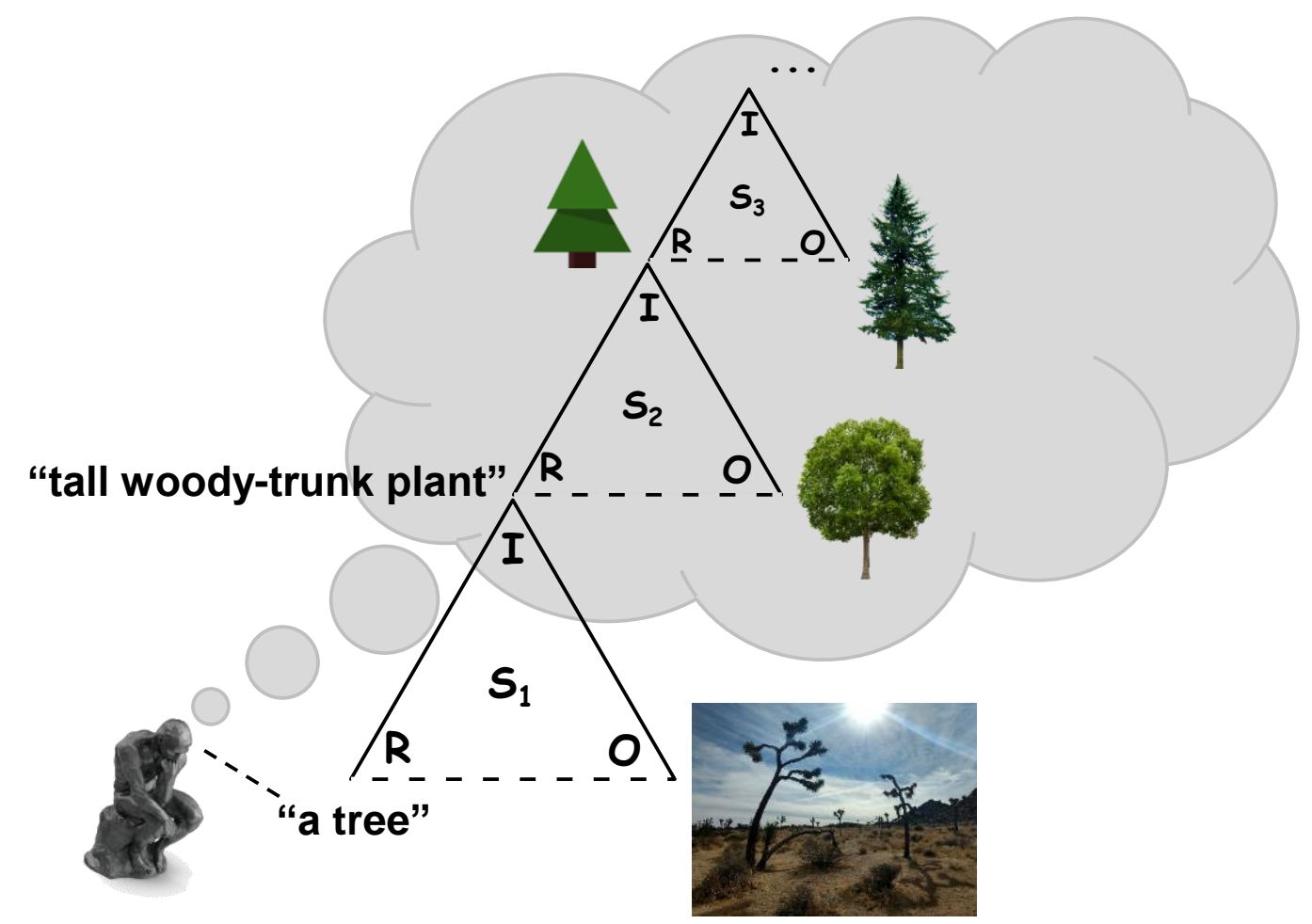

Figure 3-2 - A depiction of a Peircean sign "S" denoting a tree. The word "tree" is a sign $\mathrm{S}_{1}$ composed by its representamen " $\mathrm{R}$ " ("tree"), its object "O" (e.g. an actual tree in a forest that was seen by the writer), and its interpretant "I," which is another sign $S_{2}$. Unlimited semiosis is the process by which a sign $S_{i}$ determines its meaning through another sign $S_{j}$, which in can go on infinitely in theory.

I mentioned earlier how a sign such as a word can be (and usually is in the case of verbal language) arbitrarily associated to the object to which it refers. However, clearly this not always the case. In all languages, there are the classical examples of onomatopoeic words which imitate the sound of their referent, such as "buzz," "ring," and "smash" in English. Another familiar example in HCI is that of icons, which in HCI jargon refers to the little figures that populate graphical user interfaces on screen devices. Signs can evoke their referents by similarity to the physical object it represents (e.g. "园” stands for a trash can), by metaphors or metonymies (e.g. “回” resembles an computer diskette from old times, but when appearing in an application interface it usually stands for "the action of saving a file"), or by convention (e.g. a logo such as “畔” standing for 
the Microsoft Windows ${ }^{\circledR}$ application). In Semiotic theory according to Peirce, there are three kinds of signs:

"[I]t has been found that there are three kinds of signs which are all indispensable in all reasoning; the first is the diagrammatic sign or $i c o n^{8}$, which exhibits a similarity or analogy to the subject of discourse; the second is the index, which like a pronoun demonstrative or relative, forces the attention to the particular object intended without describing it; the third [in other texts, Peirce called it the symbol] is the general name or description which signifies its object by means of an association of ideas or habitual connection between the name and the character signified." (HOOPES, 1991, p. 181)

At a more fundamental level, these three types of signs actually map to the three ways by which a sign can represent an object:

"It follows that there are three kinds of representations:

$1^{\text {st }}$. Those whose relation to their objects is a mere community in some quality, and these representations may be termed Likenesses.

$2^{\text {nd }}$. Those whose relation to their objects consists in a correspondence in fact, and these may be termed Indices or Signs.

$3^{\text {rd }}$. Those the ground of whose relation to their objects is an imputed character, which are the same as general signs, and these may be termed Symbols." (HOOPES, 1991, p. 30)

The passage above is taken from an 1867's essay that is considered one of Peirce's most important writings called On a New List of Categories (HOOPES, 1991, p. 23-33). In this text, Peirce firstly established the elements of Firstness, Secondness and Thirdness as the most general and fundamental logical categories of any phenomenon, an idea that permeated all his investigations and, over time, became the cornerstone of Peirce's logical and philosophical doctrines, including of his Semiotics. Indeed, these are the principles behind the threefold characterization of the Peircean sign presented above, which is the simplest manifestation of these fundamental principles. According to Santaella, a sign always is and presents a composition of all three principles, but the classification depends on which one is predominant (SANTAELLA, 2002, p. 14 et seq.). In an icon, Firstness is the predominant principle in such a way that the sign is dominated by the qualities of its referent (the object) as if it could almost dispose of from its representamen and interpretant. An index in turn is a sign that

8 Notice that an icon in Peircean Semiotics is a technical concept different from the more popular one in which the word "icon" is usually used in HCI jargon and by computer users. An icon in Semiotics is not restricted to graphical pictures; the definition embraces all other kinds of signs (e.g. a sound) which evoke their referents by similarity, such is the case of onomatopoeic words just mentioned. 
manifests its meaning mainly by a relation - a physical relation such as a copresence or a causal relation - between its object and its interpretant, e.g. smoke is an indexical sign of fire. It is also an imperfect (a degenerate sign) since it can dispose of from any other third element to exist and make sense, in other words, it does not need a representamen. Finally, a symbol is the only complete or perfect sign, where all three elements - object, representamen, and interpretant-are essential and equally necessary for the sign existence and for it to function properly. Conventional signs are all symbols par excellence, such as most verbal words and abstract concepts, which allow for the most sophisticated kinds of representations that we know, namely those which support our more sophisticated reasoning through abstract thinking. 


\section{3.}

\section{Abduction, Interpretation, and Pragmatism}

According to Danesi \& Perron (1999, p. 68), semiosis is "the neurobiological capacity itself that underlies the production and comprehension of signs." As many others scholars of Semiotics, they view this process as almost instinctual to humans, so natural and so important to human life that it enables all known forms of communication and thinking enabling us to refer to things even when they are not physically present or do not exist (yet). We represent our experiences through the signs we produce to capture their meaning and, whenever we perceive a sign, we will interpret and ascribe meaning to it. But what is the meaning of something? Still according to Danesi \& Perron (ibid., p. 75-76), the meaning of meaning is itself something hard to define. They prefer to use the term "signification" to denote what is inferable from a sign, a sign being the kind of relationship discussed above. In this perspective, signification means or at least entails an inference, that is, it implies or depends on a reasoning process.

According to Peirce (developing the works of classic logicians), a (logical) reasoning happens by means of a cooperation of three distinct inference modes, namely deduction - the inference of a consequence given a cause and a known general rule; induction - the inference of a general rule given a series of observed causes and their consequences; and abduction or retroduction (CP 1.68) - the inference of a probable cause based on an observed fact (the consequence of a potential cause) and a known general rule. Peirce gives a mundane example of someone entering a room and finding some bags and a handful of beans on the table (CP 2.623; ECO, 2017, p. 119). After some searching, one finds out that one of the bags contains white beans only, following the possible inferences:

\section{"DEDUCTION:}

Rule-All the beans from this bag are white.

Case-These beans are from this bag.

$\therefore$ Result-These beans are white.

\section{INDUCTION:}

Case-These beans are from this bag.

Result-These beans are white.

$\therefore$ Rule-All the beans from this bag are white.

\section{HYPOTHESIS:}

Rule-All the beans from this bag are white.

Result-These beans are white.

$\therefore$ Case-These beans are from this bag." (CP 2.623) 
These are not Peircean inventions, since logicians and philosophers have been studying these modes of reasoning at least since Aristotle in Ancient Greece. However, it is usually attributed to Peirce (cf. HOFFMAN; KLEIN, 2017) the popularization and establishment of abduction as a distinct and legit inference mode, a "first-class citizen" together with deduction and induction, that tend to be more well-known and usually considered more "classical." Later, Peirce generalized the last argument in the following form summarizing abduction $(\mathrm{CP}$ 5.189):

The surprising fact, $\mathrm{C}$, is observed;

But if $\mathrm{A}$ were true, $\mathrm{C}$ would be a matter of course, Hence, there is reason to suspect that $\mathrm{A}$ is true.

In a more general sense, abduction-also called abductive or hypothetical reasoning - is "the provisional adoption of an explanatory hypothesis" (CP 4.541). The power of abduction lies in the fact that it is the only logical operation capable of introducing new ideas (CP 5.171). In that sense, Peirce believed that all scientific theories that stand, what would include today from Darwin's evolutionary theory to Einstein's relativity, were derived from an abduction (CP 5.172 ), which actually drives the other two logical operations by suggesting which questions to be considered afterwards (CP 4.541).

In semiotic theory, abduction is the process behind the interpretation of signs by building hypotheses in our minds to make sense of the world around us. When facing a surprising fact or sign, we will try to make sense of it by coming up with reasonable hypotheses that can, in the current circumstances and context, explain it. First, notice that a hypothesis is always provisional, in the sense that there is no guarantee that it $i s$ the case. Abduction merely suggests that something may be the case (CP 5.171). Second, a hypothesis is arbitrary and can be as reasonable as the person's background knowledge (that is, any existing theory or previous information one has), perceptions and imagination allows it to (FOLGER; STEIN, 2017; cf. REICHERTZ, 2007). “Any hypothesis, therefore, may be admissible, in the absence of any special reasons to the contrary, provided it be capable of experimental verification, and only insofar as it is capable of such verification" (CP 5.197). A hypothesis will only remain true until evidence (e.g. arising from experimental verification) is found that indicates otherwise, a new surprising fact or sign that triggers a reassessment of the hypotheses previously 
developed and, eventually, the coming up with new hypotheses capable of accounting for the new facts (cf. BURKS, 1946; FOLGER; STEIN, 2017).

In the larger sense, abduction is part of Peirce's scientific method (BURCH, $2018)^{9}$. Any non-trivial inquiry takes place through cycles of combined abductivedeductive-inductive reasoning. Take the case of the bag of beans mentioned above in Peirce's example of abduction (CP 2.623; ECO, 2017, p. 119). But now imagine you enter the room, find some white beans on the floor, and then you spot just one bag of beans. You reasonably hypothesize that the bag may be a bag of white beans and that the beans on the floor may have come from it (abduction). You can then test your hypothesis and check the bag. If it is really a bag of white beans, all beans you take from the bag should be white (deduction). If you take one or two handful of beans and see that they are white you will assume that all beans in that bag are white, even without checking them all (induction). But suppose that instead of white beans you find black beans in the bag. Then you may conjecture that there has been a bag of white beans before. Or, if you know that black beans are more expensive than white beans, you may want to check the bag further, trying to get beans from the bottom in order to make sure that it is not a bag of white beans topped with black beans to deceive you. This is a mundane example of inquiry that one may be interested if one works for an agricultural warehouse and find a handful of white beans on the floor. But to Peirce, this overall method is behind any kind of inquiry, including more serious and sophisticated ones such as scientific research, because, when systematically and rigorously practiced, he considered it to be the most correct way of thinking logically and of building legit knowledge (HOOPES, 1991, p. 144-159, "The Fixation of Belief").

In the more basic level, abduction is the mechanism that we use to interpret signs and build meanings. A scientist is expected to be trained to test their hypotheses in a systematic way by applying the scientific method rigorously and in its entirety in order to unveil universal laws of Nature. However, in ordinary

9 As pointed by Burch (2018), it is important to notice that Peirce worked for the U.S. Coast and Geodetic Survey for more than thirty years where he practiced a lot of physical sciences, for example making accurate measurements of the intensity of the earth's gravitational field by means of using pendulums that he designed himself. To a great extent, his more abstract thinking on logic, semiotics and the philosophy of science was deeply influenced by this practical scientific experience and to a great extent we can say that his scientific method was not only a theory but also fruit of his own scientific practice. 
situations, we employ abduction, perhaps followed by some simplified tests feasible at hand, to interpret and disambiguate the meaning of signs in specific contexts. In the example of the beans above, suppose that instead of one you spot two bags of food in the warehouse, one with a big "W" ink mark and the other marked with a "B." Since you know that grains are usually packaged and shipped separated by type, you reasonably hypothesize that "W" stands for "white," "B" for "black," and that the white beans on the floor came from the first bag. Again, you test your hypothesis by taking one or two handful of beans from the "W" bag. But suppose that instead of white beans you find wheat in it. Understandably, you would take the "W" to mean "wheat," and "B" as possibly standing for "beans," and you go check the other bag. Throughout this process, the signs "W" and "B" have been taken to mean different things for you, at the same time that they influenced the meaning of the original sign "white beans on the floor," which would have come from different bags in each case. This is our natural semiosic capacity at work, driven by an abductive interpretation process that happens whenever we face a previously unknown sign. Interpretation of signs can be then much more a process of inference based on perceived reality than one of decoding according to pre-existing knowledge and rules. Notice also how the meaning of a sign is intertwined with the meaning of others signs around it that collaborate with each other and form a certain system of signs, that is, a set of known representations that influence and help elucidate each other's meanings.

Interpretation by abduction accounts for an important part of human semiosis at the "sign consumer" side. Although theoretically unlimited (even as scientists, how do we know that we have gotten to the absolute truth whatsoever so that we can stop?), normally this process stops, even if temporarily, whenever a current interpretation is considered to be enough to handle the current situation and/or we run out of resources (e.g. time to think, some immediate need for action, patience, etc.). According to De Souza, "the concept of continuing semiotic interpretation of signs does not stand unless, it can be made compatible with our finite minds and finite resources. Therefore, an account of how and why the ongoing interpretive process is halted and (temporarily) instantiated as the meaning of a sign was a crucial requirement for the scientific plausibility of Peirce's theory" (DE SOUZA, 2005a, p. 39). In other words, signification cannot be a completely open-ended process, it needs to be constrained so that any 
meaning exchange (any communication) can be made possible, as we know it is. This points to the need of something able to constrain and somehow govern our semiosis processes so that we know when to stop, which is the role of Pragmatism in this work.

Perhaps the essence of Peirce's Pragmatism (later called Pragmaticism by Peirce, see: HOOPES, 1991, p. 275-278) can be summarized by his Pragmatic maxim, which more or less states that the meaning of something lies entirely in the conceivable practical consequences of that something (HOOPES, 1991, p. 246-7, p. 160-179). Once again take the modified example of the white beans on the floor derived from (CP 2.623; ECO, 2017, p. 119). If your job was to clean the warehouse, you would be probably more concerned with the possibility of a hole in a bag and if this bag is still in the warehouse, which would potentially generate more work for you. However, if you were a tax officer, your main concern would be probably to make sure that nobody is deceiving you to pay less taxes. The same sign "white beans on the floor" would be taken to mean totally different things depending solely on the role of the interpreter (e.g. "white beans on the floor" $\equiv$ "punched bag" $\equiv$ "more work" vs. "white beans on the floor" $\equiv$ "is somebody deceiving me?" 三 "less taxes collected"). Moreover, previous experiences and knowledge you might have drive your interpretation process in significantly different paths, e.g. if you knew already from experience that "W" stands for "wheat" in that kind of bag. In that sense, abduction is often defined as inference to the best explanation (cf. HARMAN, 1965; HOFFMAN; KLEIN, 2017), which implies a sort of judgement and relativeness governing the process, and I would slightly change to characterize it as inference to the best possible explanation in order to emphasize the provisional nature of any hypothesis.

Pragmatism turned out becoming a strong philosophical tradition, inaugurated by Peirce and developed by friends - most notably William James (1848-1910) — and students—most notably John Dewey (1859-1952)—primarily in the United States and then spreading to the world (cf. LEGG; HOOKWAY, 2019). As a Philosophy (with capital "P"), it can be broadly and roughly said that Pragmatism "understands knowing the world as inseparable from agency within it" (idem). But perhaps Peirce's view is more "practical" and related with "laboratory-philosophy" rather than with "seminary-philosophy" (cf. CP 1.129). In this sense, Peirce views Pragmatism as "nothing else than [...] the logic of 
abduction" (CP 5.196) and his pragmatic maxim "is in the end only a tool for clarifying meaning" (LEGG; HOOKWAY, 2019) (see also: HOOPES, 1991, p. 160-179, "How to Make Our Ideas Clear"). The most useful way to think about Pragmatism in this work is in the sense of the "economics of interpretation" (ECO, 2018, p. 160). This concept was proposed by Eco and is related to what Burch (2018) called the "economics of research" when discussing Peirce's scientific method and philosophy of science. Burch highlights how Peirce, being a scientist before anything else - a science practitioner-for a large portion of his life ${ }^{10}$, always has had in sight the fact that in real life, every inquiry endeavor has to deal with the practicalities of life and is then subject to the limited amount of resources the researcher has available, such as time, funding, background knowledge, etc. Easily, this can be extended to the researcher's entire psychological and sociological context. In that sense, although potentially any inquiry can go on until absolute truth is found, science develops by limited individual and collective (social) practice of the scientific method. The individual and social practice of inquiry is limited by the availability of concrete resources. As a practical consequence, researchers make a considerable effort to make the most out of any effort investment, seeking to maximize results and optimize for resources. Over time, the scientific method itself, if taken seriously and applied rigorously and as a collective effort, holds the potential to self-correct by eliminating wrong ideas and converge to the correct ones ("the truth"), eventually (BURCH, 2018).

The same strategy can be transposed to the more mundane and ordinary inquiries of interpreting signs around us by abductive inferences. The concept of "economics of interpretation" entails some sort of heuristics, principles or dynamic laws that constrain and somehow drive the unfolding of the semiosis process. "Economics" should be understood in the ordinary sense, as the administration of scarce resources in the means to achieve desired goals. In that sense, an effort to interpret a sign can end as soon as the current interpretation suffices and thus spare spending any further resources. "To suffice" is goal oriented and that is why meaning is inextricably linked to the practical consequences one can conceive: one can deliberately stop semiosis when the

10 See footnote ${ }^{9}$ in page 58. 
current meaning is sufficient for whatever concrete and practical use one can or needs to make in a certain context or circumstance. Contexts and circumstances can change and these changes act in the sense of triggering the reassessment of the current interpretation, just like a surprising fact challenging a current provisional hypothesis. Personal goals and resources can also change, but these are elements of a different nature, that should be considered external of the semiosis happening in the mind, at least for now.

\section{4 . \\ Culture and the Signifying Order}

If for every perceived sign we would need to develop a chain of hypotheses to grasp their meaning(s) through their possible interpretations, even if in pragmatically limited ways, any form of communication would be, for sure, an exhausting activity. Although it can be the case sometimes, most of the time we can communicate reasonably well and effortlessly with others, understanding others and making ourselves understood when accomplishing our duties and goals in ordinary social interaction. This is a fact that points that there must be another mechanism, entity or principle "optimizing" human signification processes and communication in social life. To modern Semiotics, this is done by Culture, the set of human distinct behaviors, beliefs, customs, traditions, etc. that are shared by a certain group of people (a nation, an organization, a social class, a community, a tribe, etc.). According to De Souza (2005a, p. 59), "it is our repeated exposure to the kinds of signs that are privileged in our culture and intricately related to each other that determines the conditions of convergent semiosis, necessary for any two people to communicate."

There are several different definitions and perspectives of Culture (cf. DANESI; PERRON, 1999, p. 4 et seq.; SALGADO; LEITÃO; SOUZA, 2013, p. 30 et seq.). For obvious reasons, we will use a semiotic one, which defines culture as "a communal system of meanings that provides the means for human beings to translate their instincts, urges, needs, and other propensities into representational and communicative structures" (DANESI; PERRON, 1999, p. 14). Modern semiotics and culture are so intimately linked that Semiotics itself has been 
defined as "a logic of culture" (ECO, 2017, p. 1) and "the science of signs, signification, and culture" (SANTAELLA, 2002, p. XI).

The role of culture in our semiosis should not be underestimated. Perhaps the most emphatic and intriguing evidence was explored by Carl Gustav Jung in his studies in Psychology (JUNG, 1968) as discussed by Danesi \& Perron (op. cit., p. 15-16). Jung popularized the "inkblot" test where a therapist would show dysmorphic, irregular ink figures to patients as a stimulus to trigger their free associations and then assess the underlying thoughts of a person, the unconscious mind which rules our behaviors, desires, and actions, often times in irrational and "sneaky" ways. In Jung's psychology, the unconscious could "talk" to the conscious through dreams, filled with symbolic meaning to be interpreted by a therapist or those seeking to get to know themselves. Several times, the ciphered messages embedded in dreams are told by means of archetypes, a sort of primordial images which are stored in the "collective unconscious" after being experienced repetitively by generations of a people, appearing in myths, in fairytales, and in all sorts of artwork. Jung claimed that archetypes are patterns that can be found within and across cultures and, even if we are not consciously aware of them, they can help us understand the messages that our unconscious are trying to tell the conscious mind because we all know their meanings "by osmose" in a subconscious level.

Another interesting example of the role of culture in signification processes is its influence in our perceptions, what can be noticed by our senses in more or less immediate ways. A classic example is how Eskimos, the ice people, use four different words to refer to four different physical states of what most Brazilians would call just "snow" and probably cannot even notice the difference (ECO, 2017, p. 57). Another interesting example is to look into how colors are named in different languages. We know today that colors are the manifestations of different wavelengths of electromagnetic radiation that form a continuous spectrum roughly ranging from $750 \mathrm{~nm}$ (red) to $400 \mathrm{~nm}$ (violet), which we call visible light. However, the way colors are discretized and named can vary among cultures in such a way that the occidental names of the colors of the rainbow that we know cannot be translated one by one into different names of colors for some indigenous people, for example (cf. Danesi \& Perron, 1999, p. 96 et seq.; Eco, 2017, p. 66 et seq.). Experiments showed that these people can distinguish the 
different spectrum of tones but the way they individualize and group them are different. In Danesi \& Perron's words, "Semiotically speaking, color terms are verbal signifiers, and the categories they encode are their referents. This means that people are predisposed to attend primarily to the gradations (referents) they have learned to discriminate through the color signifiers they know" (DANESI; PERRON, 1999, p. 99). The different weights and values of each color imply different meanings, suggesting the mutual influence between signification and how we sense the physical world.

Culture influences our semiosis by instituting in a social shared system of meanings what we can individualize as objects, concepts and qualities, how we can refer to them, and how they relate with others objects, concepts and qualities. In his Theory of Semiotics, Eco defines the meaning of something as a cultural unit, "something that a certain culture has defined as a distinguished unity, diverse of others, being it a person, a geographic location, a thing, a feeling, a hope, an idea, an hallucination," etc. (ECO, 2017, p. 56 et seq.). It does not resolve the problem of circular definition of "the meaning of meaning" because he is using other cultural units to define what is the concept of cultural unit itself. This definition illustrates the unlimited semiosis at work, chaining the sign "meaning" (an abstract concept), to another sign "cultural unit" (another abstract concept), to a chain of other signs (some examples that allude the core idea). The power of unlimited semiosis, Eco says, is that "it shows us how the signification (and the communication) by means of continuous displacements, which refer a sign to other signs or other chains of signs, circumscribes some cultural units asymptotically, never being able to 'touch' them directly, but making them accessible by means of other cultural units" (ibid., p 60). Nevertheless, Eco's definition does help us understand what meaning means by linking the sign "meaning" to the sign "cultural unit," which explains why he sees Semiotics as "a logic of culture" (ibid., p. 1). A better characterization of the role of culture in our semiosis is provided by Danesi \& Perron's concept of The Signifying Order.

In their book about Cultural Semiotics, Danesi \& Perron (1999) define the Signifying Order as "the overall system, or macrocode, that supplies the signs, the specific codes in which they are organized structurally, and the texts they make possible to the members of a culture" (p. 93). According to them, "the signifying order provides the means for the developing human being to organize the raw 
information that is processed by $\mathbf{h} / \mathrm{er}$ [sic] senses into meaningful wholes. But as consequence, the understanding of the world is not a direct one. It is mediated by signs and, thus, by the referential domains that they elicit within mind-space" (ibid., p. 69). My bold highlight in the passage above is to emphasize what seems to be one of the most important functions of this signifying order inscribed in culture: its organizing power. By organizing signs into certain structures and relationships within other signs, the signifying order influences the process of signification human beings engender. It allows and disallows certain signs and certain sign combinations by determining text formation rules, such as in syntactic and semantic verbal language rules; it directs the semiosis in certain paths like related signs were physically disposed closer in a "space of possible significations" so that certain interpretants can be more easily reached than others; it enable us to convey and superpose additional qualifying meanings like certain signs were associated with other qualifying signs of emotions, feelings, values, contexts, judgements, etc. In summary, the Signifying Order suggests that signs are organized (ordered) in a certain culturally dependent way that affect the ways we, as individuals immersed in that culture, use and interpret signs.

The way that the Signifying Order is built and maintained and that it influences people's signification processes is certainly not completely known yet (in the same way that individual signification processes in the mind are not either). Nevertheless, it can be characterized in certain helpful ways where I will bring in complemental and compatible elements from Eco's Theory of Semiotics (2017) to compose with Danesi \& Perron's (1999) account:

- The Signifying Order is a set of signs established in a culture. Individually, signs are triads Representamen-Object-Interpretant and can be iconic, indexical or symbolic according to their predominant logic of significationFirstness, Secondness, and Thirdness, respectively-as discussed in Section 3.2. In a signifying order, they form the elementary units and can be called cultural units following Eco.

- In the highest level, signs denote (refer directly) and connote (refer through secondary meanings) cultural units. Roughly speaking, a denotation is a reference to the core meaning of a cultural unit, such as in "the moon is brilliant tonight." A connotation is a reference to a derived meaning that can only be grasped if the core meaning is known, such as in "Peirce was a 
brilliant (i.e., shining, remarkable) philosopher" and all sorts of figurative speech.

- Signs form codes - a system by which the signs are structured as a set; textsa composition of signs from one or more codes used to convey a message; and contexts - the situated reality in which the signs are used (DANESI; PERRON, 1999, p. 92-3). Figure 3-3 depicts the main components of the Signifying Order.

- A code is structured by a syntactic, a semantic, and a pragmatic system. The first has to do with how cultural units can be combined with each other; The second, with how they refer to the objects they circumscribe; The third has to do with the rules that regulate their use in practice. I will follow Morris (1938) in his division of a Theory of Signs in syntactics - the relation of signs with other signs, semantics - the relation of signs with the objects they refer to, and pragmatics - the relation of signs to their interpretants (including their contexts of interpretation $)^{11}$.

- The principle of relativeness of meaning: meanings can never be determined in isolation but are always influenced by the relationships they hold with other meanings. My point in discussing the "meaning of meaning" above was not only to highlight the unlimited and recursive nature of semiosis. It was also intended to show that the meaning of something is always relative, that is to say, it is increasingly refined and amplified when put in perspective with other meanings, directly or indirectly related. I mentioned earlier how Umberto Eco characterized unlimited semiosis in terms of cultural units that are circumscribed but never accessed directly, only approximated asymptotically in a continuous process where a sign is replaced by another sign or chain of signs, such as symbols by figures, words by definitions, definitions by examples, and vice-versa, and so on (ECO, 2017, p. 60-62). For instance, the meaning of "to buy" can be better understood when you know what "to sell"

11 These dimensions are closer to the modern Linguistics' perspective and should suffice to ground this work, perhaps compromising precision for the sake of simplicity and generality. Eco's Theory of Codes is a very thorough account of codes, their properties, variations and functions (ECO, 2017, cap. 2). In his vision, a code is structured by a syntactic, a semantic, and a response system, as well as by the rules linking these systems (ibid., pp. 28-31). The latter two systems can be grouped into a pragmatic system, blending elements he separated in his Theory of Sign Production (ibid., chap. 3). This is a slightly different but compatible characterization to Danesi \& Perron's description of codes by means of their paradigmatic, syntagmatic, and analogical architectures (DANESI; PERRON, 1999, p. 92). 
means because these two actions are opposed to one another (antonymies). Both verbs demand an agent and (at least) an object which can connote additional meaning, such as in "to buy a person" and "to sell one's soul." Other common semantic relationships are (cf. DANESI; PERRON, 1999, p. 77): "to purchase" is the same as "to buy" (synonymies); "cyan" is contained in "blue" (hyponymies), "thirsty" is for "water" in the same sense that "hungry" is for "food" (proportionalities). A rich way to visualize and explore such relationships is by means of "semantic fields" where a subset of related words can be laid on a plane and geometrically linked to one another by their relationships (ANDERSEN, 1990, p. 327 et seq.; ECO, 2017, p. 71 et seq.; cf. LYONS, 1984, cap. 5).

- Finally, a signifying order is neither complete nor static in terms of possible and existing representations and signifiers (DANESI; PERRON, 1999, p. 99 et seq.). No signification system is a complete reference to everything that there is to know in the world. Furthermore, cultures change and evolve over time as new meanings are introduced and altered by artwork, sciences, institutions, and, above all, individuals, a consequence of the very nature of human unlimited semiosis. "[E]ven though gaps exist in a signifying order, humans have the ability to fill them any time they wish. They do this typically by inventing new signs, altering already-existing ones to meet new demands, borrowing signs from other signifying orders" (ibid., p 100). Individuals are the agents endowed with powerful creative capacities able to change the Signifying Order, being constrained by it and expanding it at the same time, by necessity or will. 


\section{The Signifying Order}

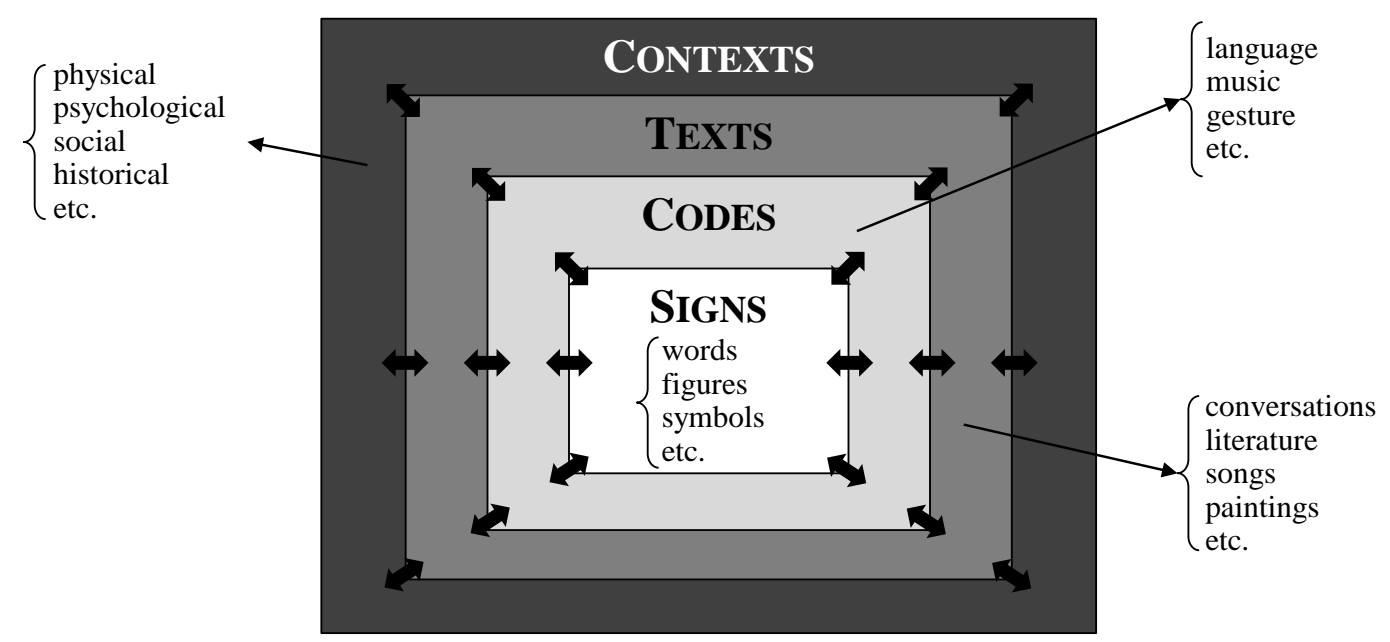

Figure 3-3 - The Signifying Order, adapted from (DANESI; PERRON, 1999, p.

$63)$.

\section{5. \\ Changing the Signifying Order: Poetry and Idiolects}

I mentioned before that semiosis by means of abductive interpretations needed an "optimizing" device to allow communication to be more fluid as we know it usually is. This device is culture and its signifying order. I will now return to abduction as one of the mechanisms that is also responsible for changing and keeping the signifying order "alive," as a vivid dynamic system. The introduction of new signs and alteration of existing ones, expanding and changing the codes, even if slightly, demand a sort of continuous re-work on the code at the interpreter's side. According to Eco (2017), when facing undetermined signs (i.e., determinants not coded yet into established cultural units):

\footnotetext{
"The interpreter of a text is obliged to challenge the existing codes and advance interpretive hypotheses that work as tentative forms of new codes. Facing new circumstances not covered by the code, facing complex texts and contexts, the interpreter sees his or herself obliged to recognize that a large portion of the message does not refer to pre-existing codes [that he or she knows] and that nevertheless should be interpreted. If this is so, there must be conventions that were not made explicit yet; and if they do not exist, they must be postulated, at least in an ad hoc way." (ECO, 2017, p. 117, my translation)
}

In Eco's theory, abduction is the first step towards expanding the semiotic code instituted in a certain culture (ibid., p. 120). Such operation can only be possible by means of relating a new sign to previously known ones, a 
metalinguistic operation of re-organizing the "semiotic space"-the signifying order, in Danesi \& Perron's terms-by incorporating new signs until the recognition and interpretation of them become established in culture, an "acquired social reflex" (ibid., 120), what Peirce would call a habit, a natural or acquired disposition to interpret a sign in a certain way (HOOPES, 1991, p. 251) ${ }^{12}$. Before spreading to culture, this process starts at the individual level as the human agents dynamically maintaining and changing the signifying order over time.

In the other part of his Theory of Semiotics, Eco provides a Theory of Sign Production (ECO, 2017, cap. 3) where he highlights the role of the aesthetic text in challenging and promoting changes in the established semiotic codes, what, despite different terminologies, refers to changes in the signifying order (ECO, 2017, p. 222 et seq.). An aesthetic text is one which the predominant function is poetic in terms of Jakobson's classic subdivision of language functions (JAKOBSON, 1960). According to Jakobson, poetic or aesthetic are one the six major language functions in his classic theory, the other five functions being: emotive, conative, metalingual, referential, and phatic. "The set [orientation] toward the message as such, focus on the message for its own sake, is the POETIC function of language" (ibid., p. 6), the canonical example being poetry. To Eco, the aesthetic text is particularly endowed with a capacity to provoke mutations of the code because it manipulates expression and content in original and innovative ways that often subvert the established rules and, therefore, the expectancies of the receiver about the code. This triggers semiosis and stimulates new interpretations about the work and/or the world. This mechanism by itself creates a mutation of the code because, if nothing else, it shows alternative and novel possibilities of using the code that become, once seen, part of the code and, therefore, changes signifying order:

12 The concept of habit as used by Peirce is very broad and should be understood as a disposition applying basically to everything, from signs - such as in "a symbol incorporates an habit" (HOOPES, 1991, p. 251); to nature-"we find that some plants take habits. The stream of water that wears a bed for itself is forming a habit" (CP 5.492); to people- "some general principle working in a man's nature to determine how he will act" (CP 2.170), "habits of reasoning; and our natural judgments as to what is good reasoning accord with those habits" (CP 2.170); to logic_-"the formation of a habit is an induction" (HOOPES, 1991, p. 76), "Induction infers a rule. Now, the belief of a rule is a habit." (CP 2.643); and most generally to his philosophical doctrine, such as in "a specialization of the law of mind whereby a general idea gains the power of exciting reactions” (CP 6.145)—see (FARIAS, 1999). 
"By obliging a reconsideration of the codes and their possibilities, [the aesthetic text] imposes a reconsideration of the entire language in which it is based. It keeps the semiosis going "absent-minded." In so doing, it challenges the organization of the existing content and, therefore, it contributes to change the way by which a culture "sees" the world." (ECO, 2017, p. 232, my translation)

The mechanism that makes it possible is a "super sign function" (ibid., p. 230) that conveys multiple coexisting messages at different levels at the same time, designed by the author (e.g. an artist) to provoke deviations from the "standard" interpretations by means of ambiguity and self-reflexivity. However, there is an underlying rule governing the intended (designed) deviations, a structure which makes the aesthetic text work as such, that is perhaps the most important message conveyed by the text (idem). Since this underlying rule is restricted to a single text that was "spoken" by a single emitter, he called it the aesthetic idiolect (idem).

In Linguistics, an idiolect is a "dialect of one individual," where a dialect refers to the particular ways a group of people use a certain language, such as particular choices of vocabulary, structures, pronunciations (better known as accents), and, to a lesser extent, even grammar (LYONS, 1984, p. 19-21). A dialect is a linguistic phenomenon that develops in certain regions and social groups within a larger population of speakers of a certain language, and is tightly coupled with social and historical aspects, such as regionalisms brought about by the influence of other cultures and languages, or discourse practices that develop around certain professions, such as those related to the protocols and etiquette of Law practitioners. According to Lyons, at the limit, each individual develops his or her own dialect, that is, their idiolect - the idiosyncratic way by which they speak the common language (ibid., p. 21).

Idiolects are not fixed, they are subject to change and extension throughout people's life (idem). An idiolect is developed by each individual as one acquires the language skill and cannot prevent people to understand one another, otherwise it would hinder the main function of the language as a communication device. Just the opposite, idiolects are a refinement of a person's linguistic skill that enables one to express one self and to act in the world in a fuller and more sophisticated way. Proficient language speakers learn how to adequate the ways they use the language in order to reach their goals according to the situation. And the only purpose of doing so is if others are able to understand the core and the underlying 
messages they want to convey. Lyons actually mentions that a person can hold a repertory of dialectal variations that one can manage according to the situation (ibid., p. 221). "Language variation in the individual and language variation in the community are two sides of the same coin. [...] As we express our personality and individuality in our linguistic behavior, we do so in terms of the social categories that are encoded, so to speak, in the linguistic variations of the community of which we are members" (ibid., p. 221-222). Therefore, idiolects are linguistic phenomena that have both an individual and a socio-cultural dimension, a twoway road where language variations spoken by individuals cannot prescind of a feedback loop when used to communicate to others.

Beyond (or before) Linguistics, idiolects have a semiotic dimension. They help "locate a message within a system of conventions, beliefs, and assumptions [of its author]" (SANZ, 2000). More generally, idiolects can be seen as manifestations of the semiotic strategies of a text ${ }^{13}$, as posed by Eco in his concept of aesthetic idiolect mentioned above - the underlying rule governing the logic of semiotic design and intended interpretations of an aesthetic text (ECO, 2017, p. 230). In the sequence, Eco extends the concept to corpus idiolect to refer to all works of an author or artist, that is, his or her "personal style" (e.g. "Picasso's idiolect"); and movement or period idiolects, when an idiolect is accepted by a community, imitated and produce mutual influences among a certain culture (e.g. the "baroque idiolect").

13 Indeed, Eco used "textual strategy" to refer to the aesthetic idiolect in later works (e.g. ECO, 2018, p. 99). 


\section{Research Design (1): Mapping the Problem Space}

This section describes my global research approach and the methods applied as well as the results obtained from each. I wish I could start this chapter by saying that I have always had a very clear research question in mind and, as a consequence, a well-defined and proven methodology to approach this research question and answer it. But this would not be true. I started this research with a general concern about the problems related to how people would interact, customize and take effective control of the emerging IoT technology. As suggested before, this concern was grounded in the fact that IoT technology has the potential to amplify and complicate existing interaction problems by changing human-computer interaction significantly, introducing new elements and spreading computing technologies in the world in an unprecedent way. In addition, it resonated with open questions regarding configurable technologies in the End-User Development literature and was shared by several researchers in this field (HINCKLEY, 2017; PATERNÒ; WULF, 2017; cf. TETTEROO et al., 2015). However, how to approach it seemed complex and lacking any sort of precise guidance.

Perhaps the hardest challenge is to navigate in a variety of approaches and technologies where theoretical and epistemological (methodological) consensus does not exist. Actually, alternatives compete with each other, because research is also "a business." Since I did not have a map, I tried to build one. The way I did it was by means of successive complementary triangulations in order to get a broad and deep understanding of the complex and novel domain of user experience with IoT technology.

Triangulation is an established strategy in conducting research in the social sciences adopted in qualitative and mixed methods research (DENZIN; LINCOLN, 2000; TASHAKKORI; TEDDLIE, 2010). Denzin \& Lincoln define it as "the use of multiple methods as an attempt to secure an in-depth understanding of the phenomenon in question" (DENZIN; LINCOLN, 2000, p. 5). According to 
Creswell, triangulation is one of the strategies to promote the validity of qualitative research (CRESWELL, 2014, p. 201), other criteria being the plausibility and traceability of researchers' unique interpretive process from concrete data to conclusions (LEITÃO; PRATES, 2017). According to Heath (2015), triangulation "can be applied to multiple operationalizations of treatments and manipulations and to the use of multiple theories, analyses, analysts, methodologies, and research designs, to name but a few applications." "By combining methodologies as different as participant observation and survey research, for example, researchers can study processes under vastly differing assumptions, biases, and errors" (idem).

According to Flick (1992), triangulation has evolved from a strategy of validation to a way to produce more in-depth understanding in qualitative research and to found the credibility of qualitative analysis. Leitão \& Prates say that triangulation aims at generating different perspectives about a research question that should be consistent with each other but not necessarily "homogeneous," suggesting a similar view about the topic (LEITÃO; PRATES, 2017, p. 84). They also highlight the increasing need for using qualitative methods in Computer Science research in order to "identify and understand non-measurable aspects of human experience with information technology" (LEITÃO; PRATES, 2017, p. 44). Mathison (1988) goes beyond and says that triangulation does not promote validity, but rather "results in convergent, inconsistent, and contradictory evidence that must be rendered sensible by the researcher or evaluator" (p. 13). According to Denzin \& Lincoln, qualitative research needs to reveal "the substance of the findings," rather than blindly following methods (which they term "methodolatry") when trying to obsessively look for "the trinity of validity, reliability and generalizability," which not necessarily reveals the essence of a narrative (DENZIN; LINCOLN, 2000, p. 390). Drawing from Richardson (1994; also RICHARDSON; ST. PIERRE, 2008), they propose "crystallization" (a metaphor to thick $3 \mathrm{D}$ triangles) as a strategy of qualitative inquiry aiming to reveal multiple facets and perspectives of an object or phenomenon under investigation (op. cit., p. 391-2).

In line with most common approaches (CARTER et al., 2014; cf. DENZIN; LINCOLN, 2000, p. 391), Turner \& Turner (2009) classify triangulation in terms of data, when one uses different data sources; methods, when one applies two or 
more different methods to collect and analyze the data; investigator, when confronting results of different researchers such as in inter-coder agreement; and theory, when one applies two or more theoretical frameworks in the interpretation of the data. According to Denzin (2017, p. 3), “empirical events must be examined from the vantage provided by as many methods as possible." Of course, practical reasons and limited resources determine what "as many as possible" means. Choosing the central problem of people interacting and customizing IoT technology, I took something in between a constructivist and a pragmatist scientific paradigm (GUBA; LINCOLN, 1994) or "philosophical worldview" (CRESWELL, 2014, p. 5-11). Constructivist because the methods I used were mostly qualitative and targeted in extracting participants' meaning, in-depth understanding of the contexts and theory generation. Pragmatist because each study was linked to each other in a problem-centric, pluralistic and real-world practice-oriented fashion, where my intended consequences directed what to do next.

The metaphor I like to think of is triangulation as a way to investigate complex problems and contexts where the application of multiple methods, theories, etc. reveals different facets or pieces of a bigger picture that complement each other in order to produce a better (broader and deeper) understanding of the phenomenon under observation. If they all relate to the same phenomenon or object of study, each piece should combine with one another but how to do it in useful ways is left to each particular research design and to the researcher to figure out. In my view, "useful" refers to what Leitão \& Prates mean by saying that "the product of triangulation is a set of meanings and interpretative categories capable of generating a deep understanding of a scientific problem and, moreover, an interpretative framework that can be (re)applied in other research contexts" (LEITÃO; PRATES, 2017, p. 84).

My global approach reflects this metaphor and is depicted in Figure 4-1, where the numbers point to the following sub-sections. By triangulating different methods, I revealed different aspects of the phenomenon of interest and produced a clearer and more complete picture of it. By composing different and partial pieces of knowledge revealed by each method, I will try to get a breadth and depth understanding of the complex and novel domain of interacting with IoT technology. In the following sections, I describe each step that I took and the 
rationale that guided me through from one study to another. I describe the background, methods and partial results in a sequence and more or less in isolation for the sake of clarity, but often times studies and analysis were conducted in parallel and revisited afterwards in light of new knowledge. Studies were not of the same size or relevance, but they all contributed with a piece of knowledge in building this thesis. As my researched progressed, the focus and role of each study became increasingly clearer. This picture will be completed in the next chapter (Chapter 5) with two more studies and the final big picture will be presented only in Chapter 6 .

\section{User Experience with IoT}

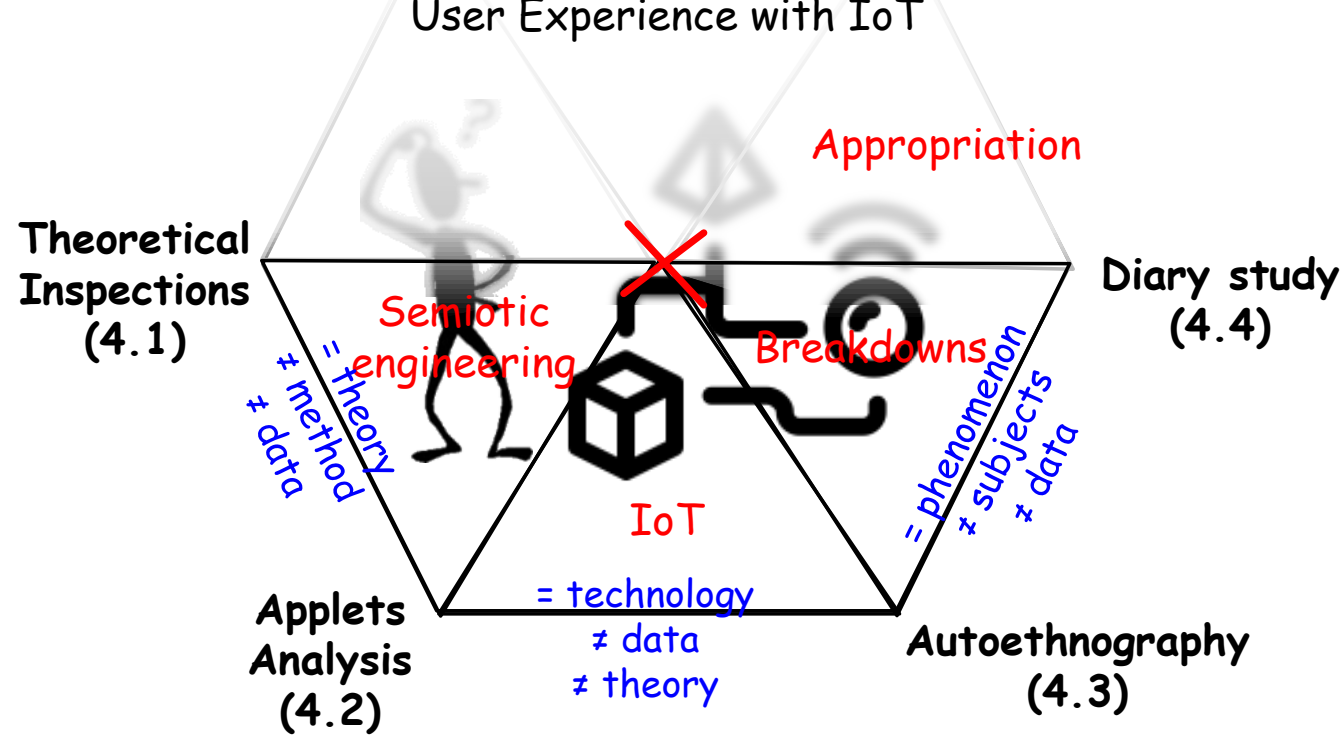

Figure 4-1 - A depiction of my research approach: a triangulation of different methods as a form of mapping the problem space.

\section{1.}

\section{Study 1: Theoretical Inspections Based on Semiotic Engineering ${ }^{14}$}

As mentioned above, I started with a general interest in End-User Development (EUD) (LIEBERMAN et al., 2006) for the IoT. Researchers have identified EUD as a useful approach to support users in smart environments in the

14 This section is adapted from a short-paper entitled "End-user development for the Internet of Things OR How can a (smart) light bulb be so complicated?" (CHAGAS; REDMILES; DE SOUZA, 2017) (C) 2017 IEEE published by me and co-authors and presented at the 2017 IEEE Symposium on Visual Languages and Human-Centric Computing (VL/HCC). 
IoT context because it allows for the combination of heterogeneous devices and user needs (BARRICELLI; VALTOLINA, 2015; BOOTH et al., 2016; e.g. BURNETT; KULESZA, 2015; HINCKLEY, 2017; JOHNSSON; MAGNUSSON, 2017; KUBITZA; SCHMIDT, 2016; PATERNÒ; SANTORO, 2017). While a relatively new topic, some related research about connected homes anticipated many aspects of the current IoT context and challenges, for example (BLACKWELL, 2004; NEWMAN et al., 2002). Today, as IoT technologies have gained momentum and speed, IoT infrastructure is much more affordable and no longer restricted to early-adopters. Barricelli and Valtolina (2015) say that "EUD represents the ideal approach for empowering the end-users and make[ing] them becoming unwitting developers in their own IoT environment" because they are "at the center of a complex ecosystem that they need to manage in efficient, effective, satisfactory, and aware manner."

\subsubsection{Method}

In this first study, I focused on studying IFTTT, an online service and an EUD tool for building task automation (IFTTT INC., 2011) ${ }^{15}$, together with the Philips Hue smart light as a representative instance of EUD for the IoT. Given the centrality of communication to Semiotic Engineering, I tried to explore the communicability of the systems in these kinds of settings. In HCI, a "discount method" (NIELSEN, 2009) to study a system is to apply an inspection method, where a trained evaluator inspects an interface following a determined procedure (NIELSEN, 1994). A theoretically grounded inspection, on the other hand, is an inspection method where an investigator conducts a principled account of a system's interface guided by a theory of choice (e.g. WHARTON et al., 1994). Semiotic engineering has proposed its own inspection method called the Semiotic Inspection Method (SIM) (DE SOUZA et al., 2006; DE SOUZA; LEITÃO, 2009).

In essence, SIM is a semiotic guided analysis of the system's interface that tries to reconstruct the designer's metacommunication message (see Box 3-1) and evaluate its quality in terms of how the message is constructed and emitted and its 
presumed effects on the receiver. The metacommunication message is first deconstructed in terms of three types of signs that can be found in a system interface, namely metalinguistic signs - online help and documentation about the system in natural language - , static signs - that is, signs that convey meaning by their static state, e.g. an icon, symbol or word-, and dynamic signs - that is, signs that convey system behavior meaning dynamically, over time, e.g. a progress bar or any process indicator. Finally, the investigator should cross check all analyses against each other in order to build a semiotic profile of the application containing his or her assessment of the quality of the metacommunication message as emitted by the designer.

A communicative analysis like SIM can only be conducted within a certain context in which the communication takes place, which determines the interlocutors and intention of any the communicative act. Therefore, SIM demands that an investigator defines a scenario for the analysis, which typically delimits a portion of the system to be analyzed and the boundaries (the scope) of the analysis. The initial step to apply SIM is then to define the context and scope of analysis. However, with an IoT device or system what and where were the system interfaces and the very boundaries of the "system" were not clear at the time. Therefore, a direct application of the SIM was not possible. A necessary previous step then was to find these boundaries and limits of this system, a framing where such method or a similar version of it could be applied to IoT systems. And that turned out to be our main goal in this study.

\subsubsection{Analysis}

In essence, a theoretical inspection grounded in Semiotic Engineering of IoT should be able to: firstly, systematically study the different interfaces with which users interact using the same ontology, principles, and theoretical foundation, since they are all, ultimately, communication artifacts; secondly, not lose sight of the "big picture," since each dialog is part of the larger context where it is immersed; and finally, be general enough to allow for its extension to other conversations as our research evolves.

15 According to Wikipedia, IFTTT was founded by Linden Tibbets and Jesse Tane in December $14^{\text {th }} 2010$ and launched in September $7^{\text {th }}$ 2011. See: https://en.wikipedia.org/wiki/IFTTT [Last 
By applying the amplified Semiotic Engineering's HCC perspective (DE SOUZA et al., 2016) applied to the EUD for IoT case, I can identify several conversations going on. The approach depicted in Figure 4-2 is a framing for the EUD for IoT problem based on the co-occurrence of several interactive conversations according to Semiotic Engineering theory. In the figure, arrows represent different conversations that are happening through different interfaces from developer (2) to developer (1) (solid black); from developer (1 and 2) to enduser developer (A) (dashed, blue and green); from end-user developer (A) to self and other end users (B) (pointed red). In particular, I highlight that: first, there is no delimited interface with the IoT and the cloud represents that idea, encompassing different systems and devices and their respective interfaces. Second, users "talk" to more than one developer at the same time: with the EUD tool developer (1 - gray) and with the IoT device developer (2 - green), to name just two of them. All conversations are important because they all will, at the end, influence the user experience and the mental model of the systems that the users build in their heads. This is a complex or "messy" group communication scenario, where collective meaning negotiation and action coordination processes are supported by communication through different artifacts.

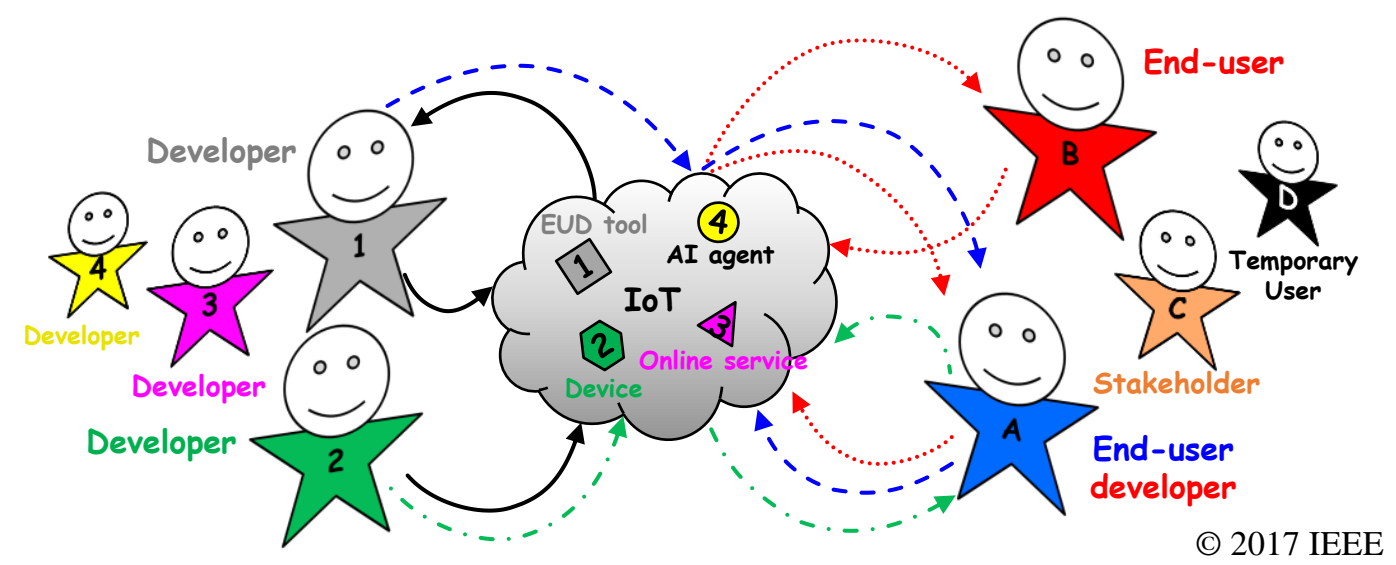

Figure 4-2 - A Semiotic Engineering framing of EUD for the IoT: Who's telling what to whom and how in the IoT ecosystem? (originally published in: CHAGAS; REDMILES; DE SOUZA, 2017). 


\subsubsection{Results}

By instantiating the framing presented in Figure 4-2 to the Hue + IFTTT case, I can identify at least four dialogs and their respective interfaces: (i) Hue developers talking to their end users through the Hue system interface; (ii) the Hue developers talking to their public API users (IFTTT developers in this case) through the API protocols and behaviors; (iii) the IFTTT developers talking to their end users (who are also end users of Hue) through the IFTTT interface; and finally (iv) the end-user developers talking to other end users through the interface of shared applets. From Semiotic Engineering perspective, each conversation entails a research question as following:

- What are Hue developers telling end users? And how?

By design, Hue developers distribute the system in several components: the bridge, light bulbs, and the mobile app. This creates a situation where, for end users, interpretation and meaning is distributed across different but interrelated interfaces. For instance, naming and identifying a light bulb, a group of lights (rooms) and scenes (a certain configuration of lights in a room) are features that are only possible to be performed by using the mobile app and looking at the physical lights at the same time, so that one can understand the final result: to discover that "lamp 1 " is the one in the left corner of "living room," for example, one needs to make it blink or change its color through "direct manipulation" (in Blackwell's (2004) sense) with the app. Thinking about an EUD scenario, where the goal is a kind of indirect manipulation of objects by means of a programming notation, users are likely to interact with both the app and the EUD tool in order simply to be able to refer to a particular light bulb, room or scene by its name. This is a communication problem that considerably increases the user effort during an EUD activity.

- What are Hue developers telling IFTTT developers (users of the Hue API)? And how? 
I assume that the Hue public API ${ }^{16}$ is the software component providing the integration of the Hue with IFTTT. IFTTT developers opted to provide a REST API that implements a stateless protocol. However, the devices (the physical light bulbs) are, in essence, "state full." This (technically understandable) decision may demand API users to write more code, for example, to handle synchronizing their apps with the actual lights' states over time. This can discourage developers from providing features for showing the lights' current state in their apps. This feature can be extremely useful in an EUD scenarios of testing and debugging a rule that stops working. Today, checking the system current state is only possible by using the Hue mobile app, the only place where the user can actually see that a light bulb is off because it is "unreachable," meaning it can be broken, or just turned off in the wall switch.

- What are IFTTT developers telling end users when creating recipes with Hue? And how?

While creating recipes with Hue, I found concepts in the IFTTT interface that are inherited from the Hue system, such as light names, groups of lights (rooms) and scenes. Again, assuming that integration between Hue and IFTTT occurs through the Hue public API, this means that the end user is confronted with the Hue API design when developing with IFTTT. More research is required to clarify API roles in EUD composition environments but for now I highlight that APIs seem to play a relevant role in mashups. In that sense, a tool such as IFTTT and other composition environments are, to a great degree, an environment for interacting with APIs. Namely, they are like a "glue" for composing third-party services. Despite the importance of the "glue" for any collage, we also must look at the parts being joined, which may need to be cleaned, polished, or cropped to elicit a better result.

- What are end-user developers telling other users about HUE when using IFTTT? And how?

Finally, I looked at what and how IFTTT applets communicate their creators' (end-user developers) intents and purposes to others users, since the

16 https://developers.meethue.com/develop/hue-api/ [Last visited: 16-Feb-2020] 
platform promotes the sharing of applets between users. However, although IFTTT presents a carefully designed wizard for creating an applet in an easy and guided way, the interface for reading an applet is overly simplified. It hides many details of the applet, forcing users browsing existing shared applets to make decisions based only on the title and description of applets, which may be difficult. For example, I found an applet which is named "DropCam Alert Turns on Hue Lights"17 and described as "Connect Your 'Gmail Account' and Your 'My Hue' Account to scare the bad guys!". It is only after turning the applet on that one can inspect how it works and figure out that it will turn the determined Hue lights on whenever one receives an email from “noreply@dropcam.com” in one's Gmail account. I assume that it depends (or depended, since it no longer exists) on the configuration of the "Dropcam" device to send alerts to a particular Gmail address. Overall, to make this single applet work properly, one needs to interact with IFTTT, the Dropcam configuration system (to configure the email alert), Gmail (to connect with IFTTT), and the Hue system (to determine which lights will turn on), what is impossible to tell from the applet reading interface alone.

\subsubsection{Conclusion}

The results above were promising but preliminary. As the main finding from this study, I discovered a new way of framing problems in EUD for IoT based on Semiotic Engineering. This framing lead focus towards the communicability of pertaining systems and their different interfaces, an approach that addresses many aspects of EUD in the IoT domain, ranging from software and hardware aspects to the context of use. By applying this framing in the IFTTT + Hue case, I illustrated how this approach can reveal some issues that have not been explored yet and that point at different problem formulations and, consequently, create the opportunity for different problem solutions. Doing so by itself has the promise to expand our knowledge about EUD in interesting ways. At that point, my approach was preliminary, but I envisioned interesting future work developing a systematic method to investigate such a complex group communication scenario, in at least some of its critical aspects. I identified that simple smart device such as a smart

17 The link used to be: https://ifttt.com/applets/222114p-dropcam-alert-turns-on-hue-lights [last visited around: 23-Jul-2017] but it looks like "DropCam" no longer exists and the link is 
light bulb can get very complicated because of its distributed interface and the need to look at it as a device immersed it in the context of a larger ecosystem of devices, applications and, most importantly, people. An HCC approach to EUD for IoT naturally drives our attention to the quality of the communication between people, developers and users, through distributed interfaces of different kinds.

I still think the framing proposed in this study is valid. But perhaps the most important discovery that I learned from this study only revealed itself as a late result and after a long time after doing it. Although co-occurring, each interactive conversation identified in Figure 4-2 have not only different media but also different emitters and receivers. An attempt, as I was trying to do, of crossing the analysis of these different conversations would be quite hard, time-consuming or of little practical use. The "key" or the "missing link" is that they are parts of different metacommunication discourses. It seems obvious now, but a principled account of a metacommunication message needs to take into account the emitter, the receiver, and the media (the system and its interface). If everything is different, a comparison or a consolidation of findings arising from the analysis of each conversation will not cross anywhere. They will be, at most, a collection of scattered findings. Some findings might be useful even if presented in this way, but literature is already full of them. As a late discovery from this study, I learned that I needed another kind of framing, one that could be more coherent with Semiotic Engineering ontology and metacommunication principles in order to really benefit or leverage from the theory. In other words, this framing, although empirically and theoretically grounded, was lacking the epistemological rigor mentioned before, which I attempted to correct with further studies and articulation presented in the next chapters of this thesis. 


\section{2. \\ Study 2: A Qualitative Analysis of IFTTT Applets Using Some Grounded Theory Techniques}

It was found out during the previous study that the interface for reading an applet mediating the communication between and end-user developer and a "regular" end user was overly simplified. Therefore, a SIM-like communicative analysis is much hindered in this case because the interface was very "thin." A feasible alternative to "thicken" this data was to invest in quantity by collecting a variety of applets that could serve as corpus to be analyzed. This would also serve as a shift to a different dataset of empirical data, serving as a triangulation in method and in data. This could be done by collecting applets that used IoT devices in order to gain insight about how and what for people were using IoT devices.

\subsubsection{Method}

I started with the following research question in mind already mentioned before:

- What are end-user developers telling other users about HUE when using IFTTT? And how?

To answer this question, I manually searched the public applets in the IFTTT platform that use the Hue service ${ }^{18}$. I found 462 different applets (until March 2017) that were scraped and downloaded in a semi-automatic way following an approach similar to (UR et al., 2016). I extracted all the public available information about each applet, including its unique identifier, title, description, author, number of installs (the number of times each applet has been turned on by some IFTTT user), the trigger and the action composing the applet. I then went through all applets to get a sense of the data and coded them. As it will become clear throughout my report, I privileged a pragmatist abductive approach to theory construction, rather than an inductive one (TAVORY; TIMMERMANS, 2013; cf. TIMMERMANS; TAVORY, 2012). That is, I resorted to theoreticallyinformed and new hypothetical insights (abductively generated) to account for my empirical observations rather than looking for "theory-free" conceptualizations of the empirical data developed through interactive analysis (induction).

18 This can be retrieved directly with the link: https://ifttt.com/hue [Last visited: 16-Feb-2020] 


\subsubsection{Analysis}

I started with an open-ended, bottom-up coding approach to data analysis. Coding is one of the main techniques for analyzing qualitative data in any qualitative method (DENZIN; LINCOLN, 2000, p. 780 et seq.), but since I tried to start "free" from previous theoretical conceptions or framings and engaged in open coding I got close to the grounded theory (GT) method (MULLER, 2014). I went through all applets and coded them bottom-up in emerging categories that could highlight particular and interesting features of each applet. The categories were interactively developed as I tried to make sense of the data, trying to capture the main distinctive features of each applet. As I iterated through the data, categories appearing less frequently or less relevant were replaced, merged or put as lower level subcategories until I found a reasonable set of codes that could describe the analyzed data. In addition, I engaged in constant comparison of datawith-data and data-with-theory until saturation, I kept my memos, I made some and theoretical sampling (idem).

However, the understanding of the data I got interested in and the final story to tell only revealed after I turned back to my working theory of choice, namely Semiotic Engineering. There is debate among grounded theorists whether this is methodologically acceptable or not (BRYANT; CHARMAZ, 2007a, 2007b; cf. CHARMAZ, 2000) and more modern versions of grounded theory (cf. CHARMAZ, 2014) accept and even encourage such approach of combining existing theory and the data-grounded one (e.g. FURNISS; BLANDFORD; CURZON, 2011). However, since I did not apply all the method techniques and I was not committed with the entire method epistemology, this study cannot be said to have been a "full-fledged" grounded theory, neither it tried to. My approach is closer to what can be best stated simply as a pragmatist qualitative method (cf. TAVORY; TIMMERMANS, 2013) using some grounded theory techniques.

\subsubsection{Results}

A first round of analysis stabilized pointing to the applet title, description, trigger and action as representants of the intended behavior and purpose of each applet. By the end of this process, an initial set of IFTTT applet categories was found: 
- Mood: when Hue lights were being used as a typical "mood light", to create a particular desired atmosphere in the ambient, for example: "Set your lights to match the album cover colors of your last listened track", that works with Deezer ${ }^{19}$, a song playlist service as the trigger;

- Notification: when Hue lights were being used as a way to notify the user (or somebody s/he wants) about some event, for example: "Automatically turn your Hue lights blue whenever it starts to rain", that uses a service of weather forecast (Weather Underground) as a trigger;

- Automation: when the main purpose of the applet seemed to be to automate a repetitive task, to happen in a regular basis and without user intervention, such as in the applet "Automatically turn your lights on at sunset";

- Remote control: when the main purpose of the applet seemed to be to create a different way to directly control the Hue lights, demanding direct user interaction just as in a remote controller, such as in the applet "Toggle your lights on/off - A one-tap way to control your Philips Hue lights from your phone" that creates a shortcut button in the users' mobile phone using as trigger the IFTTT service called "Button widget".

In a subsequent round of analysis and drawing from our Semiotic Engineering background, I noticed that the main distinctive features of each applet was actually a proxy for the applet developer (an end-user developer) intent. By the end of this process, categories were refined in the following set of presumed intents:

- Recreation: when the Hue lights were being used as a typical "mood light" to create a particular desired atmosphere in the ambient for fun or recreational purposes, for example: "Set your lights to match the album cover colors of your last listened track" (on a music streaming service);

- Notification: when the Hue lights were being used as a way to notify the user (or somebody s/he wants) about some event, for example: "Automatically turn your Hue lights blue whenever it starts to rain" (according to a weather forecast service);

19 http://www.deezer.com/ [Last visited: 25-Feb-2020] 
- Automation: when the main purpose of the applet seemed to be to automate a repetitive task, in order to make it happen in a regular basis and without user intervention, such as in "Automatically turn your lights on at sunset" (according to a weather forecast service);

- Interaction: when the main purpose of the applet seemed to be to create a new custom way for the user to directly control the Hue lights, such as in "Toggle your lights on/off - A one-tap way to control your Philips Hue lights from your phone" that creates a shortcut button in the users' mobile phone home screen.

The graphic on Figure 4-3 depicts the frequency of applet intents over the set. First row is the number of applets and the second row is the number of times each applet has been installed by some user, a proxy for the applet popularity. Intents are presumed by the researcher since I did not have access to their original authors in order to check their original intention. Sometimes, intents also overlap because categories are not mutual exclusive. For example, the applet "Flash your lights when there is an in-game update from your favorite team" was assumed to have the primary purpose of notifying a user who is not watching the game; but it can be just a matter of entertainment or celebration if one is watching the game with friends in the living room, or maybe both if one is preparing a meal in the kitchen for the same group of friends watching the game in the living room. Even if I asked the applet creators or its users, I would probably get blurred answers and multiple intents. Nevertheless, picking a "primary" category was enough to provide a reasonable and overall understanding of the kind of things people do and how they were using Hue and IFTTT. 


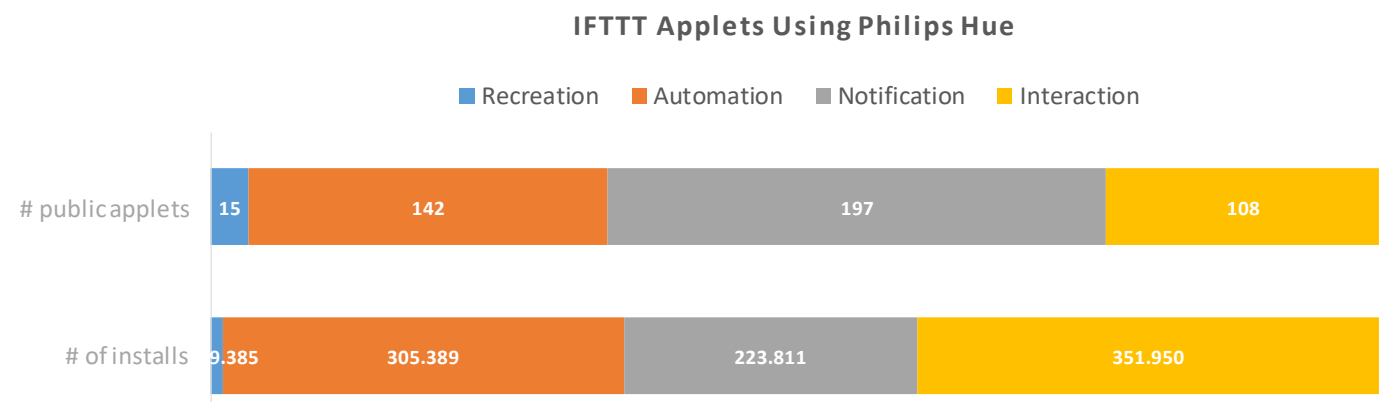

Figure 4-3 - A graphic displaying the occurrence of four categories of presumed intent found in the set of 462 IFTTT applets using the Philips Hue smart lights. First row is the number of applets and second row is the number of installations, the number of times each applet has been turned on by some user, a proxy for applet popularity.

After this point, I did what grounded theorists would call a "theoretical sampling" (CHARMAZ, 2014, p. 197 et seq.; MULLER, 2014, p. 38). I used another sample of data in order to refine this list and our emerging "theory." In this case, I used data collected from a diary study (to be described afterwards in Section 4.4), which contained data from applets people were using not only with the Philips Hue, but with a larger set of smart devices. The categories above were refined by constant comparison with the new data and a new category of configuration intent emerged:

- Information: when the main purpose of the applet seemed to be to gather information about the applet's author or the environment in order to produce awareness, self-knowledge, or reflection, a kind of "epistemic interaction" (TURNER, 2012). For instance, the applet "Keep a Google spreadsheet of the songs you listen to on Alexa" and similar records of the logs of sensor data were used by people to learn about themselves, their habits, and the environment.

I also realized that this was not only about IFTTT applets, but about all means people could use to achieve a certain goal with the technology. For example, native smart devices companion apps provided similar functions and configurations that would not demand IFTTT to work. People would meet the same intent regardless of which configuration interface one would choose. In 
general terms, these categories were translated into categories of configuration intents, which are summarized in Table 4-1. In their essence, they were referring to potential problems users were trying to solve, presumably an attempt to repair a breakdown they had had before. Taking a configuration as a conversational (communicative) act (as any interaction, in Semiotic Engineering's perspective), I derived some communicative dimensions of a configuration, namely the intent, the motivation (context), and the expression chosen.

Table 4-1 - Communicative dimensions of configurations of IoT devices:

\begin{tabular}{|c|c|c|c|}
\hline $\begin{array}{l}\text { Example of } \\
\text { configuration }\end{array}$ & $\begin{array}{l}\text { Intent } \\
\text { (What?) }\end{array}$ & $\begin{array}{l}\text { Motivation } \\
\text { (Why?) }\end{array}$ & $\begin{array}{l}\text { Expression } \\
\text { (How?) }\end{array}$ \\
\hline $\begin{array}{l}\text { "Added a trigger for } \\
\text { Alexa to change light } \\
\text { color to my girlfriends } \\
\text { favorite color using } \\
\text { "Echo, Trigger } \\
\text { 'Girlfriends' favorite } \\
\text { color." (P11) }\end{array}$ & Recreation & $\begin{array}{l}\text { Personal/innovative } \\
\text { functionality }\end{array}$ & $\begin{array}{l}\text { IFTTT applets } \\
\text { Native apps } \\
\text { specific settings, } \\
\text { e.g. light scenes }\end{array}$ \\
\hline $\begin{array}{l}\text { "Turn on [lights] when } \\
\text { arriving home (Norte)" } \\
\text { (P1) }\end{array}$ & Automation & $\begin{array}{l}\text { Efficiency (sparing time } \\
\text { and interactions) }\end{array}$ & $\begin{array}{l}\text { IFTTT applets } \\
\text { Native apps } \\
\text { features and } \\
\text { routines, such as } \\
\text { schedules, Alexa } \\
\text { routines, Flic } \\
\text { Tasks }\end{array}$ \\
\hline $\begin{array}{l}\text { "I have started to use the } \\
\text { alexa to notify me of } \\
\text { every } 3 \text { hour increments } \\
\text { in order for me to take } \\
\text { my pills." (P3) }\end{array}$ & Notification & $\begin{array}{l}\text { Awareness, usually } \\
\text { through innovative } \\
\text { modalities }\end{array}$ & $\begin{array}{l}\text { IFTTT applets } \\
\text { Native apps } \\
\text { general settings, } \\
\text { e.g. phone } \\
\text { notifications }\end{array}$ \\
\hline $\begin{array}{l}\text { "Attached the flic to my } \\
\text { nightstand by my bed. I } \\
\text { made it so that when I } \\
\text { push the button, my LIFX } \\
\text { bulb will toggle on and } \\
\text { off. I connected the two } \\
\text { devices via IFTTT." (P7) }\end{array}$ & Interaction & Accessibility, convenience & $\begin{array}{l}\text { IFTTT applets } \\
\text { Native } \\
\text { integration } \\
\text { between devices, } \\
\text { when available }\end{array}$ \\
\hline $\begin{array}{l}\text { "Record songs played } \\
\text { with Alexa with a google } \\
\text { spreadsheet" (P5) }\end{array}$ & Information & $\begin{array}{l}\text { Awareness, self- } \\
\text { knowledge, reflection }\end{array}$ & $\begin{array}{l}\text { IFTTT applets } \\
\text { Logs, historical } \\
\text { data }\end{array}$ \\
\hline
\end{tabular}

\subsubsection{Conclusion}

There are two important things that I learnt from the results above. Firstly, when end users configure IoT technology in order to make it fit within their practices, they are not only customizing technology but also their practices. When a user sets the lights' color to match the album cover colors of the last listened track, he or she is defining the experience they want to have while listening to 
music; when one automates the task of turning the lights on at a certain time one defines that one does not want to interact with the wall switch anymore; when one is notified about rainy weather by the room lights, one wants to be reminded to get the umbrella before leaving home; when one creates a shortcut in the phone to easily turn the lights on and off one plans to use the phone as a remote controller; and so on.

Each definition is a design decision the end user is taking not only regarding the technology but also the broader context of his or her practices. In other words, end users are primarily designing with IoT, and not the IoT. The follow-up question is then: What are end users primarily designing then? The original understanding of the term end user as used in End-User Development (and other related concepts such as end-user programming and end-user software engineering) is that this person in not primarily interested in programming for the sake of it, but rather in getting the work done (NARDI, 1993). Outside professional contexts in which EUD was more deeply investigated, I can say more generally that end users are ultimately designing their practices and the infrastructure that support their practices. I started to look at IoT configuration as a design activity and termed these activities as End-User Design, the design of one's everyday living practice and the infrastructure thereof.

In this sense, our characterization of end users' configurations can serve as a design space from the end-user perspective. A design space "identifies and organizes decisions do be made about the artifact, together with the alternatives for those decisions, thereby providing guidance for refining the design or a framework for comparing alternative designs" (SHAW, 2013). Engineering approaches to EUD tools tend to emphasize dimensions at the "how" column of Table 4-1 from the EUD tool designer perspective, such as in (PATERNÒ; SANTORO, 2017). This design space is based on an attempt to understand the users' perspective, therefore getting closer to the "what" and "why" of each customization, what I think can orient the proposal of other innovative tools in this domain to address some of the gaps already identified in literature, such as supporting organic evolution and designing for breakdowns as suggested by (DAVIDOFF et al., 2006).

Another important thing that I learned was about methodology. At some point, our coding of the data evolved from "general categories," to "categories of 
intent," to "communicative dimensions of configurations." Clearly, this was not grounded in the data, but in our application of Semiotic Engineering communicative perspective to the data and the emerging categories I were seeing through this particular theoretical lens. And the most important thing was that it actually promoted a richer understanding of the data. This was a maturation of my research process, when I realized that my approach was more committed with an existing theory than with a methodology. And that was not necessarily bad. By imposing a discipline derived from Semiotic Engineering ontology to the data analysis, the meanings of the configuration categories were considerably leveraged. "Data only speaks through theories," it has been said (MARTINS, 2006, p. 18). But working on the limits of a theory was not being easy, and I was in need to extend it but not sure if "building theory from the ground up" would be possible, suitable or helpful for me. Additional studies and analysis to be described in the following reinforced the more pragmatist side of my research, which led to the final results of this thesis. 


\section{3.}

\section{Study 3: Autoethnography 20}

As a third study, I conducted an autoethnography (CUNNINGHAM; JONES, 2005) as a first-person experience with existing EUD for IoT technology and tools. I experienced interaction with some commercially available smart home devices in order to gain concrete insight about them. Actually, I had been experimenting with IoT technology since the beginning of this research, researching the market and acquiring devices according to my financial possibilities and interests. Being in the United States at that time, I was aware that the IoT was leaving research labs and gaining market momentum. I observed there were an increasing diversity of purposes and brands that were offering IoT products to the general public, mostly for the smart home domain (Figure 4-4). Some of them, I acquired myself, tinkered with them, observed their interfaces, and ended-up adopting some, that is, using on a regular basis. But not all of them. It became necessary to make my observations and findings from personal experience explicit so that they could be submitted to scrutiny.

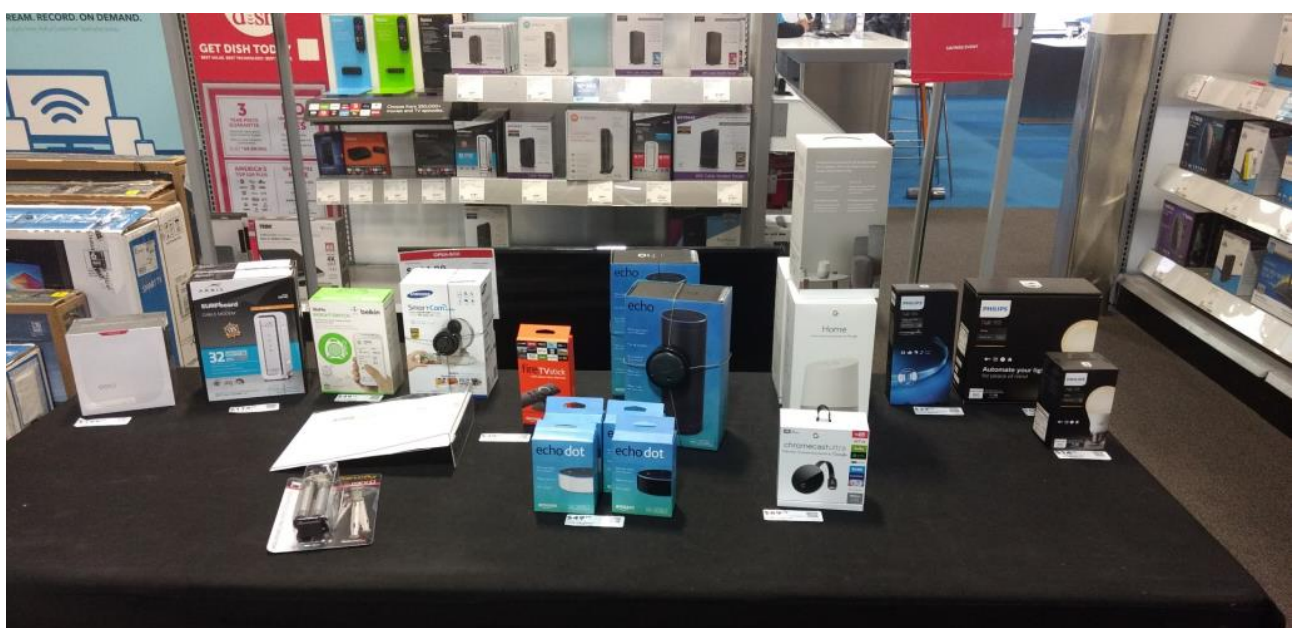

Figure 4-4 - A photo of IoT products exposed in an electronics retail store in the USA in January 2017 at Irvine, California. These are products targeted to the general consumer in the smart home domain. (Photo taken by the author at Irvine, California, USA (C BAC 2017).

20 This section is based on a research proposal entitled "End-user design for the Internet of Things: Supporting incremental evolution through breakdowns" (CHAGAS, 2017a) (C) 2017 IEEE presented at the 2017 IEEE Symposium on Visual Languages and Human-Centric Computing (VL/HCC) Graduate Consortium and exhibited as a poster during that conference. 


\subsubsection{Method}

I conducted the autoethnography by acquiring some commercially available IoT smart home technology such as smart lights, smart motion sensors, power plugs, etc. and installing then in my home and in my lab. In a continuous basis, I explored devices' possibilities, tinkered with them and tried to use and incorporate them in my daily activities and routines. I started by focusing on a single device, namely the (Philips Hue) smart light, and incrementally added new ones according to my financial possibilities. Besides glitches and interaction problems that sometimes happened, it called my attention the occurrence of breakdowns in the sense of situations where there was a mismatch between my expectation at a certain time and the technology behavior.

I noticed that even when using the simplest automations one could think of, such as turning the lights when arriving home or at a certain time, there were often unexpected situations where, although the technology was behaving "correctly" (that is, as it was configured to), I was forced to interfere, fix or change the final result. For example, when using automation based on my (phone) location, sometimes the lights turned on when I passed near my house on the way to the grocery store and I obviously did not want them to turn on at that time. If I used a time-based automation, whenever I was at home, several times I tended to "disagree" with the time I have set my own, turning the lights on, off or back on manually to bypass the automated routine. Other times, I had to open the smart light app to fix or adjust the lights' color or brightness because it was "remembering" a previous setting that was not making sense anymore. For example, night-lights I was using for reading or relaxing before sleeping were too weak in the morning when I woke up; bright lights I was using for studying were not kept when I turned them off for lunch or a coffee break and then back on using the wall switch. I got different "collateral effects" depending on if I used the voice assistant to control the lights (as at bed, just before sleeping) or the wall switch. I tried to educate myself and adapt some habits whenever I could make sense or generalize over certain behaviors. Ultimately, I got disturbed by the fact that even with a small number of smart devices, and rather simple ones, technology often presented an additional burden in many ordinary everyday situations. 
This additional burden seemed to be from a different nature, not usability or interface problems, and I felt this deserved further investigation. I noticed that the more interesting issues appeared over longer time frames, as my experience with technology unfolded, often as unpredicted or unwitting consequences of changes or configurations I have made myself. I started to use the term breakdown, in a broad sense, to refer to such kind of issues. The breakdowns turned out to be the moments when technology demanded the most of my attention as a user and decided to further investigate them.

\subsubsection{Results}

Breakdowns are actually a recurring topic in HCI literature. The importance of breakdowns as a critical moment for interaction in general has been pointed before by several works (FISCHER, 1994; SHARPLES, 1993; URQUIJO; SCRIVENER; PALMÉN, 1993; WINOGRAD; FLORES, 1986; WRIGHT; MONK, 1989). It has been defined as "the moment when the user becomes conscious of the properties of the system and has to mentally break down or decompose his or her understanding of the system in order to rationalize the problem experienced" (URQUIJO; SCRIVENER; PALMÉN, 1993). Sharples (1993) says that "breakdowns occur when the routine of work is interrupted, by straightforward technical failures, such as the loss of communication line, by social problems, such as interpersonal conflict, or by mismatches of expectation, when users become frustrated that the equipment does not fit with their needs or preconceptions." Both definitions are drawn from the original work of Winograd \& Flores (cf. op. cit., pp. 36-37).

In communication, breakdowns are disruptions in the communication flow that can have several causes, such as noise, channel failure, mismatches of expectations between parties, etc. In regular conversations, when a breakdown occurs, we engage in repair strategies that, typically, restore the communication flow, such as: "What do you mean?", "I don't understand...", "Sorry, say that again..." and the subsequent utterances that try to restore mutual understanding. However, when interacting with computer systems through their interfaces, breakdown repair is much more limited because systems can only react according to the mechanisms that systems designers and developers have anticipated and 
encoded in a computer program. During interaction, unanticipated breakdowns often cannot be repaired even if users have a good mental model of how the system behavior might be adjusted to avoid the breakdown. In this sense, EUD can be seen as a tool for changing the way a system is programmed in order to allow users to restore the effective flow of the interactive conversation. Therefore, EUD is a means to repair from breakdowns in IoT contexts and work as a possible situated solution to them.

To Semiotic Engineering, interaction failures are studied as communicability breakdowns that happen during interaction. They are signs of the quality of the system's interface and interaction design. Semiotic engineering has a method particularly targeted at detecting communication breakdowns that happen during user's interaction (DE SOUZA; LEITÃO, 2009; DE SOUZA; PRATES; BARBOSA, 1999). But breakdowns are actually much more than that. In a broader Semiotic perspective, breakdowns act as surprising facts that trigger cycles of users' abductive reasoning. They allow wrong hypothesis users might have about the system (e.g. an interpretation or expected behavior that were not in line with the actual system model and implementation) to be corrected and right ones to be improved or extended at interaction time. As in natural language communication, disruptions in the natural flow of communication demand from us extra work in order to restore mutual understanding between communication parties (e.g. MEADAN; OSTROSKY; HALLE, 2006). The first level of extra work is the abductive generation of hypothesis to explain the breakdown in order to inform, enable and support any further action e.g. an attempt to repair the communication. I saw myself engaging in this kind of process, which resonated with semiotic theory.

At this point, breakdowns were identified as ubiquitous critical phenomena. They corresponded to those situations when users get motivated, urged, or at least intrigued, to learn and adapt the technology in order to repair interaction, that is, their "conversation with the technology." I could directly observe such behavior in myself, as I started to pay more attention to it. The HCI literature mentioned above, although a little old, corroborated these observations, even if sometimes researchers would call it by a different name (e.g. LEWIS; NORMAN, 1995). Furthermore, I made contact with other related approaches that reinforced the importance of breakdowns in socio-technical contexts (LUDWIG; PIPEK; 
TOLMIE, 2018; PIPEK; WULF, 2009). In addition, the occurrences of breakdowns seemed more likely with the IoT, given the diversity of usage scenarios, contexts and devices. Breakdowns became then a source of interesting phenomena. Actually, the study of breakdowns has always been a focus to Semiotic Engineering (AFONSO, 2015; cf. DE SOUZA, 2005a, cap. 4) and surely that was influencing my inquiry too. But it seemed that there were more to unveil around this.

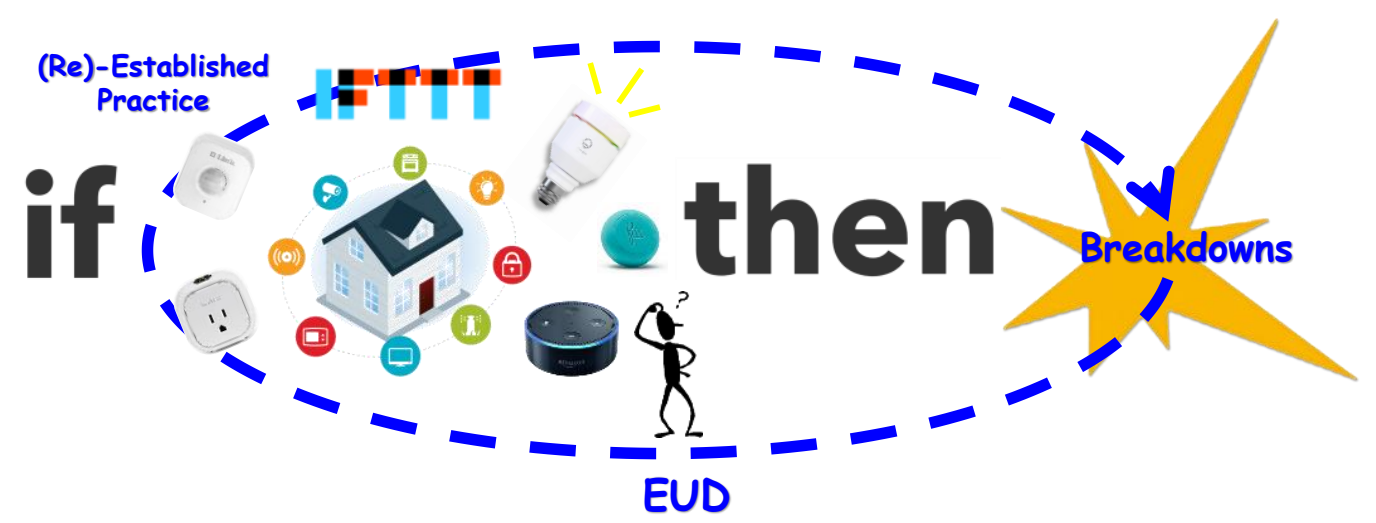

Figure 4-5 - Breakdowns with IoT technology and EUD as repair activities (from a poster presented at the 2017 IEEE Symposium on Visual Languages and Human-Centric Computing - VL/HCC).

\subsubsection{Conclusions}

My first approach at the time was to think about a kind of EUD solution that could guide users from the breakdown point onwards. For example, a breakdown in a smart home can happen when an automatic rule turns all the lights off every day at $10 \mathrm{pm}$ and, on a particular day, you need them to stay on after that time (because of a party, a repair you need to make in your house, or a late thesis you need to finish). When the lights go off in such situation, you will disagree with the system and interact with it. This situation then becomes an opportunity for evolution of the system in an incremental way.

“Continuous and organic evolution" (DAVIDOFF et al., 2006) was already identified as a requirement for EUD for IoT, but innovative and effective implementations for addressing this and related requirements are still missing (FOGLI; LANZILOTTI; PICCINNO, 2016). One possible reason is that EUD 
tools usually consider the starting point to be a "blank" design space which the user is supposed to fill. I thought about exploring an incremental approach where the solution is already there and working "perfectly" until a breakdown happens. At this point, the core function of an EUD tool would be to support the user to perform the necessary modifications in the system in order to make it match his expectations again. Although the final goal is the same, the steps the user needs to undertake can be different from that perspective. For example, starting from the breakdown point, the user would need to go through roughly the following steps:

1) Align his interpretation of the system and the situation (that is, his mental model of the system with the actual design model that is implemented and with his expectations about the situation);

2) Become aware of the modifications that are possible for him to perform;

3) Gather information about how to perform these modifications, possibly engaging in collaboration with other users;

4) Perform and test the modifications, joining techniques such as scaffolding and interactive trial-and-error;

5) Once satisfied, save the modifications to the system, until the next breakdown occurs.

By enabling the user to perform incremental modifications, "any" initial state could be modified by means of "incremental steps", situated modifications that changes the system from one working state to another which is closer to the users' model and expectations about the system and the situation.

The steps described above are aligned to Peirce's notion of abductive reasoning. Indeed, Morgan (2014) describes a very similar process when referring to John Dewey's, one of Peirce's most remarkable students and pragmatists, systematic approach to (social) inquiry. But before jumping into implementing a solution, I was not sure if the problem of breakdowns was "real" or "relevant" enough and even less sure if the steps described above would find any kind of empirical support in "natural contexts" with "real users" (besides myself). At this point of my research, the most reasonable thing to do seemed to be going to collect and analyze empirical data about breakdowns in actual IoT contexts with "external users" (that is, people other than myself that were not directly involved in researching IoT) in order to obtain unbiased data from which I could derive new insight about interactive breakdowns with IoT technology. 


\section{4. Study 4: Diary Study ${ }^{21}$}

Kuutti \& Bannon (2014) once said that "practices are the minimal units of analysis where essential and interesting social issues all come together in a natural and authentic way and become accessible for study." At this point, that was exactly what breakdowns became to my research. The studies previously described all pointed to breakdowns one way or another: failures during the interactive conversations as framed in Study 1 (Section 4.1) were breakdowns; different types of configurations performed by users with IoT technology were responses (or repairs) to breakdowns (Section 4.2); During my auto-ethnographic experience with IoT technology I was facing breakdowns continually, which was resonating with literature (Section 4.3). Drawing from Kuutti \& Bannon above, breakdowns became like the "accessible units of analysis where essential and interesting interactive issues all come together in a natural and authentic way."

At this point, I was prepared to perform a stronger triangulation by collecting empirical field data from actual users in order to get a sense of other users' experience in actual contexts. My main interest was primarily in the breakdowns that users would face and their approaches and strategies to cope with and repair them. I found an important concept that would allow apparently scattered findings to be reunited and related, apparently. In addition, this concept was a phenomenon that I knew how to reproduce in a relatively easy way: based on my own previous experience (and as a Computer Engineer and researcher of IoT technology I was far from being a naïve user), just let people use IoT technology and they will rather certainly face their own breakdowns with it.

Nevertheless, the study of breakdowns in this broad sense poses some methodological challenges. The most important are two: Firstly, breakdowns only manifest "in a natural way" over time, at least the most interesting ones, those who were not immediate consequences of interaction issues and glitches easily observed by existing (and easier to conduct) methods, such as a usability or

21 This section is adapted from two papers: "Observed Appropriation of IoT Technology: A Semiotic Account" (CHAGAS; REDMILES; DE SOUZA, 2018) () ACM 2018, presented in the $17^{\text {th }}$ Brazilian Symposium on Human Factors in Computing Systems (IHC Brasil 2018), and its extended version published into the Brazilian Journal of Interactive Systems with the title "Signs of Appropriation: A Semiotic Account of Breakdowns with IoT Technology" (CHAGAS; REDMILES; SOUZA, 2019) Creative Commons Attribution 4.0 International (CC BY 4.0: https://creativecommons.org/licenses/by/4.0/). 
communicability evaluations. Secondly, breakdowns need to be authentic, in the sense that you cannot really simulate or provoke a breakdown if a person is not really challenged by the technology or the situation at hand. Ideally, a "real breakdown" (authentic) needs to take into account the personal genuine motivations and the "history" of the breakdown, why and how it was produced at first hand, and produce an authentic surprise effect. A simulation (e.g. a lab study) would be too much biased by my own previous experience and learnings, by the scenarios that I had faced as breakdowns myself, which was precisely what I would like to triangulate at this point. This was the overall mindset that guided this study design.

\subsubsection{Method}

I designed and conducted a 4-week diary study (GOODMAN; KUNIAVSKY; MOED, 2012, cap. 10) with novice users of smart devices during the fall of 2017. Our primary goals were to observe how people would use and adapt IoT technology and to collect data about the breakdowns they would face. The study was approved by UCI Institutional Review Board for ethical compliance regarding human-subjects research. The study protocol and related IRB material can be found elsewhere (CHAGAS, 2017b). Fourteen subjects were recruited from undergraduate courses in Computer Science and related fields of an American university. Selection criteria were that participants were at least 18 years old, registered as an undergraduate student, had a mobile phone and were interested in IoT. Eleven participants completed the study, 7 males, 4 females, ages 20.5 on average (19 minimum, 25 maximum)—see Table 4-2. Participants were compensated with 30 USD in cash and the devices (approximately U\$D 200 in value) used in the study if they completed it.

The technology was chosen in order to produce a small but minimally rich IoT ecosystem. Different functionalities and brands were chosen in order to avoid any sort of bias from a particular manufacturer. Devices should not demand specialized equipment or professional installation and participants should need only their mobile phone and Wi-Fi internet to use the devices. Moreover, devices should be able to combine with each other in flexible ways. The IFTTT online 
service was chosen in order to allow devices' combinations. Each participant received a set of:

- An Amazon Echo Dot (voice assistant);

- A LIFX smart colored LED light;

- A WeMo Insight Switch (smart power plug with energy metering);

- A myDLink Wi-Fi Motion Sensor;

- A Flic button (a Bluetooth push button).

The study was divided into three parts. First, participants came to a kick-off workshop where I collected basic demographic information, distributed the devices, and gave a presentation with quick demos. In the following 4 weeks, participants submitted 3-5 diary entries per week remotely through an online form answering open questions about how they were using the devices and the changes they performed. During this phase, participants were emailed a weekly "task" that was intended to stimulate them to use the devices and to explore some functionalities and possibilities of the technology. All tasks were proposed according to the following general instruction communicated verbally to the participants: "Take the devices you got and browse for applets for them in IFTTT," where each week I suggested different IFTTT services to combine (e.g. devices alone and together, date and time service, location, etc.). After 4 weeks, participants were invited to a final individual 40-minute interview about their overall experience and about particular situations they reported.

\subsubsection{Analysis}

I performed a thematic analysis (BRAUN; CLARKE, 2006) of participants' 130 diary submissions and 11 final interviews. Data was coded for recurring and emergent themes with particular attention given to looking for breakdown situations. Whenever users explicitly reported a surprising fact (to them), an issue, or a change in some configuration (presumably as a consequence or an attempt to address a previous issue that they have had), a potential breakdown situation was marked. Around 430 breakdowns were initially coded in this way, later deduplicated into 188 unique episodes. A summary of participants profiles, diary submissions and breakdowns identified in this way is presented in Table 4-3. 
Table 4-2 - Diary study participants profiles, quantity of diary submissions and of reported breakdowns:

\begin{tabular}{|l|l|l|l|c|c|}
\hline Subject & Age & Gender & Major & \# Submissions & $\begin{array}{c}\text { \# Breakdowns } \\
\text { (total / unique) }\end{array}$ \\
\hline P1 & 19 & Male & Software Engineering & 15 & $27 / 9$ \\
\hline P2 & 22 & Male & Informatics & 12 & $43 / 19$ \\
\hline P3 & 19 & Male & Data Science & 11 & $41 / 13$ \\
\hline P4 & 19 & Male & Computer Game Science & 10 & $38 / 17$ \\
\hline P5 & 25 & Male & Computer Science & 12 & $62 / 35$ \\
\hline P6 & 19 & Female & Software Engineering & 11 & $41 / 16$ \\
\hline P7 & 20 & Female & Computer Science & 12 & $27 / 17$ \\
\hline P8 & 20 & Female & Computer Science & 13 & $45 / 23$ \\
\hline P9 & 19 & Female & Computer Science & 12 & $22 / 10$ \\
\hline P10 & 19 & Male & Computer Science & 13 & $37 / 11$ \\
\hline P11 & 25 & Male & Computer Science & 9 & $46 / 18$ \\
\hline \hline Total & & & & 130 & $429 / 188$ \\
\hline
\end{tabular}

* Because participants made multiple reports of a breakdown (e.g. in a diary submission and mentioned during interview) and a single breakdown episode could be coded as more than one category depending on the report, an effort was made to identify unique episodes afterwards.

I then applied the communicability breakdown tags of the Semiotic Engineering's Communicability Evaluation Method (CEM) (DE SOUZA; LEITÃO, 2009; DE SOUZA; PRATES; BARBOSA, 1999) to interpret and organize the results. The use of CEM tags (and the breakdown categories that they correspond to) to characterize breakdowns outside the CEM method where they were originally proposed has already been done by Afonso (2015) in studies of APIs communicability. Their evocative phrasing, representing deeper analytic categories, is helpful to reveal an immediate sense of recurring situations users face when interacting with the technology.

The Communicability Evaluation tags are informal expressions used to represent the presence of communicative breakdowns divided into three major categories: Complete Communicative Failures; Partial Communicative Failures; and Temporary Communicative Failures. Failures are analyzed not only in terms of their form and content, but more importantly in terms of presumed intent (or intentions) of communicating parties. Therefore, Complete Failures are those where all parties fail to achieve their (mutual) intent. In HCI, this accounts for designers failing to communicate their design intent and rationale to users via the system's interface and, mostly as a consequence, the users failing to communicate 
their intent to the system, via the interface. Partial Failures are those where one party's intent (the user's or the designers') is achieved, although at the expense of complete satisfaction of the other's expectations or preferences. Finally, Temporary Failures are those from which communicating parties (typically the user) recover in the course of interaction (e.g. through error correction, workarounds, etc.) and are able to restore the communication flow.

\subsubsection{Results}

During the data analysis, I identified that breakdowns were pointing to the phenomenon of technology appropriation from HCI literature. Technology appropriation refers to the process of people adopting and adapting (or adapting for adopting) technology (DIX, 2007; DOURISH, 2003), "the way in which technology or technological artefacts are adopted, shaped and then used" by the users (CARROLL et al., 2002) (see Section 2.2). To a great extent, appropriation corresponds to the cumulative experience of the end user with the technology, the final resultant of all user's interactions with technology over time. Using Semiotic Engineering as a theoretical lens to qualitatively analyze the data, I observed that the patterns of communicative breakdowns represented by the CEM tags could be related to the appropriation of technology by users. These patterns of communicative breakdowns indicate different stages of the appropriation process and potential directions of how IoT appropriation was unfolding into successful or flawed adoption. A detailed description of results and a complete discussion is published elsewhere (CHAGAS; REDMILES; DE SOUZA, 2018; CHAGAS; REDMILES; SOUZA, 2019). A summary of the data analysis correlating observed breakdowns, CEM tags, and their meanings in terms of appropriation is presented in Table 4-3. Some of the core arguments will be reproduced in the following (see footnote ${ }^{21}$ in p. 97). 
Table 4-3 - Summary of observed breakdowns, tags, and their relation to appropriation (originally published in: CHAGAS; REDMILES; SOUZA, 2019):

(CC BY 4.0: https://creativecommons.org/licenses/by/4.0/)

\begin{tabular}{|c|c|c|c|}
\hline Tag & Observed examples & $\begin{array}{l}\text { Communicability } \\
\text { meaning }\end{array}$ & Appropriation meaning \\
\hline $\begin{array}{l}\text { What's this? } \\
\text { Oops! }\end{array}$ & $\begin{array}{l}\text { P3 exploring the Flic } \\
\text { button to open up } \\
\text { different apps in his } \\
\text { mobile phone } \\
\text { ("What's this?"); } \\
\text { P8 turning off } \\
\text { (undoing) the motion } \\
\text { sensor triggering her } \\
\text { lights on IFTTT } \\
\text { applet because it has } \\
\text { become innapropriate } \\
\text { ("Oops!"). }\end{array}$ & $\begin{array}{l}\text { Temporary failures easily } \\
\text { recoverable with the } \\
\text { technology "as is." }\end{array}$ & $\begin{array}{l}\text { Users building their initial } \\
\text { interpretation about the } \\
\text { technology by exploring } \\
\text { it and discovering what it } \\
\text { means for them. These } \\
\text { breakdowns are natural } \\
\text { and desirable in an initial } \\
\text { phase and correspond to } \\
\text { what I called the } \\
\text { stabilizing phase in } \\
\text { between two } \\
\text { appropriation states. }\end{array}$ \\
\hline $\begin{array}{l}\text { What } \\
\text { happened? } \\
\text { Why doesn't } \\
\text { it? }\end{array}$ & $\begin{array}{l}\text { P1 intrigued by his } \\
\text { lights turning on "by } \\
\text { itself" because he had } \\
\text { inadvertently turned } \\
\text { on the "Day \& Dusk" } \\
\text { automation feature } \\
\text { ("What happened?"); } \\
\text { Devices losing } \\
\text { connection to the } \\
\text { network ("Why } \\
\text { doesn't it?") }\end{array}$ & $\begin{array}{l}\text { Originally, these tags also } \\
\text { refer to temporary } \\
\text { failures. Here, I am using } \\
\text { them to refer to temporary } \\
\text { breakdowns that were not } \\
\text { easily recoverable. }\end{array}$ & $\begin{array}{l}\text { Communicability } \\
\text { problems that hinder } \\
\text { users' interpretation of } \\
\text { the technology and, } \\
\text { consequentially, } \\
\text { appropriation. Depending } \\
\text { on their severity and on } \\
\text { how long they last, these } \\
\text { breakdowns can slow } \\
\text { down the stabilization } \\
\text { process or even become } \\
\text { somewhat definitive and } \\
\text { lead to stagnation in a } \\
\text { certain appropriation } \\
\text { state. }\end{array}$ \\
\hline I give up & $\begin{array}{l}\text { P6 trying to find out } \\
\text { the proper motion } \\
\text { sensor sensitivity and } \\
\text { eventually abandoning } \\
\text { the device. }\end{array}$ & $\begin{array}{l}\text { Complete failures: user- } \\
\text { designer communication } \\
\text { interrupted definitively by } \\
\text { the user. }\end{array}$ & $\begin{array}{l}\text { Users rejecting the } \\
\text { technology because they } \\
\text { were not able to make } \\
\text { sense of it. This is a } \\
\text { disappointing event that } \\
\text { leads to abandonment. }\end{array}$ \\
\hline $\begin{array}{l}\text { Looks fine to } \\
\text { me... }\end{array}$ & $\begin{array}{l}\mathrm{P} 5 \text { and P10 } \\
\text { misconfiguring the } \\
\text { location-based applet } \\
\text { to turn their smart } \\
\text { lights on and off. }\end{array}$ & $\begin{array}{l}\text { Complete failures: a } \\
\text { strong misunderstanding } \\
\text { between user and } \\
\text { designer when users } \\
\text { believe they have } \\
\text { achieved a different result } \\
\text { than what was actually } \\
\text { accomplished. }\end{array}$ & $\begin{array}{l}\text { Misinterpretations of the } \\
\text { technology that hinder } \\
\text { appropriation. I observed } \\
\text { they are not necessarily } \\
\text { definitive and can be } \\
\text { repaired. }\end{array}$ \\
\hline Uh-oh! a & $\begin{array}{l}\text { P5 and P10 realizing } \\
\text { that they had } \\
\text { misconfigured the } \\
\text { location based applet } \\
\text { to turn their smart } \\
\text { lights on and off. }\end{array}$ & $\begin{array}{l}\text { A repair of a previous } \\
\text { "Looks fine to me..." } \\
\text { breakdown. }\end{array}$ & $\begin{array}{l}\text { This tag shows how a } \\
\text { "Looks fine to me..." } \\
\text { breakdown can } \\
\text { temporary. If discovered } \\
\text { by users, the situation will } \\
\text { lead to a revised } \\
\text { interpretation state, as } \\
\text { part of the stabilizing } \\
\text { process in between two } \\
\text { appropriation states. }\end{array}$ \\
\hline $\begin{array}{l}\text { Thanks, but } \\
\text { no, thanks }\end{array}$ & $\begin{array}{l}\text { P7 not using any } \\
\text { automation function; }\end{array}$ & $\begin{array}{l}\text { Partial failures when the } \\
\text { user was able to keep the }\end{array}$ & $\begin{array}{l}\text { Users understanding the } \\
\text { technology but }\end{array}$ \\
\hline
\end{tabular}




\begin{tabular}{|c|c|c|c|}
\hline Tag & Observed examples & $\begin{array}{l}\text { Communicability } \\
\text { meaning }\end{array}$ & Appropriation meaning \\
\hline & $\begin{array}{l}\mathrm{P} 3, \mathrm{P} 4 \text {, and P11 not } \\
\text { using the recurring } \\
\text { alarm from the Echo } \\
\text { Dot because their } \\
\text { schedule varied too } \\
\text { much. }\end{array}$ & $\begin{array}{l}\text { conversation with the } \\
\text { technology flowing, but } \\
\text { the designer has wasted } \\
\text { efforts in designing } \\
\text { features that the user } \\
\text { ended-up not wanting to } \\
\text { use. }\end{array}$ & $\begin{array}{l}\text { performing a well- } \\
\text { informed rejection of it. } \\
\text { When users say "Thanks, } \\
\text { but no, thanks" they } \\
\text { might be challenging } \\
\text { important designers" } \\
\text { underlying assumptions. }\end{array}$ \\
\hline $\begin{array}{l}\text { I can do } \\
\text { otherwise }\end{array}$ & $\begin{array}{l}\text { P3, P4, and P11 } \\
\text { manually setting the } \\
\text { Echo Dot alarm every } \\
\text { night and not using } \\
\text { the recurring alarm } \\
\text { function because they } \\
\text { were unaware of it; } \\
\text { P3, P5, and P10 } \\
\text { plugging the motion } \\
\text { sensor into the smart } \\
\text { plug in order to be } \\
\text { able to turn it on and } \\
\text { off in spite of the } \\
\text { motion sensor } \\
\text { providing features that } \\
\text { allowed this } \\
\text { configuration. }\end{array}$ & $\begin{array}{l}\text { Partial failure: user keeps } \\
\text { the conversation with the } \\
\text { technology flowing, but } \\
\text { designer has wasted } \\
\text { efforts in designing } \\
\text { features that ended-up not } \\
\text { being used because users } \\
\text { were unaware of them. }\end{array}$ & $\begin{array}{l}\text { Users missing an } \\
\text { affordance leading to sub- } \\
\text { optimal appropriation: } \\
\text { their interpretation of the } \\
\text { technology is incomplete } \\
\text { and designers are most } \\
\text { likely failing in telling the } \\
\text { users about some } \\
\text { potentially useful feature } \\
\text { or affordance, a typical } \\
\text { communicability } \\
\text { problem. }\end{array}$ \\
\hline $\begin{array}{l}\text { I can work } \\
\text { around it }\end{array}$ & $\begin{array}{l}\text { P6's Flic weather } \\
\text { report "in a bit of a } \\
\text { roundabout way;” } \\
\text { P5's "Day \& Dusk } \\
\text { with colors" feature. }\end{array}$ & $\begin{array}{l}\text { An articulated expression } \\
\text { where users have used the } \\
\text { technology at hand to } \\
\text { engage into interactive } \\
\text { conversations that were } \\
\text { not originally made } \\
\text { available by the } \\
\text { designers. }\end{array}$ & $\begin{array}{l}\text { Users creating and } \\
\text { expressing new and } \\
\text { personal meaning using } \\
\text { the technology at hand. It } \\
\text { represents an advanced } \\
\text { appropriation state in our } \\
\text { framework, where users } \\
\text { have mastered the } \\
\text { technology and were able } \\
\text { to create new interactive } \\
\text { discourses that were not } \\
\text { originally anticipated by } \\
\text { the designers. }\end{array}$ \\
\hline
\end{tabular}

a Tags that are being proposed by us and are not original CEM tags. As can be noticed, they are not necessarily communicability breakdowns, but should be understood here solely as an evocative phrasing that represents recurring situations users face when interacting with IoT technologies that are relevant to our appropriation framework.

Based on this analysis, I proposed a semiotic account of the appropriation of IoT technology. Appropriation unfolds over time, as users explore, learn and get familiar with the technology, to the point when they start to incorporate it into their practices, by making more consistent use of it, often adapting themselves and their practices to the technology (CARROLL, 2004). There is an intricate relationship between using/learning the technology and practicing/reflecting about what the technology is intended to support. The interplay of these underpinnings becomes clearer when users adapt the technology to their practices but can never 
be really separated. One way to disentangle this intricate network of relationships and activities users perform is to look at appropriation as a state rather than a structured process. In this sense, I propose a definition of appropriation as following: appropriation corresponds to the stabilized state of interpretation which allows users to organize a rich and productive set of interactive discourses with the technology at hand.

Note that a rich and productive set of interactions is not the equivalent of correct interactions, expected/predicted interactions, proposed interactions, etc. All we can say is that rich and productive interactions are a subset of possible interactions (whether the designers of the technology were aware of such possibilities or not). Rich and productive interactions necessarily make sense (and therefore have meaning) to the users, regardless of whether they make sense for anybody else, including the designers of the technology. Therefore, rich and productive interactions are the result of satisfactory interpretations of the technology in the sense of users finding "the meaning" of the technology for them. For successful appropriation to happen, it is not only necessary that users understand the designer's message embedded into the system. Moreover, users also need to understand how to make practical use of this message in their own contexts and to accomplish their own goals.

Satisfactory interpretations are not the equivalent of definitive interpretations. Following Peirce's theory of abduction and its role in Semiotics, satisfactory interpretations are those that resist the test of abductive reasoning. In abductive reasoning, the "reasoner" (in our case, the user) generates hypothetical general principles that explain some observed phenomenon and resist the reasoner's limited testing of the principle, in contingently available cases. Because such testing does not cover all possible cases to which the hypothesized general principle actually applies, the reasoning may prove to be incorrect in the presence of future events (which leads to a revision of the principle, more testing, and new provisional conclusions - or interpretations - that can be revised because of counter-factual future evidence). Therefore, users can build a sense of "appropriation" that can resist for longer or shorter time, but eventually prove to be incorrect or insufficient. No appropriation is definitive, but lasts until evidence is found that falsifies or enhances the previous understanding users have built in 
their minds. A current state of appropriation is thus linked to a current a state of interpretation of the technology.

However, this state should be minimally stable in order to allow users to build interactive discourses upon it consistently, which is not possible over an ever-changing soil. If users' assumptions are not correct, attempts to use technology in practice will fail shortly, forcing users to review their hypotheses. A breakdown is the moment when the user realizes his or her current interpretation state is wrong or insufficient, triggering the pursuit for a new one. The "stabilizing process" is a series of mental (cognitive), physical (interaction) and social (e.g. collaboration with other users) activities that will follow a breakdown. If successful, users will evolve from a prior state to a richer one, in the sense of enabling other richer interactive discourses. If users are not able to sediment a new understanding, they may either remain stagnated in the same appropriation state (e.g. doing what they already knew in the way they knew), if some practical use of the technology is possible, or abandon the technology, otherwise. Both situations can be temporary, since users can never be stopped from revisiting the technology and their thoughts about it due to unlimited semiosis. I call this characterization "abductive appropriation" because this description resembles the abductive reasoning process described by Peircean semiosis (see Chapter 3). This description is depicted in Figure 4-6 showing a sequence of appropriation states triggered by a breakdown and the following stabilizing process in-between two states.

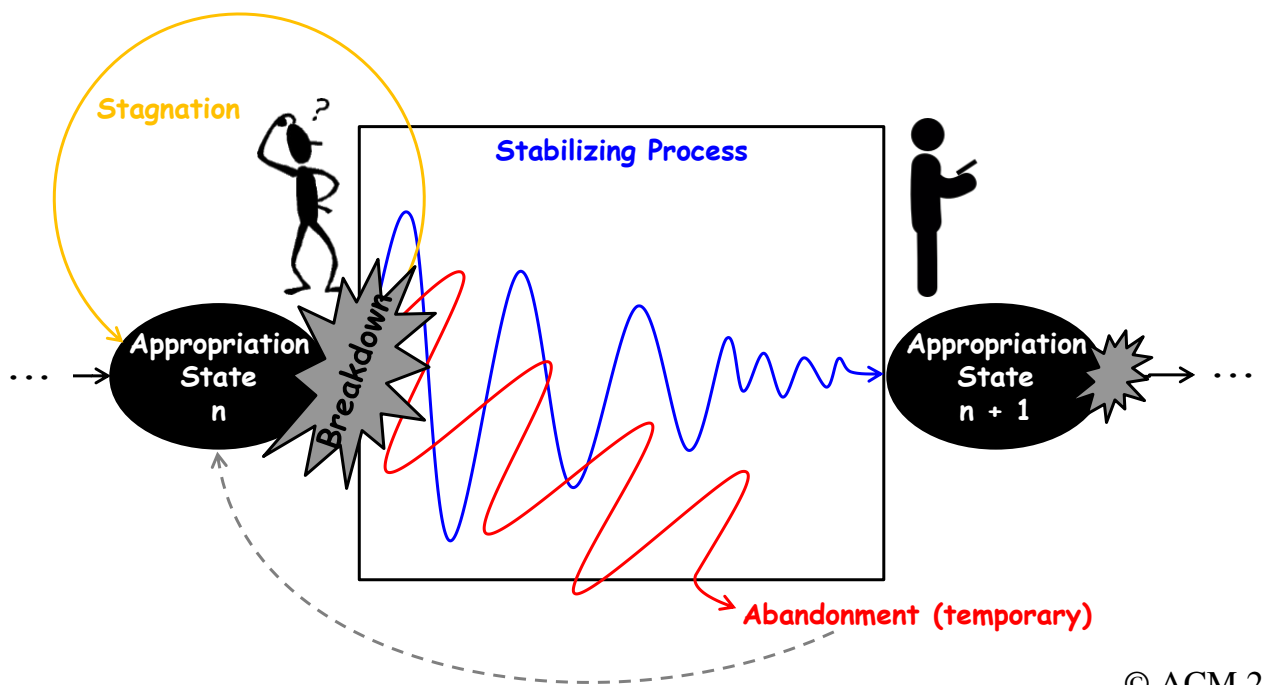

(C) ACM 2018

Figure 4-6 - Appropriation as states and the stabilizing process in-between them (originally published in: CHAGAS; REDMILES; DE SOUZA, 2018). 
This framework can describe different stages, modes and aspects of appropriation related with the tags in Table 4-3. "Oops!" and "What's this?" situations correspond to the stabilizing process of users interpreting the technology by exploring it in practice. These communicability breakdowns indicate intermediary steps of users' interpretive process. They tend to diminish when users find a stabilized interpretation that is useful for them. Only then appropriation actually happens, when this learning stabilizes and materializes in the preferred use cases and corresponding settings and configurations of the system. At this point, users reach a new state of appropriation.

Sometimes, users' interpretations do not evolve and halt in a certain state for a very long while. We observed situations like these associated with the tags "What happened?" and "Why doesn't it?". Users getting stagnated in the same appropriation state is not necessarily negative if the current state is satisfactory and fulfilling for them. However, there are situations that represent negative experiences where users either took too long to make sense of technology or were literally kept doing what they could to cope with some technical glitches they faced. Depending on the severity of the breakdown and the time users take to recover from them, they can lead to the next case.

"I give up" situations correspond to those episodes where users were unable to stabilize their understanding about the technology. Sometimes they left the motion sensor underused (stagnation), other times they just left it behind (abandonment). As participant P6 reported, she tried different settings in order to make the motion sensor work as she intended. These attempts were triggered by the breakdown of the motion sensor starting to behave differently from her expectations (that is, reacting to subtle and distant moves), a kind of "What happened?" breakdown. She explored the device and took a "trial and error" approach by selecting different sensitivities. Her primary goal was to adjust the sensor's behavior at the same time that she was making sense of how the sensor worked, making and testing hypotheses. Nevertheless, she could not find a minimally stable interpretation of the system and eventually gave up. The time and effort invested in this endeavor were proportional to her available existing knowledge, will, and patience she had at the time.

"Looks fine to me..." situations were recoverable, at least to P5. The breakdown, in his case, was caused by his own misconfiguration of the IFTTT 
applets he was using to automatically turn his light off and on when he left and arrived home, respectively. However, he was misinterpreting his light's state and the notifications from another applet as evidence that his light-automation applets were working correctly. The breakdown was fixed when he spotted a sign in IFTTT that the applet had never run. He was then able to investigate deeper, make sense of what was wrong and correct the applets, leading to a new stabilized state where he could rely on this automatic behavior and also on the tools he used to achieve it, such as IFTTT, the location trigger, and the light responding to it.

Although recoverable, "Looks fine to me..." breakdowns indicate difficulties participants had when assessing their smart technology behavior. In terms of our appropriation framework, this means users found themselves inside a wrong interpretation state which can last indefinitely, until they realize by means of a new breakdown happens that forces them to revisit their understandings. In case users realize their mistake, they will try to repair it. We propose to name such events with a new tag called "Uh-oh!", which is actually a repair that reveals the occurrence of a prior "Looks fine to me..." failure. Repairs are typical events associated with breakdowns and misunderstandings in communication (BAZZANELLA; DAMIANO, 1999; e.g. HANSEN; NOVICK; SUTTON, 1996). How to study breakdown repairs within the more abstract classification and categorization system of communicability breakdowns, of which the tags are just the most superficial sign, should be object of further research.

In "Thanks but no, thanks" breakdowns users deliberately reject some designed feature or affordance of the technology. They correspond to successful appropriation by the users when they find their own way to make practical use of the technology after experimenting with alternative options (e.g. manually controlling their stuff at will instead of automating, such as P7). In our appropriation framework, these situations signal a clear case where the technology means different things to the designers (who say they think "this feature is valuable" when they invested in designing it) comparing to users (who might just not mind). However, this will only be the case if and only if users' interpretation and decision (of not using some feature) is well informed. Otherwise, it might be the different case as following.

"I can do otherwise" breakdowns are the richest ones from an appropriation perspective. We observed users do otherwise in two different lines 
of action. First, users may simply not be aware of an affordance or feature provided by designers, corresponding to the typical traditional situation represented by the "I can do otherwise" tag. This was possibly the case with the Echo Dot's recurring alarms (blurred with "Thanks but no, thanks" tag in Table 4-3 because we did not confirm with the participants if they were aware or not of the feature) and with people using the WeMo smart plug to enable and disable the motion sensor.

A second and different type of situation occurred when users dealt with actual limitations of the technology, that is, when they wanted to do things that were not originally provided by designers. This was the case with the Flic weather report "in a bit of a roundabout way" by P6 and the "Day \& Dusk with colors" by P5. From an appropriation perspective, these situations are remarkable and we propose the new tag "I can work around it" to describe them. Again, we need to conduct further studies in order to accommodate this new tag into the relatively mature communicability breakdowns categories and abstractions originally proposed by the CEM. In a CEM-like breakdown analysis, who is failing in such situations? We think that such situations point to new design opportunities that were not anticipated by technology designers and represent opportunities for improving the technology. In that sense, this new tag corresponds to a feedback from the users to designers, a sort of inverse metacommunication message from users to designers about how users actually want to use the technology. Therefore, the failure falls in the designers' side, due to their inability to anticipate some user need. However, we can reasonably assume that a designer (and consequently the system they design) will never be able to anticipate every need of every user, an idea that is in the root of EUD techniques and approaches. Every breakdown is a sort of unarticulated talk-back from users to designers. Therefore, the failure is actually the designers' inability to listen to users' talk-back, something that computing technologies are currently not designed to support. A question we may raise then is whether computing technologies can support users talking-back to designers and how? "I can work around it" is an extreme case where users actually articulate a clear talk-back using the language of the technology they have mastered.

"I can work around it" situations represent the strongest sign of appropriation where users have mastered, modified, and re-signified the 
technology. They indicate an advanced state of appropriation in which users produce new interactive possibilities not originally anticipated by designers and engage in richer and personally meaningful conversations with the technology. It is very important that these situations be detected and deeply understood from both a research and a practical design perspective. Applying our evolutionary appropriation framework, it means users have passed by several intermediary states to get there. According to Carroll's appropriation cycle [35], these states can be very helpful when designing from appropriation if they are seen by the designers. Some questions we may ask, why some users reach this point and others not? What in technology design can favor or hinder this process? How designers can be reached and effectively listen this talk-back? We do not know how to answer these questions now.

Finally, we should say that there are appropriation states that are not signaled by breakdowns. For example, if everything is working fine, it means users are able to use the technology "as is" and are probably satisfied with it. Therefore, no breakdown happens. Indeed, we observed several situations where this was the case:

[P1] One use case that I use quite often is using the [Echo] Dot to turn on/off the LIFX light bulb and adjusting the light bulb's color. So, when entering/leaving my room, I would call out "Alexa, turn off [or on] the light." I had set the light bulb's name to "light" within the Smart Home tab in the Alexa app.

[P5] I use Alexa almost [all] day to play music.

In such cases, the absence of breakdowns is a sign of a certain stabilized state of appropriation, one where users are engaging in productive interactive conversations that fulfills their needs and preferences. This is certainly a sign of a successful technology design by designers, where their evaluation of users' goals, needs and preferences match users' actual ones. In Semiotic Engineering terms, users' goals, needs and preferences and the system's interactive logic are the gist of the metacommunication message. Of course, absence of breakdowns may happen when users are not even engaging in conversations with the technology and this is a completely different case (perhaps due to lack of interest, rejection, or after abandonment). However, when explicitly reported that this was not the case, absence of breakdowns indicates a good communicability design. 
Some breakdowns point to communicability problems that manifest in a particular way with IoT technology, such as "What happened?", "Why doesn't it?", and "I can do otherwise" breakdowns, which point to communicability problems of IoT interfaces regarding different aspects of the technology. Similarly, "Looks fine to me..." situations usually represent serious communicability problems because users end up thinking that they have succeeded when they have not. The definition and characterization of appropriation I propose does not exclude misinterpretations and mistakes. Rather, it embraces them as natural parts of human semiosis and abductive reasoning. Consequently, an important part of interaction design for appropriation is to support abductive reasoning and knowledge revisions by users. That is, technology should both: (i) help users assess their current knowledge about the technology; and (ii) support the revision of their interpretations of the technology, so that "rich and productive interactions" can be resumed whenever the user himself realizes that he is wrong. Not easy goals though. In the following, I discuss some initial implications derived from our findings that can be useful to inform designers towards better interactive and appropriable IoT technology.

IoT technology currently available comprises, in general, different specialized smart devices that can be combined with each other in order to produce more complex behaviors. In that sense, the "system" or the "application" is distributed into different devices and apps that have different responsibilities, such as the smart light to produce a desired output in the environment, the mobile phone for controlling the light or sensing the location, and auxiliary tools such as IFTTT that allows the combination of the previous two. As a consequence, setup and interaction are spread in different interfaces. Everything together demands from users the ability to cope with multiple components, often having to predict the outcome of certain combinations of settings in different times and circumstances. This scenario is more complex than traditional interaction (e.g. desktop and mobile apps) and designers should seek for ways to alleviate the arising challenges.

An immediate consequence is that successful interpretation of technology will depend not only on the design of each component in isolation, but also on the quality of the system comprised of components put all together. From a system's perspective, users deal with multiple technological components. Interactively 
speaking, users deal with multiple interfaces exposed to them. Semiotically speaking, users face different meaning systems, each one with its own sets of signs, "linguistic" rules and metaphors. This calls for, at least, two new design qualities that I propose that should be pursued in the design of IoT technologies: cross-interface consistency and cross-device coherence, illustratively depicted in Figure 4-7.

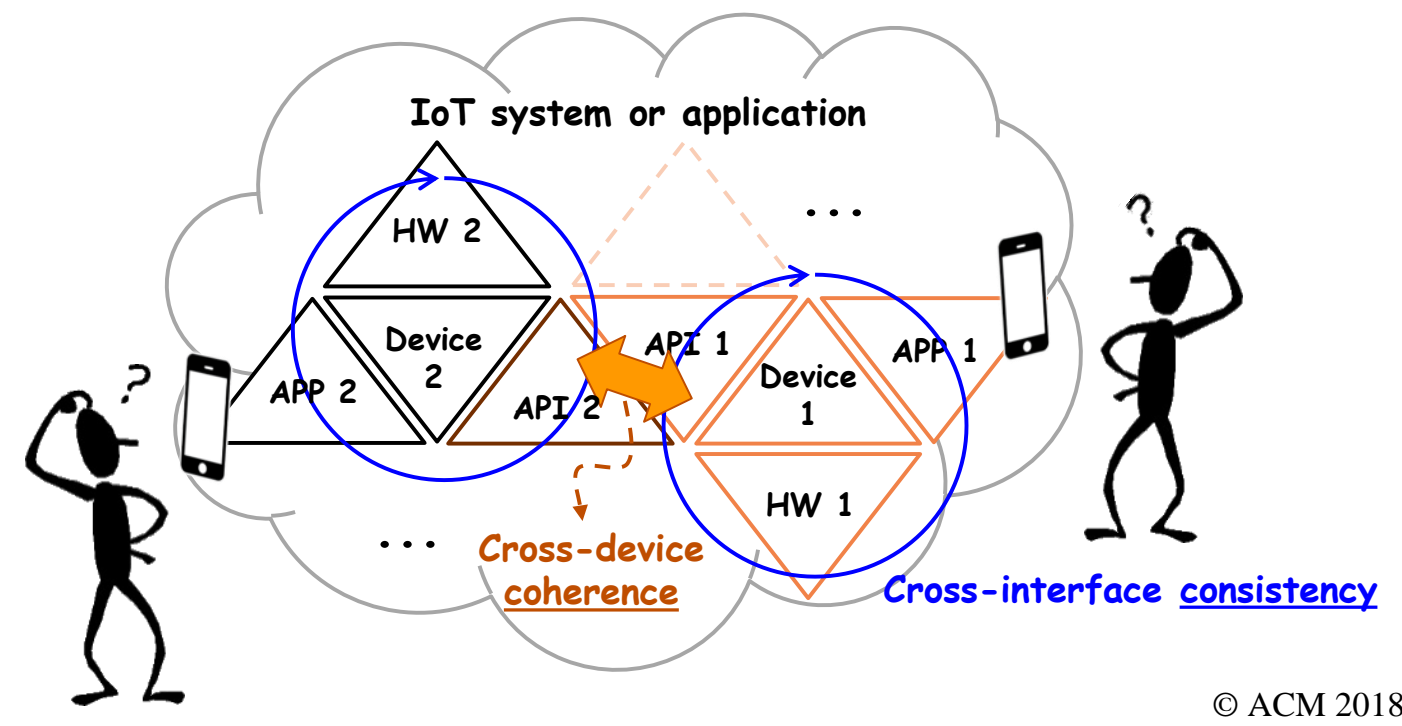

Figure 4-7 - The scope of cross-device coherence and cross-interface consistency (originally published in: CHAGAS; REDMILES; DE SOUZA, 2018).

Cross-interface consistency relates to consistency between different interfaces of a single device. A study about the Philips Hue smart device (CHAGAS; REDMILES; DE SOUZA, 2017) suggested that IoT devices currently available follow a general pattern of architecture composed by the device itself, a mobile app for remote and advanced control of it (sometimes, also a similar web app with the same purpose) and a public API for integration with other devices an apps. Users interact with all these interfaces: with the mobile app through a usual mobile interface, with the device itself (e.g. placing the device somewhere, watching its color, etc.), and also with the API indirectly when they use an auxiliary tool that plugs to it, such as IFTTT. I propose that all three components should communicate a logical and consistent message in order to promote the correct understandings of the system. In "real life," inconsistencies may easily emerge because we know designers are often split into different teams depending on the component to be developed. Moreover, the "substratum" of each interface 
is different in nature and in the types of configurations and affordances they allow (CHAGAS; FUKS; DE SOUZA, 2015).

Cross-device coherence can be even harder to achieve. It means not only that a device be logical and consistent individually but also that, when combined together, devices form a minimally unified and harmonic whole. Differently from traditional software running on a desktop or mobile, IoT devices do not have an operating system (OS) able to provide a set of functions and interaction standards that developers can use and follow in order to leverage users' interaction based on the OS's language, features and libraries. That means that each device, often from different manufacturers, has its own semiotic language, the set of meanings and representations with which they are designed and implemented, and that this language is much less constrained than in other settings (by the lack of a common OS standard, for example). The question to answer is how each device's semiotic language is able to compose with the others in order to build a well-formed whole?

For instance, the "toggle lights" action mentioned before can turn out to be a dangerous function for a smart light that can be controlled remotely. When the user is not viewing the current light state (that is, not looking at the light or at an indicator of the light's state in the mobile app, for example), it is impossible to determine the final outcome of this simple operation. A possible consequence is the occurrence of "Looks fine to me" situations, such as happened with participant P10. Investigating this situation deeper, I noticed that despite there is an action called "toggle lights" in IFTTT (to be used with a location trigger in an applet, for example) there is no toggle function (in the sense of a "blind" toggle) in the LIFX mobile app because the user can always see the current state of the light in the app screen. Therefore, we may conjecture that this situation, though not caused by, could be avoided if IFTTT, the third-party app, followed a sort of consistency rule with the native LIFX app. Going one step further, this consistency rule could be enforced (or at least encouraged) by the LIFX component that lies in-between LIFX and IFTTT, the LIFX API. Indeed, that is a "blind toggle" function in the LIFX API ${ }^{22}$ for which the response is just an "ok" status. Perhaps the designers of this programmatic interface could have reconsidered the design of such a function

22 https://api.developer.lifx.com/docs/toggle-power [Last visited: 17-Feb-2020] 
in their API if they had means to evaluate their decisions better by providing a more complete response such as the resulting on/off state of the light that could be then communicated to the user by IFTTT, for example.

The qualities I am proposing here call for new evaluation methods and design practices that should be object of further HCI research. In that sense, Semiotics and Semiotic Engineering is a very useful and powerful theoretical foundation because it naturally deals with the linguistic structure and "materials" (signs) of interfaces and systems, which end up shaping end users' interactive discourses and the (dis)appropriations that follow from them. For instance, with a different goal, Maués and Barbosa also took a semiotic approach and proposed the concept of cross-communicability, defined as "the system communicability across platforms," and an inspection method to evaluate it (MAUÉS; BARBOSA, 2013, 2014). Cross-communicability is close to the concepts I am proposing here but differs in the sense that it was originally proposed to address challenges of users interacting with the same application in different platforms (e.g. YouTube in a web browser, a mobile phone, and a smart TV). In this context, each platform app can be used isolatedly because the core application functionality is replicated and they do not depend on each other. The concepts I am proposing here are oriented to address different components not to be used isolatedly because they only make sense as a system when they are used all together (in the case of cross-interface consistency, they do not even work one without the other). Analogously to (MAUÉS; BARBOSA, 2013, 2014), potentially both the communicability concept and semiotic methods could be extended to address the cross-interface consistency and cross-device coherence of IoT technologies.

\subsubsection{Conclusion}

Appropriation has been identified as an important component of positive user experience (KARAPANOS et al., 2009; MCCARTHY; WRIGHT, 2004; TURNER, 2012) and is related to how technology becomes meaningful in one's life (DOURISH, 2003). In itself, user experience is related to the way users perceive and recall their actual experiences with technology, which invariably pass through the filters of users' personal interpretations (DOHERTY; DOHERTY, 2018). My findings suggest a clearer relation between these 
interpretations and appropriation, which was reflected in the abductive appropriation framework I proposed here. Appropriation stages are built on top of interpretation states that enable users to organize rich interactive discourses with the technology. Users interpretations do not refer only to what designers mean with the technology but also to what the technology has come to mean to the users. Thus, appropriation is tied to the practical uses the users can make of the technology in their lives based on their understanding of it.

Appropriation evolves as interpretation evolves and communicative breakdowns represent remarkable moments where users' interpretations are exposed, usually during a process of review or refinement. As in standard social communication processes, skillful interlocutors would monitor and pay special attention to these moments in order to assure that their intents are communicated effectively, efficiently, and "appropriately." In the terms of Semiotic Engineering, efficient and effective interactive communication is achieved by means of good communicability. The semiotic qualities of cross-interface consistency and crossdevice coherence are targeted at improving IoT technology communicability to support users' interpretations and abductive reasoning.

Through breakdowns, users communicate, even if in a rudimentary and unarticulated way, their personal interpretation of the technology. The CEM tags help us understand what the users were saying. Our findings suggest that they have the potential to systematically point at the directions of how IoT technology appropriation will unfold, leading to successful or flawed adoption. These patterns of failures in the designer-to-user communication, across devices and across interfaces, as they accumulate, hold the potential to help us see powerful design principles in operation that can determine successful appropriation of IoT technology by users. This semiotic account of appropriation was a step towards reveling and understanding these design principles.

Another finding that is implicit in the above analysis and results came in a "meta-level," in the level of framing and orienting our research. If breakdowns were identified as a critical phenomenon of interaction with IoT technology, I found their counterpart, namely appropriation. In line with semiotic theory, breakdowns work as triggers to users' abductive reasoning, provoking the revision of users' interpretation about the technology. Appropriation states in turn correspond to a reasonably stabilized conclusion of an abductive cycle. They are 
built upon interpretations and as such are always provisional, subject to be revised in new cycles of abductive reasoning upon a new breakdown, that is, any evidence that the current interpretation is not working for users' situated purposes.

Finally, it should be noticed that the concept of breakdowns, originally strongly tied to Semiotic Engineering's communicability problems, have gained a broader meaning. In this framework it refers to anything that triggers users' abductive reasoning, any clash between users' interpretation and reality, which can have multiple causes. Similarly, I started to take a broader stance on the appropriation concept itself comparing to how it is used in literature, usually more associated with the creative and unexpected ways people use technology (DIX, 2007; e.g. DOURISH, 2003). An appropriation state represents a personal way of using the technology, regardless if it was previously anticipated by the designer or not. "Anticipated appropriation," so to speak, is a sign of a successful technology design. Furthermore, it seems that both situations - anticipated and unanticipated appropriation - can even be related and cross-fertilize each other somehow. 


\section{Research Design (2): Converging and Evaluating Results}

So far, our approach has been to surface the complex and novel domain of user experience with IoT technology in order to get a broad and deep understanding of it by means of successive complementary triangulations. What was originally very blurred by technical, psychological, social and methodological issues is now clearer in the sense that I found some anchor concepts and relationships to organize the problem space in useful ways and orient the next steps in the most promising and feasible directions. These anchors will help as navigate the related literature, characterize the problems I want to address, and leverage our contributions.

At this point of my research, I found two anchor concepts, namely breakdowns and their counterpart, appropriation. Bringing together the theoretical background and my findings and observations so far around these two anchor concepts, I planned for a more convergent research goal: to answer our research questions as posed in Chapter 2. Since any research needs to come to an end, even if a provisional end, it's now time to converge. At this point, I planned to look for the answers to the research questions posed in Section 2.3 (see Box 2-1 and Box 2-2) and to evaluate whatever answer I find. And of course I will do it by means of two more triangulations: one targeted at confronting my answers with different data found in literature reports about appropriation, and another targeted at evaluating my answers with IoT technology designers, the other side of the story that has not been focus of our research yet and were rather overlooked so far.

The complete overall research approach is depicted as a mapping of the problem space and a process over time in Figure 5-1 and Figure 5-2 respectively, where each study is indicated by the chapter/section that describes it. This overall research design can be called a "macro-methodology" for mixing methods. But before I can go on, I first need some answers to be evaluated, even if provisional, what I will propose in the next section by turning back to the diary study data. 


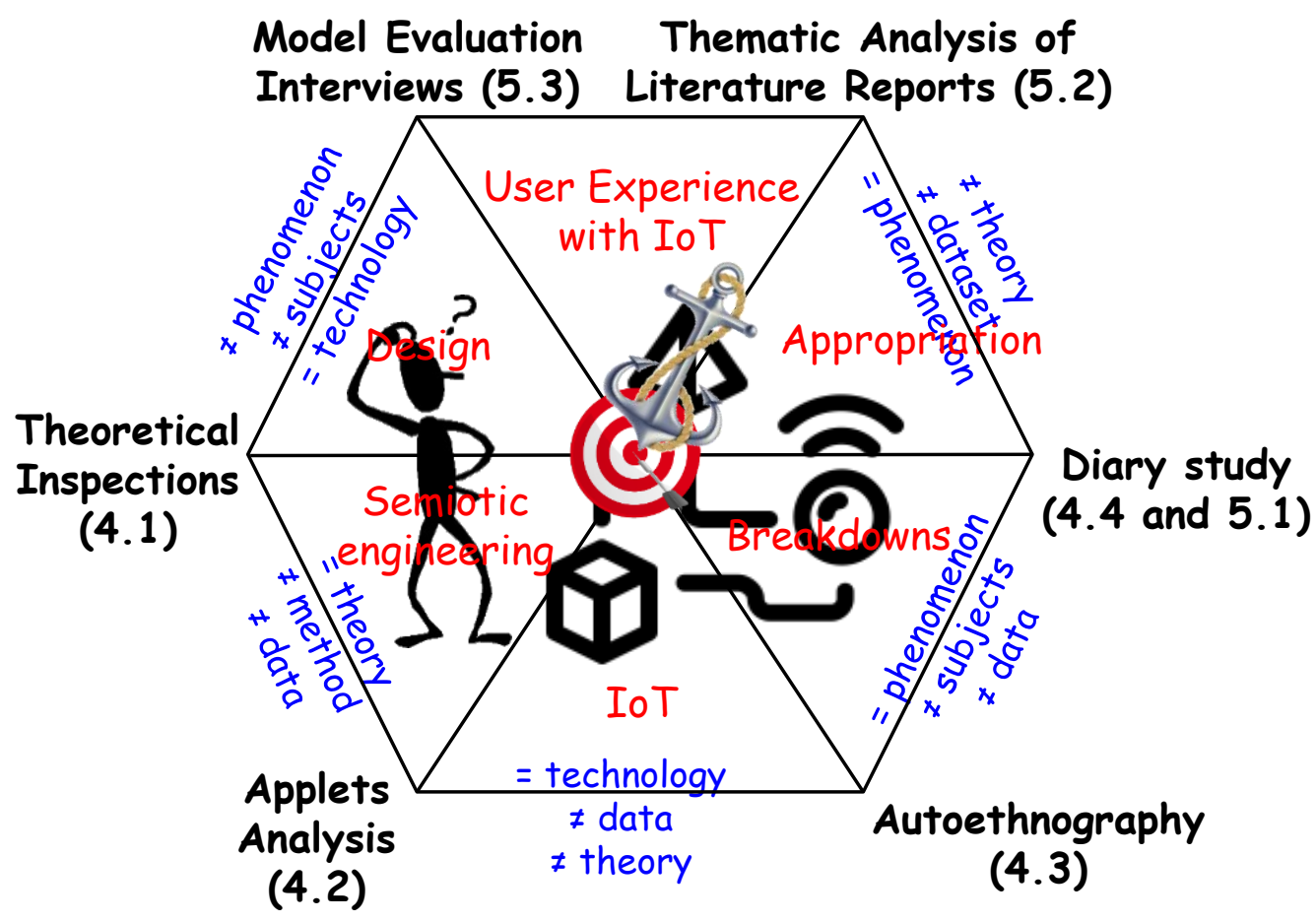

Figure 5-1 - Our macro-methodology laid over the problem space.

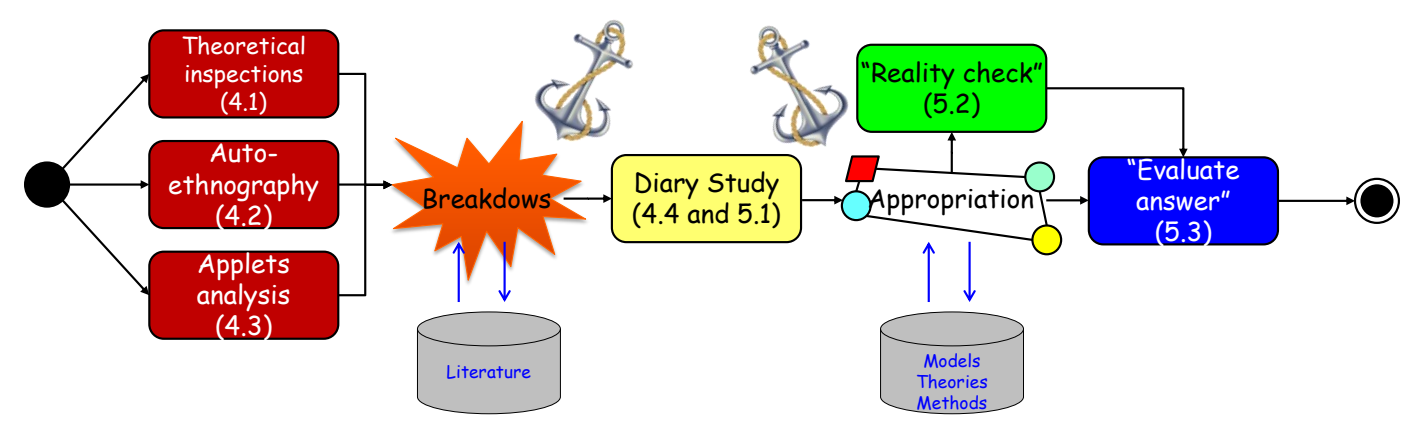

Figure 5-2 - Our macro-methodology laid over time.

\section{1.}

\section{Study 4 Continued: Proposing an Appropriation Model}

The richness of the corpus I obtained from Study 4 showed that the study overall strategy and design was quite successful. But now I could turn to it with more precise research questions in mind. In Section 2.3, I framed two research questions that were identified as relevant problems of interacting with IoT technology (Box 2-1): 
- R1) How do people appropriate IoT technology?

○ R1-A) What does "to appropriate" IoT technology mean?

In addition, I argued that I am looking for a particular kind of answer, a theoretical descriptive model of appropriation that can answer these questions in a way that is useful for the design of appropriable technology. So far, my main result of Study 4 (Section 4.4) was a semiotically grounded definition of appropriation and a framework that depicts appropriation as states related to user's interpretations that evolve by means of abductive reasoning cycles triggered by breakdowns. In this study, I performed a new round of data analysis targeted at finding more details about the appropriations I observed towards answering my research questions.

\subsubsection{Method}

This study is actually comprised of a new cycle of analysis of the data obtained in the diary study (see Section 4.4). It should be mentioned at this point that I used the QDA Miner Lite (free) edition version 2.0.5 - a computer assisted qualitative analysis software from Provalis Research ${ }^{23}$ - to perform my data analysis and interactively code the data. Until this point, I have performed roughly seven major cycles of coding following the process depicted in Figure 5-3. Rounds 1 to 7 helped in identifying patterns across participants as described in Section 4.4. Here, I performed round 8 trying to make sense of the role of breakdowns within each participant appropriation story. The complete codebook is depicted in Figure 5-4. I will discuss this process further in the following.

23 https://provalisresearch.com/products/qualitative-data-analysis-software/freeware/ [Last visited: $18-F e b-2020]$ 


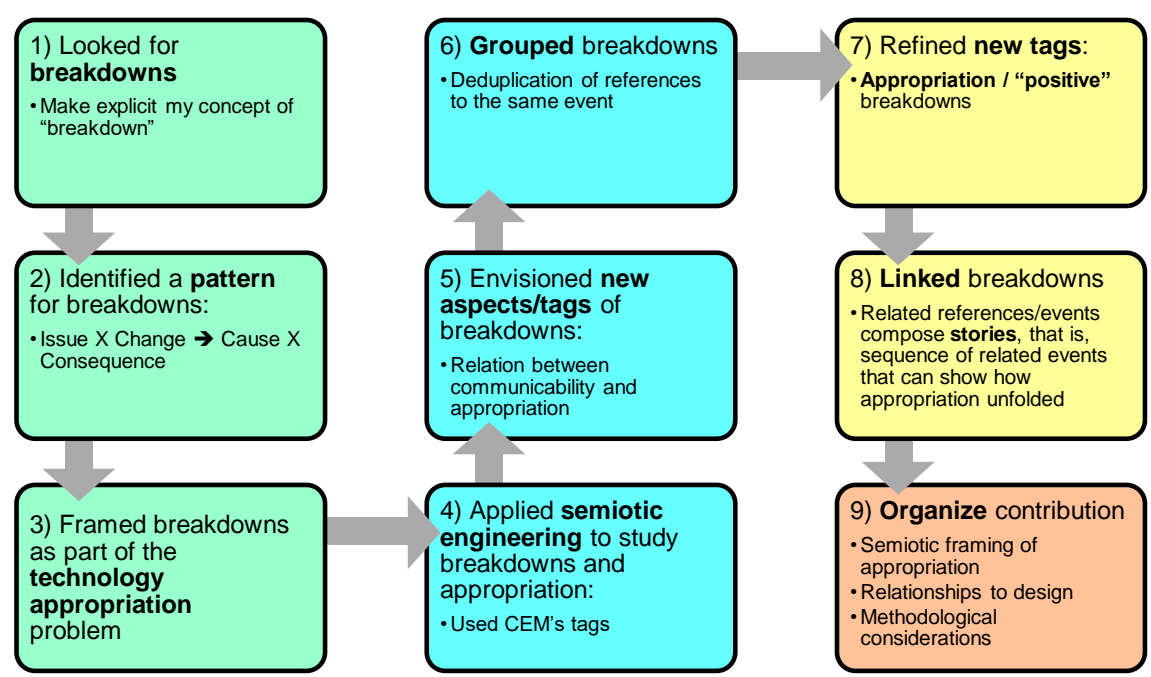

Figure 5-3 - Visualizing the data analysis process.

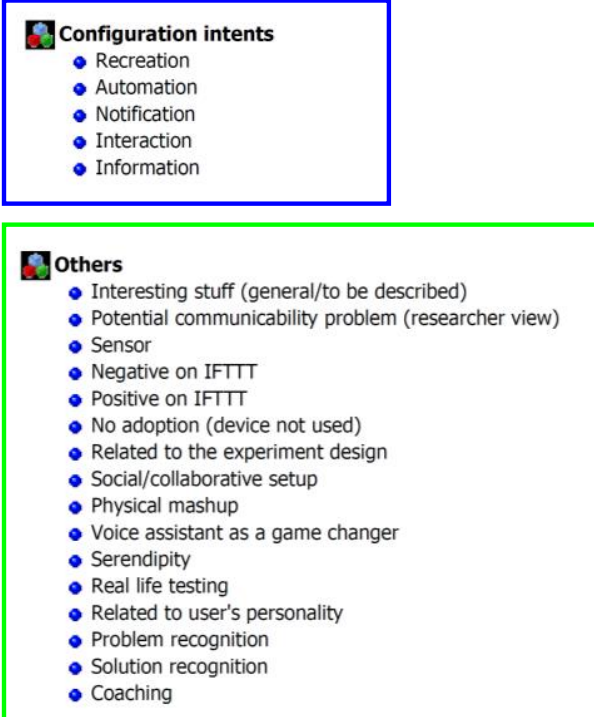

Figure 5-4 - The current codebook of the qualitative analysis of the diary study data registered in the QDA Miner software. The picture illustrates the richness of our data inventory.

\subsubsection{Analysis}

Over time, each interaction of data analysis was performed with a different motivation in mind. So far, several blocks of our codebook corresponded to scattered findings, consequence of a coding approach initiated in a bottom-up fashion, except for the breakdowns' analysis (red box in Figure 5-4), which were 
central since the beginning and continued to be so. As a consequence, the other codes were left to second plane. The analysis process depicted in Figure 5-3 is mostly related to the refinement of the analysis of the breakdowns, which drove the entire interactive data analysis process.

The results reported in Section 4.4 correspond to findings approximately until round 7 (see Figure 5-3). At a certain point, I had imposed a sort of "theoretical discipline" by applying the CEM tags in order to interpret the data. By doing so, I committed (again) to Semiotic Engineering theory in order to leverage my findings and results. And it has been being positive so far, in the sense of producing useful results and insights. To impose an ontological discipline from a theory like Semiotic Engineering does not mean "to enforce data to fit the theory" (as one might think that would be the case with a quantitative experiment of a Physics law, for example). Rather, it means leveraging from the theory ontology by identifying in the data the important concepts and relationships discovered before and already described by the theory. Often, these relationships cannot be easily seen because they get hidden underneath the surface of the data. The value of this kind of theory resides precisely in allowing an observer to not need to discover them again from the data, but to identify when they are playing a role and how this is brought about. The price to pay however is that to leverage results consistently and coherently with the theory, one needs to adhere to the theory ontology and epistemology as a whole, not in a utilitarian way, but paying attention to everything that is inside the "theoretical package."

If breakdowns are communicative, what is the system then? The system is the designer's metacommunication message, a packaged text of signs organized and delivered to the user by his deputy — the system - through its interface. This is not our results or findings, but a theoretical assumption, a theoretical tenet, actually "the" core tenet of Semiotic Engineering. And it can significantly leverage the interpretation of the data in terms of appropriation.

\subsubsection{Results}

To recap, so far, appropriation is characterized by stabilized states of interpretation which allow users to organize a rich and productive set of interactive discourses with the technology at hand. This definition characterizes 
appropriation as an abductive process. Each interpretation state is provisional (not definitive) and corresponds to users' best hypotheses about what the technology means for them. Moreover, these states are useful to the point that they enable users to organize pragmatically useful interactive discourses that they can (know how to) and want to engage with the technology. In between two states, there are breakdowns, the triggers that challenge a current interpretation state and cause the pursuit for a revised one. From a breakdown to a new appropriation state, there is a stabilizing process.

Whatever happens during this stabilizing process, it has a strong semiotic component. They are the user's approach to cope with the semiotic material provided by the designer in the technology interface. This process comprises the learning and incorporation of the interface signs by the user. Naturally, a sign can only be incorporated when interpreted by the user and the process of interpretation itself (before any appropriation can be said) is an intricate one. According to semiotic theory, interpretation is driven by semiosis, as described in Chapter 3, which can always be unlimited, but gets halted, even if temporarily, due to pragmatic conditions.

By identifying the meaning of breakdowns to appropriation according to Table 4-3 and relating episodes participants reported with one another and within the larger "appropriation story" engendered by each participant, I identified seven distinct ways of interpreting technology performed by users that are part of the stabilizing process between two appropriation states. These "ways of interpreting technology" can be best characterized as semiotic processes that, when dynamically combined, lead from one appropriation state to another. Each process elucidates how users elaborate the semiotic material they receive in the technology interface which is, in Semiotic Engineering's terms, the metacommunication message sent by the technology designers. Semiotic processes are characterized by an agent-the user in our case-, an action involving signs - in our case, signs of a metacommunication message conveyed though a technology interface- , and an outcome. The seven semiotic processes I identified were coded into the QDA Miner as depicted in Figure 5-5. They will be described in the following. 


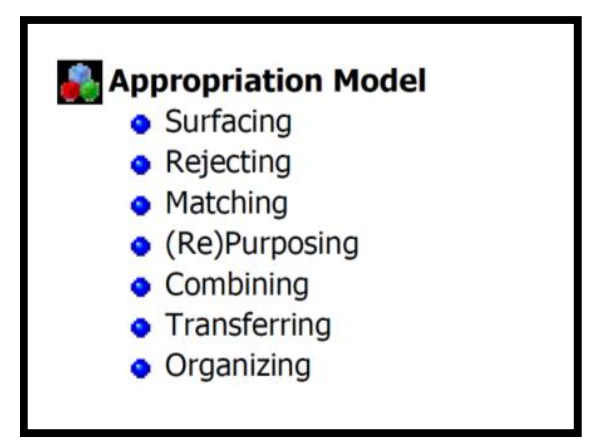

Figure 5-5 - Semiotic processes codes.

\subsubsection{Surfacing}

Surfacing is the process by which users bring to the surface the metacommunication message from the designers by interactively exploring the technology. This is the first process users engage when facing a new technology or a new surprising sign or fact. In this stage, users will try to build their initial interpretation about what they are seeing. Consciously or unconsciously, they are trying to bring to the surface the designers' metacommunication message so the s/he can make a judgement on whether the technology is useful and good for him and how it will be. This process is characterized by intensive exploratory activities, that can be easily observed by frequent occurrences of "What's this?" and "Oops!" communicability breakdowns (see Table 4-3). By means of interactive conversations with the technology, this process is analogous to an adhoc situated reconstruction of the designers' metacommunication message (see Box 3-1 in Section 3.1) in users' minds that may or may not coincide with the designers' intended one. Either way, users will form a resulting (provisional) takeaway message that will constitute a basis for subsequent refinements and interpretations they will develop as part of their unlimited semiosis stemming from each future encounter with the technology. This and others implications will be discussed further ahead.

\subsubsection{Rejecting}

Rejecting is the process by which users deliberately reject features or aspects of the technology, as the name suggests. Rejections take place after surfacing and can be of two different kinds, namely misinformed and well- 
informed. The former is a negative outcome related to a flawed metacommunication that hindered the surfacing process, preventing users to build any solid or trustworthy judgement about the technology because the tentative metacommunication contained too many gaps or inconsistencies. I observed such cases with the occurrence of "I give up" communicability breakdowns, usually preceded by episodes of "What happened?" and "Why doesn't it?", such happened with the motion sensor in the diary study with practically all participants from the diary study (see Table 4-3). In these cases, the metacommunication presented critical problems and users could not unleash their semiosis in productive directions, abandoning the technology. The latter is not necessarily a negative outcome and actually happens when designers do good communicability. The typical case is signaled by the occurrence of "Thanks but no, thanks" communicability breakdown, when users do a well-informed judgement about the technology, usually regarding advanced features and resources. It was observed with some automation features (P7), and the schedule features of the smart plug and motion sensor and recurring alarms in Alexa (P3, P4, and P11) — see Table 4-3. This and others implications will be discussed further ahead.

\subsubsection{Matching}

Matching is the process of finding a virtually perfect fit between a functionality and a practice. The user identifies a certain chunk of the metacommunication message to match his or her profile (and needs, goals, and preferences), e.g. a use case that he or she already has or does using another kind of system or technology or no technology at all. The strongest observed examples were turning the smart lights on or off remotely (by phone or voice) and listening to music with the Echo Dot, that every participant reported liking and using frequently. As a consequence, these processes are not indicated by breakdowns. For example, if everything is working fine, it means users are able to use the technology "as is" and are probably satisfied with it. Therefore, no breakdown happens. Indeed, I got reports of several situations where this was the case: on/off the LIFX light bulb and adjusting the light bulb's color. So, when 
entering/leaving my room, I would call out "Alexa, turn off [or on] the light." I had set the light bulb's name to "light" within the Smart Home tab in the Alexa app.

[P5] I use Alexa almost [all] day to play music.

In such cases, the absence of breakdowns is the sign of the semiotic process or of its outcome, one which enabled users to engage in productive interactive conversations that fulfills previously existing needs and preferences. This and others implications will be discussed further ahead.

\subsubsection{4. (Re)Purposing}

$(\mathrm{Re})$ Purposing is the process of attaching one more layer of meaning to the technology, namely, a purpose. Purposes indicate the presence of top-level communication intents or strategic goals of interaction at the user side (cf. DE SOUZA, 2005a, p. 123-125). Once users constructed a basic personal understanding of the technology and got some experience in when and how to use it, more elaborate goals emerge as they develop a bond with the technology. This bond is characterized by a clear reason of performing something, a reasonable level of confidence and skill to accomplish it, and an articulated interactive discourse developed to fulfil the envisioned purpose. Purposes can be originally anticipated by designers or not, in which case they can be called repurposes. To illustrate the process, let's take a look at the following cases:

"I thought that l'd only use the last applet ["have Alexa unsilence (sic) my phone"] in cases where I had forgotten where I put my phone and it was in silent mode. But since I keep my phone on silent often, the last applet has been more useful than I thought because I can turn the sound on without having the phone in my hand and miss significantly less messages this way." (P5, 11/27/2017)

[Researcher] You said that you used the Flic Button to control the lights too?

[P10] Aham [confirms]. That came about because I was too lazy to go into the [LIFX] app while I was at my desk and turn off the light while my girlfriend was asleep, so... And I didn't want to yell at Alexa to turn the light off, because she was asleep, so I just... I mean, it wasn't original, because I saw it in the video, but I just sort of copied the idea to turn the light on and off with the Flic Button.

[Researcher] Okay. If you recall this time, when you were setting this, how was that? [...] Tell me about it.

[P10] Yeah, it was like: That night, I was finishing up my homework and she was asleep and I wanted to turn off the lamp with the LIFX Bulb. And then I thought "oh, I can't really, like, tell Alexa to do it, because my girlfriend is 
asleep right now", and I guess I was too lazy to go into the LIFX app and turn it off from there, so I went into the Flic app and set it up so in the future I wouldn't have to deal with that problem again.

"Interesting use case(?) today. I know that these automated light bulbs can be used to deter would-be robbers for home theft. When on the bus back to Norte at 7:00PM, I remembered I had my bedroom window all the way up (the screen is still there). So, I opened the LIFX app and turned on the light." (P1, 12/5/2017)

In the first case (P5), we can reasonably assume that the purpose was anticipated by the applet designer who named the applet "have Alexa unsilence (sic) my phone.” Still, P5 developed his own personal reasons to use it. Similarly, in the second case, P10 said he copied the idea from the Flic video, but the entire use-case of "not-disturb-my-girlfriend-talking-to-Alexa" was very personal, a strong motivation that led him to prepare for future situations similar to the one he reported. Finally, in the third case, P1 found a new use case for his smart light "to deter would-be robbers" particularly useful in a certain situation he was going through. The user found a new purpose for his lights based on its existing remotecontrol abilities. At one side, we can reasonably assume that a smart light is not originally designed to be a home security device (there are no signs associated with security in its interface, it is not marketed as such, etc.). However, the participant explicitly said "I know that these automated light bulbs can be used to..." acknowledging the fact that this finding was not originally developed by himself. If not anticipated by the designers, from whom did he get this idea from? Probably, from other users, pointing to a common case of repurposing, which is actually based on things users learn from other users besides the designer.

Similarly to matching, (re)purposing cannot be identified by communicability breakdowns. Instead, they are a sign of what is commonly referred to in the cognitive sciences as the "Aha!" or the "Eureka moment" (KNOBLICH; OELLINGER, 2006; KOUNIOS; BEEMAN, 2009). This and others implications will be discussed further ahead.

\subsubsection{Combining}

Combining is the process of mixing signs and meanings from two or more different technologies. In other words, the metacommunication messages taken from two (or more) different designers are merged and this gives rise to a richer 
one that is related to both devices at the same time and cannot exist without one of them. For this combination to be possible, designers of each technology involved in the combination must have anticipated the possibility of combination and designed for it. It was observed two ways by which users can combine IoT technology. The first one is by direct integration, consisting of using a base technology, e.g. the Echo Dot, being extended with elements from another technology, e.g. the LIFX smart light. After an initial setup, usually involving some connection and authorization steps, signs from the LIFX will appear in Alexa's app, such as light and room names, enabling users to use Alexa to control their smart lights by voice, a highly valued use-case I observed (see P1 report about using the Echo Dot to control his lights in Matching and P10 with his Flic above).

Another way a combination can be made is by the use of another tool specifically designed to be a "combination aid," a "glue" between two technologies, which in our diary study was the role of IFTTT (see P5 report about the applet "have Alexa unsilence (sic) my phone," a combination of the Echo Dot and his phone). This is the same idea of mashups, a typical End-User Development technique that gained considerable popularity with the advent of the Web 2.0 during the 2000's (e.g. CAPPIELLO et al., 2011). Mashups allow for combining technology components by means of integration APIs and some sort of "gluing language" to mash them up. This and other implications for design will be discussed further ahead.

\subsubsection{Transferring}

Transferring is the process by which users bridge two distinct semiotic worlds, the designers' and their own, bringing in and out signs that migrate from one signifying system to the other. This process was observed in two different ways:

i) From user to the designer's deputy's: when users inscribe signs from their own world into the technology. The analogy here is a person describing or explaining something with their own words. A typical example is that of using custom names to refer to the technology, as can be seen in the passage below taken from P5 interview: 
[Researcher] Ok, so, l'd like to ask you about some of the things that you sent on the submissions just for us to explore a little bit more. So, let's start with the names you used, some interesting names. And then you explained that, actually, on one of your submissions that you were trying to make them more personal. So, could you elaborate more on that?

[P5] So, I named the LIFX bulb "Magic Candle" just because I thought it would [be] funny to say to Alexa "Alexa, turn magic candle on" and so on, or "turn magic candle red."

[Researcher] I see.

[P5] Yeah. And I named the D-Link motion sensor "Scrying stone" just because, I think l've mentioned it, it reminded me of a crystal ball.

[Researcher] Yeah, you said that.

[P5] So, I'm into RPGs and Might-and-Magic [games], right, so a lot of the names I chose come from that kind of mentality.

[Researcher] I see.

[P5] Yeah, like, the magic candle is in Zelda, in the original ones...

[Researcher] Got it.

[Researcher] "Hearthstone" [the WeMo smart plug] I thought it's extra funny because a hearthstone, I looked at the etymology of the word before I named it, or as I was naming it, and a hearthstone refers to the bottom part of your fireplace. I mean, for thousands of years ago even, or not thousands but maybe a thousand... So, I had the smart plug named "hearthstone" and I plugged in my powers, my energy saving power strip into that and the power strip is pretty big like this [shows me with his hands] and this has reminded me of a bottom of a fireplace. And the fact that there is electricity running through it reminds me of a fire.

ii) From the designer's deputy to user: when users start to use technology signs in other discourses, usually words that they have originally learned with the technology. The analogy here is that of learning a new word or vocabulary, when users use it in conversations outside the learning context or scope, such as with friends or relatives or any other discourse, not anymore restricted to interacting with the technology. An example is the following excerpt taken from a P1's submission:

11/18 (later that night) - I brought my Lifx and Dot to a friend's place and set it up. I showed off the Dot to essentially $\sim 7$ friends, who either had little to no experience. Again, I showed off the main stuff I showed to my other friends ("Alexa, tell me a story", play song, quiz, etc), though a few missed some of the games/skills because they arrived later. I also set the LIFX light bulb, pretty neat. We used it when we played Mafia; we had every other light off except for the LIFX for mood lighting. The game's moderator would shift the color through the LIFX app on my phone to red to signify if there's been a death, or to white/beige color if there's no death.

Throughout the different games we played, we have played/paused songs through the Dot, played specific songs (my friend logged into her Amazon Prime account into my app, i.e. "Alexa, play Taylor Swift"), and adjusted volume via voice command. My friends mostly got the hang of it. The Dot 
did a decent job of taking in a command, even though there were other people talking in the background. (P1, 11/19/2017)

Both cases entail a transferring of signs between the two parties - the user and the designer's deputy. In the first case, the designer had anticipated the need and provided features for this particular purpose, most of them associated with naming devices, places and real-world structures that can be used to personalize the device. The second case is usually enabled by verbal signs that users can talk about with other people, such as Alexa "skills" and other features or concepts associated with technology. Although transferring is not directly related to a practical interactive goal, so to speak, it showed to be a very important semiotic process, one which enables social practices and the creation of a certain culture around the technology. This and others implications will be discussed further ahead.

\subsubsection{Expressing}

Finally, expressing is the process by which users organize rich and productive interactive discourses with the signs of the technology. If the other processes actuate as input processes, more or less as "dynamic absorptions" of new signs from the technology by users, this one is an output oriented process that happens when users get to a point where they are able to express personal intents in the technology interactive language in a proficient way. Let us take a closer look at an example from P3 interview, who transformed his smart power plug into a fish tank management device:

[Researcher] So, and how did you come up [with the idea of plugging the WeMo in the fish tank light]?

[P3] So, my thought process was "ok, I have been very stressed out, right, at the finals and stuff like that so, and I have to go and feed my fish every day." And I was like "ok, I got to feed them every day, I can't create an application to go and do that, ok, I have to physically do that."

[Researcher] Ok.

[P3] But then I have to go and turn on and off this light every day, so it's like "oh man, this is getting tiring." I have to get up once, right, to go and feed the fish, go bring back down, study, then I realize, "ok, I got to turn on and turn off the light." So, at that point I thought "ok, I'm just gonna put the WeMo switch right there" and then I could just control it from my desk. Or I can have it, or just... Yeah, pretty much I think my thought process was just controlling it from my desk. And then at that point it just made things a little bit easier so I can just turn on and off the light, the lights to my fish tank. 
[Researcher] Ok. So, do they need the lights on to eat? Is that what happens? Sorry, I don't know about fish...

[P3] I actually don't know too much of fishes too [laughs]. I think fish kind of need some light to eat, too. I think it's more aesthetic, right, it just looks good, especially if you have guests over you want to turn on the light just to show it off.

[Researcher] I see.

[P3] But then it just got to a point where, you know, standing up just to go and turn off the light just became too problematic. So, why don't I just control it from my desk? So, I guess you can argue that these loT devices are making us more lazy [sic] but I guess that's the purpose.

P3 transformed his smart power plug into a fish tank management device by combining features and configurations available to him in order to support a certain set of intents around the fish tank, such as feeding the fish, showing off to friends, being lazy, etc. Expressing is the act of actually using the available interface signs to interact (talk) with the technology, engaging in the interactive conversations made available by the designer as users need and want to. Another participant started to use his colored smart lights to influence his mood, building a new practice aimed at "mood management" (P5), and developed a series of combined features and configurations made of IFTTT applets, native configurations, and the physical setting of his room that, together, were destined to support meditation and his plans for improving his quality of life. Other (P6) has developed the habit of quickly getting a daily weather report for her location on her mobile phone using the Flic button to cope with sudden weather changes.

Expressing is related to the accommodation of meanings, indicating that users have reached a stabilized state of interpretation, marking the end of a stabilizing cycle. At this point, users actually come up with something closer to a new practice using the technology. In general terms, a practice is a habit, a repeated or regular way of performing a certain task or set of tasks. A new practice emerges when users develop new goals based on what they learned about the technology and on the possibilities they have envisioned (e.g. P5 "mood management" routine); or no new goal is introduced but an old way of doing something is replaced by a technologically enhanced way that is significantly different, such as P3's smart fish tank and P6's weather report. Expressing may involve situations where users overcome perceived or actual technology limitations by working around them, producing interactive conversations that were not made available originally by the designer in order to accomplish their 
personal goals. These situations were identified by the tags "I can do otherwise" and "I can work around it" depending if the limitation is perceived or real (see Table 4-3). This and other implications will be discussed further ahead.

\subsubsection{Conclusion}

The semiotic processes described above connect what was observed in terms of appropriation (empirical data) with Semiotic Engineering theory. They account for what comes "beyond the reception" of the metacommunication message, that is, after received by users, what people do and how they actually make use of the message as understood by them in their personal ways of interacting with IoT technology. In addition, they complete the abductive appropriation framework proposed as the initial results obtained from the diary study (Section 4.4). By combining the abductive appropriation framework from Figure 4-6 with the semiotic processes described above we have a final "big picture" of IoT technology appropriation by users with a reasonable level of detail. This comprises a theoretical semiotic model of appropriation as depicted in Figure 5-6.

Although semiotic processes were described following a certain logical order of complexity that approximates a temporal order in some cases, by no means it should be understood as a strict order since semiotic processes are very dynamic and intertwined, just like our semiosis. In addition, it does not mean either that all users perform all processes all the time. As observed with our participants' appropriation stories, these processes are "optional" in the sense that a user can perform one or the other depending on the situation she or he faces. Finally, just like our semiosis, they are governed by pragmatic conditions that influence users' interpretations, halting the process temporarily anytime the current meanings accommodate and become sufficient to be used for some current goal, or the user run out of resources (time, patience, background knowledge, etc.).

Notice that the breakdowns have a critical role in this framework. As mentioned before, they refer to more than communicability breakdowns. In my model, they refer to anything that challenges users' interpretation about the technology, such as a mismatch between an interpretation and reality that is perceived by the user, which of course includes communicability breakdowns. In 
other words, breakdowns are anything that can trigger users' abductive reasoning and unlimited semiosis. According to this model, breakdowns will be handled contextually by the users by means of pragmatically bounded semiotic processes. These and other theoretical and practical implications of this model of appropriation will be discussed further ahead. Now, I will evaluate the model in the following studies.

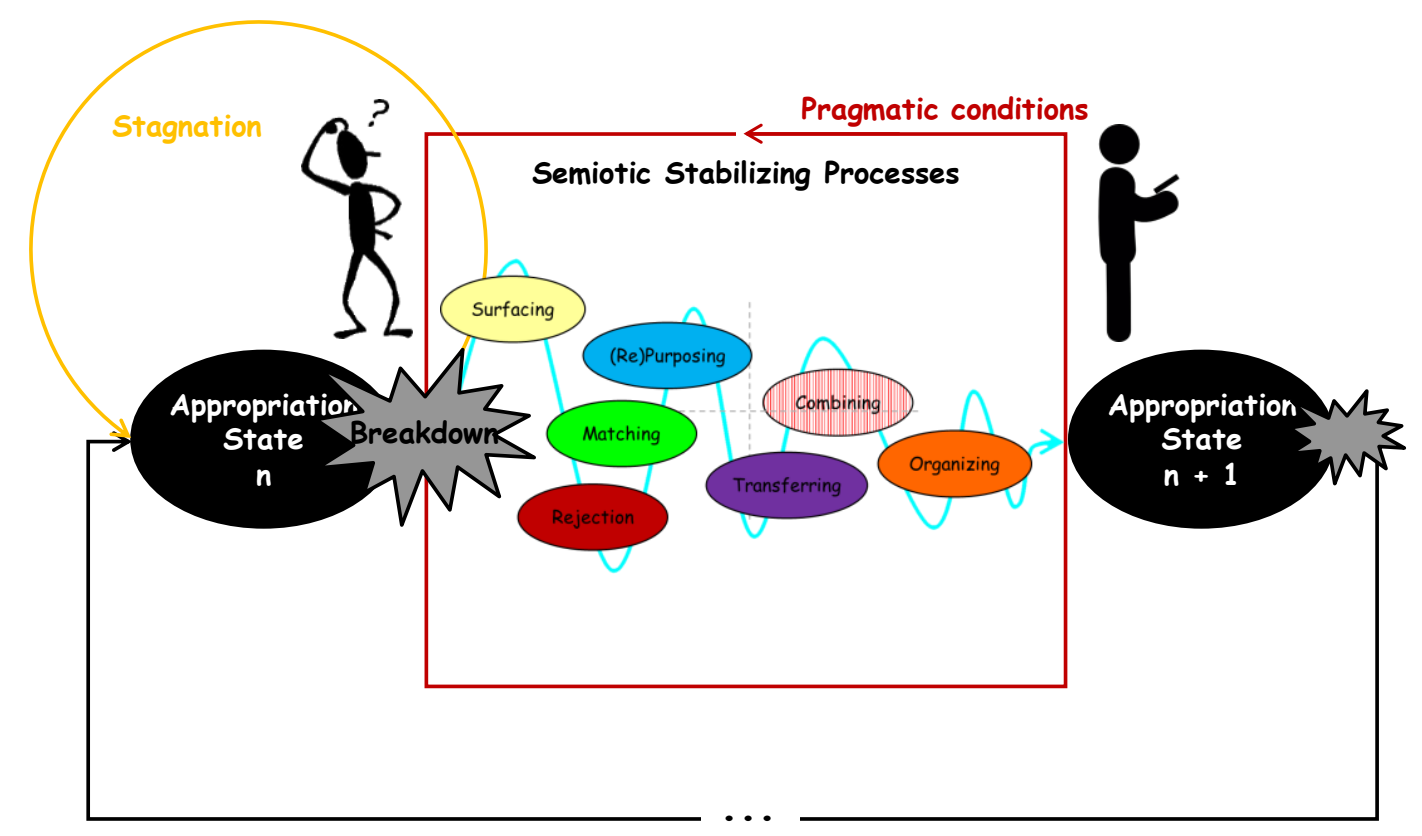

Figure 5-6 - My semiotic appropriation model showing appropriation as states, breakdowns triggering users' abduction, and the semiotic processes in between two states. 


\section{2. \\ Study 5: Thematic Analysis on Literature Reports}

The model proposed above describes appropriation of IoT technology by users with a reasonable level of detail, providing a set of semiotic processes that can support a designer or an investigator to talk about appropriation in deeper and potentially more insightful new terms. This first evaluation study is proposed to be a "reality check" intended to validate if this model is applicable to other unbiased data. I want to test if the proposed semiotic appropriation model is compatible with other cases and reports of appropriation found in literature that were observed by different researchers, from different theoretical backgrounds, and with different biases. The focus is not on proving or testing the generality of the model, but in checking if I can find traces of appropriation in other datasets that, although described in a different way by the researcher, can be described by my semiotic model, even if partially.

I have cited and discussed in Section 2.2 some works about appropriation in $\mathrm{HCI}$ and $\mathrm{CSCW}$ literature. Most of these works are qualitative studies, either ethnographical or of the kind of a design and evaluation of a tool. Qualitative studies usually present thick descriptions of data and evidences, and I will try to benefit from those in order to answer the following research questions:

- Is my semiotic model of appropriation able to describe other appropriation cases found in other datasets or reports from literature?

- Can I find the semiotic processes described above in other datasets or reports about appropriation from literature?

\subsubsection{Method}

Among the papers from literature containing empirical reports with rich descriptions of users using technology over time and with an appropriation perspective, I selected three papers. My criteria were based on: first, the topic of the paper being about IoT technologies, in order to avoid problems with the generality of the model; second, relevance and/or influence of the paper based on the venue or in its recurring mentions and citations in literature. The three following papers were selected from $\mathrm{HCI}$ and $\mathrm{CSCW}$ literature, most of them were already mentioned in Section 2.2 as they are specifically about appropriation 
or closely related, the exception being the last one, which is a classical EUD paper:

- JAKOBI, T. et al. The Catch(Es) with Smart Home: Experiences of a Living Lab Field Study. Proceedings of the 2017 CHI Conference on Human Factors in Computing Systems (CHI '17). New York, NY, USA: ACM, 2017.

- LUDWIG, T. et al. Towards Sociable Technologies: An Empirical Study on Designing Appropriation Infrastructures for 3D Printing. Proceedings of the 2014 Conference on Designing Interactive Systems (DIS '14). New York, NY, USA: ACM, 2014.

- MACLEAN, A. et al. User-tailorable Systems: Pressing the Issues with Buttons. Proceedings of the 1990 SIGCHI Conference on Human Factors in Computing Systems (CHI '90). New York, NY, USA: ACM, 1990.

Since appropriation of IoT technologies is a rather new topic, only the two first papers were about IoT technologies and provided rich descriptions while discussing appropriation in some level in order to match our criteria. The third fell under the criteria of relevance in literature about EUD and tailorability, which is closely related to appropriation.

\subsubsection{Analysis}

For each paper, I performed a "theoretical thematic analysis" (top-down coding) (BRAUN; CLARKE, 2006, p. 12), the theory being my appropriation model in this case. That is, I deliberately looked for my model in other research reports about appropriation in order to test if the proposed model would work as a useful interpretive framework in other research datasets and contexts, following Leitão \& Prates recommendations for qualitative research mentioned before (LEITÃO; PRATES, 2017, p. 84). My procedure was as the following:

- Check for a general compatibility with our abductive model of appropriation as states;

- Try to identify the semiotic processes in the reports and verify if and how they appear; 
- Organize main findings from each paper.

- Compile, consolidate and reflect over overall results.

Because the abductive framework of appropriation as states is solidly grounded in semiotic theory and rather general, most attention was paid to the semiotic processes part of the model. I looked for semiotic processes' references based on the following principles: Firstly, a "reference" to a semiotic process was identified whenever an observed case could be described as one of the semiotic process or was closely related to it, e.g. a discussion of a function or feature of the technology that was supporting or hindering one of the semiotic processes; Secondly, a semiotic process was referred in passages or excerpts directly (that is, in real case reports or participants quotes) or indirectly (that is, in researchers' interpretations of the data). Finally, we have to keep in mind that semiotic processes are always dynamic and intertwined in the sense that they mutually cooperate and can occur at the same time. When this was the case, I picked the primary process that seemed to be playing the most evident role.

\subsubsection{Results}

\subsubsection{Analysis of (JAKOBI et al., 2017):}

This paper is a report on an empirical study with smart home users over a long period of time (18 months) using a "living lab" approach. The authors report on the main problems their participants encountered while using a laboratory house equipped with several IoT devices and a management system that allowed basic and advanced configuration of the ecosystem with automation rules and the like. They reported their participants' experience organized into four phases of appropriation using Silverstone \& Haddon's (1996) framework of “technology domestication:" system setup, installation and configuration, routinized use and demands for reconfiguration and extension.

In this empirical and ethnographical report on appropriation of smart home technology, the very time-lapse division Jakobi et al. identified is compatible with our abductive appropriation model: each "phase" corresponds to a different appropriation state that users go through. This can be noticed also in the passage 
below where authors suggest a general pattern of stepwise, piecemeal appropriation:

"Noticeably, households typically defined rules in a step-by-step manner. For example, when wanting a light to switch on depending on sensed movement: First, coupling the motion sensor with the smart plug was set and tested as a rule by moving in front of the sensor. After success, the period of time where the light was to remain turned on was set and tested again. Finally, the restriction that light should only be turned on when ambient light is low was added." (installation and configuration)

Furthermore, I found evidence of the semiotic processes in several passages as following:

\section{Surfacing:}

"The core problem our participants had in making their choices was to be able to identify routines to be supported and then map how the system might support a certain use case." (during system setup)

"[...] households ran into problems getting the system running without considerable support from researchers or the vendors' support channels (hotline and live chat support)." (during installation and configuration)

\section{Matching:}

"Coming or leaving home were two very common scenarios in which households wanted to check on things or set devices to a certain state. [...] Other demands for information related to security issues, such as checking for open windows or making sure all electronics were switched off."

\section{Rejecting:}

"Second, users found limits in the product itself, posing a barrier for their intended use. For example, some configurations of includable sensors were not possible, e.g. defining the sending rate of a light detector was not possible because of the vendor's battery saving intentions. This however, limited adaptability and led to feelings of helplessness and frustration:

'I guess you have to think twice whether it is the right component to fulfill your wish? [...] But I think it is kind of an issue, when expectations of users differ from what the vendor was thinking.' (single-person household)"

\section{(Re)Purposing:}

"During the summer, however, a two-person household with cats for example wanted to check the room temperature while they were abroad:

'[..] We could control if it was too hot for the cats at home.' (twoperson household)

"Although also a frequently used interface when at home, the mobile application was primarily used abroad. Here, use cases serving a demand for security awareness prevailed. Simulating presence by switching on and off lights manually was especially considered a benefit." 


\section{Combining:}

"The most common problem touched on that of pairing devices with the gateway a necessary step for Z-wave based components. The whole process raised serious issues and was a task many participants felt uneasy accomplishing." (during installation and configuration)

"Therefore, as an alternative to missing sensors and actors in the system, more technology-experienced households themselves tried to include third-party devices into the system. In most cases, and to varying extent, this failed due to differing interpretation of the communication standard." (reconfiguration and extension)

"For example, some households had smart meters installed, which they thought would easily go with a smart home system - in fact they were considered a vital part of it. Similarly, other smart systems such as smartphones or audio systems were expected to be able to have an interface for sensors and actors, such that e.g. the smart home would be able to react to the GPS of the phone or the battery of an electric vehicle."

\section{Expressing:}

"Within this phase, participants reported a considerably reduced interaction on the software interface level, due to having found their optimized configuration." (domestication and daily use)

"For example, the same household with cats had installed a safety mechanism for their pets:

'It is dangerous for our cats if we let the window open when we leave the house because they could get hurt by getting stuck in a partly opened window.' (multi-person household)

For this purpose, they connected a small light to a smart plug next to the entrance door which switched the light on when windows are open."

"Similarly, another households set up an awareness system for the dryer which was positioned in the basement, by connecting a smart plug to the machine and defining a rule that a smart plug in the living room should make a light blink when power consumption of the dryer dropped."

\section{Transferring:}

"After presenting his idea [the safety mechanism for the cat and awareness system for the dryer mentioned above] at a regulars' table meeting, this solution was adopted by others, too." [Note: in this study, participants were invited to table meetings where they discussed and shared their experiences with other participants and the researchers]

Jakobi et al. participants performed semiotic processes in different levels of sophistication, which are in accordance to the current appropriation state users are at any given time, ranging from "newbie" to "advanced user." For example:

Advanced Surfacing: after initial understanding, “advanced users" want to learn more about the system, e.g. the historical information that it stores

"Despite households' general desire for background automation, we also found various demands for explicit information and awareness. In particular, permanent demand for historical data was mentioned. One household, for instance, which 
already manually kept track of gas and electricity consumption on sheets of paper wanted to digitalize and improve monitoring" (domestication and daily use)

Advanced Transferring: when combination is not supported by designers, users *transfer* what they learn from one technology to another, looking for "coherence in wording, style and control"

"After getting used to their system, some households explicitly tested boundaries or came up with new use cases that included other electronic devices, such as smart meters, photovoltaic systems, smartphones, IP-based gardening equipment, cameras or car-mounted GPS-sensors. The isolation of these smart systems was counterintuitive to users and often led to frustration when different smart systems were not interoperable. This separation was not reduced to single appliances and protocols [10], but rather spanned across ecosystems. On a UX and usability level, the single access points to the systems lacking coherence in wording, style and control."

\subsubsection{Analysis of (LUDWIG et al., 2014):}

This paper comprises an empirical study in two different communities appropriating 3D printers for their purposes. Ludwig et al. focus in studying users practices and the socio-technical aspects of appropriation, drawing from the concept of "infrastructures" briefly discussed in Section 2.2, and how users can be supported by "appropriation infrastructures."

Ludwig et al. report focuses on socio-technical aspects in an infrastructure perspective and seems to be compatible with our abductive model of appropriation:

"Most of the infrastructuring activities were communicative or collaborative activities involving not only technology manipulations and combinations of various kinds, but also articulations of usages or breakdowns that referred to the technologies at hand and their context. Studies on these kinds of communications are not new (most notable example (cf. ORR, 2016)), but current practices deserve a second look as the practices of communication change with the communication infrastructures users evolve along the developments of miniaturization, mobile and ubiquitous computing."

In addition, I identified some of the semiotic processes playing an important role in the appropriation of 3D printers they observed. For example:

\section{Surfacing:}

"A serious shortcoming that became apparent is that the 3D printer itself is a kind of black box for the users and lacks in methods or functionality to visualize how it works. In order to overcome this issue, we suggest providing users with more details about the current printing process. Providing the right kind of information allows them to get a deeper understanding of how the machine works and the users can become more aware of what happens when and where." 
"The general orientation of learning-by-doing and experimenting outweighed extensive reading of user manuals or background literature. The users therefore often have just a vague understanding of the printer's capabilities, functionalities and all kinds of problems arise - especially at the beginning of their printing career."

\section{Transferring:}

"Closely related to the effect of forgetting printer specifications and settings, our study showed that the documentation and sharing of the printing experiences is very cumbersome right now because it happens out of context and temporally displaced."

"Documentation and sharing is also important for asking for help under provision of all relevant contextual information, getting support and to distribute knowledge and experience to other 3D printer operators (hence, also for communitybuilding)."

"Not only the missing structuring of data impedes the searching process for help and the sharing, but the highly community-specific terminology (e.g. "warping") hampers this process. A community maintained open "dictionary", as well as an automated translator matching errors to this dictionary could help alleviate this issue."

\section{Expressing:}

"We also found evidence for infrastructuring activities in the sense that the users modified their machines (e.g. installation of cameras) in ways the manufacturers did not plan for but could be incorporated in future generations of their machines."

\subsubsection{Analysis of (MACLEAN et al., 1990):}

This paper by MacLean et al. is a classic work in the EUD literature that was responsible for introducing the concept of "gentle slope of tailorability" in order to smooth users learning curve for customizing technologies-from basic use, to tinkering with parameters, to full-fledged end-user programming. It is a report based on the design and evaluation of a tailorable system called "Buttons," that is, "screen objects in Xerox Lisp which look 'pressable' and when pressed (by clicking with the mouse) carry out an action." Although it does not refer to an IoT technology, it is noticeable that MacLean et al.'s "Buttons" is precisely what we could describe as the virtual version of the Flic button, the main difference being that Flic button is not a "screen object" but rather a "digitally enriched physical object."

The paper consists mostly of a description of the system and its features, accompanied by a report of the authors observations about how the system was used by their co-workers, a kind of informal evaluation of the system in their lab. First, I see their concept of "gentle slope of tailorability" as fully compatible with 
the model of appropriation as states and users evolving from one state (e.g. basic use) to a more advanced one (e.g. tinkering with parameters) through cycles of abductive reasoning. In addition, I identified the following semiotic processes in their report:

\section{Transferring:}

"Early on, users talked about Buttons as being "not my personal buttons" or being "sewn to the screen" (i.e. not under personal control). Later, we started getting quotes such as "I don't know what I'd do without my Buttons"* or "Buttons are my friends, always there...". Note the use of "my" in these quotes. Buttons became perceived to be very personal $[\ldots]$ "

"They are regularly distributed by email, but perhaps more interesting, it is not uncommon for someone to request "a button to do X", where "X" may be something for which a button is quite definitely not the solution. We suspect that some of these requests would not be made at all if it were not possible to articulate a putative solution in terms of something concrete and comprehensible such as a button."

\section{Expressing:}

"A specific example was one in which one of our researchers who is not a Lisp programmer observed some of us exploring new buttons which allowed us to open two-way audio-visual connections between members of EuroPARC staff. Despite warnings that some of the software on which these buttons relied was unstable and would be superceded [sic] in an incompatible way, he persuaded us to email the buttons to him. Within a short time he had modified some of the internal Lisp code to make connections relevant for his own use. He gave these buttons to a few other people as well, allowing them to explore the use of our AN infrastructure sooner than would otherwise have been possible. We were particularly impressed by this experience as it was one we had not engineered in any way - indeed we had tried to discourage it if anything."

\subsubsection{Conclusion}

I analyzed three papers from HCI and CSCW literature that explicitly discussed appropriation or closely related subjects (e.g. tailorability) and topics ranging from smart homes, 3D printers and "pure" tailorable software in a lab. Overall, all reports seemed compatible with the broad abductive framework of appropriation as states, which is not surprising due to its full accordance with semiotic theory. Regarding the seven proposed semiotic processes, they were identified in all papers, sometimes only some of them and with different emphasis depending of the report approach, emphasis and goal. These results were very encouraging because they showed evidence of the semiotic processes in data obtained by different methods, with different technologies, participants and researchers. In particular, transferring appeared in all papers and much more than 
I was expecting at first. I attribute this to the social dimension emphasized by the authors of the papers I chose, all with a strong socio-technical background.

Identifying the proposed semiotic appropriation model in other empirical corpus corroborates the model's validity and applicability. This study indicates the descriptive power of the proposed model by showing that it can serve as an organizing framework for describing several cases of technology appropriation by users. In addition, it suggests that the semiotic processes are connected to interactive features of the systems. In several passages that were selected, researchers were pointing to technical design features that hindered or fostered (or could foster if existed) semiotic process. This is very interesting because it suggests straightforward implications for the design of appropriable technologies, that is, how a technology could or could not support a semiotic process. Finally, I did not identify other aspects or processes that were not addressed by my proposed model but that was probably a confirmation bias and should be seen as a limitation of this study. I do not claim that the model is complete or that there is no other semiotic (or other kind of) process; rather, I claim that my proposed appropriation model is broad and deep enough to address relevant aspects of IoT technology appropriation by users in a robust way because grounded in both data and semiotic theory. In addition, I am looking for a model that is potentially useful for design. The fact that, in several passages above, researchers described some technology design features in relations with the proposed semiotic processes (as identified by myself, not the original authors, of course) suggests that this might be the case. To investigate the model usefulness for the design of appropriable technologies will be the main focus of the next and last study. 


\section{3. \\ Study 6: Model Evaluation Study}

The results from the previous study were promising and the overall "look and feel" of the model was making sense. At the same time, the model was being refined by discussions with peers and colleagues. This last study was mostly targeted at assessing the usefulness of the model for IoT technology designers as one of the final stages the model development. My goals were to observe designers' reception to the model and their reactions to the concepts I was introducing. At the same time, I was looking for indications about if and how IoT technology designers would think the model could be used by them in their design process and regarding opportunities for refinements and improvements, such as in the model's vocabulary, occasional "glitches" or confusing concepts, and the like. Following Semiotic Engineering overall approach, I had an idea that the model would be useful as an epistemic tool for design. But the extent to which this would really be the case needed to be tested and developed with actual IoT technology designers.

With these considerations in mind and considering the current development stage of the model, I was looking for answers to the following research questions:

- How can IoT technology designers and developers use the appropriation model I am proposing in their IoT projects?

- Do they consider the proposed model a useful tool for their design practice?

- How was the proposed model useful and how could it be improved?

\subsubsection{Method}

I planned for an initial validation, a "probe," to be performed by means of interviews with a couple of IoT technology designers with practical experience in the field. I designed and conducted a one-hour protocol where designers would be introduced to the model and then I would collect their feedback about it by means of a semi-structured interview. The most challenging part was to introduce the model to designers that were, most likely, unfamiliar with the technicalities of 
appropriation and of Semiotic Engineering as well. For this goal, I prepared a script divided into three parts:

1) Consent and collection of relevant basic demographic information and the participant's experience (IoT projects that they have participated, etc.);

2) Brief and objective presentation of the semiotic appropriation model based on an imaginary scenario pre-defined by the researcher;

3) Semi-structured interview with roughly two main inquiries:

a. Participants impressions regarding the model in general and its usefulness in the imaginary scenario;

b. Participants comments about if and how they would use or apply the model in their IoT projects.

Two pilot sessions with experienced designers were conducted in order to refine and adjust the interview protocol. The pilot studies showed how to optimize the model presentation, clarify the main points of doubts, and revealed some promising directions about how designers could actually find the model useful. I used these pre-findings to refine the study protocol. It showed not to be useful to present and discuss appropriation in detail, including the abductive framing thereof, that was completely omitted. The semiotic processes in turn showed to be of most interest to designers and that the best way to introduce them was by means of concrete examples (that was how our pilot subjects could understand what each semiotic process mean). After these pilot sessions, I abandoned any theoretical introduction of the model and focused in preparing and refining an imaginary scenario able to present the semiotic processes in more concrete terms. I orally described a hypothetical scenario where the participant would be part of a smart device design team where she or he could observe a user who acquired their device going through each semiotic process. An illustration of the semiotic processes was shown to support the discussion (Figure 5-7) and each process was introduced by means of a representative example based on the cases I observed in the diary study. A summarized version of this hypothetical scenario is presented in Box 5-1 because it provides a summarized overview of the model that is useful to recap it and will help to understand the results. 
The study was approved by PUC-Rio's Research Ethics Committee for ethical compliance regarding human-subjects research and conducted entirely with Brazilians. The study protocol and related Ethics Committee material can be found elsewhere (CHAGAS, 2019). Due to the specificity of the required profile, participants were recruited through the researcher network of contacts and by means of direct contact with potential subjects indicated by colleagues or obtained in IoT events, social network groups, and IoT companies' websites. Participants were not compensated in accordance to Brazilian national resolutions regarding research with human subjects in general (CONSELHO NACIONAL DE SAÚDE/MINISTÉRIO DA SAÚDE, 2012), and in HCI (within the Social Sciences) in particular (CONSELHO NACIONAL DE SAÚDE/MINISTÉRIO DA SAÚDE, 2016). A total of four participants were recruited, with backgrounds ranging from undergrad students with little experience to researchers and professionals with extensive experience in the field-see Table 5-1. Although a few in absolute numbers, their expertise constitutes a strong insider perspective which is very valuable considering the scarcity of the targeted profile, especially in Brazil ${ }^{24}$. They were interviewed by myself in person or remotely over Skype in November until the beginning of December of 2019.

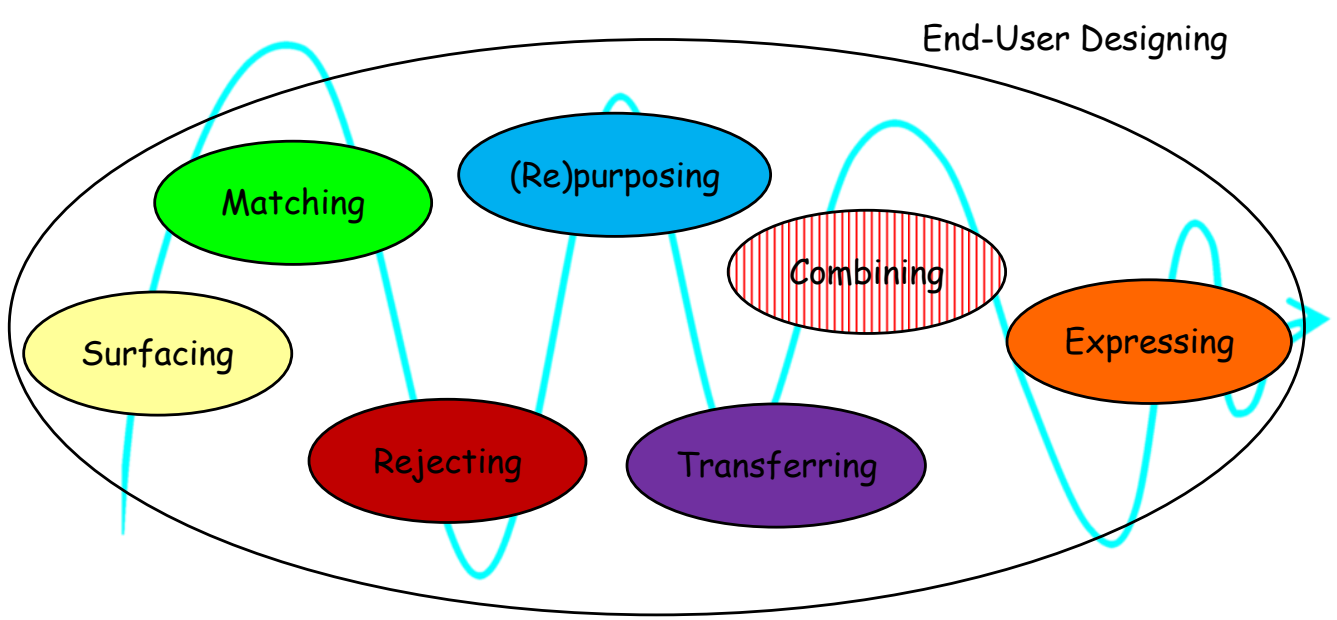

Figure 5-7 - The illustration of the seven semiotic processes of our appropriation model that was shown to the interviewees.

24 Note: Participants outside Brazil were not considered in order to avoid dealing with different human-subjects research regulations and additional complexity arising from ethical approval processes in cross-national research. 
Box 5-1 - Summarized version of the interview scenario:

Suppose that you are part of the development team of new IoT device, for example: a smart light bulb for domestic and commercial use. This light bulb is capable of emitting different colors and is controlled by a mobile phone app. The app provides remote control of the lamp for changing colors, intensity and some simple automations such as weekly schedules for turning the lights on and off and the like. In addition, the smart light can be integrated with other devices in order to allow more complex routines such as "turn on lights when someone gets home", "turn off lights when everyone leaves", etc.

Imagine now that you can observe your users when using your smart device on a daily basis and notice that they perform the following activities after their first contact with the device:

1) Initially, they explore the app to find out what the technology does and how [Surfacing]

2) At this point, they reject some features, for example: the automatic schedule or turning on the lights using the mobile phone (they often prefer to use the wall switch when entering and leaving the room where the smart light was installed) [Rejecting]

3) Although they usually don't use the phone app during the day, they usually do it when the wall switch is far, e.g. by night, after already in bed, in order to turn off the lights without having to get up [Matching]

4) One day, one user "discovers" that she can uses the smart lights to simulate presence in the house (for fun or to scare someone if the house has been forgotten opened) [(Re)purposing]

5) Some light colors have special names in your app, for example: a light orangish yellow is "Twilight light," a cold bluish white is "Concentration light," weak purple is "Night light," etc. You notice that your users start using these names when referring to other lamps in the house in ordinary conversations, e.g. "hey, put on the night light please" [Transferring]

6) By combining the smart light with a sensor on the bedroom door, they are able to automate routines, e.g. "turn on the lights when someone enters the room" [Combining]

7) After some time and experiments, the smart light bulb is delegated with a noble purpose: to light the house's fish tank at certain times so that the fish can eat and admirers can watch. The light is installed in the fish tank luminaire and a schedule for turning it on and off is created, which also helps the user to remember to feed the fish. Multiple colors have been tried and continue to be tried today, depending on who is visiting the house, etc. [Expressing] 
Table 5-1 - Study 6 interviewees: IoT technology designers' profiles and backgrounds:

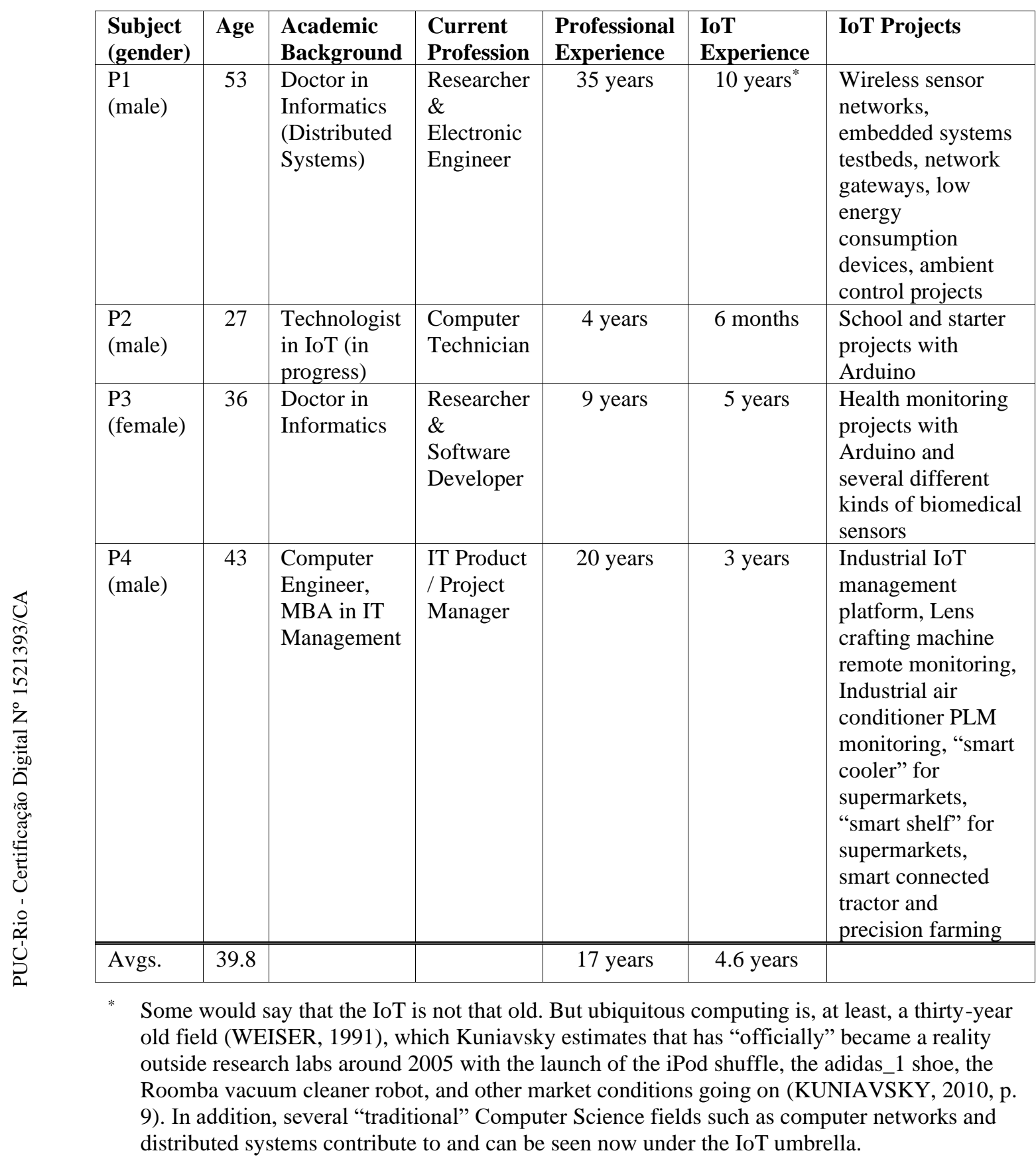

\subsubsection{Analysis}

Interviews were transcribed in Portuguese and anonymized for textual analysis conducted in the same QDA Miner qualitative data analysis software (free edition) used before. This time, I performed an "inductive thematic analysis" (bottom-up coding) (BRAUN; CLARKE, 2006, p. 12), in the sense that I was more opened to emerging themes around the study's research questions. After a 
few coding interactions, several themes emerged as part of our effort to make sense of the qualitative data, as depicted in my codebook (Figure 5-8). The most interesting passages were freely translated to English by myself for reporting purposes.

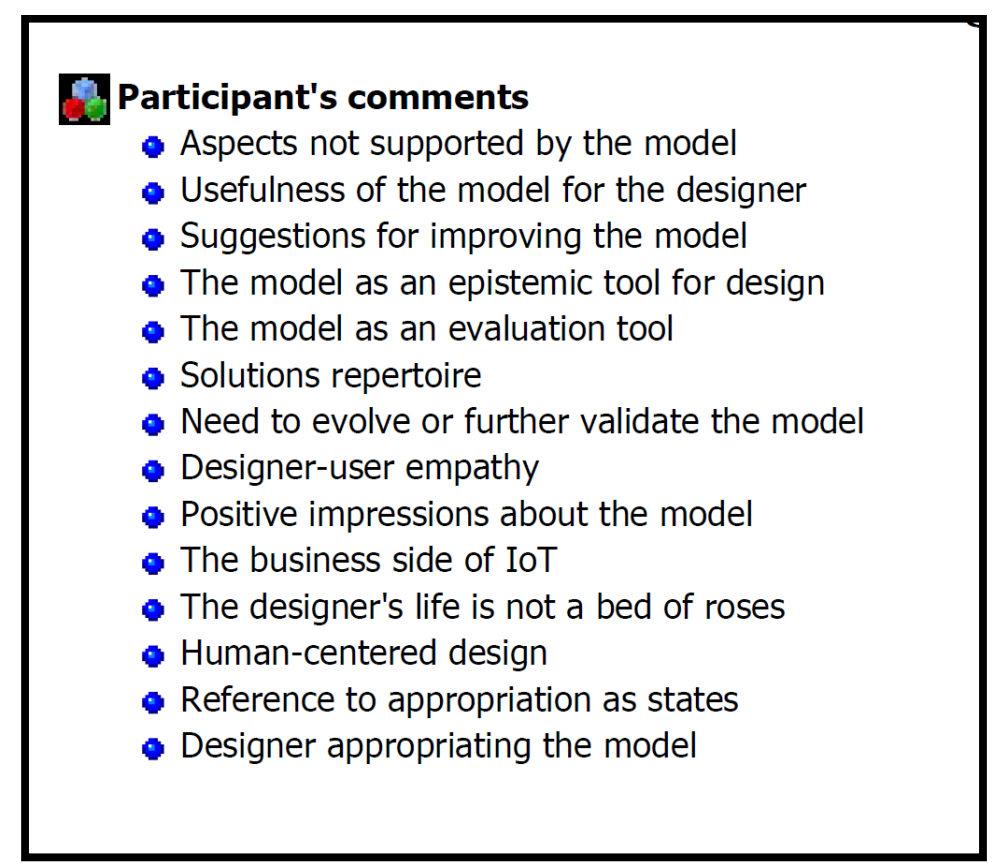

Figure 5-8 - Coding themes appearing in designers' interviews.

\subsubsection{Results}

Overall, the feedback I had about the model was positive. Participants were able to quickly grasp the meaning of the semiotic processes based on the scenario and examples I provided. One experienced participant (P1) associated the semiotic processes with a guide for identifying and refining requirements for the project:

[Researcher] This model, do you think it provides any information or insight that would be useful for the smart light designer?

[P1] Yes, I think a lot. If you think from a design point of view, you have to go back to the requirements. And if the guy thinks, let's say, he has an idea, "oh, I'm going to make a smart light that changes color here", this is a very unique requirement, very simple, right? And then when he starts to base himself on these cases here [pointing to the picture of the model] he will start saying "hey, it's not just changing the color..." If I want a combination, which is the example I gave, l'll have to allow integration with other devices. If I'm subject to a 'rejection' of features and 'matching' with other features, how do I minimize it? Can I give him two ways to get to functionality, the easy one and the hard one? Come on, from the designer 
standpoint, he can review his requirements in this vision, and it enriches a lot. I mean, you solve the project in the requirements, not in the implementation.

Actually, since the pilot sessions, I started to observe that the model triggered the designers' thinking in the direction of thinking about how to support each semiotic process. This is a very interesting usefulness for a model like this: it makes designers think about how to support appropriation in deeper and very concrete terms. Indeed, the same participant later said:

[Researcher] Think about a coworker who you can remember from one of your previous projects. Do you think this model, how do you think this model would help him or her in any sense?

[P1] l'm not even going to talk about a real colleague, when I think of transferring this to the requirements [process] model, I think of everyone who has to develop a smart device. So, I think it's a good tool for you to get..., and the other day l've heard a very interesting word that I think I'm going to start using: to provoke things [laughs]. The guy say "no, I already have my requirements here", and then you say: "so it's okay, take this here [pointing to our model] and classify your requirements here. What was missing there?" So, you provoke the guy to do a reasoning, to think about that thing, to review his requirements, right? I think there is this thing of, in this sense, really provoking, forcing the guy to rethink some things. So, before you talked about a colleague I imagined this, I think everybody would be using it. I really liked it, okay? [laughs]

The way I understand this "provocation" is that the model does not bring any ready-made solution. Rather, it orients the designing process in order to foster designers' reflection about functions and features that could or should be designed in order to support a better appropriation by the end user. Indeed, another participant (P2) said something in this line:

[P2] What I noticed about your model is that it brings different solutions, right? Like, it makes us think about different possible solutions, right? Whether in the 'surfacing area,' in the 'rejection area,' 'matching,'... It makes us think about different solutions within each area of it, right? Like, "hey, what are we going to need to do there in 'combining,' in 'transferring'," you know, it's something like that I hadn't thought about in my project here yet, you see?

Another participant (P4) put it in this way:

[P4] What I think is this: this is the first time that I see a framework like this. I don't know if you know other frameworks. But, as there are no others and you present one like this, you drive the conversation, you direct the conversation, because If you don't have a framework like this, you're too 
opened, you start talking about everything. And it is much easier, when you have a framework, a process like this, for you to drive the conversation towards each point. I think this is the key. So, can the someone disagree? Okay, he can, but let's talk! If you disagree with 'surfacing,' let's talk about what happens during this phase.

[Researcher] It gives an orientation?

[P4] That's right! Orientation, that's the word!

Even though participants were not introduced about the techno-scientific concept of technology appropriation and Semiotics (these were deliberately omitted, as mentioned before), they could identify usefulness in our model's power for describing different "things" that happen while users appropriate technology. In addition, even without being introduced to the formal definition of a "semiotic process," they could understand what it means in unformal terms and relate it to their own experience. This suggests that a background in semiotic theory is not necessary to understand the model because each process could be easily recognized in their logic of ordinary experience. It is interesting to notice that participants often related our examples even to their personal contexts as users. For instance, when I was describing the "expressing" situation with the fish tank example, participant P3 immediately replied:

[P3] Cool! I need a light bulb like this one to do this with my plants at home. I'm forgetting to water them [laughs]. Is that an 'expression'?

This is what I called "designer-user empathy" in the codebook above: when the designer relates or resorts to their own experiences as users to reflect upon the technology they need to design. I could notice this happening with all the participants in different ways:

[P2] So, it's a model that I didn't know about, it made sense when you explained this one about the smart light. Because the smart light, I already knew about it, you know, l've seen it, it's even on "Mercado Livre." But after we followed this model, I managed to visualize in it a greater utility than just a light bulb to put at home to change colors and to turn it on and off, right? I can see that I can put it somewhere else, you know, I don't know, even at my dog's house, you know [laughs]. So, knowing this model, I was able to visualize a greater use for the smart thing.

Similarly, P1 mentioned how he had to negotiate with his wife about an air conditioner remote controller at home because, according to him, they had different needs and expectancies about controlling the ambient temperature, 
causing her "rejection" of the controller they were using at the time. Similarly, P4 has said at a certain point:

[P4] Now, one thing that I see is the 'rejection' that you put in the beginning, what I'm feeling is that the 'rejection' also happens in the end. That is, the rejection also begins and exists after the 'combination.' l'll give you a clear example about this: you have your smart light, you connected it to Alexa and so, it is in the 'combining' there... Everything is working fine. Then, for some reason, there was a software upgrade, there was something and the 'combination' just stopped working. Usually, you don't come back. You say like this: "man, I'm spending too much time with it" And this is happening a lot, not only with me, but with many friends. Man, everything was working fine. Now, my fucking [sic] gate, every time I opened the gate, it turned on the lights, and it stopped working! I just want to open the gate!

Of course, he was speaking about his own experience, not positive in this regard. Most interestingly here is to notice that this is part of the designers' reflection that will be, later on, brought to the technology they will design. The fact that they have spontaneously brought their personal experiences with the technology to this conversation constitute, to my eyes, a strong evidence of designers' reflexivity. They could easily step into their users' shoes. The model was helpful in providing guidance for them to discover some questions and issues that they would need to think about and explore in order to improve the technology they design.

Finally, there were some suggestions for improving the model. P3 mentioned a project she participated where the technology they were proposing failed to be adopted by a team at a hospital because of lack of usability and other contextual (human-centered) difficulties. She concluded:

[P3] You would have to have almost a process there, right, where everyone should follow, in theory.

[Researcher] Yes, there is appropriation in the individual sphere, but there is appropriation in the group sphere, you know ...

[P3] Yes. Because in the scenario you used about the smart light, for example, you are considering the guy there isolated, right?

[Researcher] Yes, it was more an isolated person.

[P3] It's true. [...] It would be almost a "team user design", it would change a little bit.

Because of the kind of technology and context she was working with (medical technology at hospitals), the social and groupwork dimensions of appropriation were critical. Collaborative technologies need to be adopted by the 
group, not only individually. Our model does not emphasize group appropriation, although it can dialog with it, as I will discuss ahead. In addition, the kind of technology she works with poses different challenges to appropriation, including when appropriation is not desirable at all:

[Researcher] Another thing that has also occurred to me while you were talking is that, it is very specific to the area you work with, for example: do you think there are situations where an expression, or a personalization as you are calling it, may not be desired?

[P3] Yes, because for example, if the physician goes there, in the case of my work, I have the possibility, for example, to send notifications to a medical team with an indication that that alert may be false. So, for example, let's assume that the physician will get a device and say, "oh, I just want to receive a notification if it is $100 \%$ sure that this alert is not false." But sometimes, the alert prediction model... There is no "100\%!" So, if he uses it in this way, he often can miss critical events, events that present actual risks to the patient's health. So, certain customizations can compromise the use of the device, for example, it can put patient safety at risk.

As well pointed out by Salovaara (2008), appropriation in occupational health and safety-critical systems may need to be "constrained" since deviations from the strict designed purposes and interpretations of the system may harm or pose dangerous risks. Nevertheless, he thinks that a theoretical model of appropriation is useful even for such kind of systems: "by adopting the user's viewpoint, unwanted appropriations can also be better understood and, if wished, the subsequent systems engineering and design efforts can then attempt to hinder such misappropriations from taking place" (SALOVAARA, 2008, p. 211).

Other suggestion for improving the model was given by P1:

[P1] There is another thing, I don't know if it's worth representing here, it is a little associated with 'rejection,' which is: I found that I can control the air conditioner remotely, I didn't like the device I have and I go there and buy another one. I'm replacing. Before, I had nothing; but now that I know and then I didn't like this one, I go there and buy another one. So, I think there is this case, I found out that I can turn on the lamp there to do surveillance, you know, security, but I look there and "no, I'm going to buy a specific security system", or maybe one a little bit better, with some features that I want this one doesn't have. So, I think there is also this matter of the user learning from contact with technology and replacing it.

I think this has to do with the part of the model related to the abductive appropriation states, that I actually had not presented to the participants. I would 
interpret this situation as the user going from an appropriation state where the current technology has reached its limit to another one that could meet his or her new needs and expectations. The fact that the current device was exchanged by another one is not central from the user appropriation standpoint. Rather, it just reinforces how the designers' lives are not a bed of roses and, sometimes, they can even be unwittingly helping the competition by educating the users and paving the way for them to buy another device.

Other minor suggestions were:

[P1] This "self-expression"25, I would question the name "self-expression" because I would put it as "expression", not "self-expression", because with "self-expression" you restrict it to the person only. [...] I don't know if it would be just self-expression, I think you can implement "environment expressions."

[P2] I believe that 'matching' should come before 'rejection,' because the person "marrying" this product before, falling in love and having this experience with this product, that "honeymoon" experience, the 'rejection' that comes later because of one difficulty or another can be overcome. [Laughs]

[P4] The only comment is that this chart is too much colorful. [pointing to Figure 5-7] [...] You have to do "UI Design" in there in order to... [...]

[Researcher] But what do you think of the colors, is it because it seems unprofessional?

[P4] Dude, it's a bit, it's a bit... Yeah, it's not like that, like this, l'll send you two graphics, one from Gartner and one from McKinsey. You have to "look like these guys," understand?

In a broader view, I think all these suggestions mean designers were actually appropriating our model, putting it in perspective with their own personal experiences and expectations, relating it to the things they have experienced before and already know, pretty much what users do when they first encounter a new piece of technology. This is interesting in itself and suggests that the overall scope of our appropriation model may go beyond IoT technology appropriation.

25 Note: As mentioned, I took the interviews to test some variations of the semiotic processes' names and terminologies. The overall structure and core meaning were kept mostly the same, as described in the study scenario. 


\subsubsection{Conclusion}

The results from this study suggest that our model can be actually very useful to designers in the sense of providing guidance for the design of appropriable technology. This suggestion was posed by all participants that, although limited in number, made several comments that can be considered valuable expert perspectives in most cases. The model could not provide readymade solutions or answers, but provided a powerful orientation by driving their thinking in some directions and issues that opened perspectives towards solutions, functions and features that the technology could or should have in order to be more appropriable. For instance, they were following the semiotic processes (they called them simply "processes," "balloons," "boxes," “areas," etc.) as a "provoking tool" to think about possible concrete design solutions to address each one of them. By doing so, abstract and intangible "design for appropriation" was turned into a more concrete and tangible process, so concrete that even allowed them to talk about it with us. In other words, participants were using our model as a reflexivity tool — an epistemic tool— to guide them in thinking and talking about the design of appropriable technology, and this is powerful in itself.

The way participants were approaching and making use of the model showed another very important aspect that I had not seen before. The usefulness of the model for the design of appropriable technology has to do not only with the model alone, but also with the participants' approach to design. Their approach to design is aligned with a particular view of design, that of Donald Schön (1983), which brings to the first plane of the design practice the designers' reflexivity in dealing with the uniqueness of each problem and situation they face. This and others implications from this study's results will be discussed in the following chapter. 


\section{6 \\ Consolidating and Discussing the Results}

In this chapter, I will consolidate all results, relate them with the more robust theoretical background presented in Chapter 3, and present a final refined version of my contributions as answers to the research questions as posed in Chapter 2 (see Section 2.3).

\section{1.}

\section{A Semiotic Model of loT Technology Appropriation}

In Chapter 2, I framed appropriation as one of the most relevant problems of the design of interaction for IoT technology. Our research questions on appropriation were (Section 2.3, Box 2-1):

- R1) How do people appropriate IoT technology?

- R1-A) What does "to appropriate" IoT technology mean?

I also proposed that a theoretical descriptive model of appropriation can answer these questions and work as a useful epistemic tool for designing for appropriation. In this section, I describe a refined version of the semiotic model of appropriation introduced in Sections 4.4 and 5.1 in order to clarify its foundations with the theoretical background provided in Chapter 3 and discuss the main implications of all my previous study's organized results.

Ontologically, a model can be a description of a fictional (ideal) abstract object or phenomenon (a representation of an ideal object, process, phenomenon, etc.), which serves some cognitive function regarding the model itself or its target (FRIGG; HARTMANN, 2020). A descriptive model (see Section 2.3) is an ideal description of something, an ideal description of IoT technology appropriation by end users in our case. A description is ultimately a set of statements about its object. A descriptive model is composed of a set of concepts (its "vocabulary") and a set of relations that concepts may have with one another (its "rules"), forming a modelling language. Given some real object "X", descriptive models can be used in at least two ways: (A) The modeling language can be used to 
produce one (or more) ideal descriptions of observed instances of X. Ideal descriptions are useful because they separate known and important dimensions of the observed object from other known and unknown factors not relevant for some desired analysis or purpose; (B) We can generate multiple descriptions of objects independently of having observed them or not in reality. This enables us to ask "WHAT IF?" questions, which are crucial to every design process. When combined, (A) and (B) makes descriptive models work as powerful epistemic tools (cf. BOON; KNUUTTILA, 2009).

In our case, the object of study " $\mathrm{X}$ " is the appropriation of IoT technology by users. (A) was accomplished with our "ideal" scenario as presented to the interviewees in study 6 (Section 5.3)-see Box 5-1. Based on that single scenario with "canonical" examples of each semiotic process users perform while appropriating IoT technology, all participants could quickly grasp the gist of what the process means in pure "ordinary logic" terms, without the need of any thorough previous training in Semiotics. (B) in turn was accomplished by the participants themselves, when they started to reflect and speculate on possible design solutions for supporting each process in the imaginary scenario and their actual IoT projects. Will their solutions work? Some of them might actually work and were examples from other devices and experiences they had, a sort of repertoire they bring to their design practice. But the best answer is I do not know, my model will not answer this, and I think no other will, due to the inherent complexity of designing complex technologies. "It depends" is the best possible answer because each project, each device, each technology, each user, each context, each business goals and market pressures present their unique challenges, constraints, and possibilities. What the model does help though is in guiding designers in thinking about a certain set of concrete aspects (requirements, if you like) that, if addressed during the design, will increase the "appropriability" of the technology. In other words, it helps designers frame certain "WHAT IF?" questions that can turn the designed technology more appropriable.

For instance, "what if users reject our technology? And what do we do to avoid it?" "What if users want to combine it with other devices? And how do we make it possible?" These were some questions posed by the interviewed designers. To find the proper solution under each unique set of conditions inherent to a specific design project is left to the reflexivity of the designers to answer in 
practice, to their "reflection in action" (SCHÖN, 1983). The model is one more tool, an epistemic tool that can be powerful due to the provision of a new set of vocabulary and relations to enable designers think and talk about appropriation with a richer level of details and sophistication. The richer level of details and sophistication is provided by the theoretical foundation of the model.

\subsubsection{Theoretical Derivations and Working Hypotheses: Semiotic Idiolects, the Personal Signifying System, and the Poetic Function of Technology}

I will now build upon the theoretical foundation described in Chapter 3 in order to propose a number of working hypotheses that are required to articulate the main findings of this thesis. They are not general semiotic theory but locally consistent concepts articulated here in order to support the development of this thesis within our scope of investigation. I am going to start by generalizing Eco's concepts of aesthetic idiolects (see Section 3.5) "by induction" in terms of semiotic idiolects to refer to the same phenomenon in different spheres-a work of art (aesthetic idiolect), an individual (corpus idiolect), an artistic movement (movement or period idiolect). Semiotic idiolects are like the tip of the iceberg, the perceivable manifestation of an entire underlying individualized signifying system - the individual's "personal signifying order" (see Section 3.4) that one uses to express oneself and interpret the world. As an instance of the signifying order, a signifying system is analogous to a signifying order in the general structure, properties and rules, but takes place at the individual level. Like an idiolect to its mother language, the personal signifying system is developed by each individual as a person is exposed to culture, experience different portions of the same culture and even different cultures during his or her life. Therefore, a personal signifying system is determined by one's idioculture (FLOROS, 2006) ${ }^{26}$ resulting from the total sum of an individual's exposure to culture(s). It still works as "an order," an orienting principle structuring and governing signification processes, but in an idiosyncratic fashion, which allow us to distinguish two individuals from the same culture by the way the speak and express themselves,

26 I am borrowing the notion of idioculture from translation studies to mean "culture of one specific person" (FLOROS, 2006, p. 336). Notice this is rather different from the more popular concept used in sociology, where it means the unique culture of a small group (cf. FINE, 1979). 
for example. Finally, as human beings are the very agents of culture, the personal signifying system is continuously and dynamically influencing and being influenced by the signifying order while both evolve and change.

The introduction of the concepts of semiotic idiolect and personal signifying system (or "personal signifying order" reflecting one's idioculture) above are local theoretical derivations from existing Semiotic theories. I can now transpose these concepts to the problem under investigation of interaction with technology, in general, and with IoT technology, in particular. A new technology works like an "aesthetic text" in Eco's terms. Its reason of being is to introduce some innovation, a change in the state of affairs, hopefully towards a better state. And it does so by deploying an artifact which is based on and created from a very particular understanding the designer developed about the tasks or practices the technology is intended to support. Moreover, this understanding needs to be communicated to the users and will be translated in a unique interface language. This is the gist of the metacommunication phenomenon occurring through interfaces and it will be successful to the extent that the communicability works, that the interface communicates efficiently and effectively the design logic through the interface language. The design logic and interface language are, as we know, a photography of the designer's semiosis at a certain time, that will be frozen and encoded in a computable programming language so that it runs in a Turing machine. The principles ruling the design logic comprise the semiotic idiolect of the technology, a photography of a portion of the designer's signifying system at design time.

At the same time, users have their own signifying systems and semiotic idiolects. Users' signifying systems partially overlap or intersect with designer's, because they are under the same or overlapping cultures and signifying orders, what makes it possible for them to communicate with, at least, some partially common codes, e.g. natural language for example. However, the code used in the technology, once attempting to introduce innovations, challenges the established code by introducing new signs and meanings, by design(er). This new signs and meanings must be grasped by the user, what will happen by abductive interpretations the users construct and put under evaluation during technology use, new hypothesis about the interface code and the semiotic idiolect behind it. There is no guarantee that users' interpretations will coincide or even be compatible with 
the designers' intended meanings, as we know this is the source of all sorts of interaction problems. Nevertheless, wrong or right, it is the meaning constructed by the users that will be incorporated into their signifying systems, as extensions of their known codes and upon which users will build up their practices. In other words, this is when users have appropriated the technology.

Now, the classic Jakobson's communication model (sender-channelcode - message - receiver - context) can be extended in order to account for the technology appropriation phenomenon to highlight most of the action that happens in the users' signifying systems. In that sense, Figure 3-1 presented in Section 3.1 can be extended to incorporate the role of semiotic idiolects and signifying systems into the communication process as depicted in Figure 6-1:

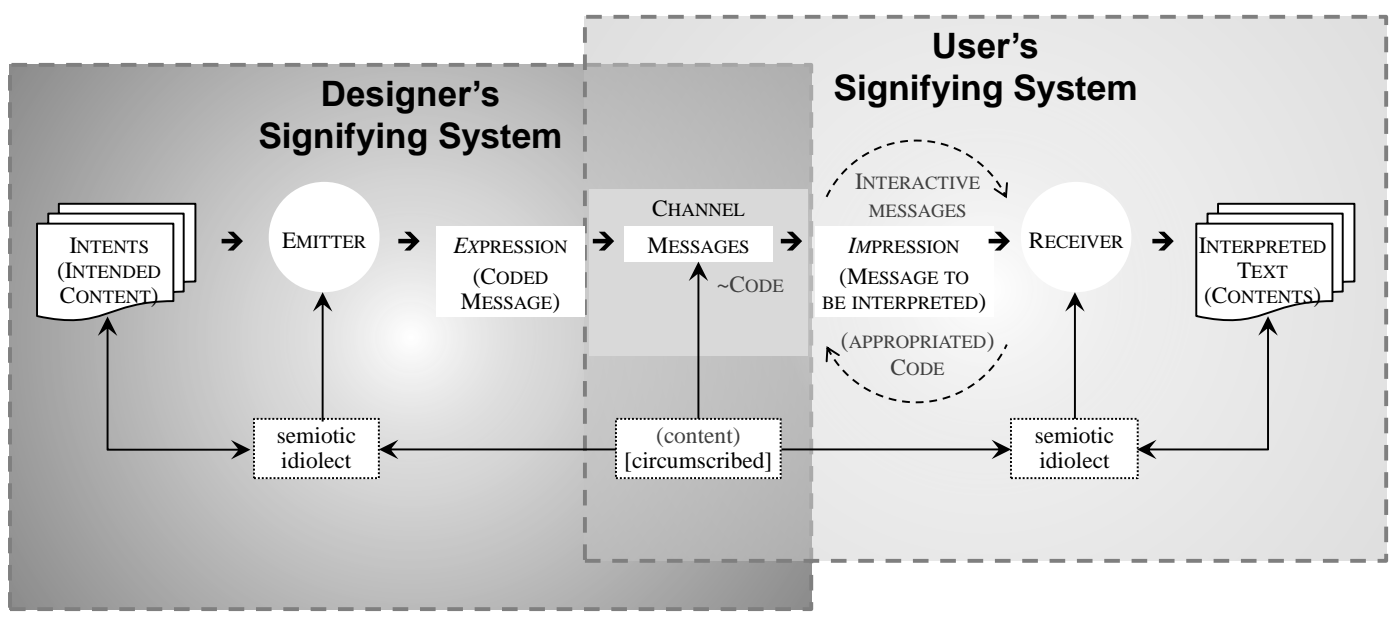

Figure 6-1 - An expanded model of the communication and design space for semiotic engineering representing the one-shot metacommunication message from designers to users. Adapted from (ECO, 2017, p. 129, Fig. 29).

The illusion that there is a common code shared by both designers and users when communicating through interaction must be dropped once and for all. Both parties have their own signifying systems and "speak" their own semiotic idiolects. Of course, there is a smaller or larger subset of common codes, but expanding the users' code with signs provided by the designers is, precisely, one the critical functions of the new technology, from an appropriation perspective. The messages sent by the technology channel have two different facets then, the message as expressed by designers and the message as impressed to users. Moreover, these messages need to play a poetic function to some degree in the 
sense that they need to call users' attention towards the message being delivered itself - the interface code and the underlying logic of design, that is, the gist of the metacommunication message. As a whole, the technology needs to work as an aesthetic text in Eco's terms in order to trigger the appropriation of the new codes deployed by the designer at the users' side. And by "reading" this "text" users will abductively mutate their working signifying system by incorporating new codes derived from those sent by the designers. In Eco's words:

"Ultimately, the aesthetic text presents itself as a model of 'pragmatic' relationship. Reading an aesthetic text means at the same time: (i) to make INDUCTIONS, that is, to infer general rules from isolated cases; (ii) to make DEDUCTIONS, that is, to check if what was hypothesized at a certain level determines the subsequent levels; (iii) to make ABDUCTIONS, it's worth saying, to put under test new codes through interpretive hypotheses. Therefore, all inference modes work together in the aesthetic text." (ECO, 2017, p. 233, my translation)

The passage above is about the reading and interpreting of an aesthetic text, and Eco was probably referring to a work of art. But it could be about the reading and interpreting a new technology. And he continues:

\begin{abstract}
"From the receiver, it is asked a responsible collaboration. He should intervene in the sense of fulfilling the semantic gaps, of reducing the multiplicity of meanings, to choose his own reading paths, to consider many at the same time-even if mutually incompatible - and to reread the same text several times, always managing contradictory suppositions." (idem)
\end{abstract}

The semiotic appropriation model was described as the main results from the diary study in Sections 4.4 and 5.1 with three main components: appropriation as provisional states of interpretation, breakdowns triggering users' abduction, and a set of seven semiotic processes as a stabilizing process in between two appropriation states (see Figure 5-6). What this model actually describes is the way by which users elaborate and rearrange their signifying systems in order to accommodate new signs presented by a piece of technology that will be incorporated into their set of known semiotic codes by means of interpretation. The seven semiotic processes are interpretive processes by which users build associations and relationships of the presented signs with each other and with the signs they already know, the only possible way of interpreting something by semiosis. Each interpretation is a set of hypotheses, that may or may not hold in 
light of new evidence that will reinforce or refute them, depending on how robust they were.

\subsubsection{The Emergence of Users' Interactive Idiolects}

Our theoretical background immediately answers research question R1-A: "What does "to appropriate" IoT technology mean?" And I will do so by “appropriating” Dourish's (2003) words cited before in Section 3.1:

"Appropriation is best thought of as the incorporation of technology not simply into practice but into systems of meaning." (DOURISH, 2003, p. 487, my emphasis)

Which "system of meaning" is Dourish talking about? According to semiotic theory, we saw in Chapter 3 that a signifying order is a "system of meaning" in the cultural level, which can be instantiated in the personal level in what I called a signifying system above (Section 6.1.1). The incorporation process takes place when the designer's metacommunication message goes through and is elaborated by the user when one tries to interpret its carrying signs in relationships with others pre-existing signs that one knows. Throughout this process, new relationships and meanings are constructed in and by one's signifying system. The new signs and relationships can, potentially, disturb the entire system, provoking also the revision of pre-existing meanings and relationships. Ultimately, this leads to a changed signifying system, enriched with the new meanings and relationships that emerged during this process, which constitute new codes that the user learns how to "speak," in other words, to new semiotic idiolects. In this case, I am referring to just a subset of users known semiotic idiolects, their interactive idiolects, "a personal way to use the [technology's] signification system to achieve communication" (DE SOUZA, 2005a, p. 139). The final output of this process is a revision of the user's code by the incorporation of new signs, which get associated to existing signs in new relationships and accommodate while users reorganizing their signifying system.

How does the appropriation process unfold? This is the answer to question R1: "How do people appropriate IoT technology?" Technically, the interpretation process unfolds by unlimited semiosis, and is bounded by pragmatic conditions of the users' contexts, halted when the current meanings accommodate and become 
able to be used for current goals, or users run out of resources that would allow them to elaborate it further (time, patience, background knowledge, etc.). Halting however is always temporary, since codes will be put into test in actual use, and the entire process is subject to re-start whenever a new sign (e.g. an unexpected response that does not align or make sense within the existing hypotheses) is able to trigger the process again.

From a breakdown to a new appropriation state, there are stabilizing processes. These processes are semiotic because they comprise actions conducted by the user that actuate in their signifying systems and affect their semiotic idiolects, that is, the set of all interactive languages that users know how to "speak." Once a new sign is incorporated into a user's signifying system, his or her interactive idiolects are enriched, and the change is both a consequence and a sign that a new appropriation state has been reached. To be incorporated into user's signifying system means to be dynamically accommodated in a logical space of preexisting signs (that is, a code) that the user already knows, finding room and a fit in between other signs by creating new relationships with them. Naturally, a sign can only be incorporated into one's signifying system as interpreted, since it is the very process of interpretation that attaches meanings to the new sign, meanings that are "materialized" by the creation of relationships to other signs. Interpretation is then the pragmatically bounded unlimited semiosis by which meanings are associated to new signs. An interpretation state is a provisional and dynamic accommodation of the new signs into users' signifying system, temporarily stabilized with the creation of new relationships that are traces of their semiosis process that stopped when a satisfactory interpretation has been found. Satisfactory means that it (the interpretation) "works" for the current goals and contingent circumstances users' face at a certain time.

I identified seven different semiotic processes that are part of the stabilizing phase leading from one appropriation state to another. Each process is part of the very dynamic, intricate and interactive larger stabilizing process that characterizes users' sense making and semiosis. One way to visualize these processes is depicted in Figure 6-2, which represents all semiotic processes in an organized space. Once the metacommunication one-shot message is delivered, users will break it down by means of semiotic processes. Along the vertical dimension, processes on the upper part are targeted at making sense of the technology "as 
designed," that is, they try to uncover the designers' meaning inscribed in technology. Towards the bottom part, things get more out of the designers' control, and these processes are related to the interpretations users build that can align with the designer's vision (the "range of purposes that fall within this vision" part of the metacommunication message template - see Section 3.1) or not at all (that is, completely new meanings and purposes unanticipated by the designers).

Along the horizontal dimension, processes closer the left side are more related to the "internal (designed) meanings" of the technology, that is, those inscribed in the technology by the designer. At the other hand, processes closer to the right side include "external meanings," that is, meanings that are more part of the users' world and that they will relate with the technology, such as other technologies that they use and their contextual meanings. Finally, all processes are regulated by the users' (and the designers') pragmatic conditions, that is, the set of contextual conditions that limit users' semiosis, such as users' personal goals, available resources, abilities, trust they have on the brand and/or the technology, values, etc. It is important to highlight that these conditions can be external to the technology but are not external to the appropriation process since they are part of the background meanings users bring in to their interpretations. In particular, some of them have been identified as critical for the IoT, such as trust which is related to privacy and security (cf. ATZORI; IERA; MORABITO, 2010). For instance, I observed in the diary study people who showed to be suspicious with the Echo Dot voice assistant because he thought that "it's a product meant to buy more products" (P10). During his interview, P10 said:

"I don't think it was their intention to make a product that would serve for speech recognition. I mean, maybe it was a part of selling the products more through Alexa." (P10, 12/19/2017)

Similarly, others participants showed judgements based on previous experience they had with a brand and other technologies. Whether they are right or wrong about those judgements is beside the point, my point here is that whatever they know or think about the brand or the technology will be in the table and influence their interpretations pragmatically. Yet, notice that pragmatic conditions are also related to "meanings" and as such are always subject to change. However, they are "deeper" and "more crystallized" meanings that I will 
assume that the interaction, at first, is not trying or able to change. Indeed, I think these meanings can change and it actually does happen when, combined with other social factors, technology changes our culture by instilling new meanings, goals and perhaps even new values in our society. Nevertheless, this is a more complex semiotic phenomenon that I will not deal directly now.

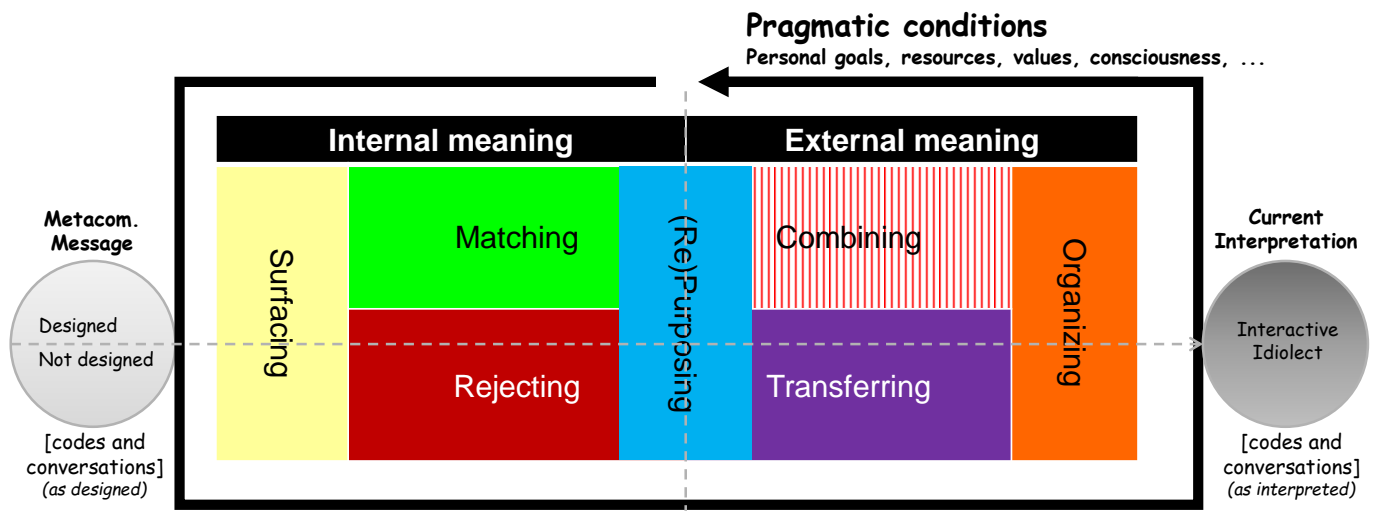

Figure 6-2 - The semiotic processes of the semiotic appropriation model.

\subsubsection{Discussion and Some Implications for the Design of Appropriable loT Technologies}

I will now explain each semiotic process further as I discuss some implications for the design of appropriable IoT technology. The metacommunication message forms a conducting line between each stage and also brings theoretical logic and coherence to our model. Other semiotic (in general) and Semiotic Engineering (in particular) concepts will be used throughout the way but they will gravitate around this core idea.

\subsubsection{Surfacing}

Surfacing presupposes an active role played by the user as the process agent. In other words, the emergence of the metacommunication message depends on users employing efforts in bringing it to the surface (e.g. "digging" for it). The outcome of this process depends on users' initiative, that they do not be passive at one hand, and that designers do not see them as such at the other. This perspective aligns with Donald Schön's reflection-in-action model of design (SCHÖN, 1983). Although Schön's scope refers to professional design activities (activities 
performed by professional designers in different professions), its applicability to design activities performed by non-professional designers such as end users has also been explored in the context of EUD (CAO et al., 2010). But reflective conversations with materials (SCHÖN; BENNETT, 1996) are performed by users all the time when interacting with technology, especially upon breakdowns. Users are thus reflective practitioners on their own, within their limited goals and scope of designing their own practices and infrastructures that they want to work with. Indeed, the name "surfacing" was inspired by Schön's frequent use of the term, for example when describing reflection-in-action:

"[Reflection-in-action] consists in on-the-spot surfacing, criticizing, restructuring, and testing of intuitive understandings of experienced phenomena; often it takes the form of a reflective conversation with the situation." (op. cit., p. 241-242, my emphasis in italics)

In our appropriation model, surfacing is a semiotic process that denotes users digging both the designer's understandings encoded into the system (the designer's deputy) and the user's own intuitive understanding thereof. A straightforward implication to design is the critical role of good communicability to support this process. Schön developed the concepts of interpersonal theories of action that drive a practitioner when facing a unique complex design problem and can lead to different degrees of success or failure of the endeavor (ibid., chap. 7). One approach is to engage in what he calls "mystery and mastery," a strategy based on controlling the other part, hiding information and self-protection, which usually limits the scope and power of reflection-in-action and, as a consequence, the quality of the resulting work. Another more fruitful one according to Schön is based on what I would call "trust and transparency," where practitioners engage in surfacing private dilemmas, in giving and getting correct information and in creating the conditions for free and informed choice of all parties, which lay necessary conditions for reflection-in-action to flow. The latter theory of action aligns with good communicability principles and I can deduce that designers should adhere to this theory of action in order to provide good communicability.

This stage is very important because for many users, sometimes the first impression is the last impression. Setup problems, so common in the current stage of available IoT devices, are likely to leave deep impressions in users' interpretations that may be hard to be changed even when the problem is 
overcome. As one of our participants of the diary study has put it when struggling with the initial setup process, "the path to smart homes is not without obstacles" (P10). From a design point of view, it is important to notice two aspects. First, the process of reconstructing the message is entirely interpretive and will depend on both the technology signs presented to users (designed and "un-designed"- that is, intentionally or unintentionally designed by designers) and users' context and background when interpreting these signs. Users will bring to their interpretation previous experiences with similar technologies (e.g. users of Google Home evaluate Alexa comparatively), conceptions and preconceptions they have about the brand (e.g. users might think Amazon is always trying to sell them stuff), and contextual circumstances, like the time they have available or psychological state at the time of their first interactions (e.g. students on the final part of the quarter might be less prone to explore and may thus leave significant parts of the message simply blank or unknown). Second, as a consequence of the former, the message users reconstruct is not necessarily the same the designers have emitted. This reinforces the importance of the design of good communicability in order to generate more assertive interpretations into users' mind. In that sense, it becomes clear that the metacommunication template can be very useful to designers as a guideline in order to eliminate blank gaps and prevent users to misunderstand them, improving the possibility of users understanding them right.

\subsubsection{Rejecting}

Rejection turned out to be a strong concern to our interviewees in study 6 (Section 5.3). Naturally, designers do not want their messages to be thrown away by users, wasting their efforts. Misinformed rejections are due to communicability problems that should be addressed by a good communicability design, just like the surfacing support. Users might reject a metacommunication message because it contains too many gaps and inconsistencies preventing them from developing any solid or trustworthy judgement about the technology. When designers do not tell users something, users will fill in the blanks by themselves, often in negative directions (e.g. by omitting instructions, a designer might be taken to say "I expect you should figure this out by yourself" and one user may reply "sorry, no time for that now"). I observed such cases with the occurrence of "I give up" breakdowns, 
usually preceded by episodes of "What happened?" and/or "Why doesn't it?" To prevent such situations, designers should try their best to express themselves properly and get understood. That is, they should make all the possible efforts and use all possible resources to get their message through and the way to do it to improve the interface communicability.

Even if designers do good communicability, users can still reject their message and that is what I called well-informed rejections before. This is signaled by the occurrence of "Thanks but no, thanks" breakdowns that I observed in the diary study. Although these cases may point to possible misalignments between designers' general beliefs about their users and the actual users' profiles (goals, needs, preferences, and contexts...), it can be the case of just a local or temporary misalignment. One example is when user's semiosis has not evolved yet to a certain advanced use case or configuration scenario that the designer had predicted before and provided appropriate support for it. In this situation, when facing an advanced interface sign, users may not dig into it or use it in practice but they will keep it for their "semiotic records," paving the way for future explorations and use when they may want or need it. Similarly, it may be the case of context fit, when users value a certain feature, but due to a certain contingent situation or required work in a certain scenario, they prefer not to deal with it at that time. Anyhow, the semiotic material is consumed and these rejections can be turned into something else as the unlimited semiosis unfolds, what has interesting implications for design.

The more subtle and perhaps more important take-away message from rejecting is that designers should not "reject" it, but rather embrace it as a natural part of user experience. In this sense, technology design can always support wellinformed and contextual rejections. A good example of such semiotic strategy can be found in systems or even in some plain old technologies, such as the remote controller in Figure 6-3. The advanced configurations are hidden and probably will not be missed in most of the use cases. Users ability to reject them probably increases the easiness and comfort in using the device. However, users in need of or looking for more advanced features (e.g. in more advanced states of appropriation) will have relatively easy access to them, without compromising the overall experience for the more frequent use cases. 

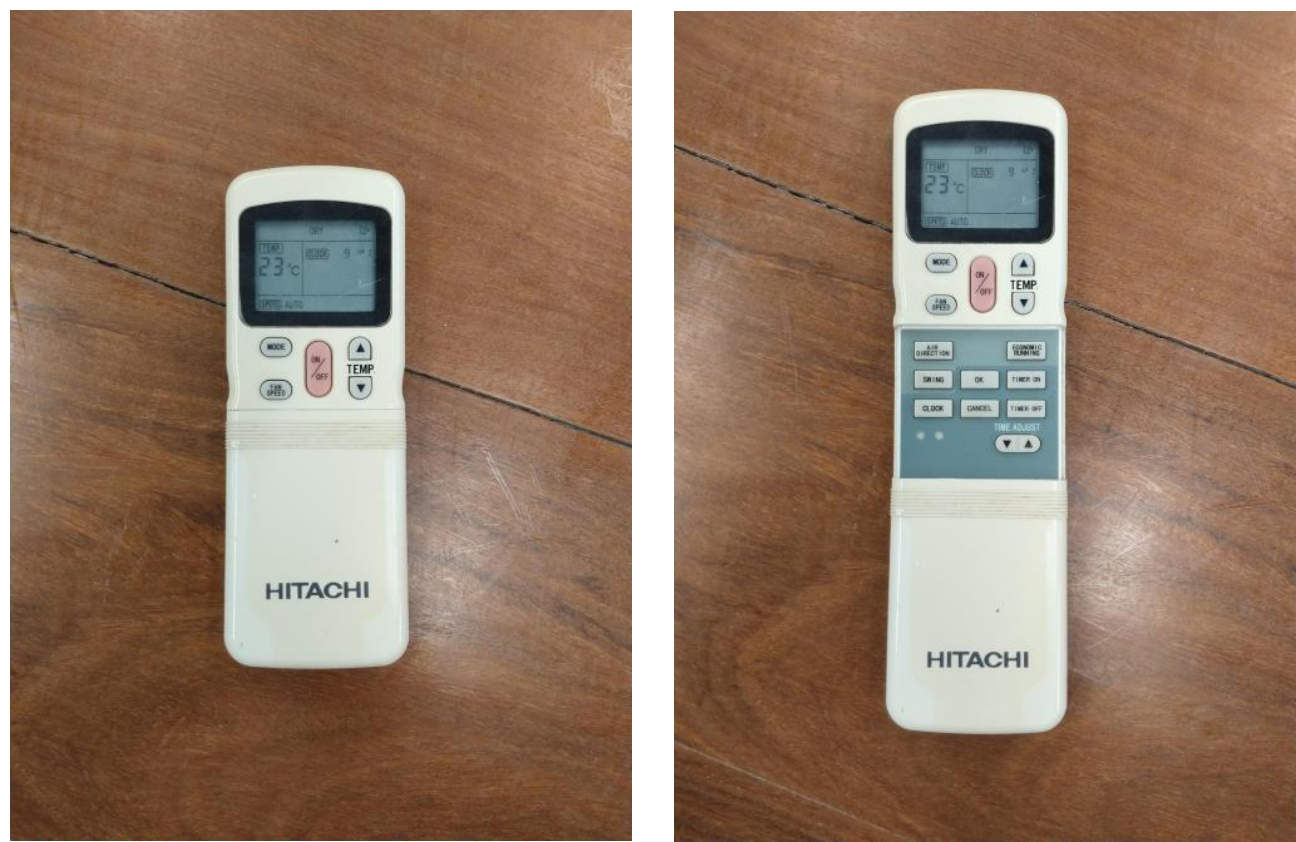

Figure 6-3 - An example of a rejection supportive interface: advanced configurations can be rejected by users not willing to deal with them in certain situations. Nevertheless, they are always accessible without compromising user's experience for the more frequent use cases. (Photos taken by the author at the Gist Lab, PUC-Rio, Brazil @ BAC 2020).

\subsubsection{Matching}

A match is certainly a sign of a successful user-centered technology design by designers, where their evaluation of users' goals, needs and preferences match users' actual ones. Notice that, first, users needed to grasp the metacommunication message to some extent (that is, they need to surface the technology before) in order to be able to identify a match. A match means users have identified themselves with parts of the designers' metacommunication message (some anticipated users' goals, needs, preferences, and contexts and the solutions to them that the designers have provided) and took it. For example, using voice assistants to play music and a mobile phone to remotely control lights were the most common use cases adopted by all participants in our diary study with smart devices.

Two important aspects to be noticed in matches. First, it is usually associated with previously existing practices at the users' side. That is, with activities that users were already accustomed to perform using some other previous generation technology or infrastructure. For example, playing music and 
turning on/off lights are ordinary activities presently undertaken with mobile phones and wall switches without any IoT technology, respectively. IoT devices came to replace some or all interactions involved in these activities. In order to be recognized by the user, a certain set of signs already familiar to them should be present, allowing a smooth transition from old to new practice. The process can be so smooth that it is almost unremarkable if it were not for our characterization grounded in the metacommunication process. The use of iconic signs like media controls and light switch buttons are usual interactive resources present in the companion apps of Alexa and the LIFX smart light. They are intended to help users bridge the transition to the new technology smoothly. Because of this smoothness, a match is characterized by the absence of breakdowns.

The second relevant aspect of a match is that it was previously designed, often by the study of users' existing practices in a user-centered design fashion. In that sense, a match is a sign of a successful design which should include, among other qualities, good communicability. I would say that a match is the hallmark sign that a successful user-centered design was realized, at least in part. Designers did a good job in getting to know their users, designing a solution to at least some of their needs, and telling the users about this solution they designed. Often, this is achieved by carefully designed use cases that users are able to perform with the technology "out of the box." But designers should notice that a match does not only happen in the functional level. Market fit and value alignment will contribute by preventing rejection because the match is based on user identification with the metacommunication message. Furthermore, there may be different layers or levels of match. In the level of fine-grained functionality, low-level matches are easier to find because they are both easier to design and less dependent on contextual factors. High-level matches (e.g. a device as a whole) are harder to observe and depend on low-level ones first.

From a communicability and semiotic perspective, a match is governed by Firstness, the representation principle of likeness in Peircean terms, when users spot signs in the interface that resemble things they already know, such as light switches and media player commands. Even so, there are interesting opportunities for communicability strategies to promote a match. A case that was reported by more than one person was using the Flic button and their phone (with a Bluetooth speaker) or Alexa to listen to music during shower. This idea was advertised in a 
promotional video of the Flic button (SHORTCUT LABS, 2017), which was showed to the participants during the kick-off workshop. Later, participants explicitly reported having tried this idea because of that video. The Firstness was broken in two semiotic steps: first, the video presented a situation where users would identify themselves, that is, taking a shower with music; later, the new device was shown, enabling the video character to control the music with the Flic button under the shower. In this sense, the promotional video was a powerful metalinguistic sign, which is in disagreement with Ferrari et al. conclusions that metalinguistic signs do not apply to IoT interaction design (FERRARI; BIM; AQUINO, 2017). In my vision, they do apply and can actually take more sophisticated forms because modern technology (IoT included) opens up a wider media space for them to be conveyed, such as videos, holograms, etc.

Matching and rejecting are in a certain sense a natural counterpart of one another. They both depend on a reasonable portion of the metacommunication message to be surfaced; they both break down the metacommunication message into chunks that will then help the user to organize their interactive discourses; they are both governed mainly by similarity, the Peircean principle of likeness or Firstness, differing only in the final outcome, that is, a match when a similarity is spotted or a (temporary or local) rejection when not (in case of well-informed rejections). More elaborated meanings will be developed in the other following semiotic processes.

\subsubsection{4. (Re)Purposing}

As mentioned before, (re)purposing has to do with top-level communicative intents (cf. DE SOUZA, 2005a, p. 123-125). Purposes are top-level communicative intents that are tied to strategic goals. As such, they determine the other levels of interactions (communicative acts), such as the operational level (that is, the detailed step-by-step approach by which a certain goal will be met) and tactic (the intermediary level between the strategic and operational goals). If matching and rejecting are related to the principle of Firstness, purposes are related to the principle of Thirdness, in the sense that a purpose is a third meaning ascribed by the user to the technology, the first being related to the practice itself and the second being the technology mediation. In this sense, purposes 
presuppose more elaborated meanings, such as justifications and reasons for performing an action in a certain way rather than another, as we saw with the examples provided before.

A purposing episode is anticipated by the designers, in which case it is similar to a match, occurring at a higher level (perhaps purposing is always preceded by matches). A repurposing happens when users take the technology as designed and use it in tasks or contexts for which it was not originally designed for. In other words, users take the designers' metacommunication message to mean something else, which they consider personally useful and valuable. The difference between the two cases is just that in the latter case, the purpose was not anticipated by the designers but constructed by the users themselves. As they evolve, repurposing can materialize into concrete customizations of the technology e.g. as a security device, the smart light can be programmed to turn on at certain times in routines called "scare away would-be robbers." In addition, users can find out or learn new purposes for the technology from other users, which suggests the importance of users interacting with other users and sharing their discoveries with others. From a design perspective, an entire set of sharing functionalities can be provided as part of the technology in order to foster the discovery and adoption of new purposes. Sharing can be targeted to other users but also to the designers themselves, who can incorporate some of the users' findings in newer versions of the technology, supporting the "design from appropriation" mentioned by Carroll in her macro-model of design and appropriation cycle (CARROLL, 2004).

I mentioned before that (re)purposing is characterized by the absence of breakdowns, similarly to matching. When created by users, new purposes not anticipated by designers have to do with what is usually called an "Aha!" or "Eureka" moment (cf. KNOBLICH; OELLINGER, 2006), or more technically an insight users have. In studies of cognition and problem solving, insights refer to both "a state of understanding" and "the sudden emergence of an idea into conscious awareness" (SCHOOLER; FALLSHORE; FIORE, 1995, p. 560) and are related to applied creativity and innovation (KOUNIOS; BEEMAN, 2009). Throughout the entire diary study I received reports of people having their "Aha!" moments that seemed to be important moments during their appropriation processes. For example: 
I actually found out the reason for the unexpected behavior for the LIFX light bulb; I had enabled the Day \& Dusk functionality. As for connection issues, I had have (sic) to force stop the LIFX app like once in the prior week, but overall, much more consistent than before. (P1)

For my Wemo switch, I was able to have my smart plug turn on every hour. This is great because I have a fish tank that is connected to the smart plug, therefore it allows me to turn on the light every hour and not manually turn it on, allowing my fish to have light occasionally. (P3)

[P5] [...] Actually, in the beginning, I messed up, I think I mentioned recently, I messed up the location setting for the automatic turn on and off when I exit...

[Researcher] Oh yeah, you told that. So, you just realized at the end that it was broken?

[P5] [laughs] So, I was leaving, coming back, thinking that it was automatically turning off but it was on all day [laughs]. I thought it was so cool, I was like "oh, look it, it turns on when I get here."

[Researcher] So, how did you realize that?

[P5] I was looking through the IFTTT applets and I entered the configuration and I saw the..., because you know it tells you, the IFTTT applets say last time they run?

[Researcher] Oh, you have like a log of executions, something like that? Oh, no, no, no, you are just checking on the applet cover, I see.

[P5] On the cover, yeah, and that's where I saw for the exit one it said "never run" and I was like "what?" So, I remember I left my house and then my phone just got a notification, and I was like "oh, it's the light" but it wasn't.

I changed the physical locations of both the Flic and the Amazon Echo Dot. I wanted to try out new configurations for both of these that will be convenient for me and won't take up space or clutter my desk like they were before. The flic works well on the nightstand since I am able to easily push the button as I go to bed to turn the lights off instead of having to get up. And the Echo Dot is now on top of my drawer, which is close to my desk still but not in my way. (P7)

As we can see by the examples above, "Aha!" moments are very rich moments for the user in semiotic terms. I think they indicate an accommodation on their signifying systems that includes and rearranges a lot of semiotic material that they have been exposed to. In our appropriation model, they correspond precisely to the introduction of the novelties, the new hypotheses (explanations, concepts, relationships, and the like) that are able to connect or explain a large set of signs that were waiting for sense. It looks like Science knows very little about how these moments are brought about, which is a large and borderline field of studies of the human intelligence (cf. STERNBERG; DAVIDSON, 1994). I think "Aha!" moments are breakdowns counterpart, but their subjective nature, often 
serendipitous, makes it hard the scientific investigation of them under the current cognitive approaches. What I can say now is that they are fully compatible with our semiotic model, which although cannot and is not intended to explain them, embrace them in the sense of embracing breakdowns, providing descriptions able to considerate the insights user have during their appropriation of the technology. The clearest cases of "Aha!" moments seem to be associated with (re)purposing, a more elaborated process in terms of including or grouping several instrumental meanings (interface and contextual signs) under higher level meanings (top-level goals).

\subsubsection{Combining}

Combinations are an important process that I observed with considerable frequency. The outcome of this process is an enriched metacommunication message, where signs from other devices and apps are combined with the original technology ones. Combining greatly enrich the scope and power of IoT technology and is the process by which the "range of purposes that fall within a device's vision" is amplified. Combinations usually depended on features that were previously designed specifically for this purpose and to support it. These features can take two forms: they can be explicit and direct combination, such as in-app options for integrating other devices; or they can be indirect, by means of a combination "gluing" tool such as IFTTT. I highlight that the latter strategy is advantageous to both designers and users. The designer can spare the efforts of building explicit compatibility with every single device or technology that exists or to appear, which tends to be specially challenging, if not impossible, with IoT growth and popularization. The user, besides gaining access to more possibilities of combinations, can rely on an orienting structure, a sort of template to build combinations that can greatly facilitates the combining process. This is precisely the case with IFTTT - "If This Then That," the popular online free mashup building service based on trigger-action rules that were used in the diary study.

Regardless of the combining strategy made available, we can say that they were anticipated by the designers. Technologically, combining is enabled by APIs, the element in between two devices or applications that enable them to talk to each other. Device designers have anticipated the need for combining by 
providing APIs that they made available to integrate their technology with other devices and apps. APIs are also interfaces-Application Programmatic Interfaces-and, as such, also convey a metacommunication message (cf. AFONSO, 2015; BASTOS; AFONSO; SOUZA, 2017; DE SOUZA et al., 2016, cap. 3.4). However, the receiver of this message is not the end user, but a thirdparty developer building another smart device or app that integrates with the original technology. If combining is so critical to IoT as it seems, as performed by all user participants in the diary study and identified by all designer interviewees in study 6, this poses new challenges to the design of IoT technology in the subject of designing APIs. In a previous paper, my co-authors and I suggested that APIs were a critical element in promoting the semiotic quality of IoT ecosystems (CHAGAS; REDMILES; SOUZA, 2019). This topic deserves special attention and will be thoroughly discussed in the Section 6.2, where I characterize IoT technology from the perspective of the designer and the main phenomenon according to Semiotic Engineering, namely the metacommunication.

\subsubsection{Transferring}

Transferring is a very important semiotic process. Apparently, it has little to do with interaction, but it is a powerful mechanism because of two reasons. First, it enables social and collaborative practices with and around the technology by enabling people to talk about it. Second, it is a sign of users' culture change that can takes place in the individual and mass scale, reinforcing each other and fostering the technology adoption.

As mentioned before, transferring can happen in two ways: from the users' world to the technology, and from the technology world to the users'. The former is often discussed in literature, the best example probably being Dourish's "placeless documents" (2003), where people could flexibly inscribe their organizing concepts and structures into the system by customizing different properties and the like. Similarly, the use of custom names and structures (e.g. devices' names, rooms, etc.) is possible in several IoT devices, such as reported in Section 5.1.3.6. The latter is more subtle, but it is actually a stronger sign of a sort of acculturation, such as the example mentioned from MacLean et al. (1990) in Section 5.2.3.3: 
"They are regularly distributed by email, but perhaps more interesting, it is not uncommon for someone to request "a button to do X", where " $\mathrm{X}$ " may be something for which a button is quite definitely not the solution. We suspect that some of these requests would not be made at all if it were not possible to articulate a putative solution in terms of something concrete and comprehensible such as a button." (my emphasis)

Notice that, as put by MacLean et al., transferring depends on people being able to talk about the technology, to articulate phrases using the technology concepts and signs. By doing so, people incorporate these concepts into their culture. When observed, this second form of transferring means that the designers' metacommunication message (or at least a part of it) made it through and the user is aware of it, a necessary but not sufficient condition for intensive adoption. In addition, notice that it is not primarily important for the transferring to happen whether they are using the "correct" meaning (that is, the one that was intended by the designer) or not, but simply the fact that one is being able to use new signs they acquired from the technology. As they use it, the sign meaning, if wrong, will be exposed to revision and improvement in future conversations with the technology or with other people about the technology.

Transferring can be designed, at least partially. Some features found in current technology designed specifically for this purpose are: (i) allow user custom naming and organizing information (transferring from user to the technology); (ii) enable sharing of users solutions, problems, desires, feedback, etc. using the technology in their actual contexts; (iii) create collaborative spaces (e.g. forums) where a common knowledge base can be found and shared; (iv) create strong and remarkable names for features of the technology that can catch users attention, strike users' curiosity, and produce some sort of "semiotic impact."

\subsubsection{Organizing}

Previously called "expressing," organizing happens when users express themselves effectively with the technology at hand, that is, when they express personal intents using the technology interactive language in a proficient way. At some point, users get able to build their own personal goals with the technology and express these new intents in the interface language in a deliberate and reasonably proficient way. Nevertheless, their expression is, at the same time, 
enabled and limited by the conversations the designers made available into the technology interfaces. Users can only "speak" what the designers have somehow anticipated that they would do. In that sense, it's not a complete and free "expression," but a constrained form limited by the interface language. Every language, as a social contract, is constrained in the sense that "we can only speak with each other words" in order to make ourselves understood by others. But natural language offers a great variety of resources that gives speakers a high degree of expressive power and freedom, for example by using figurative speech and subtle rhetorical constructions such as humor, irony, etc. However, with technology, users are much more constrained in the sense that they are not "speaking with the technology's words" but rather "speaking with the phrases and conversations that were previously designed." For that reason, I changed the process name to "organizing," in line with our definition of appropriation as interpretation states that allow users to organize rich and productive interactive discourses with the signs of the technology at hand.

Organizing involves some or all previous processes in different degrees, but it is particularly characterized by users articulating their personal goals effectively with the technology interactive language. Users have then learned to talk with the technology and acquired a new interactive idiolect to talk to it in their own ways, that are based in the current semiotic code as developed and elaborated while they performed some or all previous processes. Organizing indicates the settlement of higher degrees of motivation in using the technology as well as other positive aspects in the relationship of users with the technology, such as high sense of ownership, personal bond, dependability, etc. It denotes a reasonably conscious and free (empowered) attitude of users towards the technology, including even informed rejections of what they saw that had not fit their practices.

In certain cases, this process can be identified by the occurrence of what I have called the "I can work around it" communicability tag (see Table 4-3 in Section 4.4) that points to improvised work arounds and custom solutions users develop to accomplish goals not originally anticipated by the designers. This is usually what is associated with the idea of appropriation found in literature, what is considered to be the hallmark of appropriation. However, even when this is not the case, organizing represents a culmination of all other processes and it is no accident that this is the last process of our model. It is a sort of accommodation of 
the users' signifying system that enables the emergence of a new practice supported by the technology. The emergence of new practices using the technology correspond to old practices that were modified by the use of the new technology, or a completely new goal that emerges as a consequence of the technology. Taking some examples from the diary study, users listening to music with the Echo Dot or voice controlling their lights correspond to two examples of modified practices that, because of the voice to technology, became "hands free." At another hand, P5 who started to use his colored smart lights to influence his mood has developed a new practice of "mood management." In other words, the emergence of a new interactive idiolect is associated with the emergence of new practices and this is the hallmark that an appropriation state has been reached.

\subsubsection{On Breakdowns}

An important concept to our model is the breakdown. Breakdowns play the role of the surprise as the actual triggers that starts cycles of abductive reasoning. They allow wrong hypothesis to be corrected and right ones to be improved or extended, "on the fly." They work in the same sense as communication breakdowns, disruptions in the natural flow of communication that demand from us extra work in order to restore mutual understanding between communication parties (MEADAN; OSTROSKY; HALLE, 2006). The first level of extra work is the abductive generation of hypothesis to explain the breakdown in order to inform, enable and support any further action e.g. an attempt to repair the communication. But the way I am using breakdowns in this thesis demands some extra comments in light of the broader theoretical background provided.

In their concept of "points of infrastructuring" as the particular moments where a particular technological infrastructure needs to be reconsidered, Pipek \& Wulf (2009) propose that there are four motivational forces that can trigger this process. They were described by Ludwig et al. (2017, p. 30-31) in the following way: actual infrastructure breakdown, when the infrastructure is broken or inoperable (e.g. power failure or network outage prevents the smart home to work properly); perceived infrastructure breakdown, when the infrastructure does provide the service, but not the level of expectations of its users (e.g. slow connection or communication between devices prevent quick responsive 
behavior); extrinsically motivated practice innovation, when the contextual conditions have changed in a way that the technology is not able to support some practices as it used to do (e.g. a cloud service security platform for storing surveillance videos develops a new pricing plan or device and the customer is required to migrate); intrinsically motivated practice innovation, when the contextual conditions remain the same, but the people discover a new potential better way that raise their expectations about the technology at hand (e.g. equipping the home with new smart hub that one has seen at a friends' house and that provides more security and less spatial clutter or visual pollution in the living room). Their classification of breakdowns in actual vs. perceived and extrinsically vs. intrinsically motivated points to subtler aspects of breakdowns that are important in my theoretical model of appropriation.

In my model, a more precise definition of a breakdown would be any fact or sign that challenges the current users' signifying system and triggers the pursuit for a revised one. In this sense, breakdowns disturb users signifying systems and known codes, drawing their attention to the codes they know or thought they knew, and force users to abductively look for new meanings that change the code. In other words, breakdowns are associated with the poetic function of technology mentioned above (see Section 6.1.1), the aesthetic text in Eco's words. They are a powerful way of inculcating a new code into users' signifying system that will be part of a new interactive idiolect, another one being a manual, a metalinguistic text in Jakobson's terms. However, as manuals tend to be neglected in general, a design strategy that tries to benefit and leverage from breakdowns seems like an interesting possibility to be further explored in interaction design. This would be slightly different from Lewis \& Norman (1995) approach in the sense that it goes beyond account and embracing errors as natural and unavoidable, but actually resorting to and deliberately provoking breakdowns in order to disturb users' signifying systems, provoke changes in their interactive idiolects and enhance their interactive experience.

Indeed, I think this already happens and the acquisition of a new device constitutes an unavoidable breakdown for which designers usually pay special attention in providing quick out-of-the-box cheat sheets, first-run overlay tutorials, and the like. Other example happens when designers release a software update and enforce changes. Figure 6-4 illustrates how this has been done, probably an 
anecdotal example that everybody is familiar with in old and new technologies. However, these strategies usually do not take into consideration the users' context or needs and work much more as an enforced approach that are often inconvenient to users and leave them without choices. Based on our appropriation model, I claim for more conversational and poetic breakdowns, an interesting path of future research for the interaction design of IoT and probably any kind of technology.
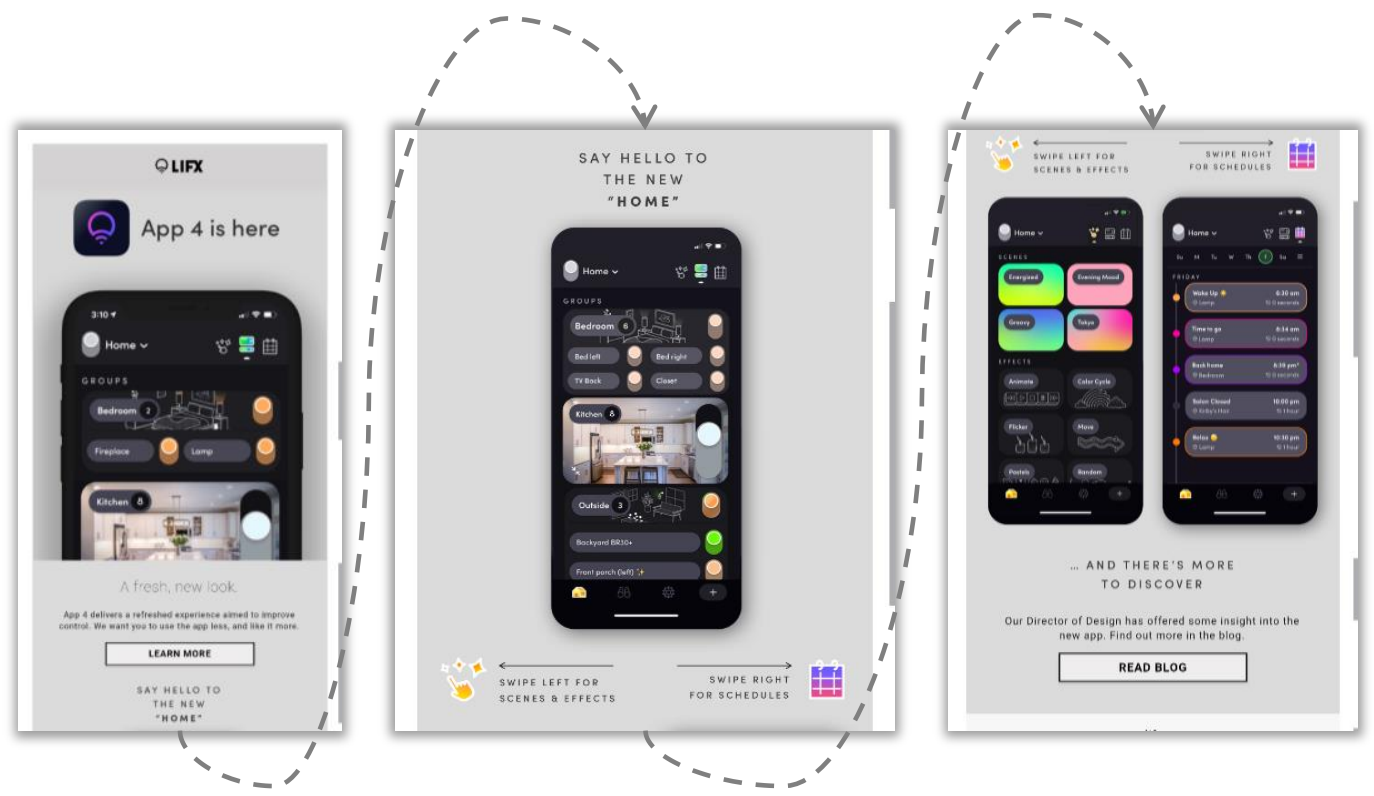

Figure 6-4 - An example of designers generating breakdowns on purpose by releasing a new version of a technology (Screenshots from a marketing email received by the author on 18-Feb-2020 - (C) LIFX 2020 used under permission).

Another important implication of our model is regarding a long-lasting debate in HCI regarding cognitive vs. communicative perspectives to interaction design. This debate is in the roots of the emergence of Semiotic Engineering and I would like to contribute to it with my approach to "mental models," a concept often used in HCI in general (ACKERMANN; TAUBER, 1990; CARROLL; OLSON, 1987; GENTNER; STEVENS, 1983; PAYNE, 1991, 2003) and in HCI for the IoT in particular (HUANG; CAKMAK, 2015; KAAZ et al., 2017; YAROSH; ZAVE, 2017). My results suggest that more important than discovering users' mental models is supporting they build their own, a process which is described by our semiotic model of appropriation: starting from a breakdown in the broad sense described here, users will elaborate, reflect and (re)build their mental model about the technology, about their practices, and about 
the fit between the two abductively, while they interpret the technology by performing the semiotic processes. The mental model corresponds to the current state of interpretation and is therefore provisional and subject to change. In this perspective, an important design feature of the technology is its ability to support the user in this abductive process. In this sense, our semiotic appropriation model is a powerful tool because it "breaks down" the intricate process of interpretation in pieces that can be translated to design features more easily. These "pieces" correspond to parallel or backdrop requirements that a designer should address in order to support and foster users' appropriation of the technology, finally linking appropriation to interaction in an a sound and practical (actionable) way for the design of appropriable technologies.

For the sake of exemplifying, this is how each process could be translated into corresponding supporting features:

- Surfacing $\rightarrow$ support exploratory and epistemic interaction (KIRSH; MAGLIO, 1994; TURNER, 2012) with good communicability design. As a designer, keep in mind that your message will be "broken down" in smaller parts as its gradually interpreted and appropriated by users. These "chunks" of metacommunication will go through to the next processes;

- Rejecting $\rightarrow$ support selective interaction, with options for temporary concealment and pruning of features;

- Matching $\rightarrow$ just follow a good user-centered design process to learn what users already do and how;

- (Re)Purposing $\rightarrow$ purpose are the user top-level intentions, so talk to the users in the level of contextualized intentions that matches their own. As a starting point, consider the five major categories of configuration intentions that were proposed in study 2 (Section 4.2) applied to the technology and context under consideration, namely: recreation, automation, notification, interaction, and information. In addition, allow users to discover and share with you and with others new purposes they find by supporting transferring (see below);

- Combining $\rightarrow$ allow for technology integration with other devices and apps, usually by means of public or opened APIs and/or development partnerships;

- Transferring $\rightarrow$ allow users to transfer meanings in both ways: from user's world to the technology, by means of custom names, structures, properties, 
etc.; and from the technology to other users' discourses, by creating cultures, supporting and promoting users to talk about the technology;

- Organizing $\rightarrow$ allow users" "mental model" to be expressed ("printed") in the technology in order to materialize them. At this point, multiple aspects related to the previous processes can be inscribed and materialized in actual configurations in the technology (parameters, objects, scripts, etc.) or in workarounds users build and EUD tools and techniques can be of help.

The interesting part is that this approach works with several initial mental models (interpretations) users might have about the technology. The good designer's ability should be in cueing or even driving users' abductive interpretations towards those more correct (that actually work!) and richer (that allow for richer interactive discourses).

\subsubsection{Related Work (and How to Use My Model)}

I am proposing a theoretical model of appropriation that can be useful in the design of better (more appropriable) IoT technologies. This approach is grounded in the importance of appropriation to user interaction and in an apparent gap between "over-descriptive and theoretically scattered" accounts of appropriation, as Belin \& Prié (2012) said, and the proposal of more practical design guidelines for post hoc validation, found to be "methodologically unsound" as Dix (2007) said. In order to address this gap, I proposed that a theoretical descriptive model of appropriation could be a reasonable answer to both describe appropriation soundly and support the design of appropriable IoT technologies. Four works were found to be closer to this line and better developed (BELIN; PRIÉ, 2012; BENAMAR; BALAGUÉ; ZHONG, 2019; SALOVAARA, 2008; TCHOUNIKINE, 2017). These works deserve a closer look.

Salovaara (2008) resorted to cognitive psychology theory to propose "a cognitive foundation for studies on appropriation" based on ecological psychology. Drawing from the work of Neisser (1976), Salovaara claims that "if appropriation is interpreted as a process of perceiving resources facilitated through previous and immediate experiences, one way to conceptualize this is to see appropriation as a cycle of perception and action, in which both parts may 
change the other" (op. cit., p. 213). He proposes a model in which users develop "usage schemata," that is, long term mental representations which structure users' actions and are built based on perceptions and interpretations users derive from explorations of artifacts. He exemplifies how to apply his framework to analyze three anecdotal cases of appropriation. Salovaara work seems to be compatible with our appropriation model in the sense that it takes into account users' interpretations ("schemata"), although using a different terminology and grounded in a different theoretical background. Although he provides a solid theoretical foundation, he ended up deriving three implications (guidelines, principles) for design, which are, as we know, hard to validate since "simple post-hoc evaluation is methodologically unsound" (Dix, 2003). To the best of my knowledge, his guidelines have never been tested or validated.

Belin \& Prié (2012) proposed the Digital Instrument Appropriation Model (DIAM) as a framework derived from instrumental theory (RABARDEL, 2003; RABARDEL; BOURMAUD, 2003). The DIAM is based in the theory of instrumental genesis and its core concept is the notion of digital instruments, "defined as a stabilized functional unit composed of customized artifacts and utilization schemes developed by a user" (ibid., p. 645). Although derived from a different theoretical background (activity theory and Piaget's genetic epistemology), it is interesting to notice that they came up to a similar conceptualization as Salovaara in terms of utilizations schemes ("usage schemata"). Drawing from previous contributions of Shipman \& Marshall (1999), their model describe the "digital instrument" in terms of "schemes" and "structures," that can be understood as the logical (mental) and the "material" (concrete) dimensions of an artifact in different levels (appropriation, interaction, computing, and storage). In their model, tensions between schemes and structures in the different levels turn the digital instrument instable, which can lead to what they call "circulations," that is, subsequent actions performed by the user in order to turn the instrument useful again. Despite different terminology, tensions and circulations are analogous to the concepts of breakdowns and repairs as I used in this work. According to the authors, the DIAM model was proposed to fulfill two core requirements: firstly, it should be able to provide a broader conceptualization of the appropriation process, and secondly, it should allow for the identification and description of particular evolutions of digital artifacts (ibid., p. 647). 
Although they claim that this model "can support designers in precisely understanding how the components of an interactive system play a role in an appropriation process" (ibid., p. 654), which is compliant to their goal, how to use this model for the design of appropriable technology was not discussed in this work or other that I am aware about.

More recently, Tchounikine (2017) proposed a theoretical account for designing for appropriation also derived from instrumental theory (RABARDEL, 2003; RABARDEL; BOURMAUD, 2003) based on the notions of "functional value"- the utility perceived by an user of an artifact for achieving some task or activity — and instruments - when an artifact is transformed into a means for some activity. Among other topics and implications he discusses, he proposes three perspectives by which the design of technology can continue in use, which is the core idea of appropriation in his view: usage-informed design, when developers take insight from actual use situations to (re)engineer the system; user adaptation/design, when users perform changes (adaptations) to the system by means of technical support such as tailorable technologies and end-user development; and community-of-users design, when the design is continued by a community of users. Most of these approaches resonate with other works from tailorable systems and End-user Development literature. It seems his main contribution is to reunite some findings and techniques from these fields around the notion of appropriation and his concepts of functional value and instruments, showing how they could leverage from them.

Also recently, Benamar et al. (2019) tried to connect appropriation and interaction design in the IoT domain, close to what I am proposing in this thesis. Their work is based on exploratory interviews with users of different brands of smart watches followed by a qualitative analysis of the data. As a result, they derived a model of appropriation that they call The Dynamic Interactions Value Appropriation (DIVA) framework. In this model, appropriation is characterized as a dynamic process of four stages - symbolic appropriation, exploration, use construction, and stabilization-where each stage relies on a combination of interactions and value creation that depends on the devices' characteristics. They relate their model more to marketing and management literature, which is not directly connected to interaction design in the sense of not providing actionable insight for the design of appropriable IoT technologies. Their notion of "value" 
goes beyond Tchounikine's "functional value" and include other dimensions, such as emotional value, social value, etc. This is compatible with our semiotic notion of interpretation: values are a meanings ascribed to the technology as interpreted. Overall, their work reinforces the vision that the link between interaction and appropriation is an open problem, which they do not seem to address directly.

All proposals of appropriation models briefly discussed above seem to make sense and are even compatible with each other and with our own. The problem does not seem to be only one of lacking knowledge about appropriation as a phenomenon, already so richly investigated under a great variety of domains and conditions, IoT included. It does not seem to be a problem of lacking or flawed theories either. Both empirical and analytical studies resort to a multitude of previous contributions from the field and theories well-accepted in other fields that either describe or explain a posteriori or propose a priori concepts, frameworks and models of appropriation. And who in Computer Science can say that theories such as social structuration (GIDDENS, 1979), ecological psychology (NEISSER, 1976), activity theory (LEONT'EV, 1979) and Vygotsky's psychology (in which instrumental theory is grounded) are wrong or broken? Very few people, and certainly not myself. Not that I see anything wrong with the previous work, but how do we know how, when and why to use them in design seems to be the missing link. And it is not possible to answer these questions appropriately if we do not take into consideration our implicit or explicit assumptions about what design is, how to do it, and the kind of knowledge it requires. In other words, I think the main problem with the previous works is of a different nature, it is a problem of epistemology. Of epistemology of practice (SCHÖN, 1983), to be precise.

To be fair, this a not a problem of research about appropriation in particular but maybe this is also a problem in some other niches or subdomains in HCI as well (or even larger portions thereof). As an answer to John Carroll's (2003) call for overcoming the scientific fragmentation of the HCI field, De Souza (2005a) argued:

"Scientific fragmentation can be improved by an appropriate epistemology. But to date, because of its interdisciplinary character, the epistemology of $\mathrm{HCI}-$ if explicitly addressed at all-has itself been a patchwork of epistemological borrowings from psychology, computer science, anthropological disciplines, engineering, and design. The result of this patchworked epistemology is that sorting scientific issues from nonscientific ones, distinguishing between essence 
and circumstance, and even identifying the permanent goals of the discipline have been extremely difficult. Implemented systems are at times taken for sufficient representations of the disciplinary knowledge they claim to contain. Fundamental research questions are abandoned because technological evolution has replaced the infrastructure where they were being investigated. Premature implementations of incomplete and imprecise knowledge are marketed and stir economic resources to accelerate progress based on assumptions that are not clearly understood by researchers themselves." (DE SOUZA, 2005a, p. 257)

De Souza has proposed Semiotic Engineering as a theory able to elastically accommodate the evolution of knowledge and technology within the same ontological perspective and without losing theoretical soundness and epistemological rigor (idem). I see the previous works mentioned above adopting this sort of "patchworked epistemology" De Souza mentions above, most of the times only implicitly assumed. And my approach to overcome this epistemological problem was threefold:

Firstly, I was explicit about my epistemology by stating the scientific paradigm I adopted as "something in between a constructivist and a pragmatist scientific paradigm (GUBA; LINCOLN, 1994) or "philosophical worldview" (CRESWELL, 2014, p. 5-11)"-see beginning of Chapter 4. More precisely, I can say now that I was "locally" constructivist within each method and "globally" pragmatist in my overall approach.

Secondly, I continuously sought for ontological discipline as a strategy for extending my working theory-namely, Semiotic Engineering. The challenge here is how to extend (or change) a theory without breaking it and, at the same time, leveraging from its existing (and accepted, that is, believed to hold) principles and constructs. Following Peirce's philosophy of science and scientific method (see Section 3.3), theories are indeed the current best hypotheses held by a scientific community of inquiry and, as such, can always fail or be shown flawed, incomplete or even useless (cf. HAACK; KOLENDA, 1977). But Semiotic Engineering is not composed by sets of logical axioms or mathematical equations that could be used to deduce consequences and induce cases, which would allow for more straightforward empirical verifications and falsification tests. Semiotic Engineering looks like an interpretive framework and sound theoretical principles derived from general semiotic theory that orient the study and design of interactive technologies. In addition, I was not actually trying to prove or falsify Semiotic Engineering. Rather, I assumed that its main principles reasonably 
worked in my phenomenon of interest because I had no reason to believe otherwise. All I needed was ways by which the theory could explain my observations and accommodate differences and/or necessary extensions. In such cases, abduction as logic of scientific discovery (cf. REICHERTZ, 2007; TIMMERMANS; TAVORY, 2012) is the way to go. In this sense, there are different approaches a pragmatist can apply to justify and legitimize his or her discoveries (cf. TAVORY; TIMMERMANS, 2013). I applied what I called ontological discipline (see Section 5.1) - a sort of "semiotic logic of interpretive extensions"- aided by discussions with my community of inquiry (cf. TAVORY; TIMMERMANS, 2013). Finally, the "ultimate test" for the validity of a theory for a pragmatist is the theory's usefulness.

Thirdly and finally, I took a final "pragmatist turn." Following Peirce's pragmatic maxim (see Section 3.3), my choice to validate my proposed appropriation model included the criteria of its practical consequences for the design of appropriable technologies. At least in part, this is achieved by the commitment with Schön's epistemology of practice as an approach to design based on reflection-in-action, fully compatible and aligned with Semiotic Engineering (DE SOUZA, 2005a, passim; DE SOUZA et al., 2016, passim). In pursuing and proposing an epistemology of practice, Schön is actually proposing the kind of knowledge reflective practitioners (designers) need or expect and how they use the knowledge they have in their situated practices. In other words, in order to propose any kind of knowledge to be used in the design of appropriable technologies, we need to take into account what the designers will do out of this knowledge, under which limits and constraints, which Schön helps us to understand.

Schön views design as a situated problem-framing and problem-solving practice, performed under unique and complex conditions that cannot prescind of the designer's active reflexivity. Perhaps his vision can be summarized by the following passage:

"The dilemma of rigor or relevance may be dissolved if we can develop an epistemology of practice which places technical problem solving within a broader context of reflective inquiry, shows how reflection-in-action may be rigorous in its own right, and links the art of practice in uncertainty and uniqueness to the scientist's art of research." (SCHÖN, 1983, p. 69, my emphasis) 
In his discussion about the patterns of reflection-in-action, Schön identifies four "constants" that practitioners in general (including designers) bring to their reflective practices, namely: their repertoires of languages, tools and solutions representing a "toolbelt" of concrete previous experiences and knowledge that they can apply; their appreciative systems by which they judge their results; their overarching theories that help them make sense of problems and situations they face; and their role frames within which they set their responsibilities and limits of personal and institutional action (ibid., p. 270). The semiotic appropriation model I am proposing in this thesis falls into the category of an "overarching theory.” In Schön's words:

An overarching theory does not give a rule that can be applied to predict or control a particular event, but it supplies language from which to construct particular descriptions and themes from which to develop particular interpretations. (ibid., p. 273, my emphasis)

An equivalent concept was proposed by Winograd (2006) regarding Winograd \& Flores' (1986) language-action perspective (LAP):

"Its value is as an orienting theory, not applied as a set of calculations, but shaping the background of interpretation a designer brings to understanding and envisioning the human situation." (WINOGRAD, 2006, p. 72, my emphasis)

Winograd believes Semiotic Engineering (as LAP) is also an orienting theory (WINOGRAD, 2017). In this sense, my model provides an orientation to guide the reflective practice of design. When combined with the other Schön's "constants" designers will bring to their practice, our model is able to support the designers in thinking and talking about the requirements they need to fulfil (as said by one of our interviewees in study 6) and leverage the results. Most closely related is the other "constant" of repertoires, solutions that can be cataloged as "tested" or "good" for supporting each semiotic process, such as the popular "design patterns" proposed in other domains and contexts (e.g. ALEXANDER; ISHIKAWA; SILVERSTEIN, 1977; GABRIEL, 1996; TIDWELL, 2010). This is how I see the appropriation model proposed here should be used.

Now, how can I show that my model is better when compared to the other ones proposed in literature mentioned in the beginning of this section? The problem seems to be epistemological in nature. Ideally, for a fair and reliable empirical evaluation of all models we would need to conduct an experiment with multiple designers, designing different technologies, and using the different 
models until finally we could compare the resulting technologies in terms of which one would be "more appropriable" by the users. Similarly to what Ellis \& Dix (2006) said about validating design principles, this is "hardly likely in a finite time", reason why they argue that "empirical evaluation of generative artefacts is methodologically unsound" (see Section 2.2). Another simpler and more limited approach would be if I myself tried to evaluate the other models using my dataset of the diary study, for example, with a certain design goal in mind to see what I would find out. However, since the authors do not provide explicit guidance on applying their models for design, this analysis would be biased by me being an interested party, by my compromised knowledge of their models in comparison to mine, as well as by my specifically defined design goals. More deeply, their lack of epistemological considerations prevents a fair comparison since I do not know if and how our models are even comparable, in terms of sharing the same scientific paradigms, philosophical assumptions and goals in terms of design. My approach to overcoming such epistemological problems here is discussed above and is intended not to diminish the value of other authors' works but rather to establish a reasonable basis upon which a fair comparison might be done. However, the burden of addressing each model's epistemological assumptions is the authors', since I cannot know how they have developed their ideas and how they think such ideas should be used and under which scientific and practical limits.

I can now answer the other research questions posed in Chapter 2 about the design of appropriable technologies (Section 2.3, Box 2-2):

- R2) How to design appropriable IoT technology?

○ R2-A) What does "to design" IoT technology mean?

A human-centered approach to design means engaging in a reflective conversation with materials (SCHÖN; BENNETT, 1996). Designing for a complex goal such as users' appropriation cannot be accomplished without a strong reflexivity component from designers. Our semiotic model of appropriation is intended to support designers' reflection and, indirectly, the users' as well. But the object of design and the "materials"-IoT technologies - are also complex in a number of different ways. In the following section, I will take a closer and deeper look at what an IoT technology is in a Semiotic Engineering's perspective. 


\section{2. Multiple Layers of Metacommunication: A Semiotic Characterization of loT Technology}

In spite of the voluminous amount of research in engineering-oriented frameworks and models (e.g. architectures, software infrastructures, etc.), interaction research for the IoT seems to be mostly focused in the development and evaluation of technologies, techniques and applications targeting particular domains or problems. Assuming that there are correct and useful theories and methods in general HCI, there are two possibilities. At one extreme, we would say that everything in the IoT is significantly different due the particular features of this kind of technology and nothing could really be availed, what does not sound reasonable. At the other, we would say interaction with the IoT is the same or so similar to interaction with traditional technologies that a straightforward application of any established HCI theory or method is possible, which does not seem to be the case either. The truth probably lies somewhere in between the two extremes, as usual, and an important research focus is to identify and characterize in which aspects interaction with the IoT is similar and different and the consequences thereof. Until we get there, some researchers try to model interaction with IoT starting from one extreme, namely, focusing in the distinct features of the technology (e.g. BARRICELLI; VALTOLINA, 2015; HORVÁTH; WANG, 2015). A complementary approach would be to start from an HCI theory and check ways to apply, extend and adapt it to the particular domain of the IoT.

My goal in this section is to outline a characterization of IoT technology from an interaction perspective that serves as basis for applying Semiotic Engineering and its methods in this domain. Such approach is useful to both orient the applications of Semiotic Engineering existing methods (possibly with adaptations) and to test the limits of the theory. Although there are some few initiatives in this this vein (CHAGAS; REDMILES; DE SOUZA, 2017; FERRARI; BIM; AQUINO, 2017), I will draw from my results described previously and from literature in order present a consolidation that represents my current best proposal of contribution in this line. 


\subsubsection{Substratum, Superstratum, and Semiotic Contiguities}

Based on a general pattern of architecture that can be observed on smart devices commercially available today, my co-authors and I suggested that research and design of IoT interaction should focus on three different types of interfaces, namely software interfaces (e.g. a smart device companion mobile app), hardware interfaces (e.g. the physical device itself), and programmatic interfaces (e.g. APIs made available by manufacturers for integration with other devices) (CHAGAS; REDMILES; DE SOUZA, 2018). This was our first attempt to address the core features of IoT technology from an interaction standpoint in a holistic way (see Section 2.1). Although it was useful as a starting point, this division does not seem precise and useful enough to capture the most important semiotic aspects that influence user interaction.

Splitting hardware and software interfaces does not seem to make too much sense because, ultimately, every interface is composed essentially by software and hardware that work tightly coupled together and provide inputs and outputs for the user to communicate with the technology. What would be the border for classifying an interface as software or hardware if we consider that any smart device is built upon one or more microcontrollers all running software (e.g. firmware), for example? At the same time, a mobile companion app is entirely based on the available inputs and outputs provided by the mobile phone, such as its touchscreen, speakers, sensors, etc. More precisely, this division has to do with the distributed nature of smart devices and the possibilities or modalities of inputs and outputs afforded by each part comprising the device. In order to account for the distributed nature of IoT, it's important to consider that there are multiple interfaces with which users can interact. And in order to account for the different modes and types of inputs and outputs that each interface can afford, it's important to consider the material media of each interface. I propose to use the concept of substratum (CHAGAS, 2015) to refer to the physical material and locus where an affordance is provided or, in semiotic terms, to the media where a sign resides.

In addition, my co-authors and I also proposed in a previous work two semiotic qualities to orient the design of IoT technology, namely cross-interface consistency and cross-device coherence to refer to the consistency between 
different interfaces of a single device and the ability of the technology to form a logical and unified system as whole when devices are combined with other devices, respectively (CHAGAS; REDMILES; DE SOUZA, 2018; CHAGAS; REDMILES; SOUZA, 2019)—see Section 4.4. I still think these qualities are useful and comprise important goals that a designer should pursuit when designing interactive technology for the IoT. However, we did not say too much about how to achieve them in practical or theoretical terms. There is a more general semiotic principle behind these qualities that can be used in order to orient the concrete realization of both cross-interface consistency and cross-device coherence, namely the principle of semiotic contiguity or continuity. By semiotic contiguity I mean a physical or logical link between two different interfaces that is perceived by the user. By providing good semiotic contiguities between the interfaces of a single device, designers provide the means for cross-interface consistency. By providing semiotic contiguities between interfaces of different devices, designers enhance cross-device coherence.

Semiotic contiguities can be afforded by means of physical or logical links. A physical link exists when signs are physically placed near one another or, more precisely, when by means of additional signs, interface signs are physically (materially and visually) connected or grouped in order to communicate the idea of belonging to the same whole. All signs of the interface of a smart light companion mobile app are contiguous because they are seen by the user under the same frame and sharing the app screen look-and-feel, for example. However, the physical smart light would have no physical link with the app. In such cases, contiguities need to be logical and can be of two kinds (see Section 3.2): based on Firstness, that is, on iconic representations in an interface of the other parts of the device; or by means of causal or temporal relationships that communicate to the user the impression of Secondness, that is, a co-presence between a certain state of the physical light in reality and in the screen of the app, for example. Another way of affording semiotic contiguities logically is by means of additional "super representations" (a third) that communicate to the user the idea of a system encompassing their smart devices and displaying the physical and logical connections between each part, such as for instance in a dashboard of smart home control system representing rooms, devices and the links between them. Although such representation can make use of iconic and indexical smaller representations, 
the distinct semiotic principle here shall be that of Thirdness used to communicate the idea of an integrated whole. I propose the concept of superstratum to refer to the way by which semiotic contiguity is afforded, which can be physical or logical and based on Firstness, Secondness, or Thirdness as described in Section 3.2.

\subsubsection{The Interpretive Abstraction and Semiotic Continuum Principles (Revisited)}

Other important considerations are related to two semiotic principles originally proposed for the evaluation of End-User Development environments and applications, namely the interpretive abstraction and the semiotic continuum principles (DE SOUZA; BARBOSA; SILVA, 2001). According to De Souza et al., these principles help evaluate end-user programming environments, such as building extensions of an application through scripting or macro programming. Although originally proposed in the context of end-user programming, these principles have important implications for interaction alone because they constitute necessary conditions for sense-making, a prerequisite for any end-user development task. The implications of these principles for EUD for the IoT will be discussed further ahead.

The interpretive abstraction principle states that an interface language $\mathrm{L}_{\mathrm{i}}$ is an interpretive abstraction of underlying programming languages $L_{1}, \ldots, L_{n}$ if and only if users can make sense (interpret) $\mathrm{L}_{\mathrm{i}}$ based only on the signs of $\mathrm{L}_{\mathrm{i}}$ appearing in the interface and their own background knowledge (that is, application domain knowledge, computer literacy, and common sense), without knowledge of the underlying programming languages $\mathrm{L}_{1}, \ldots, \mathrm{L}_{\mathrm{n}}$ (see also DE SOUZA, 2005a, p. 195). The interpretive abstraction principle constitutes a necessary condition for allowing end users to interpret the technology without needing to resort to foreign signs. The principle is breached anytime a sign from an underlying programming language leaks to the surface, a typical example being as unhandled exception throwing all the way up to the user interface. Another subtler and never discussed way to breach the principle is by omission, when the interface does not provide enough information for the user to make sense of the system.

I saw on the results from the diary study (Section 4.4) that all participants had trouble making sense of the smart motion sensor and none was able to 
appropriate it. I want to revisit the problems participants had in light of the interpretive abstraction concept because interaction with sensors is at the very core of the IoT vision (ATZORI; IERA; MORABITO, 2010; GUBBI et al., 2013; MIORANDI et al., 2012). Considering that sensors surrounding us are expected to increase in quantity and level of sophistication in the near future, this topic deserves more attention. What is the nature of such flaws?

Most problems participants faced when interacting with the smart motion sensor arose from difficulties in understanding the kind, range and intensity of the motion detected by the sensor and how to regulate its sensitivity. Technically, the device is based on a Passive InfraRed sensor (PIR) and can detect movements in a range of 8 meters (26 feet) from it according to its manufacturer ${ }^{27}$. However, as the name suggests and a quick search shows, this kind of sensor actually detects infrared radiation (heat energy) naturally emitted by all materials with temperature above the absolute zero ${ }^{28}$. A lot of engineering and specific electronics are necessary in order to make this kind of sensor detect motion. Additional circuitry is built in order to detect variations of the amount of received infrared light in such a way that it triggers in case of movements. By disassembling the device, we can see the actual PIR sensor among its parts (Figure 6-5). Detailed information about sensors of this kind can be found in electronic datasheets (PANASONIC, 2016), where a similar one was found ${ }^{29}$. The description of the detection condition states that "motion" (for the sensor) depends on four variables: the temperature difference between the target and the surroundings must be higher than $4{ }^{\circ} \mathrm{C}$, movement speed above $1.0 \mathrm{~m} / \mathrm{s}$, target body size of approximately 70x25 cm, and the target should move crossing the detection beam (Figure 6-6). I suppose that these are related to the concept of "sensitivity" appearing in the mobile app's interface, described as "the sensitivity of the sensor to motion" in the device's manual (D-Link, 2015, p. 8), but I still have no precise idea of what "sensitivity" means or how to regulate it.

In this case, the principle of interpretative abstraction is largely breached by omission because there is no way to make sense of the smart device based only on

27 See D-Link DCH-S150 mydlink Wi-Fi Motion Sensor product reference page: http://www.dlink.co.in/products/?pid=697 [Last visited: 20-Jan-2020].

28 See https://en.wikipedia.org/wiki/Passive_infrared_sensor [Last visited: 20-Jan-2020]. 
its interface language. Digging into its electronics teaches a little bit about its operation mode and gives an idea about problems that may happen, several mentioned by the sensor manufacturer's "cautions for use" (PANASONIC, 2016, p. 13). However, the "sensitivity" parameter remains an enigma even after going much further than most users would do. Sensors are an interesting case because they are basically a semiosic machine: they translate a sign that they can sense into another one, another representation of the original sign for humans to use more easily. Applying the interpretive abstraction principle, the sensor operation principles and electronics constitute an underlying language with concepts (semantic units) that need to be communicated clearly in the interface language, such as detection beam, body temperature and size, and movement speed.

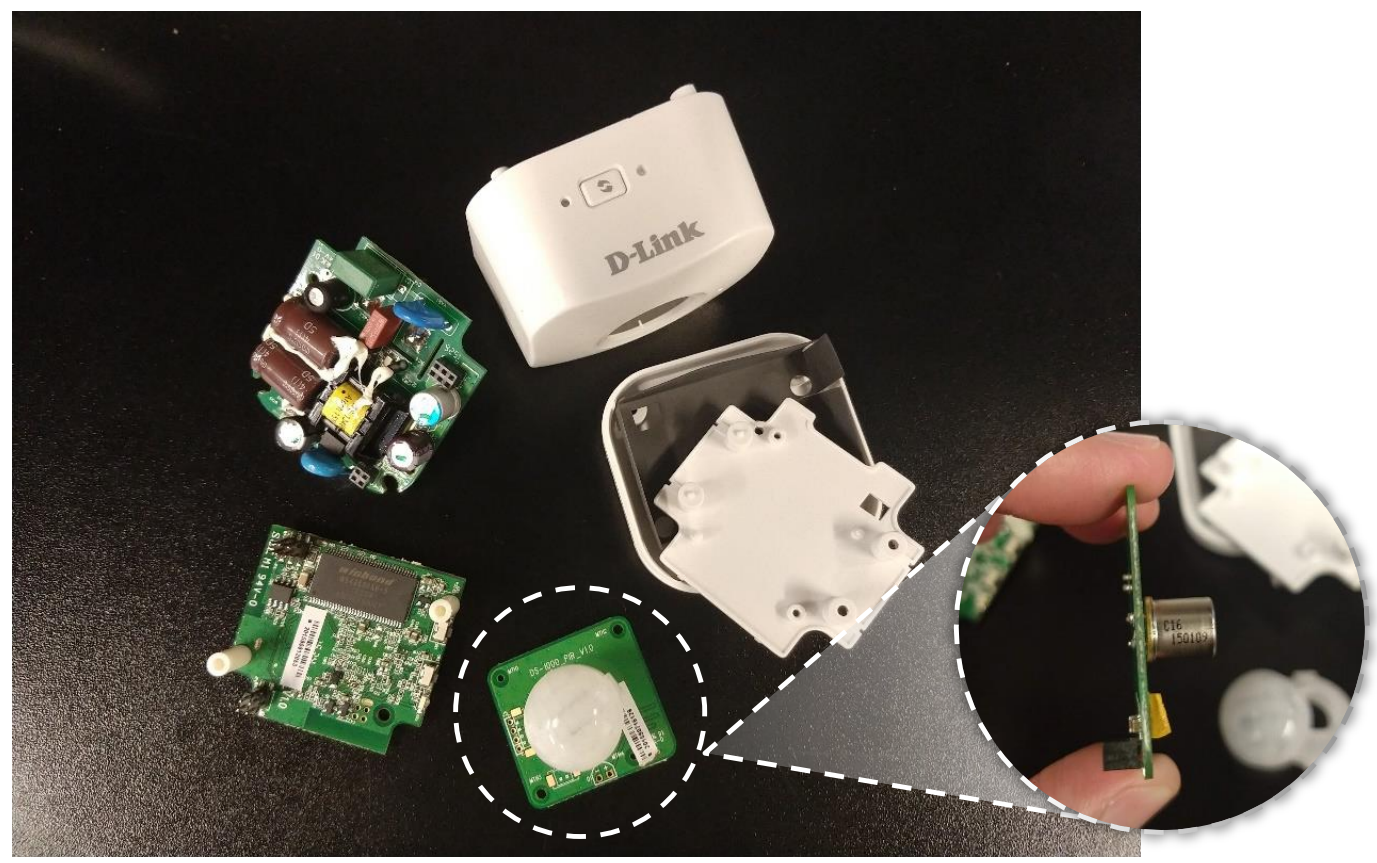

Figure 6-5 - The D-Link DCH-S150 smart motion sensor deconstructed. (Photos taken by the author at the Gist Lab, PUC-Rio, Brazil (C BAC 2020).

29 I did not find the PIR sensor with code "C16 150109" printed in the device. By similarity in appearance and behavior, I am taking the Panasonic EKMC16* family for wall installation as a sufficiently good approximation for the sake of the discussion here. 


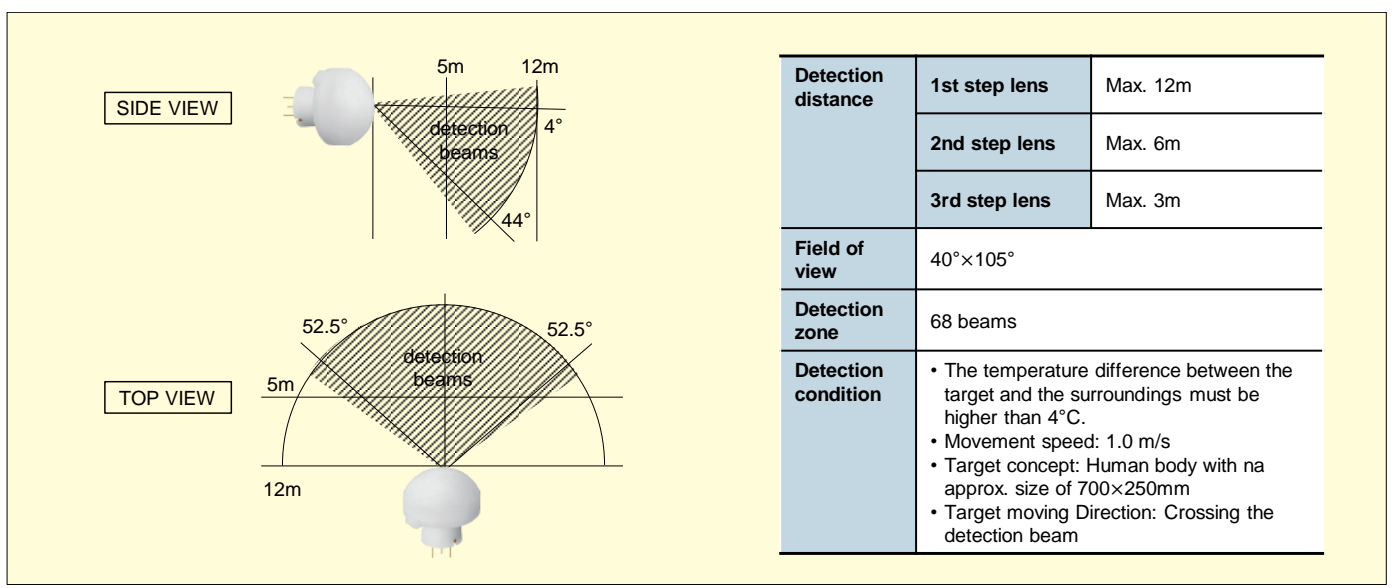

Figure 6-6 - The Panasonic PIR wall installation type detection field (adapted from: PANASONIC, 2016, p. 8).

Notice that compliance with the interpretive abstraction principle is not necessarily achieved simply by exposing lower level underlying concepts at the interface surface level. Designers should consider the form and relevance of each construct. For the sake of illustration, one easy way to improve the smart motion sensor interface would be to substitute the sensitivity toggle scale from "low" to "high" by some concrete measurement unit that could be understood by users' common sense, such as "movement speed" or "distance of detection" (depending on what it actually refers to). Another more sophisticated and innovative way would be to provide a clear visualization of the sensor's detection beam in a simulation or, even better, in the physical world using projections or holograms. Such visualization should vary accordingly to the sensitivity toggle in the app, helping users evaluate the impacts of changing this parameter in practice. This would improve the interpretive abstraction of the sensor's interface and enable users to make smarter sense and use of it, probably without them needing to look for more details behind it as I did.

The semiotic continuum principle states that an end-user programming language $\mathrm{L}_{\mathrm{eup}}$ is semiotically continue to an interface language $\mathrm{L}_{\mathrm{i}}$ if and only if: $\mathrm{L}_{\mathrm{i}}$ is an interpretive abstraction of $\mathrm{L}_{\text {eup }}$; $\mathrm{L}_{\text {eup }}$ is an interpretive abstraction of any underlying programming languages $\mathrm{L}_{1}, \ldots, \mathrm{L}_{\mathrm{n}}$; $\mathrm{L}_{\text {eup }}$ has a specific syntactic structure equivalent to texts - a compound sign linking an user's intention (illocution) to a system's function (perlocution); and an user who knows $\mathrm{L}_{\text {eup }}$ and $\mathrm{L}_{\mathrm{i}}$ can translate any arbitrary $\mathrm{L}_{\text {eup }}$ text into actual or potential signs in $\mathrm{L}_{\mathrm{i}}$ (see also 
DE SOUZA, 2005a, p. 196-7). So far, I am not focusing on end-user programming environments and languages, a topic that I will briefly discuss ahead. However, the semiotic continuum principle introduces the concept of texts, which is an important construct if we want to talk about cross-device coherence, since semiotic coherence can only be analyzed and evaluated in a compound of signs.

De Souza et al. define an end-user programming language (EUPL) text as a well-formed syntactic structure composed of an initial system-user message (the current system state), a user-system input message (a trigger for an action), and a subsequent system-user message (the resulting action) (DE SOUZA; BARBOSA; SILVA, 2001, p. 486). At the interface level, such structure corresponds to what they called the minimum cycle of interaction as "the minimum cycle required for the correct interpretation and use of an interactive element. This minimum cycle consists of three steps: application 'says' something to the user; the user 'says' something to the application that triggers an action; the application 'replies' to the user." Drawing from these definitions and the concept of semiotic texts as presented in Chapter 3, I propose that a minimum cycle of interaction constitutes an interactive phrase, a minimum set of actionable utterances in an interactive conversation, a text being the entire compound conversation resulting from a set of interactions or interactive phrases.

I claim that, in order to afford for coherence of texts when interacting with the IoT, smart devices, applications, and environments should preserve the minimum cycle of interaction of interactive phrases mentioned above. A malformed interactive phrase will not be recognized by users, hindering their interpretations, what can take two forms: first, if the activation of an interface element does not result in a recognizable effect in the system, such as in the event of a lost connection for example; second, if users cannot recognize the triggering element or event. If the first situation can be generally attributed to technical problems, the second is related to what has been called implicit interaction in ubiquitous computing, when users interact unconsciously to smart environments by means of sensors that detect and react to contextual inputs rather than (only) to explicit commands (SCHMIDT, 2000). A familiar example of a rudimentary system of this kind is the case of sensor-activated lights in public toilets and other shared spaces (e.g. emergency stairs). Sometimes, these lights go off unwittingly 
or does not turn on as expected and people would weave their arms or make strong movements in order to force them to turn on. I claim that, for the sake of textual coherence, the system needs to provide means for the users to recognize the minimum cycle of interaction in order enable them to make proper sense of it. In the scenarios of sensor-based implicit interaction, users' interpretations will be based on the hypotheses they will produce, and if they cannot develop consistent predictions, the technology will not be appropriated, such as happened with the motion sensor in the diary study, in a small scale.

\subsubsection{The Semiotic Engineering of Multi-Level and Multi-Sided Technologies}

Finally, the last aspect we need to take into account in an evaluation of IoT technology is the multiplicity of people involved, even when considering a minimum IoT ecosystem. In Section 4.1, one of my results was to propose a Semiotic Engineering framing of EUD for the IoT as group communication scenario involving multiple stakeholders, including developers of different devices and apps, end users and end-user developers. That framing was an initial attempt to characterize interaction with IoT technology as a certain kind of MultiUser Computer Application (DE SOUZA, 2005a, cap. 6). Nevertheless, although useful as a starting point to highlight the intrinsic complexity of IoT contexts, that framing has not helped to disentangle the scenario or to identify the most important aspects that a researcher or a designer should look for. I will try now to build a revised framing, fruit of further reflections in light of my consolidated learnings from the previous studies and the concepts discussed above.

Although it can be considered a Multi-User Computer Application, an IoT ecosystem is not best characterized as a collaborative system because its primary goal is not (necessarily) to support communication, interaction or collaboration between different users. Furthermore, besides multiple users, there are other types of important stakeholders, such as third-party developers, that can influence the resulting end user interactive experience, as already pointed in Figure 4-2. I identify the following four types of stakeholders around a certain smart device or IoT application "X": 
- Developers $(\mathbf{X})$ : the development team of $X$, including its designers, software and hardware developers, and business people in case of companies. I will use IFTTT as an example of "X" as the "entry point" to an IoT ecosystem;

- End users (EU): the primary group of people that use $X$ and its ecosystem;

- Third-party developers (Y): other developers willing to integrate an application or another smart device "Y" with $\mathrm{X}$ by means of a programmatic interface between $\mathrm{Y}$ and $\mathrm{X}$ (that is, an $\mathrm{API}$ ). $\mathrm{Y}$ is then part of $\mathrm{X}$ 's ecosystem and $\mathrm{X}$ users are also potential $\mathrm{Y}$ users and vice-versa;

- Adjacent users (AU): any stakeholder who has access to or can make use of $\mathrm{X}$ or of information derived from $\mathrm{X}$ and its ecosystem. Adjacent users-or simply ad-users, using the Latin prefix ad- meaning "near, by side"designate a particular kind of stakeholders which are very common in modern services supported by technology platforms. For instance, in the IFTTT platform there is a separated website with a rich set of additional features for those who want to build and deploy services for IFTTT users ${ }^{30}$. This part of the platform is not targeted to regular end users, but to people willing to offer their products and services in the IFTTT platform. In this side of the IFTTT platform, additional resources can be found, such as advanced development tools and dashboards with analytics about applets installation, usage statistics, and users' feedback. A developer of another smart device or service "Z" would have access to information of users that use $\mathrm{Z}$ and $\mathrm{X}$ through IFTTT (Y), becoming thus an ad-user of both $\mathrm{Y}$ and $\mathrm{X}$.

If the multiplicity of stakeholders in IoT ecosystems was made evident in Figure 4-2, the classification above highlights the different roles and interests that each stakeholder holds around a certain smart technology. In particular, the adusers are distinguished as a new type of player influencing other users' interaction. Ad-users are related to business models where commercial technology developers try to capitalize their platforms with economic goals. In business and economics literature, this is the typical case of so called multi-sided platformsbusinesses that "bring together two or more distinct but interdependent groups of customers" (OSTERWALDER; PIGNEUR, 2011, p. 77). The interesting part

30 https://platform.ifttt.com/ [Last visited: 20-Jan-2020]. 
about a multi-sided platform is that "the platform must attract and serve all groups simultaneously in order to create value" (id., p. 78). According to Osterwalder \& Pigneur, "offline" multi-sided platforms have existed for a long time, such as newspapers connecting readers to advertisers, credit card companies connecting buyers and sellers, and tech companies linking hardware manufacturers, users and application developers by means of an operational system, such as Microsoft Windows. However, multi-sided strategies have been increasingly gaining momentum and relevance due to internet and mobile technologies advancements that leveraged this kind of business model to an unprecedent scale. Today, this business model constitutes the core concept behind many well-known "big tech companies" such as Google, Alibaba, and Facebook as well as "tech startups" such as Uber, AirBnb, Mercado Livre, etc. (cf. EVANS; SCHMALENSEE, 2016).

Considering a piece of IoT technology as the enabler of a digitally enhanced service (see Section 2.1), the technology functions as a platform that brings together multiple people with different goals and purposes, where multiple designers and users interact with different perspectives upon it and through different interfaces. Therefore, interaction with IoT can be analyzed as a special case of Multi-User Computer Application that can be called Multi-Sided Technologies, that is, a technology (a smart device, an application, a platform, etc.) that presents multiple sides of interaction, each side constituted by a supportive interface targeted to a different user or stakeholder.

I can now take the opportunity to formalize the concepts of substratum (or substrate) and superstratum (or superstrate) discussed before and introduce a new one, the adstratum (or adstrate) (cf. LAPOLLA, 2009). These concepts were borrowed from socio and psycho-linguistics, where they are mostly used in studies of bilingualism - that is, when a speaker or people within a country or region speak two or more languages (SENNA, 1991, p. 40 et seq.)-, language contact (WEINREICH, 1970), and language change (LYONS, 1984, cap. 9). What happens is that when two (or more) languages are in contact-that is, a speaker has the competence to speak two or more languages that he or she chooses according to the social context-one language interferes in the other in different ways. A substratum influence develops when a subordinate language interferes in a dominant language, for instance when a speaker mixes foreign 
words and structures from a secondary language when speaking his or her native language. A superstratum influence is just the other way around and happens when the dominant language interferes in the subordinate language. When no dominance relationship can be determined, linguists say there is an adstratum, that is, a mutual influence that is smoothly coordinated and integrated by the speakers while both languages coexist, such as in some bilingual countries today.

I will adapt these concepts to the Semiotic Engineering of IoT technologies, also considering that a stratum in Latin simply means "a layer," in our case $a$ layer of metacommunication discourse. The two first different kinds of influences - the substrate and the superstrate - are amidst a dominance relation that one discourse has over the other. Similarly to the case with natural languages where the relationship is governed by the speaker's psycho-social conditions, with artificial (designed) interface languages the influence is determined by the metacommunication discourse that it serves, which is a projection of the designers' intents and psycho-social conditions. The "speaker" in this case is the designer's deputy, who "speaks" on behalf of the designer and where the metacommunication discourses and their languages get in contact. In this sense, a substratum is the language of each particular interface of a distributed device and is responsible to transmit the metacommunication message related to that particular facet of the device in a particular media (e.g. hardware/shape, a mobile app, a web app, a smart TV app, etc.). The superstratum is the language that carries the overall metacommunication message with the highest-level communication goals. It influences each substrata (the plural of substratum) that may exist, and imposes, if well designed, consistency and coherence to and between them all (by means of semiotic contiguities). Finally, when we include the multi-sided perspective of technology, we have the adstrata, multiple other metacommunication discourses that are integrated in the technology and influence users' interaction with the technology. If the superstratum dominates the substrata, we cannot say the same (a priori) about the adstrata, since they are potentially neutral languages designed for the ad-users that live all together side-by-side with no dominance relationship in terms of metacommunication discourses, at least a priori.

By applying the multi-sided concept combined with the Semiotic Engineering metacommunication as the main phenomenon of interest I can now 
disentangle the framing proposed in Figure 4-2 in such a way to obtain a richer human-centered account of the scenario described above. Centering the analysis on the end user and $\mathrm{X}$, there are four metacommunication messages to look for in different supportive interfaces and with different focuses (Figure 6-7):

(i) $\mathrm{X} \rightarrow \mathrm{EU}$, the metacommunication sent by $\mathrm{X}$ to end users (EU) directly through the multiple interfaces of the device or app X. This is the main metacommunication message for a user-centered analysis, keeping in mind that it can be (and usually is) spread in multiple substrata $\mathrm{X} \rightarrow \mathrm{E} U_{1 . . n}$ indicated the interface index $1 . . n$;

(ii) $\mathrm{X} \rightarrow \mathrm{Y}$, the metacommunication message sent by $\mathrm{X}$ to the third-party developers Y through X's APIs;

(iii) $\mathrm{Y} \rightarrow \mathrm{X}$, the metacommunication message sent by $\mathrm{Y}$ to the developers $\mathrm{X}$ through Y's APIs. Since we do not know a priori which API is being used, we are considering both possibilities that comprise different metacommunications (different emitters, different receivers, and different codes) and there is a chance that both play a role in the overall user experience, what needs to be identified for a better understanding of the whole picture;

(iv) $\mathrm{X} \rightarrow \mathrm{AU}$, another metacommunication message sent by $\mathrm{X}$ to ad-users $\mathrm{AU}$.

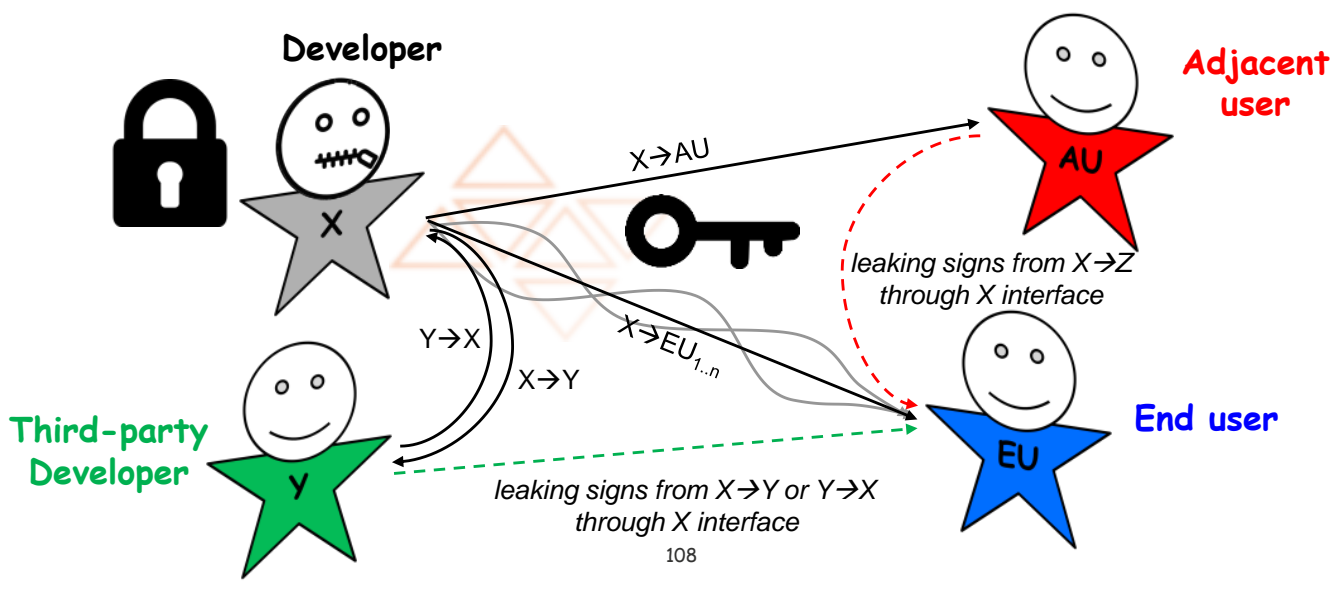

Figure 6-7 - The semiotic engineering of multi-sided technologies.

I propose that the semiotic engineering of multi-sided technologies focuses on the study of the mutual influence caused by the contact of multiple metacommunication discourses layered under a piece of technology. A particular 
way in which this phenomenon manifests is through leaking signs. This is an interesting semiotic phenomenon where signs of the metacommunication between developers with other developers and adjacent users interfere with the metacommunication to the user by "leaking" to the user interface. "Leaking" can be intentional (e.g. advertisements) or unintentional (e.g. an API untreated data or responses), and we need to trace its origin and the reason behind it in order to evaluate the effect in the metacommunication that the end user is receiving. For instance, in the IFTTT web application, there are several situations in which signs from the underlying APIs are shown to the user (see Figure 6-8) and where the user is exposed to the other sides of the platform (see Figure 6-9).

Leaking signs are trace elements of other metacommunication discourses not targeted to the end user and hence constitute evidences that the technology is supporting multiple metacommunications at the same time. This implies that end users interactive experience with the technology is determined not only by a better or worse interaction design (that is, the design of the metacommunication message to the user) but also by the other metacommunication layers that are part of the technology, which most of the users are not even aware about. The semiotic engineering of multi-sided technologies is an attempt to propose an initial framework that provides an ontology of relevant aspects and phenomena that need to be better understood and studied so that both designers and users can deal with it appropriately.

One of the most important things that this framework suggests that is that there can be relevant hidden or omitted information in the metacommunication message send to the end users that can be influencing their experience with the technology. By contrasting the multiple metacommunication messages that designers convey through technologies, an investigator can find out hidden or veiled (disguised) information that are not clearly communicated to the end users, intentionally or unintentionally. This information may be critical to the end user experience, such as the designers' deputy handling of users' data, privacy and security, for example. Furthermore, different metacommunication messages may be in conflict with one another due to competing interests e.g. ad-users and thirdparty developers looking for exploiting users' data is in direct conflict with users' privacy concerns, and developers need to satisfy multiple needs in order to promote the platform success and economic goals. This is not necessarily 
negative, since a successful technology becomes more dependable to users, but the developers' approach to addressing conflicts need to be studied and submitted to users' and society scrutiny.

(A)
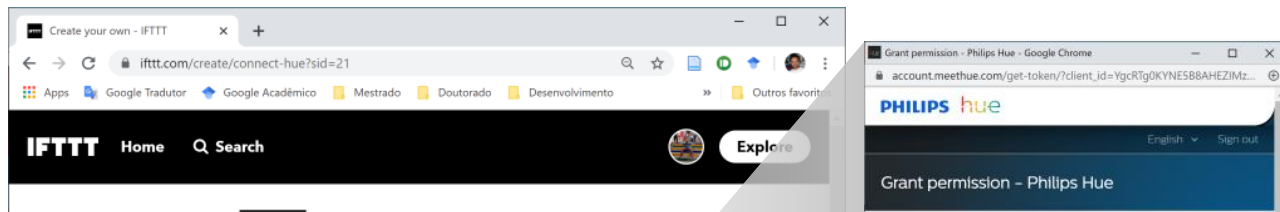

( Back hue Connect Philips Hue

Step 3 of 6

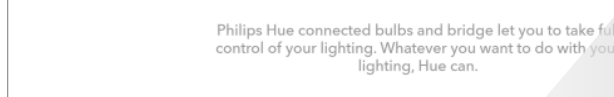

Connect

(B)
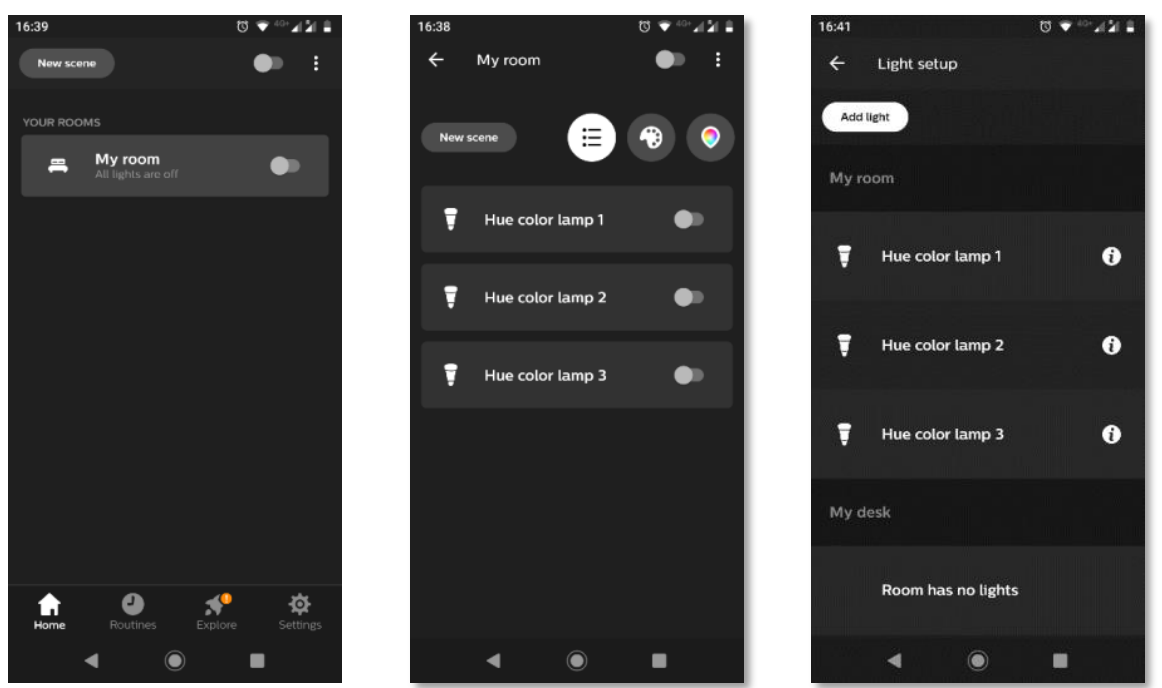

(C)

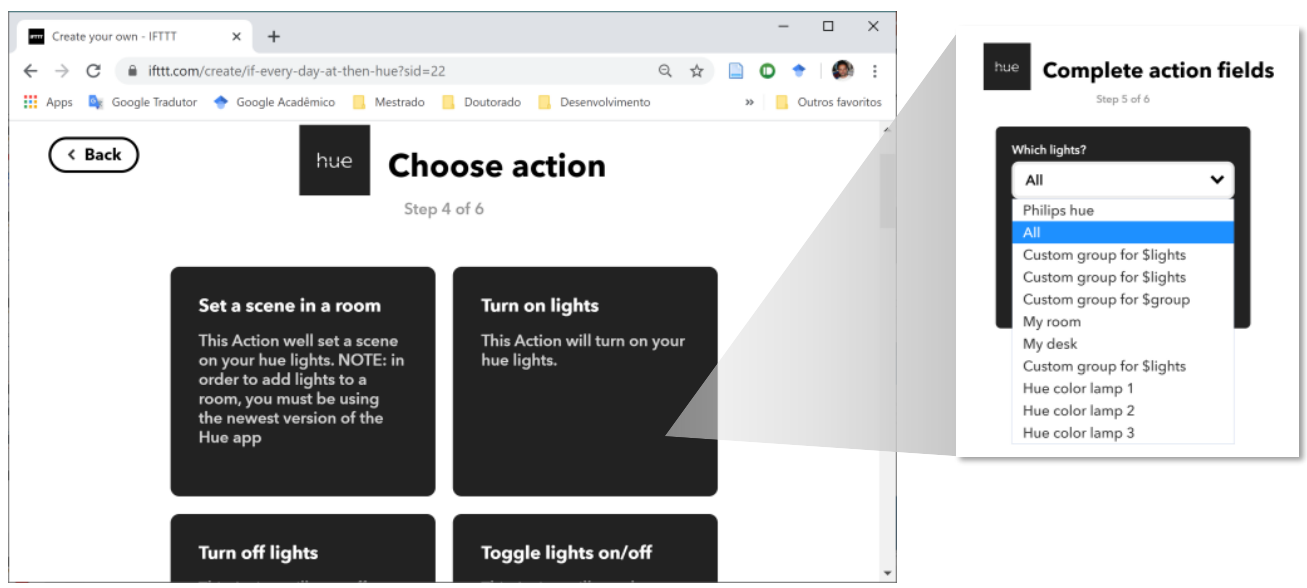

Figure 6-8 - Leaking signs from APIs in the IFTTT web application in three different moments: (A) IFTTT asking for authorization from Philips Hue; (B) Names and parameters from the Philips Hue appearing in the IFTTT interface while creating an action for a new applet in IFTTT (C). 


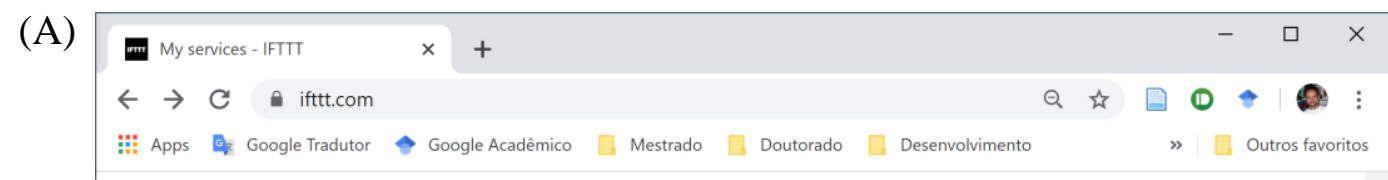

\section{IFTTT for business}

IFTTT enables your business to create the connected experiences customers want, at a fraction of the cost.

IFTTT Platform

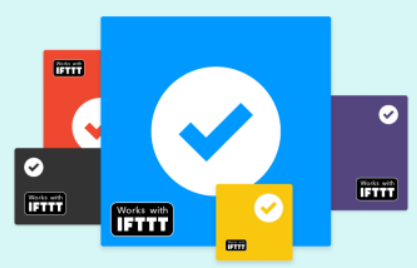

(B)

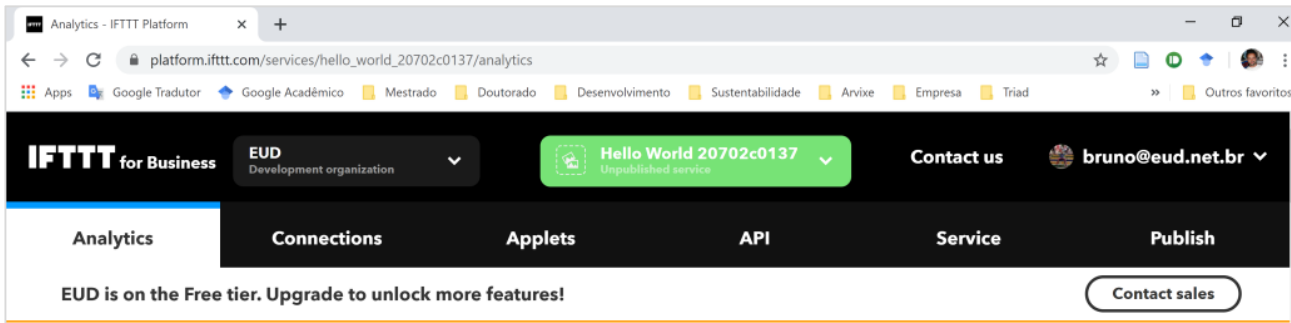

| Overview

Services chanum

Analytics

Categories casum

Applets chimum

User feedback

API health

API performance

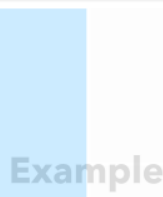

Figure 6-9 - The multi-sided aspect of the IFTTT platform: (A) an intentional leaking sign in the very bottom of the IFTTT web application points to the IFTTT interface targeted to its ad-users; (B) the IFTTT ad-user main interface.

My goal with this framework is to provide an initial basis to orient the application of Semiotic Engineering principles and methods in the IoT domain. This framework ties together all the concepts discussed before in this section, setting the stage for the development of a SIM-like inspection method for IoT ecosystems and similar multi-sided platforms. User interface inspections can be conducted considering additional metacommunication dimensions proposed here 
that complements the classification of interface signs in static, dynamic and metalinguistic in order to provide a means for considering the multiplicity of layered metacommunication discourses and the influence that they pose in one another, such as leaking signs. Multiple substrata address different physical interfaces and their respective types and modes of inputs and outputs found in IoT technologies. Multiple adstrata address multiple ad-users or stakeholders that may be involved and need to be considered. The relationship between sign types and metacommunicative dimensions is depicted in Table 6-1.

Table 6-1 - Types and dimensions of signs in multi-sided technologies:

\begin{tabular}{|c|c|c|c|}
\hline $\begin{array}{c}\text { Type I } \\
\text { Dimension }\end{array}$ & $\begin{array}{c}\text { Substratum } \\
\text { (1..n) }\end{array}$ & Superstratum & $\begin{array}{c}\text { Adstratum } \\
\text { (1..n) }\end{array}$ \\
\hline Static & \multirow{3}{*}{ 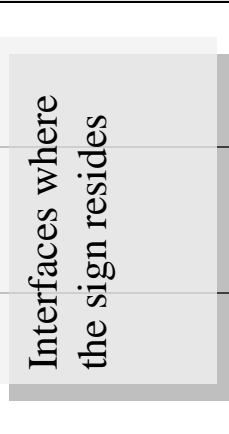 } & \multirow{3}{*}{ 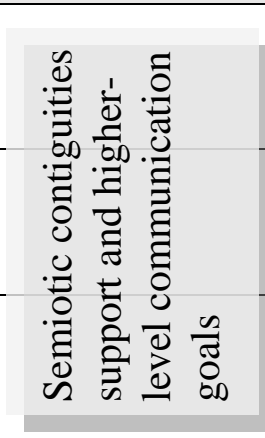 } & \multirow{3}{*}{ 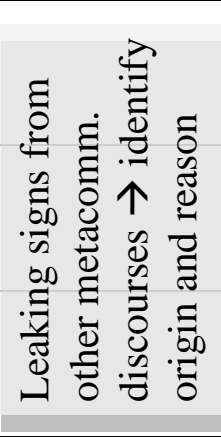 } \\
\hline Dynamic & & & \\
\hline Metalinguistic & & & \\
\hline
\end{tabular}

I propose we can visualize the multiplicity of metacommunication layers of IoT multi-sided technologies in terms of two dimensions, namely a vertical "level" and a horizontal "side" dimension, as depicted in Figure 6-10. Along the level dimension, metacommunications are stacked as developers' build an interactive technology by adding layers of abstractions from the machine to the human interface. This dimension is governed by the interpretive abstraction and the semiotic continuum principle as qualities to be pursued, as discussed before. Along the side dimension, we have multiple interfaces and multiple stakeholders (users, ad-users and third-party developers) that the technology is trying to serve. This dimension is governed by the cross-interface consistency and the crossdevice coherence as the qualities to be pursued. An IoT technology is comprised by multiple metacommunication layers - substrata, superstratum and adstratathat spread in this bidimensional space. The study of the mutual influence and effects arising from the contact between these layers of metacommunications are 
the core phenomena highlighted by the framework that cannot be easily accounted and studied without it.

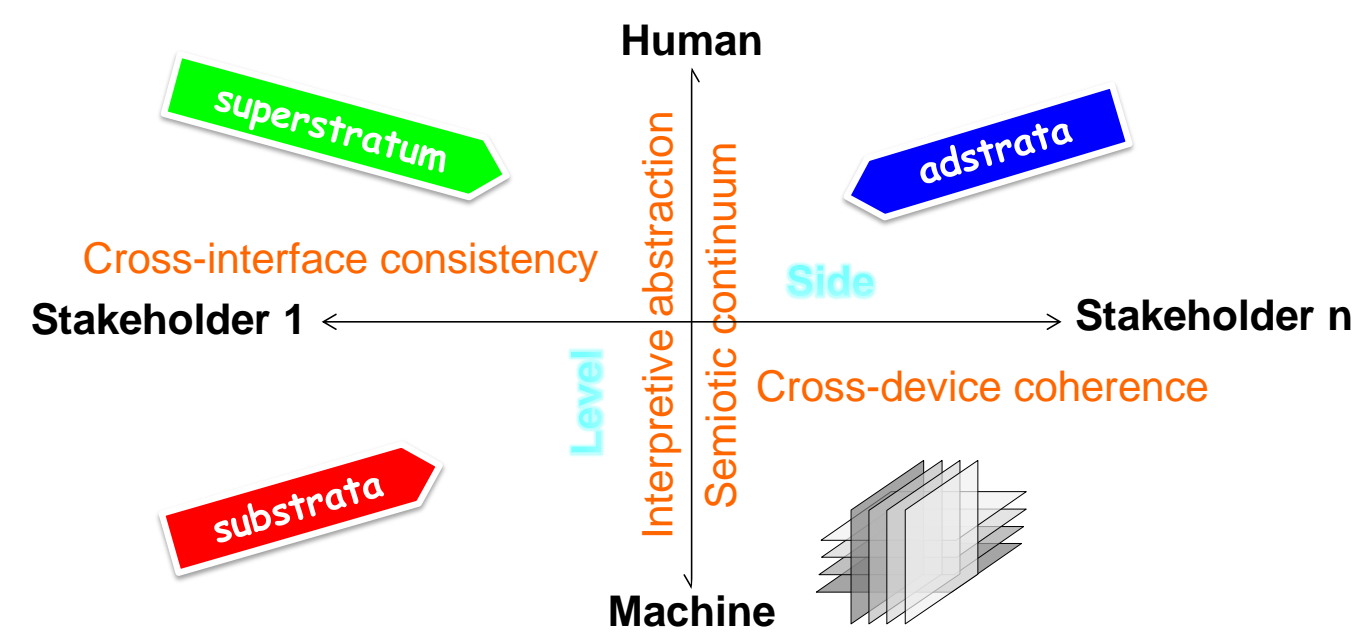

Figure 6-10 - The metacommunicative dimensions of IoT multi-level and multisided technologies.

The perspective of looking at IoT technology as layers of metacommunication discourses is interesting in itself, but it can also be very practical from a design standpoint. Along the level dimension, the complexity of IoT technologies is deconstructed in layers of different technologies and skills that can be distributed to different specialized teams, e.g. industrial design, hardware, basic software (firmware), web development, a mobile team, etc. Along the side dimension, different stakeholder needs are addressed. The power of the framework will manifest to designers and developers willing to exercise their communicative skills in putting themselves - as emitters of the message - in the shoes of others - the receivers of the message. Furthermore, teams and companies should pay extra attention to the consistency and coherence of the overall message across different interfaces and devices. Again, this framework is not suited to provide ready-made answers for any specific or general technology design problem. Rather, it is a framework to support and orient designers' and developers' reflection, since it is my firm belief that complex design solutions to human problems can only lead to successful results if properly conducted and performed by reflective practitioners, capable and opened to face the unique and 
complex challenges of the problems that are presented for them in unique and complex settings. Reflection is a necessary condition for successful design but not sufficient; frameworks to guide reflection towards what can be critical or relevant are another ingredient to be added to the designers' toolbox.

This framework may seem purely theoretical. Indeed, I mentioned before that the designers were overlooked throughout this research. However, they were not, they were with us all the time, speaking through their deputies. And that was how I noticed the "bimetalingualism" phenomenon producing interferences in the users' interfaces. Further empirical evidence was obtained from our last study. Participants from study 6 coming from an industrial background mentioned concerns about the business model that the technology was intended to support that reinforces this framework validity and applicability. For example, P1 mentioned how important it is for IoT products to follow a standard protocol for communicating with other devices, which today cannot be accomplished because of marketing competition. $\mathrm{P} 4$ mentioned a project that he has participated where a food and beverages producer was partnering with supermarkets and DVD-rental kiosks and getting data from customers who rented DVDs through their DVDrental app in order to use it in mapping the precise location of their food "smart shelves" inside the supermarkets and push promotions to customers. Similarly, when describing his current project with "smart tractors" and "precision farming," he mentioned how his company is trying to position itself in such a way that they can make use of the most possible amount of data, including from competing tractor manufacturers, in order to provide higher aggregate-value data-driven applications to customers. In my understanding, the only way to accomplish such thing is by means of industrial standards and/or data sharing agreements happening "under the hood." The "smart tractors" are supposed to serve many more that their immediate customers then.

Additionally, being a technology designer myself, this is something I have always missed in Semiotic Engineering principles and methods: how to address more directly the concerns, constraints, and goals of the designer that are not directly or strictly related with the users? Somehow, these get inscribed in the technology and several times they are the very reason of the most important design decisions a designer makes. Semiotic engineering in general and the metacommunication template in particular (Box 3-1) can easily accommodate 
these "conversation topics," but how this is done or how to do it in a useful and practical way for researchers, users and designers seems to be underdeveloped or underemphasized to date. I think this is in line with the recent advancements of Semiotic Engineering towards the HCC perspective of looking to the entire technology development cycle (e.g. DE SOUZA et al., 2016) and I think this framework can contribute to this line. To be fair, I am not aware of other theories or approaches in HCI or HCC that take these into account explicitly and systematically, an exception being Kuniavsky (2010) "service avatar" design approach. One can argue that these are business concerns. But are not these business concerns and decisions determining (or undermining) the user experience? Perhaps we should have a more clear and direct way to consider them in the interaction design and evaluation processes, methods and theories we use to study interactive technologies. This framework is also an initial attempt in this direction, suggesting that there might be something like "a metacommunication message" of businesses and services that carries a relatively important message to users.

Finally, this framework can dialogue with Espindola \& Silveira (2017) approach that studied the "conjoint discourses arising from many hands" in a multi-user EUD application, namely a virtual learning environment that they called a "multilevel EUD environment" (e.g. Moodle). Their focus was in studying the effect of multi-level configurations performed by different users in the teacher's self-expression, a key user of the system. Besides being focused in IoT and not being specific about EUD, my approach was focused in how the designer of the system sees and structures multiple metacommunications discourses directed to different users and stakeholders with which they establish a dialog through the system. I think their approach can benefit from the ontology I am proposing in this framework and the reversal (this framework benefitting from their approach) is probably also true. For example, it is rather likely that EUD technologies (such as virtual learning environments) can be analyzed in terms of substrata, superstratum, and adstrata metacommunication discourses to different types of users. In the other way around, there can well be intentional metacommunication discourses sent by ad-users to end users, perhaps a different or more sophisticated phenomenon from what I identified as leaking signs and that deserves further investigation. 


\subsubsection{Ethical Implications towards a Human-Centered IoT}

The leverage we gain by applying the framework described above is that it provides a minimum organization of the problem space of complex IoT technologies and ecosystems and highlights the phenomena of interest. It is a comprehensive and ontologically uniform (coherent) framework to study IoT technologies in a human-centered perspective. Potentially, this framing can help the identification of design problems and limitations as well as some clues about their nature and their origins by a contrastive analysis of information conveyed in co-existing layers of metacommunication messages sent to different stakeholders and their effects to the end user.

Notice that a distinction between "general IoT" and "interactive IoT" is not needed with this framework. Every IoT technology serving a certain purpose will comprise a metacommunication between the producers of the technology and its consumers. Even a distributed sensor network or a "pure" machine-to-machine system presents the two ends. Even in this kind of systems, there is either an end user or an ad-user or both being served or responsible for making use or managing the technology at the end, even if not immediately identifiable through layers of technologies. With this framework, we can deconstruct this chain into layers of metacommunication discourses flowing through different kinds of interfaces as media. In those systems which are closer to the case of "pure machine-tomachine" IoT, I think programmatic interfaces - that is, APIs - will do most of the work, calling for evolutions and refinements in approaches targeted at studying APIs interactive and communicative aspects (e.g. DE SOUZA et al., 2016, cap. 3.4). And as long as technology is designed and developed by people to people, this should be done in a human-centered perspective, and the metacommunication framework presented above can be applied.

Finally, because of the nature of the metacommunication message template and its epistemic power (see Section 3.1), an evaluation applying this framework can potentially account for ethical and values considerations, including security and privacy issues so critical in the IoT era. And it can do so by looking solely at the interfaces. In the era of "data-driven artificial intelligence powered smart technologies" it is critically important that designers and researchers have tools to assess and reflect on complex technologies (that is, platforms and ecosystems) in 
human-centered perspectives. Semiotic engineering has a strong focus in providing epistemic tools for the research and design of interactive technologies that can promote the designers' reflection. In particular, the metacommunication message template explicitly makes use of first- and second-person's discourse in order to emphasize the role of the people, both users and designers, in a deep human-centered perspective of HCI and of HCC (DE SOUZA et al., 2016, p. 53, 134, passim). This perspective is particularly suited to the point I am trying to make here.

Take the case for example of a social network platform. It has multiple users and ad-users (e.g. general user and advertisers), it has multiple interfaces to different users (e.g. Facebook the web and mobile app for end users and "Facebook Pages" and "Ads Manager" for ad-users), it is blended with the physical world by means of sensors because it keeps track of the places you visit, the device you are using, etc., and finally it has autonomous behavior based on AI algorithms and your data (e.g. producing your "news feed"). It presents most of the characteristics I highlighted as core features of IoT interactive technologies. And it is certainly not the only technology platform doing all this. With mobile phones being the most ubiquitous smart device around us today, all existing multisided platforms in the strict business sense (e.g. Uber with its clear groups of users and drivers (ad-users), each one with its specific app; the Amazon ecosystem with its multiple devices, marketplaces, smart stores, etc.) can be considered an IoT technology or platform in this perspective and would fit well in this framework.

Furthermore, as IoT ecosystems become richer and more complex, we can expect this framework to become more evident and relevant. Think about a smart city, for example. Citizens can be regarded as the primary end users of urban mobility services and applications, for example, but governments and service providers hold a significant stake that might pose strong influence in such platform features and design. At the interaction level, users access services through their mobile app, while dashboards and sophisticated data-driven algorithms may work behind the curtains using their devices and/or their data to fulfill another stakeholder need or goal. In theory, everything can happen in positive ways, in favor of everybody's best experiences, interests and intentions. However, we need ways to assess the overall user experience and the influence 
each side poses in one another in order to identify and address problems and conflicts that may emerge.

The ethical and social implications of such technological platforms today go far beyond the impacts of a better or worse pleasant interactive experience. With technology mediating most of our social practices, they tell people what deserve their attention and what does not; they influence how people think; they are used by people to help them distinguish what is true from what is not; they determine people's judgements and nations' elections. Researchers and society need instruments and frameworks to assess the extent to which technology designers are not doing better because they do not know how to or because they do not want to and how to respond to each case effectively.

Take the IFTTT case, for example. Researchers have identified a bunch of limitations associated with the over-simplified mode of trigger-action rule they make available for end users to setup their applets (HUANG; CAKMAK, 2015; e.g. UR et al., 2014, 2016). Having followed this platform over the last seven years or so, I observed different approaches they tried to allow more sophisticated configurations by the end users and regarding sharing policies until the point they are now. Initially, all end users could share their "recipes" with other users, what after a certain point was restricted to paid (premium) users, and now to the adusers of the platform only. A similar evolution happened to some advanced rules configurations they tried, now only available to ad-users. Clearly, the driver behind these decisions is not the end-user needs and preferences satisfaction alone.

I think we need to start to ask some harder questions about these technology platforms, especially considering that their presence and power in mediating social processes are being amplified by the IoT dissemination. Between apparently harmless examples from "dark patterns" (BRIGNULL; DARLO, 2010) hindering our experience using the internet to military grade weapons of massdestruction (LANDA, 1991) and of math-destruction (O’NEIL, 2017), people are subject to a continuous "technological semiotic attack" with increasing level of sophistication in our everyday lives. Systematic ways to approach this phenomenon in a human-centered perspective is the only way to account for ethical considerations related and emerging from modern technologies. Potentially, it can provide the means for society to "balance the game" in favor of 
people, what seems to me an urgent necessity of our times. To the best of my knowledge, no other such approach has ever been proposed for the IoT or other kinds of multi-sided technological platforms.

\section{3. Methodological and Epistemological Considerations}

Researching - finding new knowledge - is always challenging because it presupposes navigating in the unknown. Researching new technologies poses additional challenges, especially when related to human and social aspects, such as HCI research on new technologies. Besides the challenges that can be expected in trying to understand intriguing phenomena and discover hidden concepts and relationships, it seems there are additional challenges arising from the lack of alignment among the research community about what is actually important and deserves attention and investigation. This additional burden works as a hindrance to the evolution of the scientific knowledge because, before discussing and addressing knowledge gaps, researchers cannot actually agree in what is to be considered scientific knowledge, even less on how to produce it. In other words, it seems there is a lack of methodological and epistemological consensus. Methodological and epistemological because is not only about flawed or incomplete knowledge and how to fix and improve it but also about the scope and purpose of scientific knowledge itself, what is it for, how is it supposed to be discovered and used and under which conditions.

Research in new technologies such as IoT depends on both technical and human factors. If the technology is new, existing problems, possible solutions and established methodologies will not be easily found in literature. I discussed before how the design of interaction for the IoT is still in its infancy, where a lot of related and unrelated topics and perspectives are emphasized or ignored depending on the approach. Most often, the decision on what should be emphasized or ignored is just a matter of researchers' background and bias or of external factors (e.g. political decisions directing funding) because research is also subject to "human factors." Depending on the topic or approach, one may end up dealing with the irrelevant. For instance, a research about a certain interactive technology can become quickly outdated or lose its relevance if the technology is 
replaced by something better. Suppose that somebody finds a way to control things remotely without the use of any technology by simply using mental power. What will be made of the IoT technology research and investments in the field? This will certainly sound like fiction, but there may well be somebody out there doing this kind of paranormal research somewhere right now, and this would be a "blind spot" for the entire IoT research made in the Computer Science field. What I mean is that research is risky, especially with new technologies where "the big picture," or all facets thereof, is not yet well revealed or "smoothed" to be investigated in "standard ways."

Roughly speaking, a research project comprises a relevant and clear research question followed by a good answer, empirically and/or theoretically grounded. The kind of problems mentioned above manifests in a number of different ways throughout a research project with new technologies, but perhaps most important for practical purposes are:

- Difficulties in finding actual research gaps $\rightarrow$ A research gap is what usually leads to the relevant research questions to be answered. In the limit, everything is a research gap since what we know about the world is limited by our minds and culture and everything else is unknown in the (supposedly) infinite universe. In new technologies research, literature, our database of scientific knowledge, does not provide clear guidance because either it is not enough (few things have been investigated so far) or a minimum level of consensus or diversity in approaches prevents relevant gaps to be clearly delimited or even seen. In other words, a small database is more subject to "blind spots" that emerge when most of the scientific community look at the same problems, in the same ways, or through the same lens. As a result, traditional approaches to identifying research gaps such as systematic literature reviews cannot be of too much help in such cases;

- Difficulties in identifying what constitutes good answers $\rightarrow$ this has to do to with epistemological conflicts and can happen in every kind of research, not only with new technologies. Depending on what kind of research you do, what constitutes a "good answer" can greatly vary. In immature fields such as new technologies, a minimum level of consensus or diversity about what constitutes a "good answer" is also missing, especially when inside technocentric fields such Computer Science in general, where epistemological 
commitments and concerns are, usually, not even addressed or made explicit by the research;

- The need for speed $\rightarrow$ In addition, when researching new technologies, we have to keep in mind that industry always try to move in the fastest possible pace, trying to stay ahead of the market and discover the next "big thing," what can lead to "industrial amnesia" (DRAPER, 2017). Since research is strongly influenced by industry needs (after all, research costs money and is also a business), researching new technologies is continually under the tempting pressure of looking at "the newest coolest thing." Although important to be aware of what's going on everywhere, the pace of scientific knowledge is not always compatible with some "time-to-market" needs, what further hinders scientific relevance and rigor in detriment of immediate shortsighted results.

At this point, it is impossible for me to avoid talking about a word I think I used quite a lot throughout this text, and this word is "epistemology." I guess I talked a lot about it throughout this thesis, what is kind of unusual for a Computer Science research. But that should not be taken as a sign of arrogance or "terminological presumption." Rather, it's just a sign that I think I finally was able to understand what it actually means. Epistemology has to do with what scholars, researchers, philosophers and other investigators of the nature of scientific reasoning think about what we know about the world and how we know it, its limits, justifications and validations (cf. ARANHA; MARTINS, 1986, p. 427; DANCY, 2005; HAMLYN, 2005; STEUP; NETA, 2020). In other words, it has to with what is valid and valuable knowledge (cf. GOLDMAN, 2005; STEUP; NETA, 2020), the "currency" of science, and how to produce it. And how to produce it is determined by the scientific paradigm (GUBA; LINCOLN, 1994; MACKENZIE; KNIPE, 2006) or philosophical worldview (CRESWELL, 2014, p. 5-11) one takes.

My summarized understanding of the authors above is that are roughly four main scientific paradigms that a research approach can follow. The most classical paradigm is the positivist paradigm. It commits with the belief that there is a "universal natural law" behind the phenomenon or object of study. Knowledge is thus the revealing of these laws. It is the reign of natural sciences, experiments, 
and quantitative methods in the strict and most usual sense, those that one can make and replicate in a controlled way in order to discover and prove the gravity law, relativity, and the like. Because natural laws are thought to be "universal," replicability and generalization ability are key under this paradigm.

The constructivist or interpretive paradigm in turn do not commit to natural laws. In this paradigm, the object or phenomenon of study is only accessible through the observer perception and interpretation of the reality. Knowledge is thus whatever interpretive construction one builds. But it is more legitimate ("natural" so to speak) if coming from those directly (or "naturally") involved or immersed in the phenomenon or context of interest, that is, observed people, participants, etc. Any interpretation is valid if obtained honestly. Some will be better than others, but this depends on the observer's ability and sensibility to identify and highlight what is interesting, new, unique, remarkable, and the like. Therefore, researcher's interpretation also plays a definitive role. They will not necessarily tell you a word though about how to use their interpretations and what they are for. The interpretation has value in itself. This is the reign of social sciences, where measurements by instruments are not possible, and the cradle of qualitative research and interpretive methods to assess phenomena. Generalization and replication are not only impossible, they simply do not matter or make sense in this world because nobody expects to find two identical contexts and interpretations.

The transformative or critical paradigm takes as valid knowledge only what can interfere, change, transform the reality. A phenomenon or object of study, usually a social context, does not have interest in itself, but only for the ways by which it can be transformed. It is also dominated by qualitative methods, but knowledge is only what is applied and related to social transformations. You can use interpretive (qualitative) methods, but whatever you find out is only valuable in light of the social transformations it is able to produce. Action research (cf. SUSMAN; EVERED, 1978) is the example "par excellence." Generalization is not a goal and probably impossible, but some degree of replication may work as inspiration if well justified and research is conducted wisely.

Finally, the pragmatist paradigm is the least committed to methods of all. But this is not because it is not scientific. In the pragmatist paradigm, knowledge is valid to the extent that it can produce practical consequences. Usefulness is the 
most important criteria, that drives all other choices. If something is not true, precise, and consistent with the reality, it will not work in that reality and thus will not be suitable for any use. And since usefulness cannot be determined "in abstract," it presupposes that the observer (e.g. a researcher and a research community) has a goal and is immersed in a certain concrete real-world context while conducting inquiry. Generalization and replication are desirable because they amplify the usefulness of the results. If some result works for some goal and under certain conditions, it shall be considered "good enough," and the flow of inquiry will tell what the absolute truth is, eventually. If you read this thesis until here, you can probably trace why Peirce is considered one of the fathers of the Pragmatist paradigm. This is the reign of the so called mixed-methods, which combine qualitative and quantitative research in problem-centric fashion.

That said, a minimum awareness or acknowledgement of the worldview assumed in a certain research would prevent a lot of problems in people understanding each other's research. For instance, to look for a "universal law" in a social or human phenomenon can turn out to be a waste if it does not describe something meaningful. But what is meaningful can only be determined by human personal and cultural signification. That is what Semiotics is all about after all. Therefore, conducting quantitative research before knowing what is actually meaningful, important, worth knowing, does not sound logic, not even for the socalled natural sciences, and even more for the study of human/social phenomena. Technology is all about human/social phenomena. There is nothing "natural" in a piece of technology designed by someone to somebody under certain circumstances and with a set of goals in mind. Even more if research is focused in the interaction part, as I did.

Clearly, this research mixed a lot of methods and is closer to the pragmatist paradigm. According to Morgan (2014), "Pragmatism shifts the study of social research to questions such as: How do researchers make choices about the way they do research? Why do they make the choices they do? And, what is the impact of making one set of choices rather than another?" Throughout this thesis, I tried to answer these questions by describing my research path and what drove my decisions, a "price to pay" for being pragmatist. The useful knowledge I was looking for was something that could be useful for the design of appropriable IoT technologies. Depending on what one think design is and how it is done can 
change the entire answer, usefulness, and relevance of this thesis' findings and results. The best I can do is to make explicit my own vision of design, and argue how my results match this vision, as I tried to do. Others whose vision of design is in conflict with the one here will probably find this thesis of little use or value. My results are for reflective practitioners and are committed with this "epistemology of (design) practice." My argument in defense of such epistemology against other possible ones is because I think this is the only one able to account for human-centered perspectives, complex problems and solutions when studying technology that is designed by humans for humans.

Finally, I need to say that epistemology precedes theories, but I only found out that at the end. Thankfully, since the epistemology determines what is a theory for and how it looks like according to each worldview, I was lucky to adopt a theory that was aligned with my own worldview. In other worlds, I ended up adopting an epistemology without being very conscious, getting a ride in Semiotic Engineering constructions. I attribute it to intuition and the mysteries of Life. After gaining awareness of the process, I think I could greatly improve results and my discourse. And that can be attributed to the training and guidance I received. This is how I justify the choice of my methodological and epistemological approach.

\subsubsection{A Macro-Method for Researching New Technologies (or for New Researches in Technology)}

The way I mixed methods may seem quite unusual and far from being a traditional qualitative mix (cf. LINCOLN; GUBA, 2000) or qualitativequantitative mix as usually advocated (e.g. CRESWELL, 2014). It turns out that my unusual, somewhat "thorny" (epistemologically speaking), research approach can also be seen in a human-centered perspective of scientific research. In this sense, my research path can be useful to others in similar research contexts and for this reason I will try to systematize it in the form of a macro-method to conduct pragmatist research with new technologies.

My methodology can be roughly split in two parts, as suggested by the way I organized this thesis with two methodological chapters (Chapter 4 and Chapter 5). The first part of my methodological approach (Chapter 4) was targeted at 
identifying a relevant research gap within a topic of interest, namely interaction with IoT technologies. I called this stage mapping the problem space as a metaphor for navigating the unknown. As mentioned before, I started with a general interest in EUD for the IoT and with a "feeling" of the problems that were in need of better answers around this topic. Nevertheless, existing methodological and epistemological problems in "pure" EUD research (DE SOUZA, 2017b; cf. TETTEROO; MARKOPOULOS, 2015) added by difficulties in establishing a fruitful dialog between this field and IoT research (e.g. Ubicomp, which probably has its own methodological and epistemological problems) made it hard to advance from the very beginning.

Mapping the problem space is performed by means of successive triangulations of theoretical and empirical studies. The number, kind, and methods of studies are very opened at this point, but an interesting suggestion is to combine empirical with theoretical studies in order to be able to encompass a broad enough chunk of the problem space with reasonably different perspectives and lenses. In my research design, these phase was represented by studies 1 (Section 4.1 - theoretical inspections based on Semiotic Engineering), 2 (Section 4.2 - a qualitative analysis of IFTTT applets using some grounded theory techniques), and 3 (Section 4.3 - my autoethnography with IoT devices). In addition, theoretical studies will help you build your "theoretical platform" (MARTINS, 2006, p. 18 et seq.), a kind of "boat" for navigating complex problem spaces, which is represented by Study 1 (Section 4.1) in my case. I think this is somewhat overlooked in research about new technologies, but learning a theory is something that demands a lot of study and time, and the broader and deeper the theory, probably more time it demands. Sometimes, you confound actual theoretical problems and limits with problems arising from circumstantial conditions or even mistakes you make and the only way to see it is by deepening your theoretical knowledge and trying again. And there is nothing better to assess your theoretical knowledge than trying to apply it in practice, such as by conducting theoretical studies.

By means of triangulating different methods, I was actually trying to build a picture of the problem space in order to be able to locate a relevant research gap that would worth, has not been investigated yet and was feasible to be addressed. The more studies you do, the higher "resolution" you will have in this picture. But 
since everything has a cost and time is usually not on our favor, how do we know when to stop? At that point, I would say I failed in the sense that I did not find any clear research gap that I could articulate and all my conclusions seemed no more than scattered findings incapable to convince others or make its way through peers or relevant scientific venues. However, part of this problem was not mine, since I cannot be responsible for lacking methodological and epistemological consensus of a nascent research community, part of which was in reality importing and reproducing problems from other "older" fields such as HCI or Software Engineering. It took me while until I distinguished my own "internal" from "external" problems and even more until I find my strategy to talk to this community without "killing or being killed." I am not sure if I accomplished such goal to date, but what I did do then was that I found some support points that allowed me and my inquiry to keep flowing. As briefly mentioned before, I called these support points anchor concepts.

Anchor concepts are concepts that help to reunite scattered findings and relate theory (in the strict sense, e.g. Semiotic Engineering theory, and in the broad sense, e.g. literature reports) to empirical data. When researching new technologies, this is very useful because most relevant problems and solutions to look for as well as a reasonable level of consensus or diversity about the research approaches to be adopted cannot be found in literature. Everything is scattered findings and neither methodologies or empiricism alone can do the work because nobody knows what is actually valuable knowledge in the research domain. In other words, there is not enough methodological and epistemological consensus. Anchor concepts are not theory or findings "per se" in the sense that they do not answer any research question, but they work in the "meta-level" of the research by helping to frame the research questions to be posed. In addition, they help to establish a more fruitful dialog with the scientific community by relating with existing findings and theories, an essential requirement for peer reviewed research. Finally, they work like pivots in mapping the problem space, connecting triangulations and avoiding a continuous drift towards "the newest coolest thing," which is a strong temptation for those working with new technologies.

In this case, the anchor concept I found out was the concept of breakdown as a phenomenon around which several interesting interaction problems emerged and, in addition, was relatively easy to reproduce empirically. Once an anchor 
concept was found, I was able to design an empirical study to investigate it deeply, which was the core study of my research—Study 4 (Sections 4.4 and 5.1).

The act of investigating an anchor concept empirically should be carefully considered. In a broad sense, empirical investigations are conducted by means of experiments, that is, tests within the reality. However, the most traditional scientific paradigm - the positivist-associates "experiments" with variable controlled tests of theoretical hypotheses in order to proof or refute them (cf. GERGLE; TAN, 2014). Clearly, that was not what I was trying to do. The experiment I am talking about here was targeted at reproducing a phenomenon of interest - that is, breakdowns with IoT technology, in our case-in order to produce data about it that could teach me something.

In order to make this distinction clear, I will resort one more time to Donald Schön. This kind of experiment is in line with what Schön calls "on-the-spot experiment" (SCHÖN, 1983, p. 141 et seq.):

"In the most generic sense, to experiment is to act in order to see what the action leads to." (ibid., p. 145)

In particular, Schön defines one kind of "on-the-spot experiment" as exploratory experiment:

"When an action is undertaken only to see what follows, without accompanying predictions or expectations, I shall call it exploratory experiment. [...] Exploratory experiment is essential to the sort of science that does not appear in the scientific journals, because it has been screened out of the scientists' accounts of experimental results (perhaps because it does not conform to the norms of controlled experiment). Exploratory experiment is the probing, playful activity by which we get a feel for things. It succeeds when it leads to the discovery of something there." (idem)

In my case, I wanted to see the consequences of breakdowns in terms of users' actions and experience with IoT technology, and capture data about whatever would happen around a breakdown. In terms of goals ("get a feel for things") and measurement of success ("the discovery of something there") Schön is talking precisely about what I did. Perhaps the only difference from Schön's exploratory experiment above is that my "act" was particularly planned for collecting data and not for producing changes in a setting or artifact (as is usually the case for a reflective practitioner). But we can assume that this difference is a matter of circumstance rather than essence in the sense that it is related to the 
settings and artifacts that myself as a researcher, also a reflective practitioner as Schön would say (ibid., p. 323 et seq.), deals with during his or her practice.

Finally, the final part of our research was targeted at converging towards more precise research questions and answers in order to reunite the results and findings. This was done by evaluating our findings and results and organizing our contributions. The studies described in Chapter 5 were naturally much more focused in scope and allowed us to gain speed not only because they were simpler and smaller in size but also because the overall approach was finally leveraging from many scattered findings I had found before. Previous results and findings were leveraged by means of organizing them around what I saw would be my most relevant contributions from this research, framed in terms of the research questions as posed in this thesis. Section 5.1 is a continuation of the data analysis of the diary study oriented towards producing answers to these research questions. And then studies 5 (Section 5.2 - thematic analysis of literature reports) and 6 (Section 5.3 - model evaluation interviews with IoT designers) were targeted at evaluating these answers.

This overall research approach is depicted in Figure 6-11, which is a generalization of Figure 5-2 from Chapter 5. There are two ways that I see this approach can be useful. The first one is in research of new technologies, such as our approach to research the design of interaction for IoT technologies. In this case, this approach is justified as a way to overcome the three main inherent characteristics of new technologies as a scientific field outlined in the beginning of this section, namely: difficulties in finding actual research gaps, difficulties in identifying what constitutes good answers, and the blazing-fast pace of changes. Another way this approach can be useful is when a certain research field gets "addicted" or too habituated with one or a few prevailing approaches. I think this hinders scientific evolution due to lack of diversity, operating in a similar way when the amount of literature is not enough or there is lack of methodological and epistemological consensus. That is, the amount can be huge, but it's like everybody is doing more or less the same thing. In addition, maybe the epistemological consensus is not lacking, but has gotten hidden (implicit), making it seem that it does not exist or is not important. There is nothing particularly wrong with this, a priori. But for those who think there might be other interesting things going on or in the need or search for doing differently than the prevailing 
paradigms, this macro-method may work as guideline or a "meta-research" approach to help along the hard road ahead.

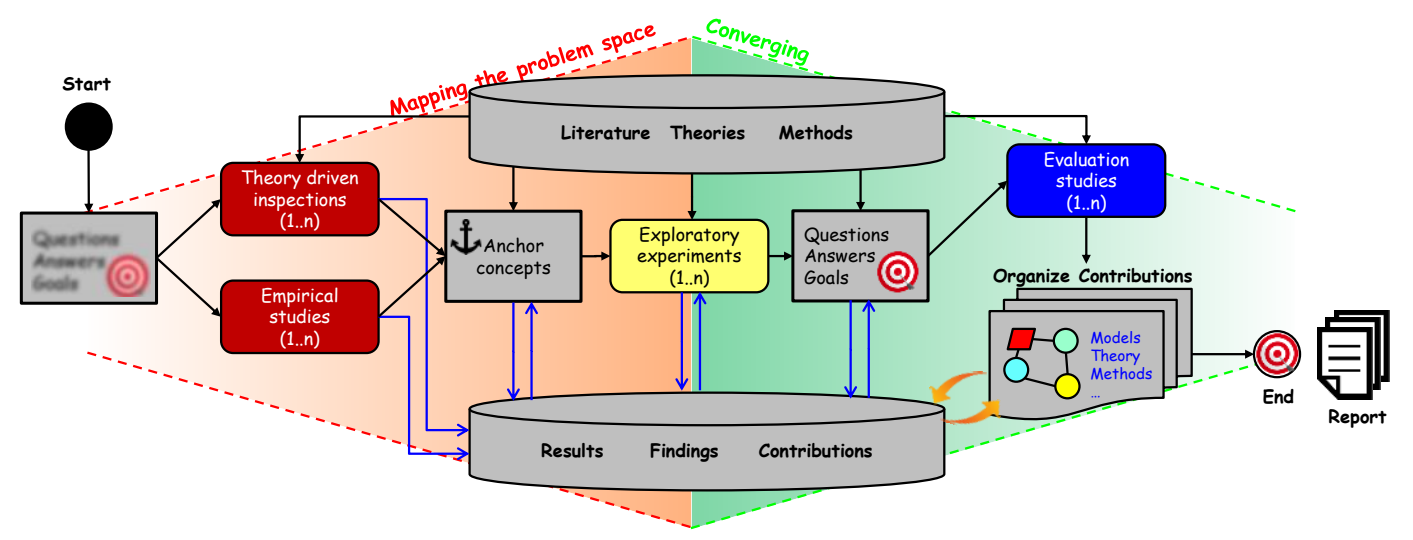

Figure 6-11 - A macro-method for researching new technologies or for new researches in technology.

In the sense described above, this macro-method can help break current paradigms and fertilize established fields with new ideas, approaches and theories by enabling the introduction of new ones into the scientific discourse. The question is then is if this research in particular and this macro-method in general is well-done and how to do it better? This is probably the topic of another thesis, but my answer here is: probably both. It is easy to say that I am committed with a certain epistemology and philosophical worldview at the "end" of the research. It is an exercise of reflection towards what was already done. But looking to the future trying to guess where you will arrive in advance when one is already flying on the plane and running against time is much, much harder. Probably impossible, without the direct and indirect help of several others. This macro-method should be taken as an orienting piece of "methodological theory," another overarching theory in Schön's terms, for the pragmatist reflective practitioners of research.

And since the purpose of describing this methodology here in a systematic way is that somebody finds it useful for conducting some other research, I will try to give a final piece of advice that cannot be written in scientific terms. Assume that you will not find the "next big thing" and just try to do something carefully. I will resort to poetry one more time:

"To be great, be whole;

Exclude nothing, exaggerate nothing that is not you. 
Be whole in everything. Put all you are Into the smallest thing you do.

So, in each lake, the moon shines with splendor Because it blooms up above." (PESSOA, 2001)

Pessoa's "above" means above the challenges, problems, bad feelings, and stuff, not superior to anybody. Everything and everybody (including yourself) will try to distract you and push you, all the time, sometimes in necessary and positive ways, others not. I keep trying. Nevertheless, do persist, as they say. 


\section{Conclusion}

The Internet of Things, under the robes of ubicomp and its supportive technologies, has been connected with human-centered computing (HCC) since HCC's inception (cf. TALBERT, 1997). According to Jaimes et al. (2007), HCC can be seen as an expansion of the interaction concept towards embracing more "human" aspects or a cross-cutting theme impacting all computer-related practices. In the former perspective, I think it's more like an expansion of the HCI field concerned with the design of interactive technologies in a way that it is more sensitized to human and social aspects at the same time that it tries to leverage from recent technological developments in order to amplify interactive possibilities in different ways. The latter seems deeper, more innovative, and harder, at least to my eyes. It is supposed to shift the focus of all computer-related research and practice towards considering the human and social aspects that influence not only technology use (interaction) but also its construction (design) and, why not, the research that supports it and has been promoting technology evolution at the current pace.

As an expanded and deeper view of HCI, user-centered approaches may suffice. This vision seems to be embraced by some researchers, because even if termed "human-centered" they do not seem to be looking for anything different than "knowing the user" in a broader and more sensitized way (BANNON, 2011; e.g. BUTZ, 2010). As a cross-cutting theme to any computer-related research and practice, we cannot forget that, in the same way that the design of interaction cannot be undertaken without studying users, users' interaction cannot be studied and improved without looking at the design practice, an HCC look at HCI practice, so to speak. In this thesis, I took this latter perspective on HCC to study and try to advance both knowledge about interaction with the IoT and the design thereof, following an approach outlined by Semiotic Engineering since its beginning and reinforced recently (cf. DE SOUZA et al., 2016). 
At the users' side, I identified appropriation as a desirable outcome and core component of user experience with the IoT and identified some gaps in knowledge about appropriation of IoT technologies and about how, at the designers' side, they could design more appropriable IoT technologies (Chapter 2). I framed these gaps in terms of the following related research questions in order to drive the answers I was looking for:

- R1) How do people appropriate IoT technology?

○ R1-A) What does "to appropriate" IoT technology mean?

- R2) How to design appropriable IoT technology?

○2-A) What does "to design" IoT technology mean?

I assumed that a theoretical model of appropriation would constitute good answers to these questions, and I chose Semiotic Engineering as a theoretical lens to study appropriation and ground my model. This theoretical foundation was chosen in order to leverage findings and results based on a set of existing theoretical concepts and principles, but Semiotic Engineering theory itself has not been extensively applied neither in the study of IoT technology nor in the study of technology appropriation, to the best of my knowledge. For this reason, I thoroughly reviewed foundational semiotic theory in order to set the stage for extending Semiotic Engineering to explain IoT technology appropriation and the design thereof in a sound way (Chapter 3).

My research design was split in two parts. The first part was targeted in mapping the problem space and empirically testing some pre-existing theoretical concepts and principles from Semiotic Engineering (Chapter 4). I started by looking at the communicative aspects of interaction with the IoT, inspecting IoT technology by applying Semiotic Engineering's main tenet to test it and see what I could learn from it (study 1 - Section 4.1). In a similar vein, but with a different qualitative method, I analyzed the communicative dimensions of the configurations people do with IoT technologies (study 2 - Section 4.2). A third study was an auto-ethnographic approach, where I have experienced myself several IoT devices on a continuous basis. At this point, I identified breakdowns with IoT technology as an anchor concept, a phenomenon of particular interest and richness, which resonated with some literature approaches but seemed rather unexplored. I planned and conducted a diary study specifically designed to produce data about breakdowns users would have with IoT technology and their 
attitude when coping with them. The main result of this study was the framing of appropriation as states corresponding to the interpretations users build abductively about the technology, with the breakdowns being the points where users revise their interpretations and can then evolve to richer appropriation states (study $4-$ Section 4.4).

The second part of my research design (Chapter 5) was target at converging towards the answers of the proposed research questions. First, I utilized the data inventory from the diary study to evolve from the abductive appropriation framework proposed in study 4 to a theoretical model of appropriation able to describe IoT technology appropriation in more detail (study 5 - Section 5.1). From the initial abductive framework to a more thorough semiotic model of appropriation, the main evolution was the identification of seven semiotic processes that are able to describe core semiotic operations users do while interpreting and appropriating IoT technologies. These semiotic processes are grounded both in data from the diary study and in semiotic theory and correspond to different ways by which users elaborate the semiotic material sent by technology designers - namely, the designers' metacommunication message embedded into the technology interface. In study 5 (Section 5.2), I conducted a "reality check" in order to verify if this semiotic model was able to describe other reports about appropriation found in literature, which was found to be the case. Finally, I conducted a semi-structured interview with IoT technology designers in order to evaluate the usefulness of the proposed semiotic appropriation model (study 6 - Section 5.3), which revealed some possibilities of using the model for the design of appropriable IoT technologies aligned with Donald Schön's (1983) reflection-in-action approach to design.

In Chapter 6, I reunited previous findings and results in three contributions that comprise the answers to the research questions and one collateral methodological contribution. Firstly, the semiotic appropriation model was refined in light of the semiotic theoretical foundation presented before (Section 6.1). Semiotically, appropriation corresponds to the incorporation of interface signs into users' signifying systems and the emergence of users' interactive idiolects by which they develop their personal ways of interacting (talking) with the technology. Several implications for the design of appropriable technologies were discussed, in particular that of leveraging breakdowns in order to produce a 
poetic effect in challenging users' known semiotic codes (in Eco's sense) and promote their acquisition of new ones. Over all, I propose the semiotic model of appropriation should be used by reflective design practitioners as an overarching theory (SCHÖN, 1983, p. 273-274) —or an orienting theory (WINOGRAD, 2006, 2017) - that is, a backdrop theory that help designers frame the problems to solve by identifying features or requirements for the appropriation of the technology they design, a sort of "backdrop" or "parallel" requirements.

At the other hand, I highlighted that designers' lives are not a bed of roses, since IoT technologies merge hardware, software and services in a considerably complex way. I characterized IoT technologies as multiple layers of metacommunications that are stacked during the design process (Section 6.2). In this perspective, "stacking" goes along two axes: in terms of levels of abstractions, from electronics, to firmwares, to APIs, to user interfaces; and in terms of sides, comprising the different stakeholders that a piece of technology is trying to serve (e.g. end users and $a d$-users). This characterization was observed in some IoT technologies and apps throughout our research and is sound with Semiotic Engineering theory. I borrowed the concepts of substratum, superstratum, and adstratum from the linguistic phenomenon of bilingualism in order to characterize IoT technologies in terms of "bimetalingualism," that is, the conjoint existence of multiple metacommunication discourses residing in a single piece of IoT technology. I propose that it comprises an initial ontology for studying and designing complex technologies such as IoT in a human-centered way. With this characterization, I intend to complement my semiotic model of appropriation, which describes phenomena at the user's side that can be useful to designers, with a description of phenomena at the designer's side that can be useful, if not directly to users, to designers themselves and to researchers trying to improve the technology users use.

Finally, I proposed that my research design can be useful as a macro-method for pragmatist research with new technologies (Section 6.3). I see that our approach of combining multiple methods can be useful in situations when there is not enough clarity about what constitute relevant problems to address and how to address them. In such cases, researchers are challenged to both approach complex phenomena and establish fruitful dialogs with the research community. However, lack of methodological and epistemological consensus may arise when there is not 
enough research available, such as with new technologies and the phenomena around them, or when there is not enough diversity in the existing the methodological or epistemological approaches. Methodological and, most importantly, epistemological implicit and explicit mismatches hinder the scientific debate and advancements in ways that are, most often, not perceived or acknowledged in Computer Science research. In particular, this macro-method emphasizes theoretical approaches as a fundamental component in helping to keep epistemological coherence and rigor, what I think is much harder in purely empirical research in such scenario because the commitment with a certain theory and epistemology helps overcoming the inconsistencies and shakings of the research field. I claim that this macro-method can help researchers in navigating complex problem spaces and fertilize research fields with new scientifically grounded ideas and/or approaches, either because the technology is new and little is known about it, or because much is known, but mostly with and around a single or a few habitual paradigms and approaches.

Now, I will discuss this research main limitations as well the new research questions or paths I see it opens.

\section{1. Limitations}

This research is committed with a particular vision or epistemology of $\operatorname{design}^{31}$ as described by Donald Schön (1983), which is not the only one possible. As mentioned before, the contributions I am proposing in this thesis fit within this vision and not necessarily with others. Perhaps most well-known "opposite" vision is Herbert Simon's technical rationality view of design (SIMON, 1996). "Opposite" between quotes because this "opposition" may be seen as exaggerated or unfair (cf. SOO MENG, 2009). However, I am sticking to Schön's emphasis on design as problem setting ("naming and framing", op. cit., chap. 2), rather than on problem solving, which is Simon's perspective, according to Schön (idem). Both visions are useful and probably complementary, but optimization problem solving requires different kinds of theories than those that I have proposed here.

31 Some would it call a theory of design (e.g. CAO et al., 2010), but I think epistemology is the most appropriate term here, in accordance with Schön's proposal of an epistemology of practice. 
Similarly, this research is mostly committed with a single theory of HCI and HCC, which means it's limited, by design, to the theory scope and goals. In our case, Semiotic Engineering focuses in the communicative aspects of technology interaction and design. There are probably other aspects that can be studied regarding IoT technology appropriation and the design thereof, such as cognitive, social, etc. The semiotic appropriation model proposed here, as well as our semiotic characterization of IoT technologies as layers of metacommunications, cannot account for all aspects of appropriation and of IoT interaction design. Other theoretical backgrounds, some of them cited before such as cognitive psychology, social structuration, instrumental theory, etc. can probably reveal other interesting and important facets of appropriation and support the design of appropriable technologies in different and complementary ways. I think that other empirical and theoretical accounts of appropriation are compatible with the one proposed in this thesis, mostly because its grounding in Semiotics inherits its broadness and power. Some evidence that this is the case were briefly explored in study 5 (Section 5.2) and in related work (Section 6.1.5), respectively. However, it does not mean that there are not "blind spots" or increments to be made in this semiotic appropriation model.

Most immediately, the social and socio-technical dimension of appropriation is often addressed by several researchers, mostly in the CSCW field, and is not the focus of our model. Probably, this is one of the most important influences that would need to be considered in order to further refine our model. By being grounded in Semiotics, I think that our model can embrace the social dimension of appropriation in relatively easy ways. Modern semiotics has highlighted the role of culture in human signification processes, as briefly discussed in Section 3.4. In addition, my model includes a "cultural gate," which I called the "transferring" semiotic process. By means of studies targeted at observing appropriation of IoT technologies in social contexts (e.g. a family, a work group, a social interactive exhibition, etc.), I think this model can be adapted or extended to address this important dimension of appropriation in useful ways.

Another important limitation is to further validate our semiotic appropriation model. At this point, I consider the model to be scientifically valid in an acceptable way. The model was derived from a rich inventory of qualitative data extensively analyzed over the course of years; the model is sound with pre- 
existing theory, both Semiotic Engineering in particular and semiotic theory in general; the model was initially validated in two different ways that were able to show it "works" and its usefulness, including some promising possibilities of application. In spite of these positive indications, the final shape and usefulness of the model need to be better tested in more extensive and detailed ways. This was mentioned by some participants in study 6 (Section 5.3) and one promising way of doing so was proposed during the pilot phase interviewing experienced designers. We could conduct a study identifying how each semiotic process is supported in a couple of existing IoT technologies and try to relate this data with some actual "success rate" related to the technology appropriation ${ }^{32}$. In other words, we could check if and how technology "success" in terms of appropriation is related to a better or worse technological support of each semiotic process of the model. For now, I do not have a precise way to qualify, quantify or compare two appropriation states yet in order to say which one is "better" and under which criteria, what already demands more research to start with (see next section). Nevertheless, the model I am proposing is able to describe different situations in sound and useful ways, and this was shown, most of the model's merits arising from its solid grounding in semiotic theory.

In a similar vein, my other contributions should be further validated. The semiotic engineering of multi-level and multi-sided technologies is proposed here as an initial theoretical ontology developed and articulated based on previous theory and that fits some technologies I investigated, what should be taken as empirical evidence. I will discuss how to develop it further in the next section as future work. In addition, if my first two contributions are found to be scientifically valid and minimally relevant, this should be taken as an evidence that corroborates that the macro-method for researching new technologies "works" in at least one instance. Other long-term research should be done in order to validate this contribution further and improve it.

Regarding Semiotics, I derived some theoretical principles in terms of semiotic idiolects, personal signifying systems and the poetic function of technology in Section 6.1.1. These are local theoretical derivations mostly based on Eco's (2017) theory of Semiotics and Danesi \& Perron's (1999) theory of

32 I thank this suggestion to Dr. Tao Wang, colleague researcher at UCI and currently at SAP. 
Cultural Semiotics that were proposed in order to explain technology appropriation as a semiotic phenomenon. I do not claim these are contributions to the semiotic field. However, I think the dialog between applied Semiotics (to technology, in our case) and "pure" Semiotics research needs to be fostered, since technology comprise today one of the most rich and vast means of communication and, as such, of semiotic phenomena of all sorts.

Finally, another important limitation to this research arises from my own bias. As the reader could see throughout the text, this research was primarily based on qualitative research approaches. A strategy to improve qualitative research validity is to clarify the researcher bias (CRESWELL, 2014, p. 202). My background, values, training, and interests shaped the direction this research took, as is always the case with any research. By making these factors explicit, I practice reflexivity (CRESWELL, 2014, p. 186) in hope to clarify the research context to the readers, helping them to understand our methods and interpretations and assess this research's merits and limitations.

First of all, I was born human, and the reason why I choose a humancentered perspective is that I insist being human, which demands a constant effort from my side. Secondly, I am a technology user. Actually, I do not see how a research about technology can be conducted today departed from this perspective since everybody uses technology for everything these days. I do not claim that I represent any sort of "standard user," just a "human user," and my autoethnography using IoT (study 3 - Section 4.3) should be seen as an explicit statement of this side of mine. And thirdly, I consider myself to be a designer. I am a Computer Engineer with formal training in Computer Science and programming and with a reasonable background in industry, where I participated in several "real-world" projects under "real-world" conditions.

I am probably other things too but I think these three factors played the most important roles in biasing this research. In particular, being a designer/developer with a strong industry background and some entrepreneurial dreams, prevented me from forgetting the "designer's side" of the story. It promoted a mix of "insider" and "external" observations throughout this research, and there is a chance that my auto-ethnography using IoT was also a kind of "UX research" in this sense too. This appeared throughout the text in some interpretations and choices I made, for instance, the introduction of some business-related concepts 
and literature. Businesses, "as usual" or not, are certainly coupled with design decisions in most technology projects, which can only be addressed by humancentered approaches such as the one I am proposing in this thesis, I think. For sure, it is a limitation of the work, but I think it improved the overall final result in the sense of guiding my research towards supporting other designers like myself in more practical terms. Nevertheless, I need to acknowledge that many other perspectives and interpretations are possible and some are probably better depending on the research goals and purposes, what does not take out the value of this thesis and can most likely enrich it.

\section{2.}

\section{Future Work}

Some interesting directions for future work were briefly outlined in the previous section as more or less direct ways of addressing this thesis immediate limitations. Mainly, they go on the line of expanding the semiotic appropriation model for addressing social appropriation and further validating the model against existing technologies and models. I should complement this line of future research with attempts to investigate also models of technology acceptance (e.g. DAVIS, 1989; VENKATESH et al., 2003), which although refer to a different phenomenon (technology acceptance), can be related to technology appropriation (cf. SALOVAARA; TAMMINEN, 2009). In addition, these models claim to provide predictive power, which turn them into interesting references for developing my appropriation model. In the remaining of this section, I will discuss some other interesting lines of research that can be undertaken as more long-term or speculative at this point, but potentially promising paths of investigation.

A line of research closely related to this thesis and that deserves further investigation is End-User Development (EUD). I started this research with the main interest to investigate EUD for the IoT, which became a kind of backdrop to this thesis after a while. As mentioned before, appropriation is closely related with EUD and tailorable systems research, usually seen as a positive and desirable outcome of a successful EUD solution or approach. Tchounikine (2017) views EUD as the very means, the technical support for appropriation. I agree that, when 
carefully designed, EUD techniques and tools work as technical support for some or parts of the semiotic processes, such as naming supporting transferring and IFTTT supporting combining through mashups, for example. However, my appropriation model suggests that EUD can account for just a part of the overall process of technology appropriation by users. Or better saying, it suggests that any customization task needs to be considered as a meaning process in which several aspects of the technology collaborate together-e.g. usability, communicability, tailorability, etc.- some of which are usually factored-out from EUD research.

Again according to Tchounikine (2017), "users should be empowered to adapt and/or interoperate all the artifacts they use, as necessary given the instruments they develop." This perspective is also suggested by others (e.g. LUDWIG et al., 2017), but how to do it in traditional software and IoT in particular remains open questions. Following Schön's ideas, I suggest that this perspective can be best characterized as End-User Designing. It is still "EUD," but in a slightly different perspective potentially more useful to address interaction and development as intertwined activities, blending the physical and digital ecologies in which people work and live. In light of the contributions proposed in this thesis, the overall appropriation process is, in the highest level, governed by users' abductive reasoning. But an EUD environment cannot support it all, since several factors are external, arise from and depend on other sources of information, such as each devices' interfaces, users' contexts, etc. In such context, a limited but useful EUD environment should focus in attaining the minimum cycle of interaction mentioned before (see Section 6.2.2), as well as the recording of small generalized (induced) rules subject to change and grow abductively and organically, which I think explains to a great part the success of IFTTT among users. Finally, "deduction" support would help users evaluate the consequences of their actual or intended configurations by means of simulations, as already suggested by others (e.g. FISCHER, 1994). An EUD tool framed as an abductionsupport tool with induction (generalized rules) and deduction (simulations) support seems to me the most powerful high-level vision for an End-User Design tool able to accommodate most of the contributions I propose in this thesis and other local or domain-specific knowledge.

Another line of interesting future work is the development of what I called the semiotic engineering of multi-level and multi-sided technologies. To my eyes, 
there are two most fruitful ways to go. The first is, as already suggested, to use this framework in the evaluation of IoT and potentially other kinds of technologies by means of a SIM-like inspection method. The main goal in this case is evaluating technologies for research or summative purposes. Another interesting way to use this framework is as another design orienting framework, where different designers or teams (or even if a single person at different moments) exercise their metacommunicative abilities by "designing by stepping into others shoes." For instance, along the vertical axis (level) hardware/firmware developers as emitters imagine the kind of interactive conversations application developers - their metacommunication receivers-will engage while using the technology they build. Similarly, application programming interface (API) developers as emitters imagine the kind of interactive conversations their API consumers will engage; front-end developers do the same regarding users; and so on and so forth. Along the horizontal axis (stakeholder sides), the most important exercise is to create consistent and coherent discourses across different interfaces addressed to the same or to different receivers. At the same time, an overall "metacommunication of the business or service" can serve as integrative framework to help mitigate conflicts and support decisions in the highest level that will then propagate to lower level messages. These possibilities seem to me promising paths of investigation that can directly leverage from Semiotic Engineering principles and methods in the design of complex technologies.

As mentioned before, an important remaining gap seems to be how do we evaluate appropriation in order to verify which technology design works better. I think this is an important requirement to allow for my semiotic appropriation model and others to be further empirically assessed in terms of its validity and usefulness for design. The challenge here is to define the criteria for "better" and "worse" appropriation. In terms of our model, this question can be translated into how to qualify and compare appropriation states? One way to do it would be to use our appropriation model to qualitatively and/or quantitatively assess the result of each semiotic process. However, this evaluation could be "circular" or biased since it would use our model to evaluate our model. A different possibility would be a comparative approach in two ways: (i) how the same technology is appropriated by different users? (compare users, similar to what I did in the diary study but with a more specific focus); (ii) how a certain technology is 
appropriated in comparison with similar ones? (compare technologies). Yet another possibility is resorting to educational contexts and the tacit wisdom of so many elementary teachers out there. Departing from "problem solving evaluations", which I think is more distant form our semiotic perspective of appropriation, there are perhaps three basic ways by which a teacher can assess if some student has learned some semiotic content (as all content is) " $\mathrm{X}$ ":

- First level: Verify if the student is able to use " $\mathrm{X}$ " in different contexts other than where she or he has learned it (e.g. a student learning a foreign word using it in different phrases);

- Second level: Verify how the user "writes" (describes) about "X" using her or his own words (signs) (e.g. a student learning a concept or theory and describing it);

- Third level: Verify how a student is able to use or apply " $\mathrm{X}$ " in some practice (e.g. in a practice lab or apprentice studio).

Not surprisingly, this resembles Peirce's levels or grades of "clarity of meaning," the highest one being determined by his pragmatic maxim (see Section 3.3). The design of a method or "test" about a piece of technology " $X$ " based on the possible approaches outlined above would be interesting starting points for establishing criteria for assessing technology appropriation in more precise and comparable terms. What can be discovered from this kind of analysis and how to do it seem to be a field of investigation yet to be developed and explored.

Speaking about teachers, appropriation and education or in educational contexts is also another promising direction of future research that I think can benefit from this thesis. There are two interesting paths of future work related to education. One promising and most immediate path to go would be to train people to interpret and appropriate technology, perhaps as part of the computational thinking curriculum our society is pushing into kids. Appropriation states may evolve organically and infinitely, but I should highlight that not all users have achieved the same appropriation state during the same amount of time they were observed in the diary study, for example. If all users (who shared a similar background and context of undergrad students of an American University in Computer Science and related fields) were given the same set of devices, this reinforces how personal aspects are important and unfold in different ways in face of even subtle changes in user contexts and backgrounds. This suggests that the 
technology alone cannot provide everything is needed to make users appropriate technology to the highest degree possible (assuming that this is a positive, desirable outcome). Users bring to the table their previous background, skills, reflective abilities, whatever they are. Therefore, we should also invest in training the users in developing the required abilities to interpret and appropriate technology.

Another possible path is to apply the ideas from this thesis to professional educational research and practice in a broader sense. Appropriation entails both "more than" learning and "less than" learning. It is "more than" learning because it's not only about learning but includes applying what one learns to a particular meaningful context or problem in a personal and pragmatic way. It is "less than" learning because one does not necessarily need to "learn" something (strictly speaking) to appropriate it, in the sense that one can have sub-optimal learning and still be able to apply it in personal and pragmatic ways (even if "wrong"). The theoretical path to go could be based on traces of connections between semiotic and educational psychology, as done by James Wertsch (1983, 1993). Bødker (2017) has indicated this path, but I would suggest a stronger commit with Schön's epistemology of practice in general and, in particular, with his perspective to "educating the reflective practitioner" (SCHÖN, 1987). Perhaps this would also be a fruitful path to look for a more precise way too assess, compare or measure appropriation states among different people and/or technology designs.

Back do Donald Schön, we can say that his perspective is deeply connected with artistry and design studio practices, such as architecture, Schön himself working for the urban planning department for most of his career at the MIT. Architecture and ubiquitous computing seems to be a "hot topic" to be explored that attracts increasing attention from architects and other "outsiders" to computing technologies (e.g. MCCULLOUGH, 2004, 2013). Actually, I had some contact with architects interested in IoT and related technologies (e.g. digital fabrication and 3D printing) during this research and could testify their increasing interest on the topic due to its potential applicability to novel construction techniques and interactive designs. At a certain point, I have heard that they know (or do) very little about evaluating buildings from the user - the inhabitantperspective, that is, after buildings are built ("post-occupancy evaluation" (POE) 
is the technical term I learned: cf. BRAND, 1995, p. 56, 65 et seq.). And if they do, to which extent whatever they know about post-occupancy evaluation today will work when applied to what will be an interactive smart building tomorrow?

Computer Science in general and HCI in particular have always imported theories and methods from several other fields and sciences-architecture included (cf. ALEXANDER, 1999) — to experiment and test if they would help to build better technology. The fact that computing technologies have received an enormous amount of investments both in research and practice (development) in the last decades allied to the malleability of our feedstock contributed to the development of an uncountable number of technology-based products, services, theories, methods and solutions by a vibrant community of researchers and practitioners all over the world. Perhaps we got to a point when it is time to pay it back. With everything becoming a computer and interactive today, buildings included, I believe that much of the knowledge discovered and built in the HCI field (this thesis included) can be applied to other professions and practices that now turn to computing technologies, architecture included. Actually, I think we should strive for that, as both an expression of gratitude for what we have taken from other sciences and fields, and as a promising highway of future research. It seems to me a path full of fascinating challenges waiting for those, computer scientists and architects, who will embrace them ahead, cross-fertilizing the sciences of both fields. And maybe this is the way to go in order to establish Winograd's (1997) interaction design as a true new field concerned with the design of the interspace:

"Taking seriously that the design role is the construction of the 'interspace' in which people live, rather than an 'interface' with which they interact, the interaction designer needs to take broad view that includes understanding how people and societies adapt to new technologies." (WINOGRAD, 1997, p. 159, my emphasis)

Architecture reminds us of arts, and one of the finest arts is Poetry. I definitely think that the theme of technology and poetry is one that deserves more investigation. I feel like I have just scratched the surface of a promising approach for interaction design with the poetic function of technology (see Section 6.1). But I am sure that there are several other aspects that make technology and poetry much closer that they might seem at first. The first time I have heard about it was in Richard Gabriel's book where he referred to abstraction (in the traditional 
software engineering sense) as a process of compression of meaning (GABRIEL, 1996, p. 5). According to him, poetry is compression "par excellence:"

"Compression is the characteristic of a piece of text that the meaning of any part of it is "larger" than that piece has by itself. This is accomplished by the context being rich and each part of the text drawing on that context - each word draws part of its meaning from its surroundings.

A familiar example outside programming is poetry whose heavily layered meanings can seem dense because of the multiple images it generates and the way each new image or phrase draws from several of the others. Poetry uses compressed language." (idem, my emphasis)

Although Gabriel is primarily concerned with software engineering (abstraction in object-oriented programming and as a means for software re-use), the principles of interpretive abstraction and semiotic continuum (see Section 6.2.2) and this thesis suggest that it can be largely applied to interaction design as well. An interface is, essentially, a compressed version of the designers' meaning (entirely and as a whole) that lies underneath it. Umberto Eco's account of the aesthetic text (see Section 6.1.1) clarifies the semiotic mechanism by which poetry does its work, but a more rigorous exploration of poetic interfaces seems a promising way to go, at least to my eyes. For designers, I can intuitively propose a "moonshot" design implication to pursuit: a good user manual can be helpful once in a while, but poetry is what conquer users. It is left for future work to elucidate this mechanism better.

In an even more audacious path, this work could contribute to the field of semiosis and cognition, a challenging and largely unknown field. According to Danesi \& Perron, "The notion of structural effects [of the signifying order] is not a theory of mind; it simply acknowledges what effects signs have on human thinking" (DANESI; PERRON, 1999, p. 101). But it could be, at least for the part of the mind in charge of significations processes. Indeed, our semiotic appropriation model can be seen as a sense making framework, which holds compatibilities and similarities with other non-semiotic sense making frameworks that have been proposed in literature (KLEIN et al., 2007; e.g. MCCARTHY; WRIGHT, 2004). The complementarity and dialog between cognitive studies and semiotics is often explored (DRIGO, 2008; FARIAS, 1999; GUDWIN; QUEIROZ, 2005; QUEIROZ, 2004; WHITSON, 1997). In addition, recent discoveries such as the phenomenon of neuroplasticity (that is, the self-healing adaptive ability of neurological tissue to restore its function in case of injuries- 
cf. Miguel Nicolelis' research) suggests that perhaps some of the more obscure Peirce's ideas (e.g. about the protoplasm: PEARCE, 2018) can dialog with modern neurosciences. In a more speculative sense, I think the model I am proposing in this thesis, based on the idea of a personal signifying system and in which appropriation is taken to mean a kind of "learning by phago-semiosis," can dialogue with this line of research too, promoting the exchange of insights between semioticists, cognitivists, and neurologists - those who care for the concrete soil where semiosis and cognition take place-, among others.

Finally, it is worth mentioning that my contributions can probably apply to technologies other than IoT. In several aspects, I believe that the similarities between IoT and other more "traditional" technologies can enable the application of my semiotic model of appropriation and of the multi-level and multi-sided technologies in other domains. For instance, we know people can send e-mails to themselves as reminders or for storing important files, a kind of (re)purposing of the e-mail tool; we talk about "copying and pasting," "downloading," and "uploading" in all sorts of real-life contexts these days, typical cases of transferring; and so on, and so forth. In a similar vein, we can roughly assume that any kind of software is composed by multiple levels of abstractions and is thus multi-level (e.g. a Model-View-Controller software has, at least, three levels). This path of research also seems promising and fruitful, but I cannot support any claim in this line now because I focused on researching IoT technologies. So, this is left to future work. 


\section{3.}

\section{Final Remarks}

The Internet of Things is an emerging technology that is already changing several of our social practices. This reality is expected to intensify as the technology matures, technical challenges are overcome, and markets and people get used to innovations and appropriate them. Due to the scope, scale and power of IoT technologies, it is critically important that we develop human-centered approaches to it, able to first, defend us from intended and unintended negative consequences arising from this technology, and second, promote positive changes in the direction to fix whatever we see needs to be fixed in our world. This work is a small contribution to this line, one that places the critical role in those who are responsible for the most critical thoughts and decisions around any technology development and adoption: the people who build it and those who use it.

I am not sure if I can emphasize it enough, but the need for human-centered approaches towards technology development is one of the most urgent challenges of our time. Imagine how crazy a world would be where, say, religious texts full of stories and concepts about humility, forgiveness, personal resignation and altruism would be interpreted as reasons and justifications for domination, violence, selfishness, self-promotion, and authoritarianism. Still, this has happened several times throughout History and is still happening today, right now, not in other people's far away countries and lands, but right around our corner and probably inside our own homes. This puts "the science of interpretation," which I think accounts for a great part of Semiotics, at a very critical position. Our entire world is being ruled by interpretations. Most of them are now mediated by technologies of different kinds, IoT being one the most prominent among them. As of today, from apparently naïve messages and comments in a social network to sophisticated technological platforms supporting services, everything seems to carry additional meaning and functions designed to accomplish somebodies' intent. In other words, above the surface, they are metacommunications from authors we usually are not even aware about. In this sense, this work is a little contribution in order to, hopefully and if properly interpreted, help mankind to overcome the challenges we face when dealing with our own face in the mirror of the technology we produce. 
I am not a skeptic regarding technology, actually just the opposite. This is precisely the reason why I see technology as a mirror of our society, a very sophisticated mirror indeed, but like any other mirror, it can only convey what someone projects on it. In these fallible, weak, imperfect beings and, often contradictorily, sensitive, talented, and strong, reside all the power to create and transform the reality. I trust people more than I do technology, and this thesis should be taken in this sense.

In between Belin \& Prié's (2012) “over-descriptive and theoretically scattered works" that cannot be directly applied or translated into practical design guidance and "methodologically unsound" design guidelines (DIX, 2007), I propose pieces of orienting theory to support reflective designers build more "human-friendly" technology. In Winograd's words:

"[An orienting theory] does not take the observer's view of existing phenomena, but provides a foundation for creating new phenomena, whether they be linguistic utterances, software, or equipment. It does not offer a method for determining what will happen, but poses a set of questions that orient the creator (designer) to concerns of the different groups of people who are affected by the design. Both phenomenology and semiotics are theories of this kind, which are of critical importance in the design of human systems." (WINOGRAD, 2017, p. 3)

As any theory, an orienting theory should be sound, find support in empirical evidence, and of course be subject to be verified and falsified. In other words, it needs to make sense, even if provisional sense. Scientific theories are a long-term and hard work though, and Peirce's scientific method is one way to go for it that is not only applicable to science but to all kinds of mundane inquiries (see Chapter 3). It may not work, but I trust people more than I do technology because people are able to reflect while and after they act. And researchers are also reflective practitioners, individually and collectively, assuring that any proposed theory will find its way towards acceptance, correction, or refutation, eventually.

I think Schön's main argument is to propose that reflection-in-action is not an aleatory, mysterious, or even mystified activity driven by talent, luck, and intuition alone, but that it follows a very particular and powerful modus operandi that can be studied and supported in order to improve the results of any practice. I think this is true especially when dealing with complex problems, such as the design of complex interactive IoT technologies. Even further, Schön sees the practice of design as being close to the practice (or art) of research: 
"The dilemma of rigor or relevance may be dissolved if we can develop an epistemology of practice which places technical problem solving within a broader context of reflective inquiry, shows how reflection-in-action may be rigorous in its own right, and links the art of practice in uncertainty and uniqueness to the scientist's art of research. We may thereby increase the legitimacy of reflection-inaction and encourage its broader, deeper, and more rigorous use." (SCHÖN, 1983, p. 69)

"The roles of practitioner and researcher will have permeable boundaries, and research and practice careers will intertwine as a matter of course. While the relative weight given to reflective research or to practice might vary considerably in the course of a career, one would normally expect practitioners to function on occasion as reflective researchers, and vice versa." (ibid., p. 325)

It seems that the designer's and the researcher's practices blend and hold more similarities than differences. Perhaps the same can be said about designers and users. To use technology is more mundane than to design it; and Design is more mundane than Science. But following Peirce, the difference between "true" and "mundane" science is more a matter of circumstance and training rather than of a fundamentally different discipline or epistemology of thought. And in this sense, this thesis echoes my own process of reflective inquiry and appropriation of some theories out there (Peirce's, Eco's, Schön's, De Souza's, ...). So far, this all should be taken as my best current hypotheses. But so probably are De Souza's, Eco's, Schön's, and Peirce's for them... 


\section{References}

ABOWD, G. D.; MYNATT, E. D. Charting past, present, and future research in ubiquitous computing. ACM Transactions on Computer-Human Interaction (TOCHI), v. 7, n. 1, p. 29-58, 2000.

ACKERMANN, D.; TAUBER, M. J. (EDS.). Mental models and humancomputer interaction 1. Amsterdam; New York, U.S.A: North-Holland; Distributors for the U.S.A. and Canada: Elsevier Science Pub. Co, 1990.

AFONSO, L. M. Communicative Dimensions of Application Programming Interfaces (APIs). Doctorate Thesis-Rio de Janeiro, Brazil: Department of Informatics, Pontifical Catholic University of Rio de Janeiro (PUC-Rio), 2015.

ALEXANDER, C. The origins of pattern theory: The future of the theory, and the generation of a living world. Software, IEEE, v. 16, n. 5, p. 71-82, 1999.

ALEXANDER, C.; ISHIKAWA, S.; SILVERSTEIN, M. A Pattern Language: Towns, Buildings, Construction. New York: Oxford University Press, USA, 1977.

AMAZON INC. Amazon Go. Available at: <https://www.amazon.com/b?ie=UTF8\&node=16008589011>. Accessed: 10 Feb. 2020.

ANDERSEN, P. B. A Theory of Computer Semiotics: Semiotic Approaches to Construction and Assessment of Computer Systems. Cambridge University Press, 1990.

ANDRIESSEN, J. H. E.; HETTINGA, M.; WULF, V. Introduction to Special Issue on Evolving Use of Groupware. Computer Supported Cooperative Work (CSCW), v. 12, n. 4, p. 367-380, 2003.

ARANHA, M. L. A.; MARTINS, M. H. P. Filosofando - Introdução à Filosofia. 1. ed. São Paulo: Moderna, 1986.

ATZORI, L.; IERA, A.; MORABITO, G. The internet of things: A survey. Computer networks, v. 54, n. 15, p. 2787-2805, 2010.

BAILER-JONES, D. M. Scientists' Thoughts on Scientific Models. Perspectives on Science, v. 10, n. 3, p. 275-301, 2002.

BAINES, T. S. et al. State-of-the-art in product-service systems. Proceedings of the Institution of Mechanical Engineers, Part B: Journal of Engineering Manufacture, v. 221, n. 10, p. 1543-1552, 2007. 
BANNON, L. Reimagining HCI: toward a more human-centered perspective. Interactions, v. 18, n. 4, p. 50-57, 2011.

BARRICELLI, B. R.; VALTOLINA, S. Designing for End-User Development in the Internet of Things. In: International Symposium on End User Development (IS-EUD 2015). Proceedings... Springer, 2015.

BASTOS, J. A. D. M.; AFONSO, L. M.; SOUZA, C. S. DE. Metacommunication between programmers through an application programming interface: A semiotic analysis of date and time APIs. In: 2017 IEEE Symposium on Visual Languages and Human-Centric Computing (VL/HCC). Proceedings... 2017.

BAZZANELLA, C.; DAMIANO, R. The interactional handling of misunderstanding in everyday conversations. Journal of Pragmatics, Misunderstanding. v. 31, n. 6, p. 817-836, 1999.

BELIN, A.; PRIÉ, Y. DIAM: Towards a Model for Describing Appropriation Processes Through the Evolution of Digital Artifacts. In: 2012 Designing Interactive Systems Conference (DIS '12). Proceedings... ACM, 2012.

BELL, G.; DOURISH, P. Yesterday's tomorrows: notes on ubiquitous computing's dominant vision. Personal and Ubiquitous Computing, v. 11, n. 2, p. 133-143, 2007.

BELlOTTI, V. et al. Making Sense of Sensing Systems: Five Questions for Designers and Researchers. In: 2002 SIGCHI Conference on Human Factors in Computing Systems (CHI ’02). Proceedings... ACM, 2002.

BELLOTTI, V.; EDWARDS, K. Intelligibility and Accountability: Human Considerations in Context-Aware Systems. Human-Computer Interaction, v. 16, n. 2-4, p. 193-212, 2001.

BELLUCCI, A. et al. Extreme Co-design: Prototyping with and by the User for Appropriation of Web-connected Tags. In: International Symposium on End User Development (IS-EUD 2015). Proceedings... Springer, 2015.

BENAMAR, L.; BALAGUÉ, C.; ZHONG, Z. Internet of Things devices appropriation process: The Dynamic Interactions Value Appropriation (DIVA) framework. Technovation, v. 89, p. 102082, 2019.

BEUREN, F. H.; GOMES FERREIRA, M. G.; CAUCHICK MIGUEL, P. A. Product-service systems: a literature review on integrated products and services. Journal of Cleaner Production, Cleaner Production: initiatives and challenges for a sustainable world. v. 47, p. 222-231, 2013.

BLACKWELL, A. F. End-user Developers at Home. Commun. ACM, v. 47, n. 9, p. 65-66, 2004. 
BNDES. Estudo "Internet das Coisas: um plano de ação para o Brasil". Avalailable

$<$ http://www.bndes.gov.br/wps/portal/site/home/conhecimento/pesquisaedados/est udos/estudo-internet-das-coisas-iot/estudo-internet-das-coisas-um-plano-de-acaopara-o-brasil>. Accessed: 28 Jan. 2020.

BØDKER, S. Meaning and ubiquitous technologies. In: BARBOSA, S.; BREITMAN, K. (Eds.). Conversations Around Semiotic Engineering. Springer, 2017. p. 13-21.

BØDKER, S.; CHRISTIANSEN, E. Poetry in Motion: Appropriation of the World of Apps. In: 30th European Conference on Cognitive Ergonomics (ECCE '12). Proceedings... ACM, 2012.

BOON, M.; KNUUTTILA, T. Models as Epistemic Tools in Engineering Sciences. In: MEIJERS, A. (Ed.). Philosophy of Technology and Engineering Sciences. Handbook of the Philosophy of Science. Amsterdam: North-Holland, 2009. p. 693-726.

BOOTH, T. et al. Crossed Wires: Investigating the Problems of End-User Developers in a Physical Computing Task. In: 2016 CHI Conference on Human Factors in Computing Systems (CHI '16). Proceedings... ACM, 2016.

BOVET, A.; MAKSE, H. A. Influence of fake news in Twitter during the 2016 US presidential election. Nature Communications, v. 10, n. 1, p. 1-14, 2019.

BRAND, S. How buildings learn: What happens after they're built. New York, USA: Penguin, 1995.

BRAUN, V.; CLARKE, V. Using thematic analysis in psychology. Qualitative Research in Psychology, v. 3, n. 2, p. 77-101, 2006.

BRIGNULL, H.; DARLO, A. Dark Patterns. Available at: <https://www.darkpatterns.org/>. Accessed: 22 Jan. 2020.

BRUSH, A. J. B. et al. Home Automation in the Wild: Challenges and Opportunities. In: 2011 SIGCHI Conference on Human Factors in Computing Systems (CHI '11). Proceedings... ACM, 2011.

BRYANT, A.; CHARMAZ, K. Introduction: Grounded Theory Research: Methods and Practices. In: BRYANT, A.; CHARMAZ, K. (Eds.). The SAGE Handbook of Grounded Theory. London, UK: SAGE Publications Ltd, 2007a. p. 1-28.

BRYANT, A.; CHARMAZ, K. Grounded Theory in Historical Perspective: An Epistemological Account. In: BRYANT, A.; CHARMAZ, K. (Eds.). The SAGE Handbook of Grounded Theory. London, UK: SAGE Publications Ltd, 2007b. p. 31-57. 
BURCH, R. Charles Sanders Peirce. In: ZALTA, E. N. (Ed.). The Stanford Encyclopedia of Philosophy. Winter 2018 ed. Metaphysics Research Lab, Stanford University, 2018. Available at: $<$ https://plato.stanford.edu/archives/win2018/entries/peirce/>.

BURKS, A. W. Peirce's Theory of Abduction. Philosophy of Science, v. 13, n. 4, p. 301-306, 1946.

BURNETT, M.; KULESZA, T. End-User Development in Internet of Things: We the People. In: CHI 15' Workshop on End User Development in the Internet of Things Era. International Reports on Socio-Informatics (IRSI), 2015.

BUTZ, A. User Interfaces and HCI for Ambient Intelligence and Smart Environments. In: Handbook of Ambient Intelligence and Smart Environments. Boston, MA: Springer, 2010. p. 535-558.

BUXTON, B. Sketching User Experiences: Getting the Design Right and the Right Design. Morgan Kaufmann, 2010.

CAMPOS, C. T. DE. O processo de apropriação do desenho à escrita. Dissertação de Mestrado-São Carlos, SP, Brasil: Universidade Federal de São Carlos, 2011.

CANALES, K.; WEINBERGER, M. The 17 most successful Kickstarter projects of all time and where they are today. Business Insider, 23 Jun. 2018. Available at: <https://www.businessinsider.com/most-successful-kickstarter-projects-of-alltime-2016-6>. Accessed: 12 Feb. 2020.

CAO, J. et al. End-user Mashup Programming: Through the Design Lens. In: 2010 SIGCHI Conference on Human Factors in Computing Systems (CHI '10). Proceedings... ACM, 2010.

CAPPIELLO, C. et al. Enabling End User Development through Mashups: Requirements, Abstractions and Innovation Toolkits. In: International Symposium on End User Development (IS-EUD 2011). Proceedings... Springer, 2011.

CARROLL, J. et al. Identity, power and fragmentation in cyberspace: technology appropriation by young people. In: Twelfth Australasian Conference on Information Systems (ACIS 2001). Proceedings... 2001.

CARROLL, J. et al. Just what do the youth of today want? Technology appropriation by young people. In: 35th Annual Hawaii International Conference on System Sciences. Proceedings... 2002.

CARROLL, J. et al. From Adoption to Use: the process of appropriating a mobile phone. Australasian Journal of Information Systems, v. 10, n. 2, 2003.

CARROLL, J. Completing design in use: closing the appropriation cycle. ECIS 2004 Proceedings, 2004. 
CARROLL, J. M. HCI Models, Theories, and Frameworks: Toward a Multidisciplinary Science. Elsevier, 2003.

CARROLL, J. M.; OLSON, J. S. (EDS.). Mental models in human-computer interaction: research issues about what the user of software knows. Washington, D.C: National Academy Press, 1987.

CARTER, N. et al. The Use of Triangulation in Qualitative Research. Oncology Nursing Forum, v. 41, n. 5, p. 545-547, 2014.

CASTillo O'SUllivan, A.; THIERER, A. D. Projecting the Growth and Economic Impact of the Internet of Things. Rochester, NY: Social Science Research 2015. Network, Available at: <https://papers.ssrn.com/abstract=2618794>. Accessed: 12 Feb. 2020.

CHAGAS, B. A. End-User Configuration in Assistive Technologies - A case study with a severely physically impaired user. Master's Dissertation-Rio de Janeiro, Brazil: Department of Informatics, Pontifical Catholic University of Rio de Janeiro (PUC-Rio), 2015.

CHAGAS, B. A. End-user design for the Internet of Things: Supporting incremental evolution through breakdowns. In: 2017 IEEE Symposium on Visual Languages and Human-Centric Computing (VL/HCC). Proceedings... 2017 .

CHAGAS, B. A. Investigating Interaction with Smart Home Devices through a Diary Study. Rio de Janeiro: SERG/DI/PUC-Rio, 2017. Available at: <http://www3.serg.inf.puc-rio.br/docs/Chagas2020-Annex01.pdf>.

CHAGAS, B. A. Avaliação de um Modelo de Apropriação de Tecnologia de Internet das Coisas. Rio de Janeiro: SERG/DI/PUC-Rio, 2019. Available at: <http://www3.serg.inf.puc-rio.br/docs/Chagas2020-Annex02.pdf>.

CHAGAS, B. A.; FUKS, H.; DE SOUZA, C. S. Lessons Learned in the Design of Configurable Assistive Technology with Smart Devices. In: Fifth International Symposium on End User Development (IS-EUD 2015). Proceedings... Springer, 2015.

CHAGAS, B. A.; REDMILES, D. F.; DE SOUZA, C. S. Observed Appropriation of IoT Technology: A Semiotic Account. In: 17th Brazilian Symposium on Human Factors in Computing Systems (IHC 2018). Proceedings... ACM, 2018. DOI: 〈https://doi.org/10.1145/3274192.3274225>

CHAGAS, B. A.; REDMILES, D. F.; DE SOUZA, CLARISSE. S. End-user development for the Internet of Things OR How can a (smart) light bulb be so complicated? 2017 IEEE Symposium on Visual Languages and HumanCentric Computing (VL/HCC). Proceedings... 2017. DOI: <https://doi.org/10.1109/VLHCC.2017.8103478>

CHAGAS, B. A.; REDMILES, D. F.; SOUZA, C. S. DE. Signs of Appropriation: A Semiotic Account of Breakdowns with IoT Technology. Journal of Interactive Systems, v. 10, n. 2, p. 3-19, 2019. 
CHARMAZ, K. Grounded Theory: Objectivist and Constructivist Methods. In: DENZIN, N. K.; LINCOLN, Y. S. (Eds.). Handbook of qualitative research. 2nd. ed. SAGE, 2000. p. 509-535.

CHARMAZ, K. Constructing Grounded Theory. 2nd. ed. SAGE, 2014.

CHUI, M.; LÖFFLER, M.; ROBERTS, R. The internet of things. McKinsey Quarterly, v. 2, n. 2010, p. 1-9, 2010.

CONSELHO NACIONAL DE SAÚDE/MINISTÉRIO DA SAÚDE. 466/12. RESOLUÇÃO Nº 466, DE 12 DE DEZEMBRO DE 2012. 12 Dec. 2012.

CONSELHO NACIONAL DE SAÚDE/MINISTÉRIO DA SAÚDE. 510/16. RESOLUÇÃO N ${ }^{\circ}$ 510, DE 7 DE ABRIL DE 2016. Publicada no DOU $n^{\circ} 98$, terça feira, 24 de maio de 2016 seção 1, pags. 44, 45, 46.7 Apr. 2016.

COOK, D. J.; AUGUSTO, J. C.; JAKKULA, V. R. Ambient intelligence: Technologies, applications, and opportunities. Pervasive and Mobile Computing, v. 5, n. 4, p. 277-298, 2009.

COUTAZ, J.; CROWLEY, J. L. A First-Person Experience with End-User Development for Smart Homes. IEEE Pervasive Computing, v. 15, n. 2, p. 26 39, 2016.

CRESWELL, J. W. Research Design: Qualitative, Quantitative and Mixed Methods Approaches. 4th edition. Thousand Oaks: SAGE Publications, Inc, 2014.

CUNNINGHAM, S. J.; JONES, M. Autoethnography: A Tool for Practice and Education. In: 6th ACM SIGCHI New Zealand Chapter's International Conference on Computer-Human Interaction: Making CHI Natural (CHINZ '05). Proceedings... ACM, 2005.

DANCY, J. Epistemology, problems of. In: HONDERICH, T. (Ed.). The Oxford Companion to Philosophy. Oxford University Press, 2005.

DANESI, M.; PERRON, P. Analyzing Cultures: An Introduction and Handbook. Bloomington: Indiana University Press, 1999.

DAVIDOFF, S. et al. Principles of Smart Home Control. In: International Conference on Ubiquitous Computing (UbiComp 2006). Proceedings... Springer, 2006.

DAVIS, F. D. Perceived Usefulness, Perceived Ease of Use, and User Acceptance of Information Technology. MIS Quarterly, v. 13, n. 3, p. 319-340, 1989.

DE SOUZA, C. S. The semiotic engineering of user interface languages. International Journal of Man-Machine Studies, v. 39, n. 5, p. 753-773, 1993.

DE SOUZA, C. S. The semiotic engineering of human-computer interaction. Cambridge, Massachusetts: MIT press, 2005a. 
DE SOUZA, C. S. Semiotic engineering: bringing designers and users together at interaction time. Interacting with Computers, v. 17, n. 3, p. 317-341, 2005 b.

DE SOUZA, C. S. et al. The Semiotic Inspection Method. In: VII Brazilian Symposium on Human Factors in Computing Systems (IHC '06). Proceedings... ACM, 2006.

DE SOUZA, C. S. et al. Software Developers as Users: Semiotic Investigations in Human-Centered Software Development. Springer, 2016.

DE SOUZA, C. S. Semiotics and Human-Computer Interaction. In: The Wiley Handbook of Human Computer Interaction. John Wiley \& Sons, Ltd., 2017a. p. 33-49.

DE SOUZA, C. S.; BARBOSA, S. D. J.; SILVA, S. R. P. DA. Semiotic engineering principles for evaluating end-user programming environments. Interacting with Computers, v. 13, n. 4, p. 467-495, 2001.

DE SOUZA, C. S.; LEITÃO, C. F. Semiotic engineering methods for scientific research in HCI. Morgan \& Claypool Publishers, 2009.

DE SOUZA, C. S.; PRATES, R. O.; BARBOSA, S. D. J. A Method for Evaluating Software Communicability. In: Second Brazilian Workshop in Human-Computer Interaction (IHC ‘99). Proceedings... 1999.

DE SOUZA, C. S. DE. Semiotic Engineering: A Cohering Theory to Connect EUD with HCI, CMC and More. In: New Perspectives in End-User Development. Springer, 2017b. p. 269-305.

DENZIN, N. K. Sociological Methods: A Sourcebook. Routledge, 2017.

DENZIN, N. K.; LINCOLN, Y. S. Handbook of qualitative research. 2nd. ed. Sage, 2000.

DERBOVEN, J.; GEERTS, D.; DE GROOFF, D. Appropriating virtual learning environments: A study of teacher tactics. Journal of Visual Languages \& Computing, Semiotics, Human-Computer Interaction and End-User Development. v. 40, n. Supplement C, p. 20-35, 2017.

DESANCTIS, G.; POOLE, M. S. Capturing the Complexity in Advanced Technology Use: Adaptive Structuration Theory. Organization Science, v. 5, n. 2, p. 121-147, 1994.

DEY, A. K.; LJUNGSTRAND, P.; SCHMIDT, A. Distributed and Disappearing User Interfaces in Ubiquitous Computing. In: CHI '01 Extended Abstracts on Human Factors in Computing Systems (CHI EA '01). Proceedings... ACM, 2001.

DIX, A. Designing for Appropriation. In: $21^{\text {st }}$ British HCI Group Annual Conference on People and Computers: HCI...But Not As We Know It - Volume 2 (BCS-HCI '07). Proceedings... BCS Learning \& Development Ltd., 2007. 
D-LINK. D-Link DCH-S150 User Manual (version 2.0). Available at: <http://www.dlink.co.in/products/?pid=697>. Accessed: 12 Jan. 2019.

DOHERTY, K.; DOHERTY, G. The construal of experience in HCI: Understanding self-reports. International Journal of Human-Computer Studies, v. 110, p. 63-74, 2018.

DOURISH, P. The Appropriation of Interactive Technologies: Some Lessons from Placeless Documents. Computer Supported Cooperative Work (CSCW), v. 12 , n. 4 , p. $465-490,2003$.

DOURISH, P.; BELL, G. Divining a digital future: mess and mythology in ubiquitous computing. Cambridge, Mass: MIT Press, 2011.

DRAPER, N. Fail Fast: The Value of Studying Unsuccessful Technology Companies[1]. Media Industries Journal, v. 4, n. 1, 2017.

DRAXLER, S.; STEVENS, G. Supporting the Collaborative Appropriation of an Open Software Ecosystem. Computer Supported Cooperative Work (CSCW), v. 20, n. 4-5, p. 403-448, 2011.

DRIGO, M. O. Comunicação e Cognição. Semiose na Mente Humana. 1. ed. Sorocaba: EDUNISO, 2008.

DUMAS, B.; LALANNE, D.; OVIATT, S. Multimodal Interfaces: A Survey of Principles, Models and Frameworks. In: Human Machine Interaction. Lecture Notes in Computer Science. Berlin, Heidelberg: Springer, 2009. v. 5440, p. 3-26.

ECO, U. Tratado Geral de Semiótica. Tradução: Antônio de Pádua Danesi; Tradução: Gilson Cesar Cardoso De Souza. 5ª ed. São Paulo: Perspectiva, 2017.

ECO, U. Os Limites da Interpretação. 2a ed. São Paulo: Perspectiva, 2018.

EDWARDS, W. K.; GRINTER, R. E. At Home with Ubiquitous Computing: Seven Challenges. In: International Conference on Ubiquitous Computing (Ubicomp 2001) Proceedings... Springer, 2001.

EJAZ, W. et al. Internet of Things (IoT) in 5G Wireless Communications. IEEE Access, v. 4, p. 10310-10314, 2016.

ELLIS, G.; DIX, A. An explorative analysis of user evaluation studies in information visualisation. In: 2006 AVI workshop on BEyond time and errors: novel evaluation methods for information visualization (BELIV '06), Venice, Italy. Proceedings... ACM, 2006.

ENCARNAÇÃO, J. L.; KIRSTE, T. Ambient Intelligence: Towards Smart Appliance Ensembles. In: HEMMJE, M.; NIEDERÉE, C.; RISSE, T. (Eds.). From Integrated Publication and Information Systems to Information and Knowledge Environments: Essays Dedicated to Erich J. Neuhold on the Occasion of His 65th Birthday. Lecture Notes in Computer Science. Berlin, Heidelberg: Springer, 2005. v. 3379, p. 261-270. 
ESPINDOLA, L. DA S.; SILVEIRA, M. S. Self-expression and discourse continuity in a multilevel EUD environment: The case of moodle. Journal of Visual Languages \& Computing, Semiotics, Human-Computer Interaction and End-User Development. v. 40, n. Supplement C, p. 36-50, 2017.

EUROPEAN COMMISSION. The Internet of Things. Available at: <https://ec.europa.eu/digital-single-market/en/internet-of-things >. Accessed: 28 Jan. 2020.

EVANS, D. S.; SCHMALENSEE, R. Matchmakers: The New Economics of Multisided Platforms. Boston, Massachusetts: Harvard Business Review Press, 2016.

FARIAS, P. L. Semiótica e Cognição: Os conceitos de hábito e mudança de hábito em C.S.Peirce. Revista Eletrônica Informação e Cognição (Cessada), v. 1, n. 1, p. 12-16, 1999.

FERRARI, M. I.; BIM, S. A.; AQUINO, P. T. The Signs of Semiotic Engineering in the IoT Interaction Design. In: International Conference on Applied Human Factors And Ergonomics, Advances in Neuroergonomics and Cognitive Engineering, Advances in Intelligent Systems and Computing. Proceedings... Springer, 2017.

FINE, G. A. Small Groups and Culture Creation: The Idioculture of Little League Baseball Teams. American Sociological Review, v. 44, n. 5, p. 733-745, 1979.

FINGER, S.; DIXON, J. R. A review of research in mechanical engineering design. Part I: Descriptive, prescriptive, and computer-based models of design processes. Research in Engineering Design, v. 1, n. 1, p. 51-67, 1989.

FISCHER, G. Turning breakdowns into opportunities for creativity. KnowledgeBased Systems, v. 7, n. 4, p. 221-232, 1994.

FLANAGAN, J. et al. Human-Centered Systems: Information, Interactivity, and Intelligence. National Science Foundation Workshop, Crystal Gateway Marriott Hotel, Arlington, VA., 1997. Available at: <http://www.ifp.illinois.edu/nsfhcs/final_report/nsfhcs_report.doc >. Accessed: 18 Jul. 2016.

FLICK, U. Triangulation Revisited: Strategy of Validation or Alternative? Journal for the Theory of Social Behaviour, v. 22, n. 2, p. 175-197, 1992.

FLOROS, G. Towards establishing the notion of idioculture in texts. Text and Translation: Theory and Methodology of Translation, p. 335-347, 2006.

FOGLI, D.; LANZILOTTI, R.; PICCINNO, A. End-User Development Tools for the Smart Home: A Systematic Literature Review. In: International Conference on Distributed, Ambient, and Pervasive Interactions. Proceedings... Springer, 2016.

FOLGER, R.; STEIN, C. Abduction 101: Reasoning processes to aid discovery. Human Resource Management Review, v. 27, n. 2, p. 306-315, 2017. 
FRIGG, R.; HARTMANN, S. Models in Science. In: ZALTA, E. N. (Ed.). The Stanford Encyclopedia of Philosophy. Spring 2020 ed. Metaphysics Research Lab, Stanford University, 2020. Available at: $<$ https://plato.stanford.edu/archives/spr2020/entries/models-science/>.

FROSINI, L.; PATERNÒ, F. User interface distribution in multi-device and multi-user environments with dynamically migrating engines. In: 2014 ACM SIGCHI symposium on Engineering interactive computing systems, Rome, Italy (EICS '14). Proceedings... ACM, 2014.

FURNISS, D.; BLANDFORD, A.; CURZON, P. Confessions from a Grounded Theory PhD: Experiences and Lessons Learnt. In: 2011 SIGCHI Conference on Human Factors in Computing Systems (CHI '11). Proceedings... ACM, 2011.

GABRIEL, R. P. Patterns of software. Oxford University Press New York, 1996.

GARRETT, J. J. The Elements of User Experience: User-Centered Design for the Web and Beyond. 2nd. ed. Berkeley, CA: New Riders, 2010.

GENTNER, D.; STEVENS, A. L. (EDS.). Mental models. Hillsdale, N.J: L. Erlbaum Associates, 1983.

GERGLE, D.; TAN, D. S. Experimental Research in HCI. In: OLSON, J. S.; KELLOGG, W. A. (Eds.). Ways of Knowing in HCI. New York: Springer, 2014. p. 191-227.

GERSHENFELD, N.; KRIKORIAN, R.; COHEN, D. The Internet of Things. Scientific American, v. 291, n. 4, p. 76-81, 2004.

GIDDENS, A. Central Problems in Social Theory: Action, Structure, and Contradiction in Social Analysis. University of California Press, 1979.

GOLDMAN, A. Knowledge. In: HONDERICH, T. (Ed.). The Oxford Companion to Philosophy. Oxford University Press, 2005.

GOODMAN, E.; KUNIAVSKY, M.; MOED, A. Observing the User Experience, Second Edition: A Practitioner's Guide to User Research. 2nd. ed. Morgan Kaufmann, 2012.

GREENFIELD, A. Everyware: The Dawning Age of Ubiquitous Computing. New Riders, 2010.

GREGOR, S. The Nature of Theory in Information Systems. MIS Quarterly, v. 30, n. 3, p. 611-642, 2006.

GREWAL, D.; ROGGEVEEN, A. L.; NORDFÄLT, J. The Future of Retailing. Journal of Retailing, The Future of Retailing. v. 93, n. 1, p. 1-6, 2017.

GRINTER, R. E. et al. The Work to Make a Home Network Work. In: Ninth European Conference on Computer-Supported Cooperative Work (ECSCW 2005). Proceedings... Springer, 2005. 
GUBA, E. G.; LINCOLN, Y. S. Competing Paradigms in Qualitative Research. In: DENZIN, N. K.; LINCOLN, Y. S. (Eds.). Handbook of qualitative research. Thousand Oaks: Sage, 1994. p. 105-117.

GUBBI, J. et al. Internet of Things (IoT): A vision, architectural elements, and future directions. Future Generation Computer Systems, Including Special sections: Cyber-enabled Distributed Computing for Ubiquitous Cloud and Network Services \& Cloud Computing and Scientific Applications - Big Data, Scalable Analytics, and Beyond. v. 29, n. 7, p. 1645-1660, 2013.

GUDWIN, R.; QUEIROZ, J. Towards an introduction to computational semiotics. In: 2005 International Conference on Integration of Knowledge Intensive Multi-Agent Systems. Proceedings... 2005.

HAACK, S.; KOLENDA, K. Two Fallibilists in Search of the Truth. Proceedings of the Aristotelian Society, Supplementary Volumes, v. 51, p. 63-104, 1977.

HAMLYN, D. W. Epistemology, history of. In: HONDERICH, T. (Ed.). The Oxford Companion to Philosophy. Oxford University Press, 2005.

HANSEN, B.; NOVICK, D.; SUTTON, S. Prevention and repair of breakdowns in a simple task domain. In: AAAI-96 Workshop on Detecting, Repairing, and Preventing Human-Machine Miscommunication. Proceedings... 1996.

HARMAN, G. H. The Inference to the Best Explanation. The Philosophical Review, v. 74, n. 1, p. 88-95, 1965.

HARPER, E. R. et al. (EDS.). Being Human: Human-Computer Interaction in the Year 2020. Microsoft Research Ltd, 2008.

HARPER, R. Inside the Smart Home. Springer Science \& Business Media, 2006.

HARWELL, D. Ring and Nest helped normalize American surveillance and turned us into a nation of voyeurs. Washington Post, 18 Feb. 2020. Available at: $<$ https://www.washingtonpost.com/technology/2020/02/18/ring-nest-surveillancedoorbell-camera/>. Accessed: 18 Feb. 2020.

HASSENZAHL, M. User Experience and Experience Design. In: The Encyclopedia of Human-Computer Interaction, 2nd Ed. Interaction Design Foundation, 2013. Available at: <https://www.interactiondesign.org/literature/book/the-encyclopedia-of-human-computer-interaction-2nded/user-experience-and-experience-design>.

HEATH, L. Triangulation: Methodology. In: WRIGHT, J. D. (Ed.). International Encyclopedia of the Social \& Behavioral Sciences (Second Edition). Oxford: Elsevier, 2015. p. 639-644.

HELlENSCHMIDT, M.; KIRSTE, T. A Generic Topology for Ambient Intelligence. In: Ambient Intelligence EUSAI 2004. Proceedings... Springer, 2004. 
HELPNETSECURITY. Number of connected devices reached 22 billion, where is the revenue? Help Net Security, 23 May 2019. Available at: <https://www.helpnetsecurity.com/2019/05/23/connected-devices-growth/>.

Accessed: 12 Feb. 2020.

HERZOG, A. L. O Brasil na onda das smart grids. EXAME, 29 Apr. 2013. Available at: <https://exame.abril.com.br/revista-exame/o-brasil-na-onda-dassmart-grids/>. Accessed: 10 Feb. 2020.

HINCKLEY, K. ACM Trans. Comput.-Hum. Interact., May 2017 - Special Issue EUD for IoT. New York, NY, USA: ACM, 2017. v. 24, issue 2.

HOFFMAN, R. R.; KLEIN, G. Explaining Explanation, Part 1: Theoretical Foundations. IEEE Intelligent Systems, v. 32, n. 3, p. 68-73, 2017.

HOOPES, J. (ED.). Peirce on Signs: Writings on Semiotic by Charles Sanders Peirce. New edition. Chapel Hill: The University of North Carolina Press, 1991.

HORVÁTH, I.; WANG, J. Towards a Comprehensive Theory of Multi-Aspect Interaction With Cyber Physical Systems. In: ASME 2015 International Design Engineering Technical Conferences \& Computers and Information in Engineering Conference (IDETC/CIE 2015). Proceedings... 2015.

HUANG, J.; CAKMAK, M. Supporting Mental Model Accuracy in Triggeraction Programming. In: 2015 ACM International Joint Conference on Pervasive and Ubiquitous Computing (UbiComp '15). Proceedings... ACM, 2015.

HUET, E.; ZALESKI, O. Silicon Valley's \$400 Juicer May Be Feeling the Squeeze. Bloomberg.com, 19 Apr. 2017. Available at: <https://www.bloomberg.com/news/features/2017-04-19/silicon-valley-s-400juicer-may-be-feeling-the-squeeze>. Accessed: 11 Feb. 2020.

IFTTT INC. IFTTT - If This Then That. Available at: <http://ifttt.com/>. Accessed: 21 Apr. 2017.

INTEL. A Guide to the Internet of Things Infographic. Available at: $<$ https://www.intel.com/content/www/us/en/internet-of-things/infographics/guideto-iot.html >. Accessed: 12 Feb. 2020.

ISO. ISO 9241-210:2019. Available at: <https://www.iso.org/cms/render/live/en/sites/isoorg/contents/data/standard/07/75 /77520.html>. Accessed: 14 Feb. 2020.

JAIMES, A. et al. Guest Editors' Introduction: Human-Centered ComputingToward a Human Revolution. Computer, v. 40, n. 5, p. 30-34, 2007.

JAKOBI, T. et al. The Catch(Es) with Smart Home: Experiences of a Living Lab Field Study. In: 2017 CHI Conference on Human Factors in Computing Systems (CHI '17). Proceedings... ACM, 2017. 
JAKOBI, T. et al. Evolving Needs in IoT Control and Accountability: A Longitudinal Study on Smart Home Intelligibility. Proc. ACM Interact. Mob. Wearable Ubiquitous Technol., v. 2, n. 4, p. 171:1-171:28, 2018.

JAKOBSON, R. Linguistics and poetics. In: Style in language. MA: MIT Press, 1960. p. 350-377.

JALALI, S.; WOHLIN, C. Systematic literature studies: Database searches vs. backward snowballing. In: 2012 ACM-IEEE International Symposium on Empirical Software Engineering and Measurement. Proceedings... 2012.

JESSUP, L. M.; ROBEY, D. The relevance of social issues in ubiquitous computing environments. Communications of the ACM, v. 45, n. 12, p. 88-91, 2002.

JOHNSSON, B. A.; MAGNUSSON, B. Towards end-user development of graphical user interfaces for internet of things. Future Generation Computer Systems, 2017.

JUNG, C. G. (ED.). Man and His Symbols. New York, NY: Dell Publishing Co., Inc., 1968.

KAAZ, K. J. et al. Understanding user perceptions of privacy, and configuration challenges in home automation. In: 2017 IEEE Symposium on Visual Languages and Human-Centric Computing (VL/HCC). Proceedings... 2017.

KAMMERSGAARD, J. Four different perspectives on human-computer interaction. DAIMI Report Series, n. 203, 1985.

KARAPANOS, E. et al. User Experience over Time: An Initial Framework. In: 2009 SIGCHI Conference on Human Factors in Computing Systems (CHI '09). Proceedings.... ACM, 2009.

KIRSH, D.; MAGLIO, P. On distinguishing epistemic from pragmatic action. Cognitive Science, v. 18, n. 4, p. 513-549, 1994.

KLEIN, G. et al. A data-frame theory of sensemaking. Expertise out of context: In: Sixth International Conference on Naturalistic Decision Making. Proceedings... Lawrence Erlbaum, 2007.

KLEINA, N. Juicero: como uma máquina de fazer suco virou a startup mais odiada dos EUA, 25 Apr. 2017. Available at: $<$ https://www.tecmundo.com.br/startups/116084-maquina-espremer-suco-viroustartup-odiada-internet.htm>. Accessed: 12 Feb. 2020.

KNOBLICH, G.; OELLINGER, M. The Eureka Moment. Scientific American Mind, v. 17, n. 5, p. 38-43, 2006.

KOPETZ, H. Internet of Things. In: Real-Time Systems. Real-Time Systems Series. Springer, Boston, MA, 2011. p. 307-323. 
KORTUEM, G. et al. Smart objects as building blocks for the Internet of things. IEEE Internet Computing, v. 14, n. 1, p. 44-51, 2010.

KOUNIOS, J.; BEEMAN, M. The Aha! Moment: The Cognitive Neuroscience of Insight. Current Directions in Psychological Science, v. 18, n. 4, p. 210-216, 2009.

KUBITZA, T.; SCHMIDT, A. Rapid Interweaving of Smart Things with the meSchup IoT Platform. In: 2016 ACM International Joint Conference on Pervasive and Ubiquitous Computing (UbiComp'16): Adjunct. Proceedings... ACM, 2016.

KUNIAVSKY, M. Smart Things: Ubiquitous Computing User Experience Design. Amsterdam: Morgan Kaufmann, 2010.

KUO, L. China brings in mandatory facial recognition for mobile phone users. The Guardian, 2 Dec. 2019. Available at: <https://www.theguardian.com/world/2019/dec/02/china-brings-in-mandatoryfacial-recognition-for-mobile-phone-users>. Accessed: 12 Feb. 2020.

KUUTTI, K.; BANNON, L. J. The turn to practice in HCI: towards a research agenda. In: 2014 SIGCHI Conference on Human Factors in Computing Systems (CHI '14). Proceedings... ACM, 2014.

LANDA, M. D. War in the Age of Intelligent Machines. USA: Zone Books, 1991.

LAPOLLA R. J. Causes and Effects of Substratum, Superstratum and Adstratum Influence, with Reference to Tibeto-Burman Languages. Senri Ethnological Studies, v. 75, p. 243-253, 2009.

LATIF, S.; ZAFAR, N. A. A survey of security and privacy issues in IoT for smart cities. In: 2017 Fifth International Conference on Aerospace Science Engineering (ICASE). Proceedings... 2017.

LAUGWITZ, B.; HELD, T.; SCHREPP, M. Construction and Evaluation of a User Experience Questionnaire. In: HCI and Usability for Education and Work (USAB 2008). Proceedings... Springer, 2008.

LEE, E. A. Cyber Physical Systems: Design Challenges. In: 2008 11th IEEE International Symposium on Object and Component-Oriented Real-Time Distributed Computing (ISORC). Proceedings... 2008.

LEE, I.; LEE, K. The Internet of Things (IoT): Applications, investments, and challenges for enterprises. Business Horizons, v. 58, n. 4, p. 431-440, 2015.

LEGG, C.; HOOKWAY, C. Pragmatism. In: ZALTA, E. N. (Ed.). The Stanford Encyclopedia of Philosophy. Spring 2019 ed. Metaphysics Research Lab, Stanford University, 2019. Available at: <https://plato.stanford.edu/archives/spr2019/entries/pragmatism/>. 
LEITÃO, C. F.; PRATES, R. O. A Aplicação de Métodos Qualitativos em Computação. In: Jornadas de Atualização em Informática 2017. Porto Alegre/RS: Sociedade Brasileira de Computação - SBC, 2017. p. 43-90.

LEONT'EV, A. N. Activity, Consciousness and Personality. Englewood Cliffs; London: Prentice Hall, 1979.

LEVIN, S. Squeezed out: widely mocked startup Juicero is shutting down. The Guardian, $\quad 1 \quad$ Sep. $2017 . \quad$ Available at: <https://www.theguardian.com/technology/2017/sep/01/juicero-silicon-valleyshutting-down>. Accessed: 11 Feb. 2020.

LEWIS, C.; NORMAN, D. A. Designing for Error. In: BAECKER, R. M. et al. (Eds.). Readings in Human-Computer Interaction. Interactive Technologies. Morgan Kaufmann, 1995. p. 686-697.

LI, S.; XU, L. D.; ZHAO, S. The internet of things: a survey. Information Systems Frontiers, v. 17, n. 2, p. 243-259, 2015.

LIEBERMAN, H. et al. End-user development: An emerging paradigm. In: End user development. Springer, 2006. p. 1-8.

LINCOLN, Y. S.; GUBA, E. G. Paradigmatic Controversies, Contradictions, and Emerging Confluences. In: DENZIN, N. K.; LINCOLN, Y. S. (Eds.). Handbook of qualitative research. 2nd. ed. SAGE, 2000. p. 509-535.

LU, Y.; PAPAGIANNIDIS, S.; ALAMANOS, E. Internet of Things: A systematic review of the business literature from the user and organisational perspectives. Technological Forecasting and Social Change, v. 136, p. 285297, 2018.

LUDWIG, T. et al. Towards Sociable Technologies: An Empirical Study on Designing Appropriation Infrastructures for 3D Printing. In: 2014 Conference on Designing Interactive Systems (DIS '14). Proceedings... ACM, 2014.

LUDWIG, T. et al. A Practice-Oriented Paradigm for End-User Development. In: New Perspectives in End-User Development. Cham: Springer, 2017. p. 23-41.

LUDWIG, T.; BODEN, A.; PIPEK, V. 3D Printers As Sociable Technologies: Taking Appropriation Infrastructures to the Internet of Things. ACM Trans. Comput.-Hum. Interact., v. 24, n. 2, p. 17:1-17:28, 2017.

LUDWIG, T.; PIPEK, V.; TOLMIE, P. Designing for Collaborative Infrastructuring: Supporting Resonance Activities. Proc. ACM Hum.-Comput. Interact., v. 2, n. CSCW, p. 113:1-113:29, 2018.

LUDWIG, T.; TOLMIE, P.; PIPEK, V. From the Internet of Things to an Internet of Practices. In: SORO, A.; BRERETON, M.; ROE, P. (Eds.). Social Internet of Things. Cham: Springer, 2019. p. 33-47.

LYONS, J. Linguagem e Linguística - Uma Introdução. Tradução: Marilda Winkler Averbug; Clarisse Sieckenius De Souza. 1. ed. LTC, 1984. 
MACKENZIE, N.; KNIPE, S. Research dilemmas: Paradigms, methods and methodology. Issues in educational research, v. 16, n. 2, p. 193-205, 2006.

MACLEAN, A. et al. User-tailorable Systems: Pressing the Issues with Buttons. In: 1990 SIGCHI Conference on Human Factors in Computing Systems (CHI '90). Proceedings... ACM, 1990.

MADAKAM, S.; RAMASWAMY, R.; TRIPATHI, S. Internet of Things (IoT): A Literature Review. Journal of Computer and Communications, v. 03, n. 05, p. $164,2015$.

MAGNUSSON, M.; PRAMLING, N. Signs of knowledge: the appropriation of a symbolic skill in a five-year-old. European Early Childhood Education Research Journal, v. 19, n. 3, p. 357-372, 2011.

MANWARING, K.; CLARKE, R. Surfing the third wave of computing: A framework for research into eObjects. Computer Law \& Security Review, v. 31, n. 5, p. 586-603, 2015.

MARTINEZ-MALDONADO, R.; CARVALHO, L.; GOODYEAR, P. Collaborative Design-in-use: An Instrumental Genesis Lens in Multi-device Environments. Proceedings of the ACM on Human-Computer Interaction, v. 2, n. CSCW, p. 118:1-118:24, 2018.

MARTINS, G. DE A. Estudo de caso: uma estratégia de pesquisa. São Paulo: Atlas, 2006.

MATHISON, S. Why Triangulate? Educational Researcher, v. 17, n. 2, p. 1317, 1988.

MAUÉS, R. DE A.; BARBOSA, S. D. J. Cross-Communicability: Evaluating the Meta-communication of Cross-Platform Applications. In: Human-Computer Interaction - INTERACT 2013. Proceedings... Springer, 2013. p. 241-258.

MAUÉS, R. DE A.; BARBOSA, S. D. J. Reflections on the Cross-Platform Semiotic Inspection Method. In: Human-Computer Interaction, Part I, HCII 2014 Proceedings... Springer, 2014. p. 533-544.

MCCARTHY, J.; WRIGHT, P. Technology As Experience. Interactions, v. 11, n. 5, p. $42-43,2004$.

MCCUllough, M. Digital Ground: Architecture, Pervasive Computing, and Environmental Knowing. Cambridge, Mass: The MIT Press, 2004.

MCCUllough, M. Ambient Commons: Attention in the Age of Embodied Information. MIT Press, 2013.

MEADAN, H.; OSTROSKY, M. M.; HALlE, J. W. "What?"; "I Don't Understand"; and "Pardon?": Using Communication Breakdowns to Encourage Communication. Young Exceptional Children, v. 9, n. 3, p. 2-9, 2006. 
MENNICKEN, S.; HUANG, E. M. Hacking the Natural Habitat: An In-theWild Study of Smart Homes, Their Development, and the People Who Live in Them. In: International Conference on Pervasive Computing. Proceedings... Springer, 2012.

MINSKY, M. Matter, Mind and Models. Artificial Intelligence, Memo No. 77, 1965.

MIORANDI, D. et al. Internet of things: Vision, applications and research challenges. Ad Hoc Networks, v. 10, n. 7, p. 1497-1516, 2012.

MOGHADDAM, H. M. et al. Watching You Watch: The Tracking Ecosystem of Over-the-Top TV Streaming Devices. In: 2019 ACM SIGSAC Conference on Computer and Communications Security (CCS '19). Proceedings... ACM, 2019.

MORGAN, D. L. Pragmatism as a Paradigm for Social Research. Qualitative Inquiry, v. 20, n. 8, p. 1045-1053, 2014.

MORRIS, C. W. Foundations of the Theory of Signs. In: International Encyclopedia of Unified Science. Chicago University Press, 1938. v. I, No. 2. p. $1-59$.

MORRISON, M.; MORGAN, M. S. Models as mediating instruments. In: MORGAN, M. S.; MORRISON, Margaret (Eds.). Models as Mediators: Perspectives on Natural and Social Science. Ideas in context. Cambridge University Press, 1999. v. 52, p. 10-37.

MOZUR, P. One Month, 500,000 Face Scans: How China Is Using A.I. to Profile a Minority. The New York Times, 14 Apr. 2019. Available at: $<$ https://www.nytimes.com/2019/04/14/technology/china-surveillance-artificialintelligence-racial-profiling.html>. Accessed: 12 Feb. 2020.

MULLER, M. Curiosity, Creativity, and Surprise as Analytic Tools: Grounded Theory Method. In: OLSON, J. S.; KELLOGG, W. A. (Eds.). Ways of Knowing in HCI. New York, NY: Springer, 2014. p. 25-48.

MURGIA, M.; YANG, Y. Facial recognition: how China cornered the surveillance market. Financial Times, 6 Dec. 2019. Available at: <https://www.ft.com/content/6f1a8f48-1813-11ea-9ee4-11f260415385>.

Accessed: 11 Feb. 2020.

MYERS, B. A. et al. Programmers Are Users Too: Human-Centered Methods for Improving Programming Tools. Computer, v. 49, n. 7, p. 44-52, 2016.

NARDI, B. A. A Small Matter of Programming: Perspectives on End User Computing. MIT Press, 1993.

NEISSER, U. Cognition and Reality: Principles and Implications of Cognitive Psychology. W. H. Freeman, 1976. 
NEWMAN, M. W. et al. Designing for Serendipity: Supporting End-user Configuration of Ubiquitous Computing Environments. In: 4th Conference on Designing Interactive Systems: Processes, Practices, Methods, and Techniques (DIS '02). Proceedings... ACM, 2002.

NIELSEN, J. Usability Inspection Methods. In: 1994 Conference Companion on Human Factors in Computing Systems (CHI '94). Proceedings... ACM, 1994.

NIELSEN, J. Discount Usability: 20 Years. Nielsen Norman Group, 14 set. 2009. Available at: <https://www.nngroup.com/articles/discount-usability-20years/>. Accessed: 26 Feb. 2019.

NORMAN, D.; MILLER, J.; HENDERSON, A. What you see, some of what's in the future, and how we go about doing it: HI at Apple Computer. In: 1995 Conference Companion on Human Factors in Computing Systems (CHI '95). Proceedings... ACM, 1995.

OLLMAN, B. Alienation: Marx's Conception of Man in a Capitalist Society. Cambridge University Press, 1976.

O'NEIL, C. Weapons of Math Destruction: How Big Data Increases Inequality and Threatens Democracy. Reprint edition. New York: Broadway Books, 2017.

ORLIKOWSKI, W. J. The Duality of Technology: Rethinking the Concept of Technology in Organizations. Organization Science, v. 3, n. 3, p. 398-427, 1992.

ORLIKOWSKI, W. J. Using Technology and Constituting Structures: A Practice Lens for Studying Technology in Organizations. Organization Science, v. 11, n. 4, p. 404-428, 2000.

ORR, J. E. Talking about machines: An ethnography of a modern job. Cornell University Press, 2016.

OSTERWALDER, A.; PIGNEUR, Y. Business Model Generation: A Handbook for Visionaries, Game Changers, and Challengers. 1st. ed. Hoboken, NJ: John Wiley and Sons, 2010.

OULASVIRTA, A. When Users "Do" the Ubicomp. interactions, v. 15, n. 2, p. 6-9, 2008.

PANASONIC. PaPIRs - Panasonic PIR Motion Sensors Datasheet, 2016.

PATERNÒ, F.; SANTORO, C. A Design Space for End User Development in the Time of the Internet of Things. In: New Perspectives in End-User Development. Cham: Springer, 2017. p. 43-59.

PATERNÒ, F.; WULF, V. New Perspectives in End-User Development. Cham: Springer, 2017.

PAYNE, S. J. A descriptive study of mental models. Behaviour \& Information Technology, v. 10, n. 1, p. 3-21, 1991. 
PAYNE, S. J. Users' mental models: The very ideas. In: CARROLL, J. M. (Ed.). HCI models, theories, and frameworks: Toward a multidisciplinary science. 2003. p. 135-156.

PEARCE, T. "Protoplasm Feels": The Role of Physiology in Charles Sanders Peirce's Evolutionary Metaphysics. HOPOS: The Journal of the International Society for the History of Philosophy of Science, v. 8, n. 1, p. 28-61, 2018.

PEIRCE, C. S. The Collected Papers of Charles Sanders Peirce. Electronic ed. Cambridge, MA: Harvard University Press, 1931-1958. v. I-VIII. Partially available

<https://edisciplinas.usp.br/pluginfile.php/285778/mod_resource/content/1/The\% 20Collected $\% 20$ Papers $\% 20$ of $\% 20$ Charles $\% 20$ Sanders $\% 20$ Peirce $\% 20 \% 282904 \mathrm{~s}$ \%29.pdf>. Accessed: 12 Mar. 2020.

PERERA, C. et al. Context Aware Computing for The Internet of Things: A Survey. IEEE Communications Surveys Tutorials, v. 16, n. 1, p. 414-454, First 2014.

PESSOA, F. Poems of Fernando Pessoa. Tradução: Edwin Honig. Reprint edition. San Francisco: City Lights Publishers, 2001.

PIPEK, V. From tailoring to appropriation support: Negotiating groupware usage. Doctoral dissertation-Oulu, Finland: University of Oulu, 2005.

PIPEK, V.; WULF, V. Infrastructuring: Toward an integrated perspective on the design and use of information technology. Journal of the Association for Information Systems, v. 10, n. 5, p. 447, 2009.

POSLAD, S. Ubiquitous Computing: Smart Devices, Environments and Interactions. John Wiley \& Sons, 2011.

POSTSCAPES. List of Failed IoT Startups. Available at: <https://www.postscapes.com/closed-iot-companies>. Accessed: 12 Feb. 2020.

PRATES, R. O.; DE SOUZA, C. S.; BARBOSA, S. D. J. Methods and Tools: A Method for Evaluating the Communicability of User Interfaces. interactions, v. 7, n. 1 , p. 31-38, 2000.

QUEIROZ, J. Semiose Segundo C. S. Peirce. São Paulo: EDUC, 2004.

RABARDEL, P. From artefact to instrument. Interacting with Computers, v. 15, n. 5, p. 641-645, 2003.

RABARDEL, P.; BOURMAUD, G. From computer to instrument system: a developmental perspective. Interacting with Computers, v. 15, n. 5, p. 665-691, 2003.

RAJKUMAR, R. (RAJ) et al. Cyber-physical Systems: The Next Computing Revolution. In: 47th Design Automation Conference (DAC '10). Proceedings... ACM, 2010. 
REICHERTZ, J. Abduction: The Logic of Discovery of Grounded Theory. In: BRYANT, A.; CHARMAZ, K. (Eds.). The SAGE Handbook of Grounded Theory. London, UK: SAGE Publications Ltd, 2007. p. 214-228.

REN, J. et al. Information Exposure From Consumer IoT Devices: A Multidimensional, Network-Informed Measurement Approach. In: 2019 Internet Measurement Conference (IMC '19). Proceedings... ACM, 2019.

RETORE, A. P.; ALMEIDA, L. D. A. Understanding Appropriation Through End-User Tailoring in Communication Systems: A Case Study on Slack and WhatsApp. In: Social Computing and Social Media. Design, Human Behavior and Analytics - HCII 2019. Proceedings... Springer, 2019.

RICHARDSON, L. Writing: A method of inquiry. In: DENZIN, N. K.; LINCOLN, Y. S. (Eds.). Handbook of qualitative research. Thousand Oaks, CA: SAGE, 1994. p. 516-529.

RICHARDSON, L.; ST. PIERRE, E. Writing: A method of inquiry. In: DENZIN, N. K.; LINCOLN, Y. S. (Eds.). Collecting and interpreting qualitative materials. 3rd. ed. Los Angeles: SAGE Publications, 2008. p. 473-500.

ROGERS, Y. Moving on from Weiser's Vision of Calm Computing: Engaging UbiComp Experiences. In: International Conference on Ubiquitous Computing (UbiComp 2006): Proceedings... Springer, 2006.

ROGOFF, B. Observing sociocultural activity on three planes: participatory appropriation, guided participation, and apprenticeship. In: WERTSCH, J. V. (Ed.). Sociocultural Studies of Mind. Cambridge University Press, 1995.

RUSE, M. Models. In: HONDERICH, T. (Ed.). The Oxford Companion to Philosophy. 2nd. ed. Oxford University Press, 2005a.

RUSE, M. Theory. In: HONDERICH, T. (Ed.). The Oxford Companion to Philosophy. Oxford University Press, 2005b.

RUTHERFORD, S. Fitbit Is Killing Off Pebble in June, For Real This TimeGizmodo, 24 Jan. 2018. Available at: <https://gizmodo.com/fitbit-is-killingoff-pebble-in-june-for-real-this-tim-1822394036>. Accessed: 12 Feb. 2020.

RUYTER, B. DE; AARTS, E. Experience Research: a Methodology for Developing Human-centered Interfaces. In: Handbook of Ambient Intelligence and Smart Environments. Boston, MA: Springer, 2010. p. 1039-1067.

SAlGADO, L. C. DE C.; LEITÃO, C. F.; SOUZA, C. S. DE. A Journey Through Cultures: Metaphors for Guiding the Design of Cross-Cultural Interactive Systems. London: Springer-Verlag, 2013.

SALOVAARA, A. Inventing New Uses for Tools: A Cognitive Foundation for Studies on Appropriation. Human Technology: An Interdisciplinary Journal on Humans in ICT Environments, 2008. 
SAlOVAARA, A. Studying Appropriation of Everyday Technologies: A Cognitive Approach. In: CHI '09 Extended Abstracts on Human Factors in Computing Systems (CHI EA ’09). Proceedings... ACM, 2009.

SALOVAARA, A.; TAMMINEN, S. Acceptance or Appropriation? A DesignOriented Critique of Technology Acceptance Models. In: ISOMÄKI, H.; SAARILUOMA, P. (Eds.). Future Interaction Design II. London: Springer, 2009. p. 157-173.

SANTAELLA, L. Semiótica aplicada. $1^{\mathrm{a}}$ ed. São Paulo: Cengage Learning, 2002.

SANZ, R. L. THE TRANSLATION OF IDIOLECT IN CHANGING PLACES: SOME PRAGMATIC AND SEMIOTIC CONSIDERATIONS. The Grove, $p$. $119-135,2000$.

SCHMIDT, A. Implicit human computer interaction through context. Personal Technologies, v. 4, n. 2-3, p. 191-199, 2000.

SCHMIDT, A. Ubiquitous Computing: Are We There Yet? Computer, v. 43, n. 2, p. 95-97, 2010.

SCHÖN, D. A. The reflective practitioner: How professionals think in action. Basic books, 1983.

SCHÖN, D. A. Educating the reflective practitioner: Toward a new design for teaching and learning in the professions. San Francisco, CA, US: Jossey-Bass, 1987. v. xvii

SCHÖN, D.; BENNETT, J. Reflective Conversation with Materials. In: WINOGRAD, T. (Ed.). Bringing Design to Software. New York, NY, USA: ACM, 1996. p. 171-189.

SCHOOLER, J. W.; FALLSHORE, M.; FIORE, S. M. Epilogue: Putting insight into perspective. In: STERNBERG, R. J.; DAVIDSON, J. E. (Eds.). The nature of insight. Cambridge, MA, US: The MIT Press, 1994. p. 559-587.

SEBE, N. Human-centered computing. In: Handbook of ambient intelligence and smart environments. Springer, 2010. p. 349-370.

SEBEOK, T. A. Biosemiotics: Its roots, proliferation, and prospects. Semiotica, v. 2001, n. 134, p. 61-78, 2006.

SENNA, L. A. G. Pequeno manual de lingüística geral e aplicada. Rio de Janeiro: Universidade do Estado do Rio de Janeiro, 1991.

SHARPLES, M. A study of breakdowns and repairs in a computer-mediated communication system. Interacting with Computers, v. 5, n. 1, p. 61-77, 1993.

SHAW, M. Role of Design Spaces in Guiding a Software Design. In: Software Designers in Action: A Human-Centric Look at Design Work. 2013. p. 29-44. 
SHI, J. et al. A survey of Cyber-Physical Systems. In: 2011 International Conference on Wireless Communications and Signal Processing (WCSP). Proceedings... 2011.

SHIPMAN, F. M.; MARSHALL, C. C. Formality Considered Harmful: Experiences, Emerging Themes, and Directions on the Use of Formal Representations in Interactive Systems. Computer Supported Cooperative Work (CSCW), v. 8, n. 4, p. 333-352, 1999.

SHORTCUT LABS. Official Flic Hub video, 2017. Available at: <https://www.youtube.com/watch?v=4w5U2rVhdUE>. Accessed: 27 Jan. 2020.

SILVERSTONE, R.; HADDON, L. Design and the domestication of information and communication technologies: technical change and everyday life. In: MANSElL, R.; SILVERSTONE, R. (Eds.). Communication by Design: The Politics of Information and Communication Technologies. Oxford, UK: Oxford University Press, 1996. p. 44-74.

SIMON, H. A. The sciences of the artificial. Cambridge, Massachusetts: MIT press, 1996.

SOO MENG, J. C. Donald Schön, Herbert Simon and The Sciences of the Artificial. Design Studies, v. 30, n. 1, p. 60-68, 2009.

STAR, S. L.; BOWKER, G. C. How to infrastructure. In: Handbook of new media: Social shaping and social consequences of ICTs, p. 230-245, 2006.

STERNBERG, R. J.; DAVIDSON, J. E. (EDS.). The nature of insight. Cambridge, MA, US: The MIT Press, 1994.

STEUP, M.; NETA, R. Epistemology. In: ZALTA, E. N. (Ed.). The Stanford Encyclopedia of Philosophy. Spring 2020 ed. Metaphysics Research Lab, Stanford University, 2020. Available at: $<$ https://plato.stanford.edu/archives/spr2020/entries/epistemology/>.

STEVENS, G.; PIPEK, V.; WULF, V. Appropriation Infrastructure: Supporting the Design of Usages. In: 2009 International Symposium on EndUser Development (IS-EUD 2009). Proceedings... Springer, 2009.

SUSMAN, G. I.; EVERED, R. D. An Assessment of the Scientific Merits of Action Research. Administrative Science Quarterly, v. 23, n. 4, p. 582-603, 1978.

TALBERT, N. Toward human-centered systems. IEEE Computer Graphics and Applications, v. 17, n. 4, p. 21-28, 1997.

TASHAKKORI, A.; TEDDLIE, C. Sage handbook of mixed methods in social \& behavioral research. 2nd. ed. Los Angeles, CA: SAGE Publications, 2010.

TAVORY, I.; TIMMERMANS, S. A Pragmatist Approach to Causality in Ethnography. American Journal of Sociology, v. 119, n. 3, p. 682-714, 2013. 
TCHOUNIKINE, P. Designing for Appropriation: A Theoretical Account. Human-Computer Interaction, v. 32, n. 4, p. 155-195, 2017.

TETTEROO, D. et al. Proceedings of the CHI 2015 - Workshop on End User Development in the Internet of Things Era. In: CHI 2015 Workshops. International Reports on Socio-Informatics (IRSI), 2015.

TETTEROO, D.; MARKOPOULOS, P. A review of research methods in end user development. In: 2015 International Symposium on End User Development, Madrid, Spain (IS-EUD 2015). Proceedings... Springer, 2015.

TIDWELL, J. Designing Interfaces: Patterns for Effective Interaction Design. O’Reilly, 2010.

TIMMERMANS, S.; TAVORY, I. Theory Construction in Qualitative Research: From Grounded Theory to Abductive Analysis. Sociological Theory, v. 30, n. 3, p. 167-186, 2012.

TUKKER, A. Eight types of product-service system: eight ways to sustainability? Experiences from SusProNet. Business Strategy and the Environment, v. 13, n. 4, p. 246-260, 2004.

TURNER, P. Everyday Coping: The Appropriation of Technology. In: 29th Annual European Conference on Cognitive Ergonomics (ECCE '11). Proceedings... ACM, 2011.

TURNER, P. Outlining Epistemic Interaction. In: 30th European Conference on Cognitive Ergonomics (ECCE '12). Proceedings... ACM, 2012.

TURNER, P.; TURNER, S. Triangulation in practice. Virtual Reality, v. 13, n. 3, p. 171-181, 2009.

UR, B. et al. Practical Trigger-action Programming in the Smart Home. In: 2014 SIGCHI Conference on Human Factors in Computing Systems (CHI '14). Proceedings... ACM, 2014.

UR, B. et al. Trigger-Action Programming in the Wild: An Analysis of 200,000 IFTTT Recipes. In: 2016 CHI Conference on Human Factors in Computing Systems (CHI '16). Proceedings... ACM, 2016.

URQUIJO, S. P.; SCRIVENER, S. A. R.; PALMÉN, H. K. The Use of Breakdown Analysis in Synchronous CSCW System Design. In: Third European Conference on Computer-Supported Cooperative Work, 13-17 September 1993, Milan, Italy (ECSCW '93). Proceedings... Springer, 1993. p. 281-293.

VENKATESH, V. et al. User Acceptance of Information Technology: Toward a Unified View. MIS Quarterly, v. 27, n. 3, p. 425-478, 2003. 
VERMAAS, P. E. Design Theories, Models and Their Testing: On the Scientific Status of Design Research. In: CHAKRABARTI, A.; BLESSING, L. T. M. (Eds.). An Anthology of Theories and Models of Design: Philosophy, Approaches and Empirical Explorations. London, UK: Springer, 2014. p. 4766.

VOSOUGHI, S.; ROY, D.; ARAL, S. The spread of true and false news online. Science, v. 359, n. 6380, p. 1146-1151, 2018.

WEBSTER, J.; WATSON, R. T. Analyzing the Past to Prepare for the Future: Writing a Literature Review. MIS Quarterly, v. 26, n. 2, p. xiii-xxiii, 2002.

WEINREICH, U. Languages in contact, findings and problems. Mouton, 1970.

WEISER, M. The Computer for the 21st Century. Scientific American, v. 265, n. 3, p. 94-104, 1991.

WEISER, M. Some Computer Science Issues in Ubiquitous Computing. Commun. ACM, v. 36, n. 7, p. 75-84, 1993.

WEISER, M. Creating the invisible interface: (invited talk). In: $7^{\text {th }}$ Annual ACM Symposium on User Interface Software and Technology. Proceedings... ACM, 1994.

WERTSCH, J. V. The Role of Semiosis in L. S. Vygotsky's Theory of Human Cognition. In: BAIN, B. (Ed.). The Sociogenesis of Language and Human Conduct. Boston, MA: Springer US, 1983. p. 17-31.

WERTSCH, J. V. Beyond Vygotsky: Bakhtin's Contribution. In: Voices of the Mind: Sociocultural Approach to Mediated Action. Cambridge, Mass: Harvard University Press, 1993. p. 46-66.

WERTSCH, J. V. Mind As Action. New York: Oxford University Press, 1998.

WHARTON, C. et al. The cognitive walkthrough method: a practitioner's guide. In: NIELSEN, J.; MACK, R. L. (Eds.). Usability inspection methods. New York: John Wiley \& Sons, 1994. p. 105-140.

WHITMORE, A.; AGARWAL, A.; XU, L. D. The Internet of Things-A survey of topics and trends. Information Systems Frontiers, v. 17, n. 2, p. 261-274, 2015.

WHITSON, J. A. Cognition as a Semiosic Process: From Situated Mediation to Critical Reflective Transcendence. In: KIRSHNER, D.; WHITSON, J. A. (Eds.). Situated Cognition: Social, Semiotic, and Psychological Perspectives. 1997. p. 97-149.

WINOGRAD, T. The Design of Interaction. In: DENNING, P. J.; METCALFE, R. M. (Eds.). Beyond Calculation: The Next Fifty Years of Computing. New York, NY: Springer, 1997. p. 149-161. 
WINOGRAD, T. Designing a New Foundation for Design. Commun. ACM, v. 49, n. 5, p. 71-74, 2006.

WINOGRAD, T. Clarisse's Visit at CSLI Stanford, 1991-2. In: BARBOSA, S.; BREITMAN, K. (Eds.). Conversations Around Semiotic Engineering. Springer, 2017. p. 13-21.

WINOGRAD, T.; FLORES, F. Understanding Computers and Cognition: A New Foundation for Design. Addison-Wesley, 1986.

WINTHER, R. G. The Structure of Scientific Theories. In: ZALTA, E. N. (Ed.). The Stanford Encyclopedia of Philosophy. Winter 2016 ed. Metaphysics Research Lab, Stanford University, 2016. Available at: $<$ https://plato.stanford.edu/archives/win2016/entries/structure-scientifictheories/>.

WORLDOMETER. Worldometer - real time world statistics. Available at: <http://www.worldometers.info/>. Accessed: 12 Feb. 2020.

WRIGHT, P.; MONK, A. F. Evaluation for Design. In: (A. Sutcliffe, L. Macaulay, Eds.) People and Computers V. Fifth Conference of The British Computer Society Human-Computer Interaction Specialist Group. Proceedings... Cambridge University Press, 1989.

XIA, F. et al. Internet of Things. International Journal of Communication Systems, v. 25, n. 9, p. 1101-1102, 2012.

YAROSH, L.; ZAVE, P. Locked or Not?: Mental Models of IoT Feature Interaction. In: 2017 CHI Conference on Human Factors in Computing Systems (CHI '17). Proceedings... ACM, 2017.

ZIMMERMAN, J.; FORLIZZI, J. Service Design. In: The Encyclopedia of Human-Computer Interaction, 2nd Ed. Interaction Design Foundation, 2013. Available at: <https://www.interaction-design.org/literature/book/theencyclopedia-of-human-computer-interaction-2nd-ed/service-design $>$. 